Strategies of Care

Changing Elderly Care in Italy and the Netherlands

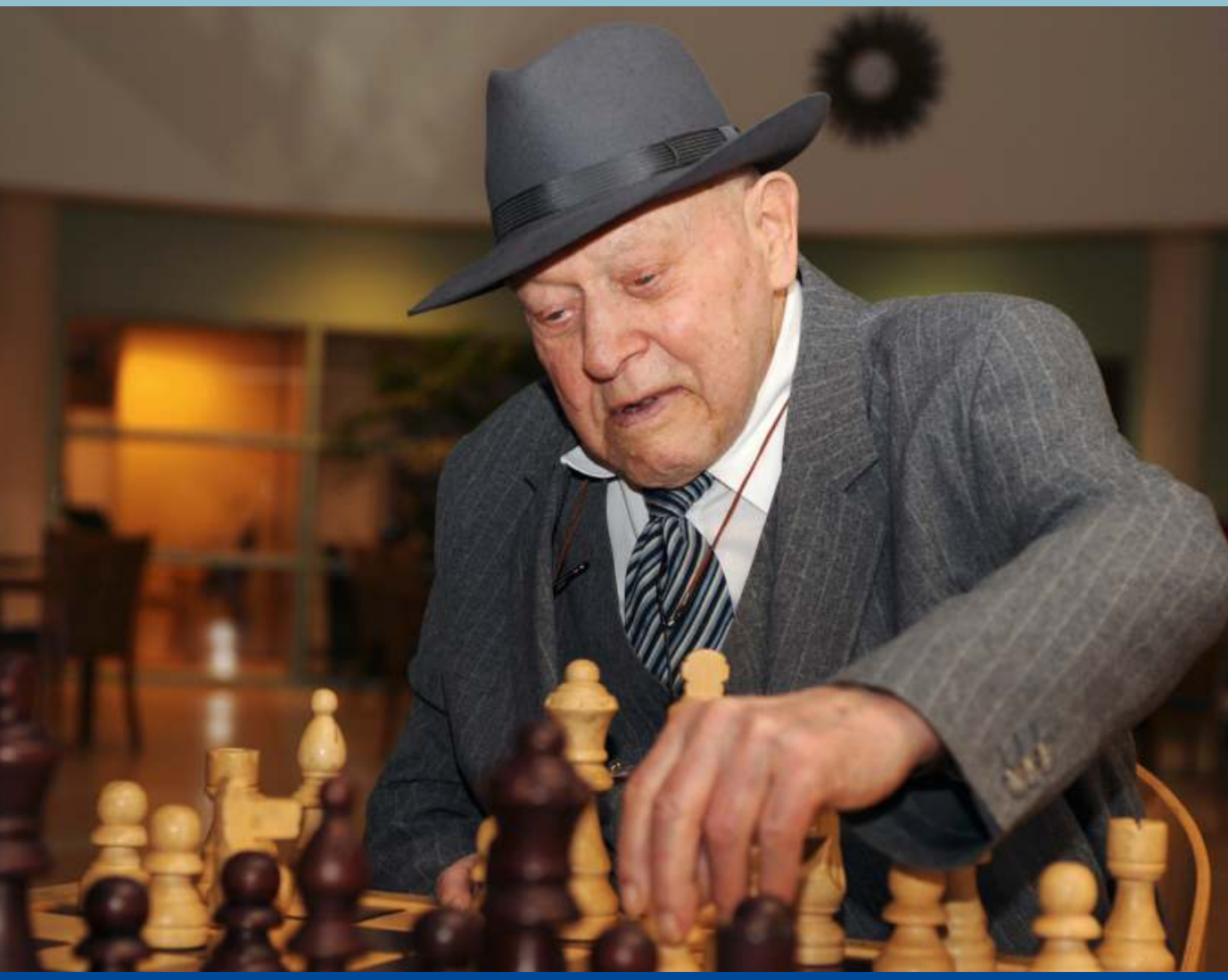

Amsterdam University Press 
Strategies of Care 


\section{CARE \& WELFARE}

Care and welfare are changing rapidly in contemporary welfare states. The Care \& Welfare series publishes studies on changing relationships between citizens and professionals, on care and welfare governance, on identity politics in the context of these welfare state transformations, and on ethical topics. It will inspire the international academic and political debate by developing and reflecting upon theories of (health) care and welfare through detailed national case studies and/or international comparisons. This series will offer new insights into the interdisciplinary theory of care and welfare and its practices.

\section{SERIES EDITORS}

Jan Willem Duyvendak, University of Amsterdam

Trudie Knijn, Utrecht University

Monique Kremer, Netherlands Scientific Council for Government Policy

(Wetenschappelijke Raad voor het Regeringsbeleid - WRR)

Margo Trappenburg, Utrecht University, Erasmus University Rotterdam

\section{PREVIOUSLY PUBLISHED}

Jan Willem Duyvendak, Trudie Knijn and Monique Kremer (eds.): Policy, People, and the New Professional. De-professionalisation and Re-professionalisation in Care and Welfare 2006 (ISBN 9789053568859 )

Ine van Hoyweghen: Risks in the Making. Travels in Life Insurance and Genetics 2007 (ISBN 9789053569276 )

Anne-Mei The: In Death's Waiting Room. Living and Dying with Dementia in a Multicultural Society 2008 (ISBN 978905356077 8) 


\title{
Strategies of CARE
}

Changing Elderly Care in Italy and the Netherlands

\author{
Barbara Da Roit
}


Cover illustration: (C) Frank Muller / Hollandse Hoogte

Cover design: Sabine Mannel, NEON graphic design company, Amsterdam

Lay-out: JAPES, Amsterdam

ISBN 9789089642240

e-ISBN 97890485 I 2270

NUR 740

(C) Barbara Da Roit / Amsterdam University Press, Amsterdam 20ıо

All rights reserved. Without limiting the rights under copyright reserved above, no part of this book may be reproduced, stored in or introduced into a retrieval system, or transmitted, in any form or by any means (electronic, mechanical, photocopying, recording or otherwise) without the written permission of both the copyright owner and the author of the book. 


\section{Table of Contents}

I Changing Care Systems: An Introduction 9

I.I The problem of long-term care 9

I.2 Changing care policies for the elderly IO

I.2.I Elderly care models in the early I990s Io

I.2.2 The policy shift in the I990s: Common trends I2

I.2.3 ... and different trajectories $\quad$ I3

I.3 Analysing care systems transformations: Comparing Italy and the Netherlands $\quad$ I5

I.3.I A care system approach

I.3.2 Care production and allocation between family, state
and market

I.3.3 Care strategies, the family and the institutional context I8

2 The Context and Policy Trajectories 2I

2.I The comparative logic 2I

2.2 The Dutch model 22

2.2.I The policy framework in the Netherlands 22

2.2.2 The debate on the formal care model and social policy changes 23

2.2.3 Which trajectory for the Dutch model? 27

2.3 The Italian model $\quad 28$

2.3.I Long-term-care policies in Italy 28

2.3.2 The debate in the iggos 30

2.3.3 The development of private care $\quad 32$

2.4 Emerging questions $\quad 35$

3 The Challenge of Dependence $\quad 37$

3.I Analysing dependence $\quad 37$

3.I.I Population ageing and disability trends 37

3.I.2 Aims and methods 38

3.2 Dependence in Italy and the Netherlands 39

3.2.I Incidence and trends 39

3.2.2 Household dependence and family insertion of
dependent elderly people

3.3 Why are there more dependents in Italy than in the
Netherlands?

3.3.I Demographic structure and social stratification $\quad 44$

3.3.2 The role of (de)institutionalisation policies 50

3.4 Conclusion $\quad 53$ 
4 Changing Care Packages 55

4.I Analysing changes in care packages

4.I.I Care packages and welfare system transformations $\quad 55$

4.I.2 Sources of support and packages $\quad 56$

4.2 The Dutch trajectory 57

4.2.I Informal care 57

4.2.2 Formal care 60

4.2.3 Market care 6I

4.2.4 Care packages $\quad 63$

4.3 The Italian trajectory $\quad 64$

4.3.I Informal care 65

4.3.2 Formal care $\quad 67$

4.3.3 Market care 69

4.4 A comparative overview $\quad 72$

4.5 Provisional conclusions and open questions 75

5 Care Packages in Practice 77

5.I Disentangling care packages $\quad 77$

5.I.I The qualitative study $\quad 77$

5.I.2 Looking into care packages $\quad 78$

5.2 Formal home care packages $\quad 79$

5.2.I The content of formal home care packages
in Amsterdam

5.2.2 The absence of formal home care packages in Milan $8 \mathrm{I}$

5.3 Informal care packages 83

5.3.I A similar hierarchy of informal assistants $\quad 83$

5.3.2 Welfare context variations $\quad 85$

5.3.3 Social context variations $\quad 88$

5.4 Commercial home care packages 90

5.4.I Migrant paid caregivers in Milan 90

5.4.2 Paid care in Amsterdam 996

5.5 Residential care packages 99

5.5.I Changing characteristics of the institutions and of the residents 99

5.5.2 Who cares in nursing homes and care homes I00

$\begin{array}{ll}5.5 .3 \text { Who pays for residential care } & \text { IO3 }\end{array}$

5.6 Preliminary conclusions 105

6 The Creation of Care Packages and the Transformations of Care

$\begin{array}{ll}\text { Systems } & \text { IO7 }\end{array}$

6.I Contextualising care strategies: Who decides what and when I07

6.I.I Long-term vs. short-term decisions; strategies vs. coping behaviours $\quad$ I08

6.I.2 Individual vs. family decisions III

6.I.3 Intermediate organisations in the making of care packages II3

$\begin{array}{ll}6.2 \text { Crucial choices } & \text { I2O }\end{array}$ 
6.2.I Gradualism vs. shocks $\quad$ I2O

6.2.2 Staying at home vs. moving to an institution $\quad$ I22

6.2.3 Staying at home vs. moving into a child's home or moving to a parent's home $\quad$ I26

6.3 Who assumes the care tasks at home? I29

6.3.I Filial responsibility in Milan and Amsterdam I30

6.3.2 Resources, opportunities and variations in care packaging

I35

6.4 Care strategies and care systems' transformations I4I

6.4.I The changing family care model $\mathrm{I}_{42}$

6.4.2 The resilience of the formal care model $\mathrm{I} 45$

7 Conclusions $\quad$ I49

7.I The Dutch resilience and the Italian shift $\quad$ I49

7.I.I The context and the problem $\quad$ I49

7.I.2 The two care system's trajectories I50

7.2 Explaining change and resilience $\quad$ I52

7.2.I The role of organisations and families in the Netherlands

152

7.2.2 The role of organisations and families in Italy $\quad$ I53

7.2.3 Actors within institutions $\quad$ I55

$\begin{array}{ll}\text { Appendices } & \text { I57 }\end{array}$

Appendix I

Data and methods of the quantitative analysis $\quad$ I57

Appendix 2

Tables not included in the text - chapter $3 \quad{ }^{6} 64$

Appendix 3

Tables not included in the text - chapter $4 \quad$ I66

Appendix 4

$\begin{array}{ll}\text { Note on the qualitative study } & \text { I73 }\end{array}$

$\begin{array}{ll}\text { Notes } & \text { I95 }\end{array}$

Bibliography 203

$\begin{array}{ll}\text { Index } & 217\end{array}$

$\begin{array}{ll}\text { TABLE OF CONTENTS } & 7\end{array}$ 



\section{Changing Care Systems: An Introduction}

\section{I.I The problem of long-term care}

The link between welfare regimes and the provision of services has long been recognised as a central one (Esping-Andersen I990; I999), but it was only fairly recently that care needs and resources actually became part of the debate regarding the welfare state transformations. Feminist scholars have emphasised the link between the social organisation of care and the position of women in society (Lewis I992; I997a; 2002a; Orloff I993; Knijn and Kremer 1997). However, less attention has been paid to the importance of the social organisation of care and intergenerational relations (Naldini 2006), also in relation to the fact that most research and theoretical reflection has concentrated more on childcare than on care for the elderly. Alongside the demographic transition, the recent literature on 'new social risks' (Bonoli 2005), and the interest in new policy developments in the field of long-term care, care for the elderly has progressively emerged as a politically and scientifically relevant issue and given rise to comparative research (Bettio and Plantenga 2004; Jensen 2008; Taylor-Gooby 2004; Lewis et al. 2006; Ungerson and Yeandle 2003). The research presented in this book will contribute to the debate by looking at the current challenges and transformations in care for the elderly as a paradigmatic case of how care systems work and change.

The current demographic transition is boosting long-term care needs. While the ageing process may mean a longer life expectancy, poor health and disability often characterises the later years of life. In the past, dependence used to affect a few "survivors", and it has now become the norm for a considerable portion of the elderly alive today (Jacobzone et al. 1999; Pacolet et al. 2000): people in all developed countries experience a loss of autonomy in their everyday activities in the last years of their lives. Moreover, this sizeable growth in needs is facing a decline in care resources. The increasing pressures on public budgets alongside the declining availability of informal caregivers and of the formal care workforce represent important factors in this puzzle.

The ways in which care for the elderly is produced and distributed in each society has an influence on the elderly dependents, on the one hand, and on the care providers, whether paid or unpaid, on the other. 
The transformations in elderly care offer a way to analyse the stakes, conflicts and distribution of resources from the standpoints of care users, of informal caregivers and of (semi)professional caregivers. The extent to which elderly care remains within the informal sphere of unpaid family labour or is transferred to the domain of social welfare provision or the market, as well as the specific ways that externalisation takes place, all have relevant consequences on the care arrangements, namely in terms of gender, class and intergenerational relations and inequalities.

By comparing two most different cases - Italy and the Netherlands - this book explores the nature of care systems, how they change and the relationships between social policy changes, societal transformations namely changes in gender and intergenerational relations - and the care system results.

\section{I.2 Changing care policies for the elderly}

Despite signs of the convergence of social policies along a set of principles and instruments throughout the I990s, the trajectory of each national system of social welfare for elderly dependents is less clear due, on the one hand, to the interactions with existing institutional arrangements and, on the other hand, the unclear implications at the level of actual care practices.

\subsubsection{Elderly care models in the early $1990 \mathrm{~s}$}

Following Anttonen and Sipila (1996), at the beginning of the I990s, at least four social policy models in the domain of elderly care emerged in Europe. ${ }^{\mathrm{I}}$ Differences were found mainly in the levels of residential and home care services that were being provided and the logics that underpinned these social provisions. Nordic countries and the Netherlands had the, comparatively speaking, highest level of service provision. Access to services in these countries was based on citizenship and residency and was neither linked to previous contribution nor to socio-economic conditions. Co-payments, when present, were based on a user's income. The public sector (and a regulated non-profit sector in the Netherlands) had a crucial role in service provision. At the other extreme, in the Southern European countries, despite a certain amount of growth and some attention in public debates throughout the I980s, social services for the elderly remained a residual part of social policy. The access to the limited, existing services was either means tested or subject to discretionary and territorially scattered criteria. The UK, where social services for the elderly were rather well developed, was found in an intermediate position, closer to the Nordic countries. Nevertheless, relevant changes were already being introduced in the $1980 \mathrm{O}$ in the direction of a 
neoliberal model and based on the introduction of individual responsibility, which somehow anticipated the trend that emerged in the course of the I990s across Europe (Lewis 2002b). Finally, Central Europe's access to services ranked somewhere between Southern Europe and the UK. Even if many continental European countries showed that they had better services, their functionality and underlying logic were not that different to those found in the Southern European countries.

Besides the variations in social policies, important differences emerged between the various systems with respect to the availability of informal care, i.e. the care provided by relatives and other members of the informal network of the elderly who need support. Despite the fact that informal care has remained an important source of support in all societies (Daly and Lewis I998; Rostgaard and Fridberg I998; Sundström et al. 2002) and that families have not only maintained an important role in fostering the circulation of both money and care far beyond the nuclear family (Comailles and Martin I998; Dechaux I990), the extent, intensity and nature of informal caregiving varied greatly country to country. Comparative research suggests that in countries with more developed social services the overall volume of help provided by family members was higher, but of a lower intensity, less oriented to heavy personal care and more spread across a larger number of different caregivers, compared to countries with less developed services, where caregiving is more intensive and less voluntary (Daatland I990; Ogg and Renault 2006; Igel et al. 2009; Albertini et al. 2007). Accordingly, the legal obligations towards elderly relatives reflected the various logics of the individual country's social policies: the stronger the legal obligations, the weaker the provision of services (Saraceno and Naldini 2007). The legal obligations one has towards one's parents are the strongest in Southern European countries, where they do not solely concern elderly parents, but a wider range of relatives as well. There are also legal obligations in countries such as France, Belgium, Austria and Germany, while they are absent in the UK, the Netherlands, and the Scandinavian countries ${ }^{2}$ (Jenson and Jacobzone 2000).

Despite the fact that little information is available on market arrangements at the beginning of the I990s, a truly market-based system could not be identified and it is very likely that market solutions mainly concerned a minority of better-off individuals and families.

To summarise, in the early I990s, responses to the care needs of the elderly were based on a variety of combinations between care provided by public or publicly funded and regulated agencies and informal care provided by the family and other informal sources. In Southern European countries, the mix had a more important family component. Nordic countries and the Netherlands were characterised more by social services and less by family responsibilities. The rest of the European countries were either similar to the Southern European model or, like the UK, closer to the Nordic model. The differentiation of care policies, 
in this perspective, corresponds to the classic Bismarck-Beveridge divide, with the Scandinavian model being "the luxury version of the Beveridge model" and the Mediterranean model being "the cheap version of the Bismarckian (conservative) model" (Abrahamson 1999: 34).

\subsubsection{The policy shift in the 1990s: Common trends}

The I99os represent a crucial turning point in the definition of strategies to cope with elderly dependence. This is when a set of common social policy trends in the field of elderly care began being observed in most European countries. Two factors are prominent in these developments: financial concerns and the ideology of clients' empowerment (or responsibility). While some of the subsequent reforms are specifically linked to developments in long-term care, others are intertwined with general shifts in social policies.

Firstly, the containment or reduction of residential care - in some cases beginning in the I980s - was pursued by most European countries, with the aim of shifting from more costly institutional services to less costly home-care services and allowing the elderly to live in their own social environment as long as possible (Hutten and Kerkstra I996; Jacobzone et al. I999).

Secondly, while chronic illnesses were traditionally being treated (partly) within the framework of health care systems, attempts were made to shift the rising costs from health care to social care. A typical example of this is the identification of new criteria for hospital admittance, which applied stricter criteria so that the elderly who needed longterm care could be increasingly diverted to nursing homes. At the same time, residential care was made available to those elderly with severe health and care needs, while beds in care homes, which had traditionally provided social care, were either reduced in number or converted into nursing home beds (OECD I996b; Pacolet et al. 2000).

Thirdly, the strategies of cost reduction or containment were put in place in the management of home care services, under the pressure of demographic developments and the consequences of the deinstitutionalisation process. In several contexts, stricter eligibility criteria and, implicitly, higher co-payments further targeted the beneficiaries (Knijn 200I; Szebehely 2005).

The externalisation of the production of services and the introduction of competition between providers was also considered a way of increasing productivity. In fact the fourth trend involves the introduction of "new public management" ideas (Ferlie et al. 2007) in the field in order to achieve cost reductions and flexibilisation of the supply. The provision of services was often shifted from the public to the private sector via outsourcing - which involved almost all of the Western countries, including Scandinavian countries such as Sweden and Denmark (Domberger I998; Young 2000) - or via the creation of a "quasi-market", based on 
the separation of service production and purchasing functions ${ }^{3}$ (Barlett and Le Grand 1993).

Fifthly, cash-for-care schemes emerged as a new form of social provision in the domain of elderly dependence. The introduction of different types of cash transfers to the elderly dependent and/or their informal caregivers instead of the provision of in-kind services (Weekers and Pijl I998) was accompanied by the adoption of consumer-choice models (Pacolet et al. 2000). This development can be seen as an attempt, on the one hand, to reduce care costs via the "informalisation" or the "marketisation" of care and, on the other, to empower the users by making care more flexible and demand oriented.

Sixthly, policymakers have placed increasing emphasis on informal care. A home-care-centred strategy relies heavily on the availability of informal resources. 24-hour domiciliary assistance, is probably as expensive as institutional care or even more if provided solely through formal care labour (OECD I996b). Informal care therefore became an important (and cheaper) form of support, which needed to be developed and sustained (Zandbergen 1995) either via cash benefits or via support and counselling services.

Lastly, the decentralisation of social policies in the domain of elderly care was implemented. The relationship between central and local governments represents a problematic knot not only in continental Europe and the UK, but also in the Scandinavian countries, where national regulations are open to various interpretations by local authorities. Research has shown that different levels of service provision were observed in relation to the place of residence, both in terms of quality and quantity (Hanssen 1997; Kroger 1997; Trydegard and Thorslund 200I). The reduction in services occurred throughout the I990s and mostly at the local level in countries like Sweden. A stricter interpretation of the rules concerning need assessment, alongside the use of a fee system as a deterrent and the reorganisation of supply, which reduced staff continuity, have been used to limit access to home care (Trydegard 2003). This discretionary power at the local level implied what was called the rise of "welfare municipalities" (Simonen and Kovalainen I998).

\subsection{3 ... and different trajectories}

These common trends took place in very different contexts. In some cases, depending on the starting point, there was a containment or reduction in the provision of care, while in other cases the reforms were accompanied by an increase, particularly in the field of home care services and care allowances. As a result, the above-mentioned developments cannot be called welfare retrenchment or restructuring in all cases: social rights were sometimes restricted and sometimes broadened. 
The changes that occurred in the Nordic countries and the Netherlands were often deemed as likely to undermine universalism and the degree of inclusiveness of the system. The combined effect of the deinstitutionalisation policy, the limited growth or, in some cases, reduction in the numbers of home-care receivers as a result of explicitly stricter eligibility criteria or implicit rationing implied a decreasing level of coverage for the target population and a concentration of available resources on a smaller and needier group of beneficiaries (Sunesson et al. I998; Simonen and Kovalainen I998). As a result, an increased access to market solutions and informal care in Sweden, for instance, was observed (Szebehely 2005) where the cutbacks fostered a "reverse substitution" between formal care and informal care (Johansson et al. 2003), particularly among the lower classes. Meanwhile, commercial care options for the better off increased as well (Trydegard 2003). Similar concerns have been expressed in the Dutch case too (Knijn 200I). Nevertheless, as noted, these transformations did not affect each Scandinavian country equally. Recent developments probably did introduce more diversity within the Nordic cluster (Trydegard 2003). In the UK, the shift towards "community care" was already happening in the I980s, where there was an increased emphasis on individual and family responsibility and on community solidarity (Lewis 2002b). The introduction of meanstested services and the targeting of beneficiaries meant that social policy for elderly dependents became increasingly based on a neoliberal model (Anttonen and Sipila 1996).

Meanwhile, several European countries that have traditionally been involved in the public provision of services devoted increased attention to elderly care policies. New welfare schemes were introduced in order to provide broader coverage for the elderly in Germany (Götting et al. I994; Goerke 1996; Evers 1998; Alber 1996; Wegner 200I), Austria (Österle 200I), Luxembourg (Pacolet et al. 2000) and France (Sueur 2000; Martin (ed.) 2002). It is difficult to assess the results of these rather heterogeneous developments on this group of countries. However, one should note that new social risks (or needs) were recognised by the political system. The new rights were translated into social interventions under the influence of the new "policy instruments" such as care at home, mainly provided via cash-for-care schemes instead of via the direct provision of services, with a strong emphasis on informal care as a key element in care arrangements (Da Roit et al. 2007; Pavolini and Ranci 2008).

These developments did not occur in the Southern European countries, which have undergone less noticeable changes in social policy. Given the limited availability of residential care services, a true deinstitutionalisation process never took place here. The growth of home-care services occurred at a pace that was too slow to actually keep up with demographic changes. The recourse to care allowances was in line with the history of elderly care and social policy more at large in these coun- 
tries. In any case, it did not represent a broadening of social rights. The substantial reform of elderly care policies has been either totally absent, as in the case of Italy (Naldini and Saraceno 2008; Da Roit 2009) or occurred only very recently so that the results still have to be measured as in the case of Spain (Costa-Font and Garcia-Gonzalez 2007). Meanwhile, there have been relevant changes in the actual care practices in other Southern European countries as a large private-care market has begun to emerge. The visibly increasing recourse to paid (migrant) caregivers hired directly by the families has, in fact, been observed since the mid-I990s (Castegnaro 2002; Ambrosini and Boccagni 2002; Vaiou 2002; Ramirez 1999).

\section{I.3 Analysing care systems transformations: Comparing Italy and the Netherlands}

If dependence in old age represents a challenge for the consolidated ways in which each society responds to care needs, the forms, motives and mechanisms underlying such challenges vary across countries and are likely to reveal different results and trajectories. Moreover, a focus on social policies and their transformations, which does not consider the ongoing changes within other welfare spheres and agencies is likely to overlook the transformations that are occurring in welfare systems. In order to tackle these two problems, we compare the trajectory of two distinct and, for many reasons, opposed long-term care systems.

\subsubsection{A care system approach}

This book offers an analysis of care systems and the transformations care systems have undergone, which is empirically based on a comparison of two contrasting cases - Italy and the Netherlands - between the early I990s and 2003-2004. The book starts out by discussing the logic of this comparison and reconstructs the context in which this analysis takes place (chapter two). The social policy trajectories of the Dutch and Italian cases are presented, together with the specific challenges posed by the ageing processes and with the possible trajectories of the two care systems. In the domain of elderly care, the Netherlands represent a quasi-Nordic country, with a well developed system of protection of the dependent elderly, and Italy a Southern European country, where family involvement in care for the elderly has traditionally been the core of the system.

In the Netherlands, several attempts were made in the I990s to contain social care provision, and to foster both informal care and market solutions in response to rising care needs. Italy, meanwhile, imposed a discernible "freeze" on public policy, which led to the emergence of a private and unregulated care market. 
Some obvious questions emerge from these two distinct cases. What happened to the two care systems? Has the Netherlands become a more familialised and marketised system? Does Italy still represent a familialistic care model or does it have a more market-driven system? How and why did all of this happen? What are the underlying forces that guided these changes (if any)? On the one hand, the goal of this research is to unravel the issues of if and how the policy reforms implemented in the Netherlands have been coupled with a substantial transformation of care practices. On the other, it is to investigate to what extent and how this transformation of a care system takes place.

There is a complex interrelationship of relevant institutions and actors who provide support to the dependent elderly. There is also the situation of their reciprocal influences that define and transform care practices, and so, rather than investigate the transformations of the welfare state the focus is on the transformations of the welfare system, and more specifically, the care system. Esping-Andersen (I990) defined "welfare regimes" or "welfare systems" not simply as different types of social policy, but as social systems where a specific combination of "state", "market" and "family" can be identified as welfare agents. Each type of welfare regime - with a typology based on the criteria of de-commodification, re-stratification (Esping-Andersen I990) and de-familisation (EspingAndersen 1999) - is clustered around a specific combination of modes of protection and represents a specific type of "societal integration".

\subsubsection{Care production and allocation between family, state and market}

Each care system has its own specific solution for the cost disease (Baumol I967). The rising costs of the production of services may be internalised by the public sector (the social service model), sustained by the families (the family model) or by an under-paid and under-protected workforce (the liberal model) (Baumol I968; Skolka I977; Esping-Andersen I990; 1999). A care system transformation implies a change in the division of responsibilities for solving the cost disease between state, families and labour market.

As emphasised by Szebehely (2005), the double question is "who cares", on the one hand, and "who pays", on the other. ${ }^{4}$ The production and allocation of care might not respond to the same logic within a system. In a simplified situation, we identify three ideal-typical systems, each dominated by one institution - social policy, the family or the market - and one mode of production and allocation of care - redistribution, reciprocity or market exchange. The social service system that most resembles the Dutch case at the beginning of the I990s was one that was dominated by care services produced (or regulated) and distributed by the public sector, and thus removed from both market logic and reciprocity. A family-based system, which most resembles the Italian case at the 
beginning of the I990s, was dominated by the production and allocation of care within the family and other informal networks according to the rules of reciprocity. In a market-based system - which would have been difficult to find in the Europe of the early I990s - care is produced based on the logic of labour market forces and is purchased like a commodity. The ongoing transformations have led to a divergence of the logic of production and allocation within each system. This divergence may be the result of policy developments. For instance, cash allowances may commodify informal care (Ungerson 1997; 2000) or introduce new care markets. As a result, the allocation of services often remains independent of market forces and the family, while the production of services may be more dependent on the market or the family. But perhaps it is the families who choose to externalise care tasks by purchasing them on the market. This would imply the (permanence of) familisation with respect to the allocation of care resources and the marketisation of production.

In order to determine to what extent policy- and non-policy-oriented transformations have altered the nature of a care system we need to analyse whether the prevailing mode of production and allocation of care services shifts from one institutional form to another - from state to the market or to the family (in the Dutch case) or from the family to the market (in the Italian case).

Firstly, the research looks at the trends in the incidence of dependence over time in the two countries and the extent to which the increasing care needs have represented a challenge for the two societies in recent years (chapter three). What emerges from the analysis is that socio-demographic (age and social structure) and institutional factors (the distribution between the elderly living at home and living in institutions) contribute to making dependence in old age a much stronger challenge for the Italian compared to the Dutch society. The "risk" of dependence increased in the Netherlands during the period considered as a consequence of the implementation of deinstitutionalisation policies. However, this is not the case in Italy where the risk remained stable over time. Against this background, the macro-transformations of the two care systems are discussed (chapter four). The investigation is based on the analysis of (changing) "care packages", i.e. the combination of different sources of support for older dependents, in Italy and the Netherlands between the early I990s and the early 2000s. For this purpose, we use cross-sectional micro-data available at different points in time (early I990s, late I990s and early 2000s) in Italy and the Netherlands that provide information on dependence - i.e. limitations in daily activities and on the resources employed by households in order to cope with care needs such as social services, family support and commercial services. ${ }^{5}$ The analysis shows that when we look at developments in care practices, surprisingly there were only very limited changes in the Netherlands. On the one hand, the Dutch care system remained mostly based on formal 
care, while we see a decrease in the availability of informal care. On the other hand, the Italian care system experienced a shift from mostly informal care to an increasing dependence on market solutions while experiencing a dramatic decrease in the availability of informal resources.

\subsubsection{Care strategies, the family and the institutional context}

These results are then analysed to better understand the social mechanisms that made the Dutch care system relatively resilient while causing significant transformations in the Italian system. From a macro-analysis, we move to a micro-analysis. In chapters five and six, we analyse the qualitative data connected with long-term care and look at the social mechanisms that constructed the care packages, which are comprised of the social interactions of individuals and families with other relevant social actors such as professionals, care workers, various organisations. All of them are embedded in a set of existing "rules of the game", or institutions. As observed by Lewis "the tendency has been to treat the family as a dependent variable, but the family as a major provider of welfare also warrants consideration as an independent variable" (1997b: 307). If the family represents one of the main structures on which the principle of reciprocity is based, it can also be seen (together with individuals within it) as a social actor that combines resources, makes choices and defines strategies in order to cope with social risks or face specific needs.

Families do not necessarily lose their economic role and may continue to act as welfare agents, which means that the possibility of social change as a consequence of changes in family relations, behaviour and strategies should be seriously considered. On the one hand, new strategies of care may be found in systems that, from a policy perspective, are relatively stable and, on the other hand, family strategies, choices, decisions will interact with new policy directions. Individual and family strategies, and their choices, decisions and behaviour may influence the welfare system by approving or resisting a particular policy or they independently may initiate policy transformations.

The reconstruct the logic of the packaging (the behaviour, choices, decisions, strategies that determine specific care packages) instituted by families is the lens through which the transformation of the two systems is analysed (chapters five and six). The underlying idea is that social change and persistence may be analysed through how care packages are constructed at the individual and family levels, within a system of institutional and structural constraints. We must also keep the relations and contacts with intermediate localised social actors in mind. The qualitative study, which was conducted in Milan and Amsterdam in 20032004, reconstructed the specific local contexts via policy documents and conversations with key actors (professionals, care institutions managers, etc.), interviews with caregivers (informal, formal and commercial caregivers) to provide insights into how the care packages are constructed. 
Chapter five illustrates the actual content of the care packages in each context and sorts out the relevant actors in each system. Chapter six looks at how key choices in care for the elderly are made, in relation to the contextual factors that facilitates them and the consequences for the welfare system. A general conclusion of the research is presented at the end of the book (chapter seven). 



\section{The Context and Policy Trajectories}

\section{I The comparative logic}

European societies are facing the challenges posed by dependence in old age from uneven positions. The nature of these challenges varies greatly in relation not only to different paces and timing of the ageing process, but also to different consolidated institutional arrangements in the domain of long-term care. Existing social, economic and institutional developments contribute to the defining of the specific situation in which each society finds itself, the specific stakes and the social and political construction of dependence as a problem.

The two cases studied in this book were chosen for their contrasting features: the objective of analysis is to observe the modes of transformation and the trajectories of care models originally based on contrasting principles and affected by different policy trends. In mainstream welfare analysis, the Dutch case usually falls into the "continental-conservative" welfare family, even though it qualifies as a very special case, in terms of the general welfare context (Esping-Andersen I990). It is also special in relation to recent transformations and increased women's participation in the labour market (Green-Pedersen 200I; Visser and Hemerijk 1997). The Netherlands does not fully qualify as a social service model similar to the Scandinavian countries, because its development of childcare services is traditionally quite limited compared to Scandinavia (Anttonen and Sipila 1996). Nevertheless, in the domain of care for dependent elderly people, it shows a high level of risk socialisation and a widespread provision of services compared to other European countries (OECD I996b). The Italian case is even more contested in the framework of welfare studies. One the one hand it was included in the conservative cluster by Esping-Andersen (1990; 1999); on the other it has been argued that, based on the importance of the family as an agent of welfare and the weak and fragmented state intervention in social policy, it is part of a separate model (Ferrera I996; Leibfried I993; Saraceno 2003; Mingione 1997). When analysing the domain of elderly care, Italy is usually considered as a family-based model with residual social policies. While socialised responses to old age dependence are prevalent in the Netherlands, family responsibilities play a more important role in Italy, as reflected by aggregated data on the provision of institutional, day care and home care for elderly people (Anttonen and Sipila I996). If, at the beginning of the I990s, these two national cases represented the two ex- 
tremes along the European continuum, they also represent contrasting trajectories of change. The Netherlands embodies a case of continuous policy reform since the early I990s in the field of long-term care, while Italy is characterised by substantial levels of immobility. The Italian and Dutch cases thus allow us to analyse policy-driven and non-policy-driven trajectories.

The present chapter looks at the challenges that the dependence in old age poses for the established equilibrium in each system and the relative stakes.

\subsection{The Dutch model}

The Dutch model was shaped in the I960s and I970s and has traditionally been dominated by formal care and a high degree of the socialisation of risk. However, the transformations introduced in social policy since the I990s may have undermined this and introduced a new trajectory. The debate is whether, and to what extent, the Dutch system has undergone a process of re-familisation and marketisation of care as a consequence of increased needs, on the one hand, and progressively more restrictive social care policies, on the other.

\subsubsection{The policy framework in the Netherlands}

When considering the institutional framework for elderly care in the Netherlands, it is necessary to look at the interrelationship between housing policy, health and social care policies (De Boer I999). The high percentage of the elderly living in care institutions - one of the most important traditional features of the Dutch care system for the elderly throughout the I970s and I980s is, in fact, related to the growth of social housing policies. ${ }^{\mathrm{I}}$ The second post-war period was a crucial time for the development of both the care and housing policies. ${ }^{2}$ After WWII, an acute housing shortage emerged in the country because of the devastations caused by the war. The solution was to construct new housing for the elderly so that younger couples with children could live on their own and introduced the notion of care homes (verzorginghuizen) for the elderly (Van den Heuvel I997). This development was a combination of national government action and that of the private non-profit housing organisations (woningcorporaties). In order to properly supervise the care homes, regulations on housing and care for the elderly were subsequently released: ${ }^{3}$ houses that met the criteria were entitled to public funding. In the I96os, nursing homes (verpleeghuizen) began to develop, for the provision of care for those with more serious health care needs. Because it was thought that the chronically ill did not need specialist medical treatment, their hospitalisation could be drastically minimalised. This also had to do with the refusal of insurance companies to 
cover acute care expenses for the chronically ill patients - and so many of them were moved to nursing homes. Intensive residential long-term care has been financed by a specific national compulsory insurance, the AWBZ, ${ }^{4}$ since the late I96os. It covers not only the "exceptional health risks" of the elderly who need nursing and care but also of the mentally ill and adult handicapped. ${ }^{5}$ This mandatory insurance covers all Dutch residents, regardless of their citizenship, with no age limits, and is financed via income related contributions. ${ }^{6}$ The extremely high costs of long-term care are therefore socialised. Benefits can be received after claimants are assessed by an independent regional board, ${ }^{7}$ which evaluates care needs and recommends the proper interventions.

Until the early I970s, services covered by the AWBZ were mainly residential. The proportion of institutionalised elderly people has grown considerably over the years. In fact, the Netherlands had the highest institutionalisation rates of elderly people in Europe during the I970s and I980s (OECD I996a; I996b). However, the AWBZ, which was originally created for funding care in nursing homes, was progressively expanded to cover home care expenses and later elderly homes as well. ${ }^{8}$

Elderly care has long been largely defamilised in the Netherlands, at both the production and allocation of services levels, due to a system of housing and care provisions. Family members were not responsible for providing care or for paying for that care. The elderly could rely on social services and they and their families did not need to have to pay for these services, which were mainly provided by non-profit organisations that were legally licensed. This does not necessarily imply that informal care was no longer of any importance. On the contrary, recent research has shown that informal assistance provided by family members and friends remained a relevant form of support (De Jong Gierveld et al. I997; De Klerk and Hessing-Wagner I999; Van Doorne-Huiskes et al. 2002). In I999, a national survey reported that $9 \%$ of the population aged I6 and over was then currently providing some assistance to a person with a chronic illness, while $2 \mathrm{r} \%$ had been caring for someone over the last three years. In $43 \%$ of the cases, the cared-for person was a parent who no longer lived in the same household (Timmermans et al. 200I).

\subsubsection{The debate on the formal care model and social policy changes}

Reconsiderations of this formal care model have risen dramatically in public debates in the Netherlands. This is due to two different developments. First, the dominant social policy discourse has emphasised the need to contain and reduce the costs of long-term care, accompanied by that of making individuals more responsible for their own care and for each other. The purported need to shift from a "welfare state" (verzorgingsstaat) to a "welfare society" (verzorgingsmaatschappij) (Kuiper et al. I983; I987) dates back to the I980s among the Christian Democrats and has been increasingly emphasised, until it became the conceptual 
basis for an all-encompassing reform of social welfare and the care sector in the mid 2000s - the WMO (Wet Maatschappelijk Ondersteuning) or Social Support Act. The reform was specifically aimed at fostering individual responsibility, informal care and the decentralisation of care policies to ultimately reduce the health care budget (VWS 2005). Second, organisations representing the disabled, and later on the elderly, have demanded greater independence, empowerment and choice for the users of these services (Kremer 2006). The users' organisations pushed for the rights of dependent people to determine and choose their own care arrangements. This would override a burdensome bureaucracy that was deciding over people's care needs and solutions. At the intersection of these different claims the Dutch care model was put into question. There has been a continuous process of reform of long-term-care policies in the Netherlands since the I990s, which has resulted in a series of policy innovations and retrenchments (De Boer I999, Knijn 200I) that are consistent with both the above-mentioned perspectives.

The deinstitutionalisation process represents the first and, by now, more traditional challenge to the Dutch care system. The first signs of change in Dutch long-term care can be traced to concerns about the large proportion of the elderly living in institutional settings. The process of "extra-muralisation" was predicated on arguments that the elderly actually preferred to live independently as long as possible. While shifts in policy debates and policy goals have been going on since the midI970 , it was only in the later I980s that new policies affecting the independence of the elderly began to be implemented and affect the living circumstances of the elderly (Van den Heuvel I997). In 1965, the capacity of elderly homes was $6.7 \%$ of the elderly 65 and over; it rose to $8.8 \%$ in 1970 and $9.7 \%$ in 1975 . Moreover, if we add the capacity of nursing homes to this total it rises to over I2\% in I975. Ten years later the institutionalisation rate was still 10\% of people aged 65 and over but this figure had dropped to 6\% by 2003 (de Boer 1999:30, table 2.2; Statistics Netherlands, StatLine). Besides the argument that many individuals prefer home care, de-institutionalisation is also based on the assumption that home care services are less costly than institutional services. However, there are crucial implications of this assumption. Although deinstitutionalisation plays a considerable role in cost reduction strategies, it also represents a major challenge, as increased support for home care has to be provided somehow (Jacobzone et al. 1999). A switch to community care may result in care that is as expensive as institutional care if all of the costs are taken into account (Weissert and Cready I989). Community care may appear to be less expensive when a vast range of informal services are called upon to replace much more expensive professional care. As a result, this sharp de-institutionalisation trend challenged the organisation of home care services and required more involvement of informal caregivers. 
New forms of home care services evolved, including round-the-clock and weekend support. The expansion of the home care sector throughout the I990s can be seen in the increasing number of home-care employees: 126,000 in 1995 and 580,000 in 1999 (Arts 2002: 10). The development of home-care services uncovered an even greater population of dependent elderly people already living at home who were eligible for these services. This put even more strain on home-care services (and informal caregivers) and led to increased calls for even more cost containment and measures to increase productivity such as the "taylorisation" of tasks (Knijn 200I) or the introduction of competition among the providers. These contradictions were made evident by the cutbacks, on the one hand, and labour shortages in the home-care sector, on the other (Arts 2002).

While they were virtually nonexistent in the traditional health and social care sector (De Boer 1999), co-payments by home care receivers (income-related tariffs per hour of home care received) developed rapidly in the I990s. Some argue that these developments were going to limit the use of home care among both the low and high-income groups. Although low-income earners have the right to social assistance when they cannot afford the individual payments themselves, they would increasingly attempt to access informal care (therefore free of charge) instead of requesting social assistance. High-income earners, on the other hand, would try to solve their care problems via the market (Knijn 200I: I72). According to government advisory boards, these developments threatened to alter the nature of the AWBZ as a general collective insurance (Commissie Sociaal-Economische Deskundigen 1999).

Until I995 care was only provided in kind while organisations that represent the elderly and the disabled were demanding the right to arrange their own care. Care allowances were first introduced in the Dutch health care system in the mid-I990s. The introduction of PGB (Persoonsgebonden budget - personal budget) raised a considerable amount of debate, as cash allowances represented a major break with the traditional system of care in kind, for the beneficiaries, as well as for policymakers and providers. In I995, with the introduction of the PGB a limited number of those eligible for home care were provided with a cash allowance instead of in-kind services. This allowance was not a direct cash payment, but rather a budget that beneficiaries could use to arrange their own care (Kraan et al. I99I). Since I995, a limited but increasing portion of the annual AWBZ budget was going to PGB applicants for home care. By 200I, everyone who had been approved for home care for at least three months were declared eligible for a PGB, with no overall budget limit. The number of budget holders rose steeply since the second half of the I990s: from slightly more than 5,000, to 60,000 in 2003 (De Boer and De Klerk 2006: 15I) and 80,000 in 2007 (VWS 2007). Nevertheless, since its inception, opting for a PGB seemed to be more popular among the younger handicapped than among the older dependents (Mil- 
tenburg and Ramakers 1998). In 2005, those 65 and over with a budget comprised $43 \%$ of the total (De Boer and De Klerk 2006: I52). Estimates show that in 2007 the younger clients represented approximately I०\% of all those receiving AWBZ-compensated care and $5 \%$ of the elderly receiving AWBZ-financed care ( $7 \%$ of the elderly receiving AWBZ-reimbursed extramural care). ${ }^{9}$ PGB beneficiaries can spend available resources to compensate non-professional caregivers, private professional services or traditional home-care services. An early study found that ca. $25 \%$ of PGB holders purchased care from the traditional (not-for-profit) home-care organisations. But they used commercial home-care services or self-employed caregivers more frequently. In ca. $20 \%$ of the cases, care was provided by informal caregivers (Miltenburg and Ramakers I998). In 2007, one-third relied solely on informal care, one-third on formal care and one-third on a combination of the two (VWS 2007).

In 2003, major changes took place in the allocation of care benefits. Since then, territorial boards no longer evaluate the care needs of AWBZ applicants in terms of service assigned and type of provider - i.e. home care, care home, or nursing home - but in terms of the amount and type of care that will be made available to a particular client. ${ }^{\text {IO }}$ All types of care by individual professional providers are available as long as they comply with the Care Professionals Act (BIG). This is also valid for any careproviding institution that complies with the AWBZ criteria. The emphasis was on the empowerment of the users as well as on the incentives for care providers to adopt a more market-oriented attitude to attract paying customers.

A tendency towards decentralisation in policies focusing on the elderly has been observable in recent years. This was considered a strategy for the improvement of the response to local differences and for the achievement of better relations between supply and demand. Local authorities have been responsible under the Welfare Act for the economic welfare of the elderly since I988. Moreover, local authorities have since the midI990s also been responsible for the implementation and partial funding of their care. Nevertheless, these developments have mainly affected services not included in personal care and home help covered by the AWBZ, but by other complementary agencies. ${ }^{\text {II }}$ Later on, the Dutch care system underwent a substantial transformation in January 2007 with the implementation of the new Social Support Act (WMO). Some of the benefits that had traditionally been covered by the AWBZ - namely home help - have been handed over to the municipalities. The consequences have been twofold: a citizenship right has been transferred to a domain of social policy - locally managed social assistance and care - where discretionary power is more important while a service that was once integrated (health, social and household care) has been split into distinct provisions (health and social care on the one side, and household care on the other), which respond to different logics. 


\subsubsection{Which trajectory for the Dutch model?}

The developments in long-term care policies in the Netherlands since the early I990s challenge the centrality of the formal care model and tend to foster informal care and market-related principles. However, the extent of this shift is not yet entirely clear.

Embedded in the shift from institutional care to home care is the expectation that informal support may complement or substitute home care as to reduce the cost of services. Increased co-payments may reduce the attractiveness of social services, particularly for lower income elderly people, who may prefer more informal care. The personal budget strategy, which consists of providing care users with more freedom of choice regarding their care, was also aimed, in part, at stimulating (cheaper) alternative informal care. It is, however, unclear to what extent these developments may be responsible for an increased involvement of informal networks in the instrumental support of the frailer among the elderly or to what extent ongoing changes might encompass a re-familisation of elderly care. Policy changes may not end up producing immediate and straightforward results. The strategies of the elderly living at home and of their informal network are likely to play a significant role in mediating the above-mentioned policy shifts. Have families - namely women - become more involved in the care of the elderly than in the past? The (increased) availability of informal care is probably going to be limited by structural conditions, such as the distance between children and their ageing parents or the participation of children (daughters) in the labour market, for instance, (Bouget 2003; Attias-Donfut et al. 2002; Johnson and Lo Sasso 2006; Lundsgaard 2005), but also the unavailability of new generations of women to care more for the elderly (Gaymu et al. 2008), especially in a context where this type of care has long been defamilised. Moreover, the reorganisation of care along community and not family lines has to be confronted with the clear evidence that broader informal networks - which may be important in providing emotional support and occasional instrumental support - are unlikely to be involved in heavy care provision (Broese van Groenou I995). Moreover, the successive reforms - with the exception of the most recent introduction of the WMO - have never challenged the core of the long-term care system in the Netherlands, which is a national arrangement that guarantees general basic financial coverage. If these factors significantly reduce the impact of the predicted re-familisation of care, it is possible that the effects of the new policy are not the same for the entire population and that different outcomes reveal increasing social inequalities. Alongside traditional socio-economic stratification, a potential additional division has to be taken into consideration here: the changing composition of the elderly population in terms of ethnic origins. "Traditional" coping strategies, i.e. based on family responsibilities, may be more prevalent among families of non-Dutch origin (Yerden 200I; Poort et al. 200I). 
The liberalisation and the introduction of competition in the provision of home care services and the personal budget arrangements are both challenges to the formal care model and undermine its very nature. First, the empowerment of the clients and the introduction of competition have in part transformed care into a commodity that can be purchased in the market. The volume of home care services financed via the AWBZ increased considerably during the period of the early I990 to the mid-2000s, even if individual costs have not, particularly since 2000 (Egging et al. 2008: 25-26). It seems that the cutbacks have had more of an influence on the price of formal care (and possibly its quality) than on the availability of that care. In fact, marketisation mainly concerns the production side of care. By contrast, the allocation of benefits continue to be based on citizenship and need. The centrality of the national scheme of social welfare and its high degree of regulation, together with its well-regulated labour market should reduce the impact of marketisation.

As this discussion shows, besides the clear tensions, one should also consider the possibility that there has been substantial resistance to any change since the early I990s. The pressures in favour of the familisation and commodification of care are no doubt going to come up against sizeable resistance. In fact, the system of formal care is well developed and part of a highly regulated and centralised institutional arrangement, which implies that changes introduced via social policy in the I990s may not be as successful in transforming the system as has been thought.

\subsection{The Italian model}

Although informal care of the elderly has always been crucial in every type of welfare system, in countries like Italy it has a specific shape, weight and meaning. The needs of the dependent elderly traditionally have been met within the (extended) family, usually thanks to the unpaid work of spouses, daughters and daughters-in-law, as has been documented by various empirical studies (Taccani 1994; Facchini 1996; Micheli I996; IRER 2000). The legal responsibilities of family members in supporting relatives have remained an important aspect of the care system (Millar and Warman 1996; Saraceno and Naldini 2007; Naldini 2002), in a context of weak policies.

\subsubsection{Long-term-care policies in Italy}

Compared to the Netherlands, Italian long-term-care policies are much more fragmented, as a result of their historical development (for detailed historical accounts see: Fargion 1997; Ferrario 200I; Giumelli 1994). Charities, especially in the field of institutional (residential) care for the 
poor and the disabled, played a very important role since the second half of the nineteenth century. The core of Italy's social policy also after their nationalisation in the I89os, consisted of financially and politically controlling these traditional and fairly rich institutions. ${ }^{12}$

During the Fascist regime under Mussolini, the institutionalisation of so-called deviants and the disabled remained a key feature of social policies through the activities of the (formally nationalised) religious entities. Moreover, a series of new national ad hoc interventions that focussed on care were introduced between the two world wars that favoured specific groups (war veterans, war orphans and, later on, "the deaf", "the speechless", etc.). Newly established national institutes administered specific policies, which were generally based on cash allowances. By contrast, Italian municipalities played a marginal role with limited responsibilities in caring for the handicapped or elderly poor, including those with no families to care for them.

Despite the new outlook of the post-WWII Republican Constitution, Italian social policies until the late Ig6os followed a consistent path: the establishment of new national bodies, similar to those introduced by the Fascists, merely added new "categories" of beneficiaries who were eligible for national cash benefits. Moreover, the policies that governed the institutionalisation of the handicapped, elderly and children remained intact. It was only in the I970s, after regional institutions were put in place and the decentralisation of competences in the domain of social assistance that the idea of establishing regional and local social services became part of the social and political debate. Nevertheless, the introduction of new policies was on a small scale and merely superimposed new services over old interventions. As a result, social services developed, to a limited extent, at the local level next to (but not connected to) national allowances directed to specific "categories" of citizens. Finally, while the national health system was being implemented in 1978 , a similar social welfare scheme failed to pass in Parliament. This contributed to separate developments in the fields of social care and health care and to the further marginalisation of social services and social support. Without a national framework of legislation on social services, each region had to adopt its own normative framework both in the domain of social services implemented by local authorities (within a limited scope and with minimal financing) and in the domain of health care policies, which were relevant for establishing residential and home health care. The analyses of social programmes and social expenditures show a clear North-South divide regarding the degree of social policy development (Fargion I997; Labos 1992, 1994) as well as a fragmentation of social interventions in these regions (Artoni and Ranci Ortigosa 1989; Da Roit 200I) and the development of different health care models.

Despite important territorial differences, social interventions in the domain of long-term care are generally limited. The supply of residential care has traditionally been scarce: the national institutionalisation rate 
for the elderly has never been more than $2 \%$ of the population aged 65 and over, ranging from I\% in the south, to $1.5 \%$ in central Italy and $3 \%$ in the north in the early 2000s (ISTAT 2002, 2006a; Bonarini 2002). Despite a certain amount of growth, public home care services implemented by local authorities have never reached more than $4 \%$ to $8 \%$ of the elderly in some Northern regions to only $2 \%$ in some Southern regions (ISTAT 2006b). Moreover, these services guarantee only a limited number of hours of actual care per week in even the most developed contexts. Although the home health care administered by local health authorities may show a higher percentage of the elderly covered, it is primarily aimed at providing either intensive short-term, post-acute care or specialised support, as shown by the limited number of hours of service delivered (Ministero della Salute 2005). Over all, home care services do not represent a substantial alternative to either institutionalisation or intensive informal care (Da Roit and Castegnaro 2004). Access to both residential and home care is not considered a social right with access limited by a variety of more or less formalised criteria that vary across municipalities, regions and sometimes even providers. The costs of residential care may vary considerably across the country and are generally quite high for end users (Da Roit 2009).

The only general policy that focuses on elderly dependents is a national cash allowance: the Indennità di accompagnamento (companionship allowance). This measure was originally intended for disabled adults, not the elderly. It was meant to supplement the means-tested assistance that disabled adults receive and to be provided to those individuals who have been assessed as disabled or "totally unfit for work" and in need of continuous care, without regard to their incomes. Once expanded in the mid-I98os to cover people aged 65 and over and due to changing demographics, the benefit became increasingly used for the dependent elderly. By 2007, in fact, circa 10\% of people aged 65 and over were receiving the Indennità di accompagnamento (Micheli and Rosina 2008). This benefit actually represents the most important source of welfare for elderly dependents. The budget spent on the benefit is equal to half the resources that the national government deploys for social assistance benefits and are overwhelmingly more important than any other regional or local funding for social interventions (Da Roit 2009). The benefit (472 euros in 2009) may be used in a discretionary way; beneficiaries do not need to justify their expenses.

\subsubsection{The debate in the $1990 \mathrm{~s}$}

During the I990s, the issue of elderly care entered the social and political arenas, even if it was restricted mainly to the sector's experts and policymakers. The debate on long-term care policies echoed some of the themes that were being heard throughout Europe: "maintaining older dependent people at home as long as possible" and giving the users 
choice. However these slogans acquired a very specific meaning in the Italian context, when the main problem that decision makers and government agencies faced was the containment of the demand for (already scarce) residential care. In fact, while official government documents claimed that the development of home care services were a valid alternative to institutionalisation (similar to developments in the Northern countries, such as the Netherlands) these services were largely unavailable, inadequate and under-funded. On the other hand, developments particularly in northern regions since the I990s, show increases in residential care, as a result of the accreditation of private nursing homes that were funded via health care funds and the conversion of care homes for the elderly, previously dedicated to the care of the elderly with low or no care needs (Da Roit 2007c; Da Roit and Gambino 2005).

Another response to the increasing pressure on social services was the local policy that provided monetary support to elderly people still living at home. Since the late I990s, regional and local authorities, again mainly in the central and northern regions, have tended to introduce supplementary care allowances for low-income elderly dependents needing intensive care. These measures were meant to reduce the demand for both institutional care and home care services. The strategy, backed up by arguments that were similar to those used in other contexts to introduce cash-for-care allowances, was supposed to lead to more flexibility, choice, and the empowerment of clients. The actual availability of these new local cash-for-care benefits is dispersed across regional and local jurisdictions and based on the application of diverse eligibility criteria. Moreover, Italy's local care allowances were not one solution among many for the dependent elderly - as was the case in the Netherlands - but the sole solution in a context of very few available formal services. These measures were also always means tested, regardless of the specific eligibility criteria (Gori and Torri 200I). Although in some not all - cases, care allowances were supposed to be co-administered by public officials and the family members of elderly dependents, the actuality was that bureaucratic shortcomings meant that the benefits were basically monetary transfers to the elderly and their families, with no administrative oversight. Beneficiaries were ultimately free to spend their local allowances in a discretionary manner. In other words, the local response to increased needs was a simple monetary stipend similar to the Indennità di accompagnamento but at the local level. This response shows that the impact of these measures is basically very limited, especially considering their scant resources and the limited number of eligible beneficiaries (Da Roit 2007b).

Much of the national effort, in the second half of the I990s, was dedicated to developing new framework social service legislation. ${ }^{13}$ The parliament tried to come up with a more integrated social services policy in Italy. However, several restrictions had a negative impact on this new initiative. ${ }^{\mathrm{I}} \mathrm{A}$ commission set up to evaluate the "macroeconomic com- 
patibility of social expenditures" prior to the adoption of new legislation recommended that the system of disability insurance be reformed and proposed a scheme of protection in favour of dependent elderly. The commission envisaged the institution of a national fund, which would also include existing funding for the Indennità di accompagnamento that could provide allowances and services for dependent people (Commissione Onofri 1997: 19). However, new social service legislation introduced in 2000 did not substantially reform the system of social welfare for elderly dependents. The traditional division between national allowances (namely the Indennità di accompagnamento) and the discretionary local provision of services has, in effect, not been altered. A lot of emphasis was placed on the institutional arrangements and decision-making processes, while the actual content of the social welfare measures ended up being neglected. Only limited changes were made to the budget and the social policies within the framework of social assistance remained local efforts with some national monetary assistance. The additional national resources earmarked for reforms were very limited and, as well as additional regional and local public and private resources (FORMEZ 2003). The traditional division between national allowances, which are the basis of individual social rights and local provision of services, for which no individual right is recognised, was maintained. As a result, the new law led to very little innovation in the domain of care for elderly dependents. Moreover, the $200 \mathrm{I}$ constitutional reforms that introduced the principle of individual rights to social services - to be set by the state and ensured by regions and local authorities - has not yet been deployed to any effect.

\subsubsection{The development of private care}

While Dutch social policies experienced a considerable transformation in the I990s, not much actually happened in Italy (Naldini and Saraceno 2008). Any changes that did take place, were likely not the result of any government shifts in policy.

In the early 2000s, the issue of long-term care gained wider exposure in public debate in Italy, which was largely due to significant increases in the use of an immigrant labour force among the elderly living at home (Castegnaro 2002; Gori, ed., 2002). This saw the emergence of a new type of caregiver - the badante, a migrant woman who often co-habited with an older dependent and provided round-the-clock assistance and worked in the grey market without a residence permit. Migrant care workers - predominantly from South America and Eastern Europe were hired directly by the elderly or family members, usually relying on personal contacts, "informal" agencies such as volunteer organisations, retiree or elderly associations, or networks of migrant workers (Da Roit 2002; Da Roit and Castegnaro 2004; Caponio and Colombo 2005; Carchedi et al. 2003). 
Italy is a relatively recent immigration country and hosts increased numbers of documented migrants as well as significant numbers of undocumented foreigners, ${ }^{15}$ who are employed in the agricultural, industrial and service sectors, with a particularly high concentration in the domestic services sector (Colombo 2003). The vast majority of immigrants find their jobs via the underground economy, being encouraged by periodical ex-post regularisations of undocumented migrants, the general tolerance of the underground economy and the high demand for care sector workers (Reyneri 200I; Naldini and Saraceno 2008). Italy's chronic inability to control the migratory flows plus the high demand for foreign labour has led to countless legalisation processes for many of these migrant labourers (Reyneri 200I; Barbagli et al. (eds.) 2004). The importance of the care provided by migrant women and the peculiar characteristics of this market became more evident during the period 2002 and 2003. New legislation on migratory flows was introduced encompassing, on the one hand, more rigid regulations regarding non-EU labour and, on the other hand, amnesty to numerous undocumented migrants who were already working in Italy. ${ }^{16}$ While domestic labour has always represented a significant proportion of the overall labour force legalised during previous amnesty efforts, ${ }^{17}$ migrant care workers became a key element in the debates that accompanied the 2002-2003 amnesty initiatives. Some 750,000 applications were submitted, half of which concerned domestic workers. When considering that there were 224,000 registered domestic sector employees in 2002 (Inps, Osservatorio sui lavoratori domestici), ${ }^{18}$ the amnesty initiative let emerge a vast grey labour force. The legalisation initiative was supposed to establish basic employment and residency rights for the migrants, but this motion encountered the same problems similar initiatives had had: it was not comprehensive and did not have long-lasting effects. A considerable number of care workers were unable to benefit from this initiative. Many others were legalised but did not gain full protection regarding working conditions, which remained in part unregulated. Considerable numbers lost their jobs after legalisation and often lost their residency permits (Da Roit and Castegnaro 2004; Mesini et al. 2006). A new regularisation initiative was introduced as early as six years later, in 2009 .

The current figures for migrant care workers are unknown due to the nature of this situation. However, estimates range from 700,000 to I,000,000 in the mid-2000s (i.e. 6 to 8 for every roo people aged 65 and over) (Da Roit and Castegnaro 2004; Mesini et al. 2006; Simonazzi 2009). If these estimates are accurate, then migrant labourers outnumber the formal social care sector employees (2005) and represent a true "care drain" (Bettio et al. 2006).

Largely inadequate policy responses were put forward as a reaction to a transformation of society and embraced the migrant caregiver model, without sufficiently questioning traditional Italian care policies. At the 
national level, the issue of migrant care workers has mainly been framed as a migration issue. At the regional and (above all) local levels, it has been looked at as a "social care issue" within the limits of the traditional models of intervention in this domain.

Italy does not have a clear long-term care policy, but with the emergence of the migrant care work force, the Italian government has repeatedly treated long-term care as a problem related to migration policies. The badanti were considered, as we mentioned above, a specific target group for the 2003 amnesty initiatives and provided a specific quota in the programmed yearly immigration flows. At the local level (and to a lesser extent at the regional level), the recent debate on care for the elderly has clearly shifted to the need to "regulate" and "qualify" the existing unregulated care market, in an attempt to include migrants in the local "network of services". In fact, it is at the local level that the contradictions of this arrangement clearly emerge. Several regions, provinces and municipalities (predominantly in the central and northern areas of the country) have introduced a set of ad hoc interventions, some of which provide training for migrant care workers employed by families and upon completion of the training, "accreditation". A smaller number of initiatives provide cash benefits to dependents for the sole purpose of hiring a care provider on a regular contractual basis (see, for example, a pilot programme introduced by Regione Veneto: Da Roit 2007b). Other programmes facilitate the matching of the supply and demand for care provided by domestic (predominantly migrant) workers through local public or publicly funded agencies (see, for instance, in Lombardy: Mesini et al. 2006). In some cases, local initiatives combine the various measures. These initiatives are severely limited. Firstly, attendance at the training courses has been low as have the numbers of migrant workers who have been accredited. The quality and qualification criteria cost the care providers or their employers money that is not refunded or reimbursed. For instance, the hours spent in these training sessions are not paid for. Secondly, these opportunities lead to higher expectations among the care workers for improved pay and employment conditions, as well as better jobs in the care sector, which cannot be wholly met and thus undermine the need to retain these workers (Da Roit and Castegnaro 2004). Finally, it has also been shown that both the families and the care providers are not that interested in the regularisation of the working conditions (Mesini et al. 2006). Unless substantial economic incentives become available to contract workers in the regular market, it is very unlikely that families and workers will opt for this solution. Thus, we have a situation where the limited resources for local projects undermine their chances for success. The persistent widespread prevalence of grey labour and undocumented migrants, in turn, prevents local and regional authorities from effectively reaching these workers and including them in their public programmes. 


\subsection{Emerging questions}

In the domain of elderly care, the Dutch case represents a model that is strongly dominated by formal care and a high degree of the socialisation of the risk of dependence in old age. However, since the I99os, ongoing policy reforms have been introduced, which have led to sharp reductions in the provision of formal care in institutions, along with the selection of the more "needy" elderly for residential care eligibility. A strong emphasis was subsequently put on the development of home care arrangements and policymakers explicitly called for more informal care and more individual and family responsibility. Market principles in the provision of care services were explicitly fostered. Decentralisation and the split of previously integrated functions have been at the core of the most recent reforms. These different social policy initiatives - meant to contain public expenditures, create more interdependence between family members and empower the end users - raise the issue of the Dutch care model shifting to a more marketised and more familised model. If the above-mentioned developments represent clear sources of tensions and possible stimuli for change, further investigation is necessary to determine to what extent the care system has actually changed. Moreover, the specific social processes that have either fostered or hindered these transformations need to be highlighted.

The Italian case is quite different from that of the one we have described for the Netherlands. Throughout the I990s, it represented a highly familised system of care for the dependent elderly that has resisted changes in social policies. Unlike the Netherlands in the early I990s, Italy lacked a general social welfare scheme that would cover the risk of dependence in old age. Long-term care interventions consisted of a combination of different measures with diverse scopes, aims and institutional arrangements that varied from region to region and from municipality to municipality. However, the general picture is that of little development in terms of long-term care interventions. Despite this situation of inaction, important signs of change began to emerge in the second half of the I99os, with the rise of a specific care market that involved many migrant workers being hired directly by families on the grey market. The absence of any important social policy shifts and the rise of new forms of care for the elderly raise some questions regarding the conditions, motives and mechanisms underlying changes in welfare systems. First, we should see to what extent recent developments represent shifts in the Italian care model and how they interfere with traditional care arrangements. Second, we need to appreciate which social processes underlie these transformations, in other words, under what conditions and due to which forces did the shift from a family-based informal care system shift to a new model that embraced market care arrangements. Finally, the social consequences of these transformations must be explored. 
The empirical analysis presented in chapters three to six focuses on the conditions, the extent and the mechanisms that underlie the changes in the modes of production and allocation of care in the Dutch and Italian contexts. 


\section{The Challenge of Dependence}

\section{I Analysing dependence}

Before we begin to analyse the transformation of how the care needs of the elderly are handled in Italy and the Netherlands, we shall first look at the extent to which dependence represents a challenge for the two societies. We shall further observe the trends in the incidence and distribution of dependence that can be found in the early-I99os to the early2ooos period.

\subsubsection{Population ageing and disability trends}

Longevity has grown considerably in all Western societies over the past decades; people in the West do indeed live increasingly longer lives. But general health and one's functional abilities tend to worsen with age. Due to the simultaneous increase in life expectancy and the increase in age-related chronic diseases and disabilities, a growing proportion of Western populations suffers from the physical limitations in daily activities. As a consequence there is an increased need for care and assistance.

The recent debates about the combined trend of increased longevity coupled with the growing incidence of disability in old age has raised the key question of whether the prolongation of life brings with it more years of good or of bad health. According to the "expansion of morbidity" theory (Gruenberg I977; Olshansky et al. I991), life expectancy has increased due to a reduction in the fatality rate of those with chronic diseases and not the decreasing incidence of such diseases. Thus, increases in longevity should be associated with more years spent in poor health. Meanwhile, Fries (I989) proposed a "compression of morbidity" theory, which states that although the onset of chronic diseases is postponed, the average maximum life span will not exceed a certain age. Morbidity should thus be compressed into a shorter period at the end of life. Different scenarios arise when we try to combine these two opposing theories. The "relative expansion of morbidity" hypothesis proposes a decrease in the ratio of healthy years to life expectancy in combination with an increase in the number of healthy years. This hypothesis predicts a decrease in the ratio of unhealthy years to life expectancy combined with an increase in the number of unhealthy years (Robine and Mathers I993). Despite some controversial empirical tests and various 
measurement problems, ${ }^{\mathrm{I}}$ recent evidence tends to reveal some more optimistic results in this respect (Waidmann and Manton I998).

Notwithstanding the importance of the developments in extending mortality and morbidity, it must be acknowledged that people in developed countries will probably end up living a number of years with a disability towards the end of their lives. Increased longevity means that people experience dependence in later life for relatively longer periods of time than in the past. Moreover, epidemiological developments are not the only relevant factors in identifying the magnitude and nature of the challenge that welfare systems face with increased longevity. The everincreasing incidence of dependence is accompanied by a relative decrease in the proportion of the adult population. Between 1960 and I990, the continuous increases in the adult population balanced the effects of ageing. However, since 20I0, the ratio of the elderly to general adult population is expected to rise sharply in most OECD countries (Jacobzone et al. 1999), presenting welfare systems with even greater challenges.

Moreover, an ageing population entails an increased need for longterm care in a context of declining availability of informal care, due to the increasing labour market participation of older (women) workers, new norms and attitudes towards care and intergenerational solidarity and, in the long run, lower birth rates (Gaymu et al. 2008; Bouget 2003; Attias-Donfut et al. 2002; Johnson and Lo Sasso 2006; Lundsgaard 2005; Sundström 1994). Therefore, an analysis based solely on epidemiological developments would probably lead to an underestimation of the socially and institutionally conditioned character of dependence in old age and the challenges it poses to welfare systems.

\subsubsection{Aims and methods}

This section investigates the incidence and distribution of old-age dependence in Italy and the Netherlands between the early I990s and the early $2000 \mathrm{~s}$. The examination provides the background for understanding the pressures that this risk puts on each society, and for analysing the transformations in the responses to care needs.

In order to answer these questions we use data provided by six surveys: for the Netherlands the AVO surveys repeated in I99I, I999 and 2003 (AVO9I, AVO99, AVOo3) and for Italy the Multiscopo Condizioni di Salute surveys repeated in 1994, I999-2000 and 2004-2005 (Consal94, Consal99, Consalo4). For the study, the dependence of the elderly was operationalised as the (partial) limitation in being able to autonomously carry out basic daily activities (ADLs) among individuals aged 65 and over, such as moving inside and outside one's home, taking care of one's personal care and hygiene. The analysis is conducted both at the individual and family levels. At the individual level, we distinguish between independent, moderately dependent (unable to carry out one ADL 
or suffering some limitations in at most two ADLs) and severely dependent individuals. At the household level, households scoring up to three points on an ADL dependence scale are considered mildly dependent, while those scoring at least four points are considered "severely dependent". ${ }^{2}$

We first look at the extent to which dependence represents a challenge in the two countries and how much the pressure of this new risk has increased over the period considered. Moreover, we consider the demographic, social and policy factors that might explain the differences and the trends observed over time.

\subsection{Dependence in Italy and the Netherlands}

According to our data, throughout the early-I990s to early-2000s period, dependence was much more widespread among the elderly living at home in Italy than in the Netherlands. This is when we consider dependence in a broader sense, which includes the moderately as well as the severely dependent elderly, and in a stricter sense, which includes the severely dependent ones only. However, due to distinct trends over time a partial convergence can be observed.

\subsubsection{Incidence and trends}

In the early I990s, people aged 65 and over who were living at home and suffering from either moderate or severe limitations in their daily activities represented one-third of the total number of elderly in the Netherlands and one-half in Italy. Moreover, the percentage of the elderly suffering severe limitations was $15 \%$ in the Netherlands and $28 \%$ in Italy (table 3.I). These figures are consistent with the results of previous European comparative research that showed how unhealthy conditions and disability among the elderly is not evenly distributed across Europe. In I994, in the fifteen EU member states, $58.7 \%$ of the male population and $66.4 \%$ of the female population aged 60 and over reported poor health conditions. Among men, the proportion reporting poor health was $70.6 \%$ in Italy and $40.0 \%$ in the Netherlands; among women it was $80.2 \%$ in Italy and $50.5 \%$ in the Netherlands. The prevalence of longterm disabilities among women was $40.4 \%$ in the Netherlands and $45.5 \%$ in Italy; among men $49.8 \%$ in the Netherlands and $54.8 \%$ in Italy (Huisman et al. 2003: 868).

By the early 2000 s, the overall dependence rate had shown a decline in Italy and an increase in the Netherlands, where an increase especially in severe dependence can be observed. Notwithstanding this partly convergent development, the proportion of the dependent and severely dependent elderly in Italy remains significantly higher than in the Netherlands (table 3.I). 
Table 3.1 Dependence rate (*) and severe dependence rate (**) among elderly people living at home. The Netherlands, Italy and Italian macroareas. 1991 (1994), 1999, 2003 (2004)

\begin{tabular}{|c|c|c|c|c|c|c|}
\hline & \multicolumn{2}{|c|}{1991 (IT:1994) } & \multicolumn{2}{|c|}{1999} & \multicolumn{2}{|c|}{2003 (IT:2004) } \\
\hline & 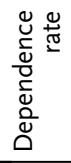 & 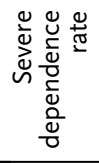 & 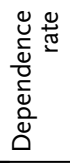 & 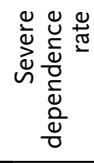 & 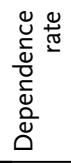 & 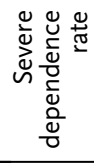 \\
\hline The Netherlands & 33.2 & 15.4 & 35.5 & 18.6 & 39.7 & 21.6 \\
\hline Italy & 49.5 & 28.3 & 45.1 & 26.6 & 45.7 & 26.4 \\
\hline Italy: North & 43.7 & 23.6 & 38.5 & 21.7 & 38.6 & 21.4 \\
\hline Italy: Centre & 48.0 & 27.8 & 42.5 & 24.8 & 44.6 & 26.2 \\
\hline Italy: South & 59.3 & 35.8 & 56.6 & 35.2 & 57.1 & 34.2 \\
\hline
\end{tabular}

Source: elaborations on AVO91, AVO99, AVOo3; Consal94, Consal99, Consalo4

(*) percentage of people aged 65 or above with difficulties in carrying out at least one basic activity of daily living

$(* *)$ percentage of people aged 65 or above unable to carry out more than one activity of daily living

Table 3.2 Dependence ratio (*), severe dependence ratio (***), ageing ratio (****), The Netherlands, Italy and Italian macroareas. 1991 (1994), 1999, 2003 (2004)

\begin{tabular}{|c|c|c|c|c|c|c|c|c|c|}
\hline & \multicolumn{3}{|c|}{1991 (IT: 1994) } & \multicolumn{3}{|c|}{1999} & \multicolumn{3}{|c|}{2003 (IT: 2004) } \\
\hline & 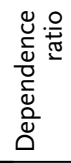 & 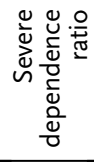 & 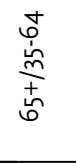 & 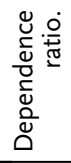 & 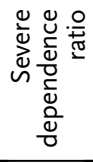 & 志 & 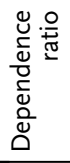 & 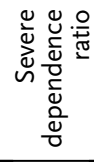 & 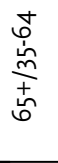 \\
\hline The Netherlands & 10.9 & 5.1 & 33.0 & 11.5 & 6.0 & 32.6 & 12.4 & 6.8 & 31.4 \\
\hline Italy & 20.2 & 11.6 & 40.9 & 19.7 & 11.6 & 43.6 & 21.1 & 12.2 & 46.2 \\
\hline Italy: North & 18.1 & 9.9 & 41.5 & 17.2 & 9.7 & 44.5 & 18.1 & 10.1 & 47.0 \\
\hline Italy: Centre & 20.9 & 12.1 & 43.5 & 19.5 & 11.4 & 45.9 & 21.9 & 12.9 & 49.0 \\
\hline Italy: South & 22.8 & 13.7 & 38.4 & 23.1 & 14.4 & 40.9 & 24.8 & 14.8 & 43.4 \\
\hline
\end{tabular}

Source: elaborations on AVO91, AVO9g, AVOo3; Consal94, Consal99, Consalo4

(*) population aged $65+$ with difficulties in carrying out at least one basic activity of daily living over population aged 35 to 64

(**) population aged $65+$ unable to carry out more than one activity of daily living over population aged 35 to 64

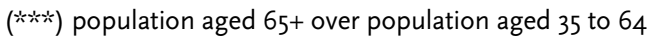

Italy not only displays higher dependence rates but also a higher ratio between the older and adult populations and therefore a higher ratio between the (severely) dependent elderly and the general adult population. At the beginning of the period we are studying, for every roo peo- 
ple aged 35 to 64 there were ten older people with some limitations in everyday activities in the Netherlands versus 20 in Italy. Moreover, the ratio of the severely dependent elderly to the general adult population was twice as high in Italy compared to the Netherlands: 5.I in the Dutch sample, against Iı.6 in the Italian sample. Moreover, the gains in Italy were derived from a slight decrease in the dependence rates throughout this period and were, in any case, basically absorbed by the relative decrease in the number of younger Italians. In the Netherlands, the increase in dependence rates among the elderly living at home was offset by a slight decline in the ratio between the old and the young (table 3.2).

It is worth pointing out that the Italian data show considerable regional differences in the dependence rates. Dependence and severe dependence rates are lower in the north, higher in the centre and highest in the south. Actually, by the end of our research period, northern Italian dependence rates were similar to those of the Netherlands, with a considerable difference with the other two macro-regions (table 3.2). The operationalisation of dependence is based on one's self-reported ability or inability to carry out a set of daily activities and does not include administrative definitions such as the entitlement to social benefits or disability pensions. The regional disparities in the access to disability benefits should, however, not be the cause for the differences in dependence rates. ${ }^{3}$ (table 3.2).

\subsubsection{Household dependence and family insertion of dependent elderly people}

In Italy, households with older dependents are much more common than in the Netherlands. In the early I990s, only $22 \%$ of Dutch households had at least one member aged 65 or over, while the figure was $35 \%$ for Italian households. Moreover, the incidence of dependence in households was more than double in Italy (I\%\%) and the incidence of severe dependence three times higher (ז2\%) than in the Netherlands (respectively $8 \%$ and $4 \%$ ). By the end of the I990s, this situation had changed slightly. By the end of our case study period, dependent elderly people in households became slightly more common in the Netherlands (I0\%; $5 \%$ for severe dependence). In Italy, the percentage of households with dependents remained stable (18\%; ז2\% for severe dependence). As a result, the proportion of households in the early 2000 s with severely elderly dependents in Italy was still almost twice as high as in the Netherlands (table 3.3).

The fact that someone is living alone or as part of a couple or as a member of a younger household changes the situation for elderly dependents, with regard to the degree of involvement of potential caregivers and the demand for services. Even if informal support to elderly dependents is provided not only within the same household but also from one 
Table 3.3 Households with at least one elderly member, with moderate and at severe dependence levels (*). The Netherlands, Italy and Italian macroareas. 1991 (1994), 1999, 2003 (2004)

\begin{tabular}{|c|c|c|c|c|c|c|c|c|c|}
\hline & \multicolumn{3}{|c|}{1991 (IT: 1994) } & \multicolumn{3}{|c|}{1999} & \multicolumn{3}{|c|}{2003 (IT: 2004) } \\
\hline & 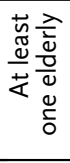 & 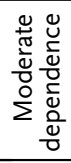 & 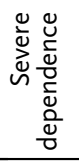 & 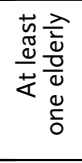 & 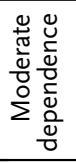 & 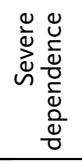 & 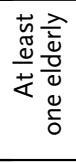 & 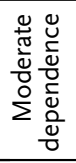 & 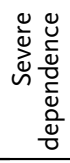 \\
\hline The Netherlands & 21.9 & 8.4 & 4.2 & 22.9 & 9.5 & 5.2 & 22.7 & 10.5 & 6.1 \\
\hline Italy & 34.6 & 19.0 & 12.2 & 35.3 & 17.8 & 11.8 & 35.9 & 18.5 & 12.0 \\
\hline Italy: North & 35.7 & 17.8 & 11.0 & 35.6 & 15.6 & 9.9 & 35.7 & 16.0 & 9.8 \\
\hline Italy: Centre & 35.9 & 19.2 & 12.5 & 37.1 & 17.9 & 11.8 & 37.8 & 19.3 & 12.6 \\
\hline Italy: South & 32.2 & 20.3 & 13.9 & 33.7 & 20.9 & 14.5 & 35.1 & 21.8 & 14.9 \\
\hline
\end{tabular}

Source: elaborations on AVO91, AVO99, AVOo3; Consal94, Consal 99, Consalo4

(*) see appendix $\mathrm{I}$ for the operationalisation of household dependence levels

Table 3.4 Family insertion of men aged 65 and above by level of dependence, The Netherlands, Italy. 1991 (1994), 1999, 2003 (2004)

\begin{tabular}{|c|c|c|c|c|c|c|c|c|c|}
\hline & \multicolumn{3}{|c|}{ IT94 } & \multicolumn{3}{|c|}{ IT99 } & \multicolumn{3}{|c|}{ ITo4 } \\
\hline & $\overline{\bar{\alpha}}$ & 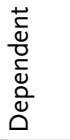 & 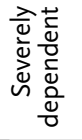 & $\overline{\bar{\alpha}}$ & 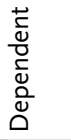 & 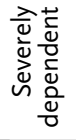 & $\overline{\bar{\alpha}}$ & 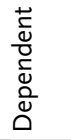 & 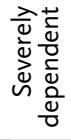 \\
\hline Single & 10.8 & 13.3 & 15.0 & 12.4 & 14.5 & 15.3 & 13.9 & 16.6 & 18.5 \\
\hline Couple & 54.3 & 56.7 & 56.7 & 51.5 & 53.4 & 51.4 & 51.6 & 54.0 & 52.3 \\
\hline \multirow[t]{3}{*}{ Other } & 34.8 & 30.0 & 28.3 & 36.1 & 32.1 & 33.0 & 34.4 & 29.3 & 29.2 \\
\hline & \multicolumn{3}{|c|}{ NL91 } & \multicolumn{3}{|c|}{ NL99 } & \multicolumn{3}{|c|}{$\mathrm{NLO}_{3}$} \\
\hline & $\overline{\bar{\alpha}}$ & 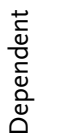 & 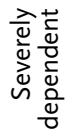 & $\overline{\bar{\alpha}}$ & 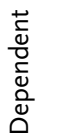 & 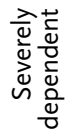 & $\bar{\varepsilon}$ & 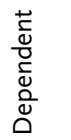 & 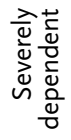 \\
\hline Single & 17.5 & 21.6 & 22.0 & 19.7 & 29.6 & 32.6 & 20.2 & 27.7 & 30.2 \\
\hline Couple & 71.3 & 67.4 & 62.2 & 70.9 & 63.3 & 57.9 & 71.4 & 64.4 & 61.2 \\
\hline Other & 11.2 & 11.1 & 15.9 & 9.4 & 7.0 & 9.5 & 8.4 & 7.9 & 8.5 \\
\hline
\end{tabular}

Source: elaborations on AVO91, AVO99, AVOo3; Consal94, Consal99, Consalo4

household to another, a co-resident elderly dependent represents a greater risk for relatives (Broese van Grenou i995). The majority of older men in both Italy and the Netherlands live as one-half of a couple, with or without other household members (respectively c. 50\% and 70\%). The proportion of older men living alone is much lower in Italy (10\%) compared to the Netherlands (I7\%) (table 3.4). The proportion of women liv- 
ing alone is higher than that of men and considerably more important in the Netherlands than in Italy (respectively c. 50\% and 35\%). It is worth noticing that over the period considered, the proportion of severely dependent elderly people living alone - men and women - increased in both Italy and the Netherlands (tables 3.4, 3.5).

Table 3.5 Family insertion of women aged $6_{5}$ and above with different degrees of dependence, The Netherlands, Italy. 1991 (1994), 1999, 2003 (2004)

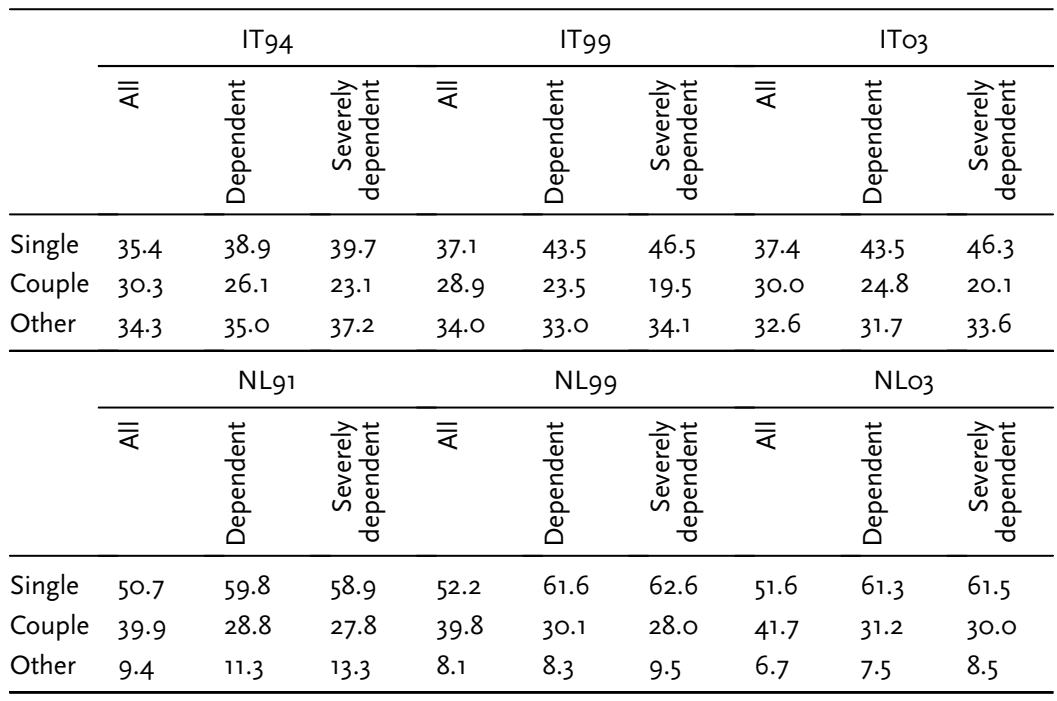

Source: elaborations on AVO91, AVO99, AVOo3; Consal94, Consal99, Consalo4

Thus, the increasing incidence of single elderly dependents represents a considerable transformation in both countries.

\subsection{Why are there more dependents in Italy than in the Netherlands?}

Data show that dependence among the elderly living at home is much more common in Italy - where regional differences are evident - than in the Netherlands, when we look at the prevalence of dependence both among individuals and in households. What are the main causes of these cross-national (and intra-national) differentials in dependence rates? Other than epidemiologic factors - which fall outside the scope of this study - three other factors can be distinguished from the literature: different demographic structures; gender differences and social inequalities in health. As dependence rates increase with age, the internal structure of the older population is important in determining the overall dependence rate. A high prevalence of "older old" people among those 
classified as old is likely to raise dependence rates. Moreover, while mortality rates are lower among women, women tend to experience more severe health problems in old age. Women thus live longer than men and live longer with a disability (Arber and Ginn I993; Arber and Cooper 2000). Finally, there is evidence that socio-economic factors are important in the explanation of health conditions in old age (Breeze et al. I999a; Rahkonen and Takala I998; Dahl and Birkelund I997; Broese van Groenou and Deeg 2000; Liao et al. I999; Huisman et al. 2003; Dalstra et al 200I).

\subsubsection{Demographic structure and social stratification}

Italy has experienced a far more advanced ageing process than the Netherlands as reflected in internal composition of their elderly population, especially the "oldest old". In fact, in 2003, Italians aged 85 years and over who lived at home comprised $9 \%$ of the total elderly population, compared to $6 \%$ in the Netherlands. When we realise that dependence rates have a positive correlation to age, the structure of the population may account for part of the difference in dependency rates between Italy and the Netherlands. However, this does not account for differences within Italy as the three macro-regions have fairly similar age structures. Moreover, the data show that there are considerable differences within each age group in the disability rates between the Netherlands and Italy but even more so between the Italian macro-regions (table A2.I). ${ }^{4}$

One's educational level serves as an indicator of social inequality and stratification; it has also proved to have a strong correlation to the health conditions and levels of functioning among the elderly. Educational levels among the Italian elderly (but not exclusively) population are much lower than among the Dutch. In 2003, the proportion of Italians who lived at home and had received a higher education in our sample was $8.5 \%$ in the $55-64$ age group, $4.5 \%$ for those $65-74$, and $3.4 \%$ for those $75+$, compared to $21.5 \%, \mathrm{I} 3.0 \%$ and $10.5 \%$ respectively among the Dutch. The percentage of elderly Italians living at home with low educational levels was $70.4 \%$ in the $55-64$ age group, $83.3 \%$ for those $65-74$ age, and $88.8 \%$ for those $75+$, compared to $\mathrm{I} 6.6 \%, 32.0 \%$ and $45.2 \%$ respectively among the Dutch. The differences in the educational levels among older Italians per macro-region were rather small. (tables A.2.2 and A.2.3). Thus, if education accounts for some of the differentials in dependence rates between the Netherlands and Italy, this factor should not explain the differentials in dependence rates between Italian macro-regions because they have very similar compositions.

The 2003-2004 data show that the elderly with lower educational levels in both countries and across macro-regions in Italy are more dependent and severely dependent compared to their higher educated counterparts within the same sex and same age group (tables 3.6-3.9). The dependence rate of women aged 75 and over in the Netherlands, for in- 
stance, decreases from $69.4 \%$ to $54.6 \%$ and to $50.0 \%$ and that of older men from $54.2 \%$ to $4 \mathrm{I} .7 \%$ and $29.2 \%$ when we look at the lower- to midand higher-educated groups. In Italy, the dependence rate of women aged 75 and over decreases from $71.5 \%$ to $59.4 \%$ and to $50.0 \%$ and that of older men from $57.6 \%$ to $42.4 \%$ and to $42.2 \%$ when we observe the lower- to mid- to higher-educated groups (table 3.6). Similar patterns were observed in the distribution for severe dependence (table 3.8). If these data suggest that social and demographic factors account for some of the dependence differentials between the two countries, there are certain persistent differences noted between age, gender and education groups in the two countries; the dependence rates among the Dutch remain slightly lower than in the Italian sample (tables 3.6 and 3.8).

Table 3.6 Incidence of dependence (mild or severe) among older individuals, by sex, age group and educational level (year 2003); Italy and the Netherlands

\begin{tabular}{llllllll}
\hline & & \multicolumn{3}{c}{$\mathrm{NL}$} \\
\cline { 3 - 8 } & Educational level & $65-74$ & $75+$ & Total & $65-74$ & $75+$ & Total \\
\hline \multirow{2}{*}{ Man } & Low & 31.1 & 54.2 & 41.4 & 25.8 & 57.6 & 39.0 \\
& Medium & 24.9 & 41.7 & 30.3 & 13.6 & 42.4 & 23.1 \\
& High & 14.1 & 29.2 & 19.0 & 12.3 & 42.2 & 24.4 \\
& Low & 39.7 & 69.4 & 55.1 & 37.5 & 71.5 & 54.8 \\
& Medium & 30.4 & 54.6 & 39.8 & 23.0 & 59.4 & 36.3 \\
& High & 35.0 & 50.0 & 41.7 & 17.1 & 50.1 & 29.0 \\
\hline
\end{tabular}

Sources: elaborations on $\mathrm{AVOO}_{3}$ (NL); Consalo4 (IT)

Table 3.7 Incidence of dependence (mild or severe) among older individuals, by sex, age group and educational level (year 2003)

\begin{tabular}{lllllllllll}
\hline & & \multicolumn{3}{c}{ North } & \multicolumn{4}{c}{ Centre } & \multicolumn{3}{c}{ South } \\
\cline { 2 - 11 } & Educational level & $65-74$ & $75+$ & Total & $65-74$ & $75+$ & Total & $65-74$ & $75+$ & Total \\
\hline \multirow{2}{*}{ Man } & Low & 19.1 & 49.8 & 31.6 & 23.8 & 55.3 & 37.5 & 36.4 & 69.7 & 50.3 \\
& Medium & 10.9 & 34.6 & 18.2 & 14.6 & 32.4 & 20.0 & 19.2 & 61.2 & 36.1 \\
& High & 8.7 & 35.7 & 20.3 & 13.1 & 45.5 & 28.2 & 16.6 & 52.1 & 28.2 \\
\multirow{3}{*}{ Women } & Low & 28.8 & 65.0 & 47.3 & 35.7 & 71.7 & 54.5 & 51.4 & 81.7 & 66.4 \\
& Medium & 18.4 & 51.6 & 31.1 & 19.0 & 69.7 & 38.3 & 34.1 & 67.0 & 44.7 \\
& High & 18.5 & 42.3 & 28.2 & 7.1 & 54.5 & 21.2 & 25.2 & 60.1 & 37.4 \\
\hline
\end{tabular}

Sources: elaborations on $\mathrm{AVOO}_{3}$ (NL); Consalo4 (IT)

A similar pattern emerges when we look at the Italian macro-regions: the higher the educational level, the lower the incidence of both dependence and severe dependence in all three macro-regions. What is striking, however, is the much higher incidence of dependence and severe 
dependence, even within the different age, gender and educational subgroups when we compare the north with the centre and south. Among lower-educated women aged 75 and over dependence is $65 \%$ in the north, $71.7 \%$ in the centre and 81.7\% in the south (table 3.7). The incidence of severe dependence among the same subgroups is $27.5 \%$ in the north, $33.4 \%$ in the centre and $43.1 \%$ in the south (table 3.9). These data suggest that factors other than demographic and socio-economic composition of the population are at work in determining dependence rates.

Table 3.8 Incidence of severe dependence among older individuals, by sex, age group and educational level (year 2003), Italy and the Netherlands

\begin{tabular}{llllllll}
\hline & & \multicolumn{3}{c}{ NL } & \multicolumn{3}{c}{ ITA } \\
\cline { 3 - 8 } & Educational level & $65-74$ & $75+$ & Total & $65-74$ & $75+$ & Total \\
\hline \multirow{2}{*}{ Man } & Low & 18.3 & 31.3 & 24.1 & 10.4 & 35.1 & 20.7 \\
& Medium & 11.0 & 19.1 & 13.6 & 3.0 & 20.9 & 9.0 \\
& High & 7.1 & 20.8 & 11.6 & 4.3 & 26.4 & 13.2 \\
& Wow & 22.8 & 46.6 & 35.1 & 17.0 & 49.7 & 33.6 \\
& Medium & 11.8 & 28.1 & 18.1 & 9.5 & 36.0 & 19.2 \\
& High & 22.5 & 31.3 & 26.4 & 6.4 & 32.8 & 15.9 \\
\hline
\end{tabular}

Sources: elaborations on AVOo3 (NL); Consalo4 (IT)

Table 3.9 Incidence of severe dependence among older individuals, by sex, age group and educational level (year 2003)

\begin{tabular}{llllllllllll}
\hline & & \multicolumn{3}{c}{ North } & \multicolumn{3}{c}{ Centre } & \multicolumn{3}{c}{ South } \\
\cline { 3 - 11 } & Educational level & $65-74$ & $75+$ & Total & $65-74$ & $75+$ & Total & $65-74$ & $75+$ & Total \\
\hline \multirow{2}{*}{ Man } & Low & 7.2 & 29.0 & 16.1 & 9.5 & 34.5 & 20.4 & 15.4 & 43.6 & 27.2 \\
& Medium & 3.1 & 15.6 & 6.9 & 2.6 & 15.0 & 6.3 & 3.4 & 33.3 & 15.5 \\
& High & 2.1 & 22.0 & 10.7 & 6.4 & 32.1 & 18.4 & 5.9 & 29.7 & 13.6 \\
\multirow{4}{*}{ Women } & Low & 12.1 & 42.3 & 27.5 & 15.7 & 49.5 & 33.4 & 25.1 & 61.3 & 43.1 \\
& Medium & 7.5 & 30.9 & 16.5 & 11.2 & 47.1 & 24.9 & 11.7 & 36.4 & 19.6 \\
& High & 6.9 & 33.1 & 17.5 & 2.8 & 29.7 & 10.8 & 9.4 & 34.8 & 18.3 \\
\hline
\end{tabular}

Sources: elaborations on AVOo3 (NL); Consalo4 (IT)

The multivariate analysis confirms that the above-mentioned age, gender and educational level factors all have a (statistically significant) influence on dependence, both in the Netherlands and Italy. A simple logistic regression model shows that the chances of being dependent in the Netherlands are higher for women and older age groups and they are lower for individuals with a medium- or higher-educational level in all three years of the survey. The results are the same for the Italian samples in the same three-year period (table 3.Io for the Netherlands and table 
3.II for Italy). When we take the macro-regions in the case of Italy into account, we find that the chances of being dependent during this threeyear period in the centre and south are higher than in the north, also when controlling for other socio-demographic variables. This confirms what has been emphasised in the descriptive analysis: there are factors at work in determining the higher incidence of dependence in the centre-south of Italy that go beyond the socio-demographic characteristics of the population (table 3.II).

Table 3.10 Logistic regression models: factors affecting dependence among older individuals in the Netherlands (in bold statistically significant results at the 0.05 level)

\begin{tabular}{|c|c|c|c|c|c|c|c|}
\hline \multirow{3}{*}{$\overline{\text { Sex }}$} & \multirow[b]{3}{*}{ Female } & \multicolumn{2}{|c|}{1991} & \multicolumn{2}{|c|}{1999} & \multicolumn{2}{|c|}{2003} \\
\hline & & \multicolumn{2}{|c|}{$95 \%$ C.I. $\operatorname{Exp}(B)$} & \multicolumn{2}{|c|}{$95 \%$ C.I. $\operatorname{Exp}(B)$} & \multicolumn{2}{|c|}{$95 \%$ C.I. $\operatorname{Exp}(B)$} \\
\hline & & 1.139 & 1.864 & 1.550 & 2.374 & 1.266 & 1.883 \\
\hline \multirow[t]{3}{*}{ Age } & $65-74$ (ref) & & & & & & \\
\hline & $75-84$ (ref) & 1.673 & 2.749 & 1.837 & 2.835 & 1.833 & 2.748 \\
\hline & $85+$ & 3.541 & 12.599 & 4.247 & 10.242 & 4.475 & 12.183 \\
\hline \multirow[t]{3}{*}{ Education } & Low (ref) & & & & & & \\
\hline & Mid & 0.554 & 0.941 & 0.430 & 0.700 & 0.512 & 0.772 \\
\hline & High & 0.380 & 0.793 & 0.325 & 0.690 & 0.287 & 0.575 \\
\hline Constant & & \multicolumn{2}{|c|}{0.323} & \multicolumn{2}{|c|}{0.285} & \multicolumn{2}{|c|}{0.465} \\
\hline $\mathrm{R}_{2}$ & & \multicolumn{2}{|c|}{$9.6 \%$} & \multicolumn{2}{|c|}{$14.9 \%$} & \multicolumn{2}{|c|}{$13.3 \%$} \\
\hline N. & & \multicolumn{2}{|c|}{1376} & \multicolumn{2}{|c|}{1853} & \multicolumn{2}{|c|}{1942} \\
\hline
\end{tabular}

Source: elaborations on $\mathrm{AVO}_{91}, \mathrm{AVO}_{99}, \mathrm{AVO}_{3}$

Moreover, a logistic regression model has been used to investigate if there is a significant difference in the chances of being dependent, both in Italy and in the Netherlands, from one year to the other, independently from the composition of the older population in terms of gender, age and educational level. The results of the descriptive analysis are confirmed: in the Netherlands the chances for the elderly living at home of being dependent have increased from I99I to 2003 (while the parameter is not significant for the year 1999) and in Italy for the elderly living at home the chances of being dependent have decreased, independently from changes in the structure of the population (table 3.12).

Finally, a model was used to observe the differences in dependence rates between the Netherlands and the Italian macro-regions over time. The results confirm that in the first year there was a statistically significant increase in the chances of being dependent when one moved from the Netherlands to any of the three Italian macro-regions, but even more so in the south. However, in 2003, the chances of dependence in northern and, to a lesser extent, central Italy are lower than in the Nether- 


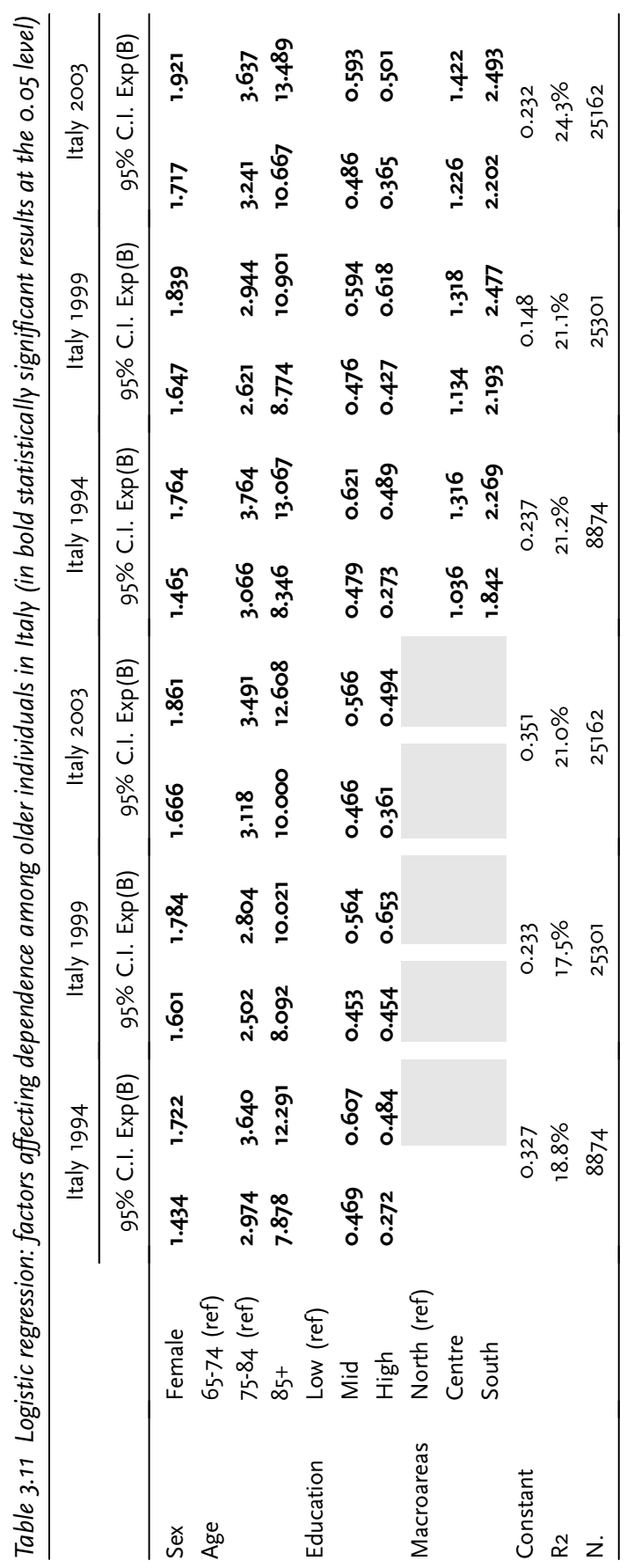


lands, while in southern Italy they remain consistently higher (table $3 \cdot 13)$.

Table 3.12 Logistic regression models: factors affecting dependence among older individuals in the Netherlands, years 1991-2003 (in bold statistically significant results at the 0.05 level)

\begin{tabular}{|c|c|c|c|c|c|}
\hline \multirow{3}{*}{$\overline{S e x}$} & \multirow[b]{3}{*}{ Female } & \multirow{2}{*}{\multicolumn{2}{|c|}{$\frac{\text { Netherlands }}{95 \% \text { C.I. Exp(B) }}$}} & \multicolumn{2}{|c|}{ Italy } \\
\hline & & & & \multicolumn{2}{|c|}{$95 \%$ C.I. $\operatorname{Exp}(B)$} \\
\hline & & 1.444 & 1.853 & 1.687 & 1.813 \\
\hline \multirow[t]{3}{*}{ Age } & $65-74$ (ref) & & & & \\
\hline & $75-84$ (ref) & 1.967 & 2.536 & 3.014 & 3.252 \\
\hline & $85+$ & 5.115 & 9.171 & 9.963 & 11.575 \\
\hline \multirow[t]{3}{*}{ Education } & Low (ref) & & & & \\
\hline & Mid & 0.553 & 0.723 & 0.504 & 0.573 \\
\hline & High & 0.378 & 0.575 & 0.399 & 0.499 \\
\hline \multirow[t]{3}{*}{ Macroregions } & North (ref) & & & & \\
\hline & Centre & & & 1.194 & 1.315 \\
\hline & South & & & 2.205 & 2.389 \\
\hline \multirow[t]{3}{*}{ Year } & $1991(\mathrm{nl}) / 1994(\mathrm{IT})$ (ref) & & & & \\
\hline & 1999 & 0.827 & 1.133 & 0.663 & 0.738 \\
\hline & 2003 & 1.208 & 1.647 & 0.682 & 0.759 \\
\hline \multicolumn{2}{|l|}{ Constant } & \multicolumn{2}{|c|}{0.315} & \multicolumn{2}{|c|}{0.201} \\
\hline \multicolumn{2}{|l|}{ R2 } & \multicolumn{2}{|c|}{$13.2 \%$} & \multicolumn{2}{|c|}{$22.5 \%$} \\
\hline $\mathrm{N}$. & & \multicolumn{2}{|c|}{5171} & \multicolumn{2}{|c|}{33512} \\
\hline
\end{tabular}

Table 3.13 Logistic regression models: the importance of the territorial variables, Italy, years 1991-2003 (in bold statistically significant results at the 0.05 level)

\begin{tabular}{|c|c|c|c|c|c|c|c|}
\hline \multirow[b]{3}{*}{ Sex } & \multirow[b]{3}{*}{ Female } & \multicolumn{2}{|c|}{ 1991/1994 } & \multicolumn{2}{|c|}{1999} & \multicolumn{2}{|c|}{2003} \\
\hline & & \multicolumn{2}{|c|}{$95 \%$ C.I. $\operatorname{Exp}(\mathrm{B})$} & \multicolumn{2}{|c|}{$95 \%$ C.I. $\operatorname{Exp}(B)$} & \multicolumn{2}{|c|}{$95 \%$ C.I. $\operatorname{Exp}(B)$} \\
\hline & & 1.455 & 1.731 & 1.661 & 1.848 & 1.701 & 1.895 \\
\hline \multirow[t]{3}{*}{ Age } & $65-74$ (ref) & & & & & & \\
\hline & $75-84$ (ref) & 2.899 & 3.502 & 2.592 & 2.900 & 3.147 & 3.515 \\
\hline & $85+$ & 8.061 & 12.285 & 8.605 & 10.620 & 10.399 & 13.067 \\
\hline \multirow[t]{3}{*}{ Education } & Low (ref) & & & & & & \\
\hline & Mid & 0.511 & 0.644 & 0.485 & 0.593 & 0.510 & 0.609 \\
\hline & High & 0.330 & 0.520 & 0.426 & 0.594 & 0.364 & 0.486 \\
\hline \multirow[t]{4}{*}{ Country } & Netherlands (ref) & & & & & & \\
\hline & Northern Italy & 1.164 & 1.547 & 0.837 & 1.052 & 0.555 & 0.698 \\
\hline & Central Italy & 1.335 & 1.838 & 1.015 & 1.297 & 0.726 & 0.928 \\
\hline & Southern Italy & 2.347 & 3.163 & 1.948 & 2.448 & 1.293 & 1.631 \\
\hline \multicolumn{2}{|l|}{ Constant } & \multicolumn{2}{|c|}{0.290} & \multicolumn{2}{|c|}{0.275} & \multicolumn{2}{|c|}{0.381} \\
\hline $\mathrm{R}_{2}$ & & \multicolumn{2}{|c|}{$21.1 \%$} & \multicolumn{2}{|c|}{$21.2 \%$} & \multicolumn{2}{|c|}{$23.7 \%$} \\
\hline N. & & \multicolumn{2}{|c|}{10250} & \multicolumn{2}{|c|}{27154} & \multicolumn{2}{|c|}{27104} \\
\hline
\end{tabular}


These results confirm that dependence is associated with age, gender and one's educational level. The higher incidence of dependence in Italy compared to the Netherlands can in part be explained by the different (older, more feminised and lower-educated) composition of the older population. However, other factors seem to determine the distribution of dependence in Italy's macro-regions, a decreasing incidence of dependence in the northern and (to a lesser extent) central regions of Italy over time and an increasing incidence of dependence in the Netherlands. Important roles in this respect include the respective country's past and present institutionalisation policies.

\subsubsection{The role of (de)institutionalisation policies}

Our analysis of the incidence of dependence among the elderly living at home excludes part of the older population - the institutionalised elderly - who is likely to have higher dependence rates. While the exclusion of the institutionalised elderly from surveys in countries with very low institutionalisation rates will probably not result in a significant difference in the calculated prevalence of dependence in the older population, this is not the case in presence of higher institutionalisation rates. ${ }^{5}$ But this is not just a computational problem. We are interested here in a specific social policy item - the (de)institutionalisation policy and practices, which determine the numbers and the characteristics of those elderly living in institutions and those living at home - that should account for more than just some of the differences (between contexts and over time) in dependence rates of the elderly living at home and also contribute to shaping the risk of dependence.

The proportion of the institutionalised elderly in the Netherlands, almost 10\% of those aged 65 and over in 1984 , had dropped to $6 \%$ by 2003 (Statistics Netherlands, StatLine). Moreover, while the decrease in institutionalisation rates was particularly dramatic in care homes for the elderly, the same phenomenon did not occur in nursing homes with its more acutely dependent elderly. In I984, the percentage of the elderly who lived in elderly homes was $8 \%$; this fell to $6.6 \%$ in I99I, to $5.4 \%$ in I996 and to $5 \%$ in I998. By contrast, nursing homes during the I990s showed a slight increase in absolute numbers of users, while the percentage of the overall older population remained constant. In fact, in I99I, nursing home residents comprised less than $3 \%$ of the population aged 65 and over and ultimately stabilised at ca. $2.5 \%$ in subsequent years (De Klerk and Hessing-Wagner I999: I35-6; De Boer et al. 200I: I90). The enacted deinstitutionalisation policies both reduced the supply of residential services and selected more dependent users. The proportion of the elderly living in institutions declined over time and their demographic details changed: they tended to be older and more in need than in the past. Between I990 and I999, the percentage of people aged 85 and over increased to $2.6 \%$ in care homes and to $1.5 \%$ in nursing 
homes, while institutionalisation rates under 85 declined (de Boer et al. 200I: I94; Statistics Netherlands, StatLine). It has also been shown that the care needs of nursing home residents increased in the I980s and stabilised in the I990s (de Boer et al. 200I: 193-194), while the care needs of residents in care homes continued to increase throughout the I990s (De Boer and De Klerk 2006: I44; de Boer et al. 200I: I93; Timmermans et al. I997: I28; Schoemakers-Salkinoja and Timmermans 200I: II5).

The deinstitutionalisation policies thus resulted in two distinct processes: the reduction in the percentage of institutionalised elderly and an increased concentration of the more severely dependents in institutions. Despite the fact that the first of the two processes speeded up during the mid-I980s to early-I990s period, this had little effect on the level of disability of those living at home since the more severely dependent ended up in institutions. The proportion of the more severely dependent elderly living in institutions began to decrease in the mid-I990s, as a result of the fact that the "room to manoeuvre" the composition of the instititutionalised became smaller (table 3.I4). These processes are related to the previously observed increasing disability rates of those living at home since the early I990s, and particularly in early 2003.

Table 3.14 Population aged 65+ living in care homes and in nursing homes and estimates of the population aged $65+$ with severe disabilities (*) living in care homes and in nursing homes as a percentage of the total population aged $65+$

\begin{tabular}{llllll}
\hline & 1984 & 1991 & 1996 & 1998 & 2003 \\
\hline Living in care homes & 8.0 & 6.6 & 5.4 & 5.0 & 3.5 \\
Severely dependent in care homes & 4.8 & 4.4 & 3.6 & 3.4 & 2.6 \\
Living in nursing homes & 2.0 & 2.5 & 2.5 & 2.5 & 2.5 \\
Severely dependent in nursing homes & 1.9 & 2.3 & 2.3 & 2.3 & 2.4 \\
Living in institutions & 10.0 & 9.1 & 7.9 & 7.5 & 6.0 \\
Severely dependent in institutions & 6.7 & 6.7 & 5.9 & 5.7 & 5.0 \\
\hline
\end{tabular}

Sources: own elaborations on: De Boer et al 2001: 193-194; De Boer and De Klerk, 2006: 144; Schoemakers-Salkinoja and Timmermans 2001: 115; Statistics Netherlands, StatLine; Timmermans et al, 1997: 128

(*) The definition of "severe disabilities" used here is not immediately comparable with the one used in the first part of the chapter relative to the population living at home and depends on a different definition provided by the sources on which this estimate is built. In this context it should be taken as a rough indicator of the increasing care needs of the institutionalized population.

Institutionalisation rates in Italy, by contrast, have remained traditionally low. There was an increase in the absolute numbers of the elderly living in institutions throughout the I990s. The number of people aged 65 and 
over living in care homes and nursing homes expandend from I75,93I in I99I to 222,548 in I999, an increase of $26 \%$. However, because the population was also ageing, the overall rate of institutionalisation remained stable at $2.0 \%$ of those aged 65 and over. The significant regional differentiation in institutionalisation rates is a consequence of the fact that regional authorities are responsible for arranging and (partially) financing elderly homes and nursing homes. In fact, northern regions show higher institutionalisation rates $3.2 \%$ throughout the I990s into early 2003); while the central regions display an intermediate rate, but still below the overall national average (I.5\%), and the southern regions and islands show the lowest rates (0.8\%) (ISTAT 2002; 2006a). Despite the stability of the institutionalisation rates during the period we studied, there were some significant changes in the demographics of the elderly living in residential settings. The transformation of existing care homes into nursing homes that addressed higher levels of care needs significantly increased the percentage of the dependent elderly who were institutionalised. The increases were particularly significant in the I990s, but continued thereafter as well. In I99I, for instance, less than half of the elderly living in institutions were classified as "disabled" by ISTAT, but by 2004 , this proportion had risen to $63 \%$ by 1999 and $60 \%$ by 2004 (table 3.15).

Table 3.15 Population aged $65+$ in residential care; percentage of disabled among the institutionalised (*); and percentage of the population aged $65+$ with disabilities in residential care (*) as a percentage of the total population aged $65+$; Italy and Italian macro areas (1991-2004)

\begin{tabular}{llllll}
\hline & & 1991 & 1999 & 2001 & 2004 \\
\hline \multirow{2}{*}{ taly } & Institutionalisation rate & 2.0 & 2.1 & 2.0 & 2.0 \\
& \% Disabled & 46.8 & 63.3 & 66.1 & 70.2 \\
& Disabled in institutions /population & 0.9 & 1.3 & & 1.4 \\
\multirow{5}{*}{ North } & Institutionalisation rate & & 3.2 & 3.2 & 3.1 \\
& \% Disabled & 69.7 & & 77.2 \\
& Disabled in institutions /population & & 2.2 & & 2.3 \\
\multirow{4}{*}{ Centre } & Institutionalisation rate & & 1.5 & 1.5 & 1.5 \\
& \% Disabled & & 0.7 & & 57.3 \\
& Disabled in institutions /population & & 0.8 & 0.8 & 0.8 \\
\multirow{5}{*}{ South } & Institutionalisation rate & & 44.4 & & 46.3 \\
& \% Disabled & & 0.4 & & 0.4 \\
\hline
\end{tabular}

Sources: own elaborations on Istat 2002: 62, 64; Istat 2006a

$(*)$ The definition of disability adopted here is elaborated by Istat and is not immediately comparable to the one we have been using for the operationalisation of dependence. It therefore only represents a rough indicator of trends in health and autonomy conditions of the institutionalised population. 
Like the situation in the Netherlands, the composition of the institutionalised continued to change throughout the ig9os. As a consequence, a clear move towards the concentration of the dependent and severely dependent people in institutions, by the late I990s, there was a larger percentage of the elderly with at least some inability to perform some daily activities than in the early I990s living in institutions. The concentration of the elderly dependent in elderly homes and nursing homes was noticeably higher in northern regions, which also provided more residential care services than in central and southern Italy. Here not only the percentage of the institutionalised elderly is lower, but the institutionalised elderly also tend to be "less dependent" (table 4.I8). In the south, in 2004, less than half (of the few of) the elderly institutionalised were "dependent". This has important consequences for the distribution of the elderly with greater care needs between the home and institutions and may help explain the different and diverging trajectory of the incidence of dependence among the elderly living at home in the various macroregions. In 2004, the elderly with severe care needs who lived in institutions in the north represented $2.3 \%$ of the older population, while the percentage was much lower (0.9\%) in the centre and the lowest (0.4\%) in the south (table 3.15).

These figures emphasise how institutionalisation policies and practices in the early I990s contributed to the convergence of the incidence of dependence among the elderly living at home in the Netherlands and in northern Italy compared to Italy's central and southern macro-regions.

\section{$3 \cdot 4$ Conclusion}

Dependence among the elderly living at home was much more common in Italy than in the Netherlands in the early I990s because of differences in socio-demographic structures, social stratification and the traditional features of institutionalisation policies. The percentage of the elderly with (severe) dependence and the proportion of households with elderly dependents were considerably higher in Italy. However, while the incidence of dependence declined in Italy between 1994 and 2003, it increased in the Netherlands between I99I and 2003. Moreover, there was a common trend in the two countries during this period with increased percentages of older dependents living on their own - which was already more prevalent in the Netherlands than in Italy.

In Italy, the percentage of (severely) dependent elderly people of the total elderly population living at home declined slightly, although the ratio between older dependents and the total adult population did not. De-

spite the fact that our analysis does not consider the duration of dependence and its intensity in an elaborate manner - two aspects that are likely to contribute to the pressure exerted on a care system - it does 
present a picture of relative stability during the period considered. However, considerable territorial differences do emerge in the Italian case. The northern region had a lower (severe) dependence rate than central and southern Italy in 1994 and even more so in 1999 and 2003. Given the fact that the socio-demographic structure of the elderly is fairly similar, part of this difference may be due to various institutionalisation patterns: residential services are relatively unavailable in the south, and are more developed in the north and (to a lesser extent) in the centre. During the case study period the increased availability of residential care for very dependent elderly people in the north - and not the south - played a relevant role in the widening gap between the various macro-regions.

By contrast, the prevalence of (severe) dependence among the elderly living at home in the Netherlands and the ratio of the elderly dependents to the general adult population increased during the I990s. The higher incidence of dependence is probably related to the deinstitutionalisation policies enacted during the I990s. The ageing process was accompanied by a reduced availability of space in residences and a higher concentration of heavily dependent elderly people in institutions. The second trend eventually could no longer compensate for the first, which led to an increase of the (severely) dependent elderly living at home. 


\section{Changing Care Packages}

\section{I Analysing changes in care packages}

According to the literature on welfare models in the domain of care for the more frail among the elderly, the Italian and Dutch cases should fit into two distinct clusters. Italy, given its limited social services for elderly dependents and considering the primary importance of the family as an agent of welfare, represents a residual type of social policy with a familistic bias. The Netherlands lies at the other extreme with its highly defamilised system with universal access to long-term-care services. The transformations that occurred during the I990s and into the 2Ist century should nevertheless call into question how much the Dutch case continues to adhere to the model, especially in light of increased refamilisation and/or the commodification of the risk of dependence as a consequence of major social policy changes. This trend should be reinforced as care needs increased in the Netherlands during the period we studied (see chapter three).

The main goal of this chapter is to analyse the importance of different sources of support for households with older (dependent) persons. We shall therefore look at the various sources of support available in Italy and the Netherlands and their transformation during the early-I990s to early-200os period as a way of analysing the transformations the two care systems underwent.

\subsubsection{Care packages and welfare system transformations}

The notion of care packages is drawn from studies on income packaging. The tool of income packages was originally used to understand how social policy affected families. The proliferation of different schemes of social protection made it increasingly difficult to evaluate the actual impact of social policy on families. The first attempts were made in studies on income support where welfare analysts referred to families as units of analysis receiving "income packaging”, i.e. a specific combination of services and income provided by various social policy measures (Rainwater et al. I986). Similarly, comparative studies on "child benefit packages" place the family at the centre of the analysis and investigate the effects of combining different care policies (Bradshaw et al. I993; Bradshaw I998). The resource packaging (of income or care) first emerged as an analytical tool in order to better understand the complexity of social poli- 
cies and their impact on individuals and families. A few attempts have been made to broaden the concept of packaging and thus include resources from outside of social policy sources such as the market and intra-family or inter-family solidarity. For instance, comparative welfare research has employed income packaging to study the sources of support for the unemployed (Bison and Esping-Andersen 2000) and retirees (Pedersen 2004). Although previous applications have mainly been restricted to the combination of benefits coming from the sphere of redistribution, it is possible to extrapolate this basic idea to encompass all of the welfare institutions. Maintaining individuals and families as units of analysis allows one to look not only at the impact different social policies have on packages received, but also on the kind of support received from other sources of support be it by means of reciprocity or market exchange.

The assumption is that there is a strong relation between macro-welfare arrangements and the ways in which individuals and households find support in coping with specific risks and needs (Bison and EspingAndersen 2000). The main characteristics of the care regime should be reflected by the micro-level packages, which, in turn, represents the ways in which individuals and families mobilise different resources: informal support, public or publicly organised services, market resources. The prevalent source of support (or specific combinations of resources) received by individuals and families in the different systems should also differ.

\subsubsection{Sources of support and packages}

The first issue is whether Italy and the Netherlands in the early I990s actually fit into, respectively, the familist and the social service models. The second question concerns whether the two models changed over time, to what extent and in which directions. Because of some limitations in the available data, these questions will be addressed by first looking at the uses of three different sources of support - informal, formal and commercial ${ }^{\mathrm{I}}$ - and, subsequently, at various combinations of these three. The level of analysis is the household where we shall look at the type of help received by households with at least one older person displaying varying degrees of dependence.

In the Netherlands, the universalistic defamilised elderly care model should imply a (comparatively) limited amount of informal support for the elderly in the Netherlands. Nonetheless, according to the hypotheses on the effect of retrenchment policies we should notice an increase of informal sources of support over time. In fact, the policy mechanisms introduced in the I990s were aimed at stimulating greater individual and family responsibility. This also happened as the shift from more costly residential care to less expensive domiciliary care occurred, which relied mostly on inexpensive informal support. In Italy, it is usually as- 
sumed that family members will be the most important care providers for their elderly dependent family member. Their ability to respond to their care needs has seldom been questioned and the decreasing availability of informal care is seen more as a possible future development than as a current issue.

Based on the characteristics of the two models, one would think that home care services would be an important element in the care for the elderly in the Netherlands and a more marginal one in Italy. But because of policy changes that occurred over the course of the I990s we should observe a decline in this type of help in the Netherlands.

Commercial services should not account for a significant part of the responses to the care needs of the elderly in the early I990s in the two contexts. Both in a familistic system and in a social services system the level of paid care should be quite low. In the Dutch case, hypotheses concerning the transformation of the system as a consequence of retrenchment policies suggest that a shift towards commercial services should have taken place by the end of the period under consideration here. On the other hand, the apparent growth of paid care in the second half of the I990s in Italy with the proliferation of migrant care workers raises questions about the scope and characteristics of this development.

\subsection{The Dutch trajectory}

The Dutch data allow us to perform a detailed analysis of the various sources of care available to households and how they were combined during this period. Dutch questionnaires made a distinction between (informal, formal and commercial) help with personal care and household assistance. This makes it possible to appreciate the sources of assistance supplied in relation to the various degrees and types of needs as well as the level of personal and physical involvement of the care providers. The importance of single types of support is analysed before we present the results in relation to combined strategies (the care packages).

\subsubsection{Informal care}

With respect to informal care, the questionnaires distinguished between assistance received by households from co-habitant relatives and non-cohabitant members of a social network such as other relatives, friends and neighbours. ${ }^{2}$ The help offered by other household members was very limited both with respect to personal care and household tasks performed during our case study period: only in 3\% to $4 \%$ of all households with at least one elderly member assistance was exchanged within the household throughout the study period. This proportion is higher among households with severe care needs, but is only II\% in I99I and $9 \%$ in 2003 . Interestingly, there seems to be a small increase in the per- 
centage of households with heavier care needs exchanging assistance with personal care and a decrease in the percentage of households with heavier care needs exchanging household assistance between the beginning and the end of the period (table 4.I). The proportion of households counting on informal support from non co-residents is fairly limited as well, particularly with respect to personal care assistance. Only $2 \%$ to $3 \%$ of the households with at least one older member received informal personal care from outside the household, while the proportion is $6 \%$ to I0\% for household assistance. Informal support was expectedly more prevalent, but decreasing, with more intense levels of need: the proportion of households receiving personal care was II\% in I99I and I999 but only $3 \%$ by 2003 and the proportion of households receiving household assistance was $25 \%$ in I99I, $20 \%$ in I999 but only I4\% in 2003 . A decrease in the availability of informal care is apparent during the period under consideration (table 4.2).

Table 4.1 Households with at least one person aged $65+$ receiving informal help with personal care and/or household assistance from members of the household, by level of care needs (weighted cases), the Netherlands, 1991, 1999, 2003

\begin{tabular}{lllll}
\hline Type of care received & Care needs & 1991 & 1999 & 2003 \\
\hline Personal care & None & 0.3 & 0.9 & 1.7 \\
& Medium & 0.3 & 1.4 & 0.7 \\
& High & 4.7 & 5.3 & 6.2 \\
Household assistance & Total & 0.7 & 1.5 & 2.2 \\
& None & 1.5 & 1.8 & 1.0 \\
& Medium & 3.5 & 1.4 & 2.8 \\
& High & 7.9 & 4.6 & 3.3 \\
Personal and/or hh care & Total & 2.7 & 2.0 & 2.0 \\
& None & 1.8 & 2.2 & 2.7 \\
& Medium & 3.8 & 2.4 & 3.5 \\
& High & 11.0 & 9.3 & 8.8 \\
& Total & 3.3 & 3.0 & 4.0 \\
& & 1096 & 1472 & 1513 \\
\hline
\end{tabular}

Source: elaborations on $\mathrm{AVO}_{91}, \mathrm{AVO}_{99}, \mathrm{AVO}_{3}$

These figures show no increase in the levels of informal care in the Netherlands during the period of the early I990s to the early 2000 s. Moreover, the information available on the number of hours of assistance received by households with care needs suggests that non-cohabiting informal care providers generally provide low intensity support. In the three specific years we looked at $86 \%$ to $89 \%$ of the households with mild or severe limitations received less than ten hours of household assistance from all informal care providers per week; more than $50 \%$ of the households received less than five hours per week. ${ }^{3}$ 
If we look at the differences in levels of informal support based on the educational level of the head of household - which is a rough indicator of socio-economic status - we predictably find that households with lower levels of education are more likely to receive informal care provision, even if the bivariate relationship is less clear for high levels of needs. However, the proportion of households with lower care needs that are supported by informal networks decreases over time for all educational levels, also for the lower educated (table A3. $\mathrm{I}^{4}$ presents the figures of personal care or household tasks performed by non-household members). When we look at the gender and age of the head of household, type of household and level of need by means of a logistic regression model, the educational level is not statistically significant except for I999. The level of need is significant in all of the three specific years we observed where households with higher care needs were more likely to receive informal support (table $\mathrm{A}_{3} .2$ ).

Table 4.2 Households with at least one person aged 65+ receiving informal help with personal care and/or household assistance from non members of the household, by level of care needs (weighted cases), the Netherlands, 1991, 1999, 2003

\begin{tabular}{lllll}
\hline Type of care & Care needs & 1991 & 1999 & 2003 \\
\hline Personal & None & 0.6 & 1.6 & 0.8 \\
care & Medium & 1.6 & 3.1 & 1.8 \\
& High & 11.1 & 11.2 & 2.9 \\
Household & Total & 1.9 & 3.1 & 1.5 \\
assistance & None & 5.9 & 5.8 & 2.6 \\
& Medium & 14.9 & 13.0 & 8.8 \\
& High & 25.2 & 19.7 & 14.2 \\
Personal care & Total & 10.4 & 9.6 & 6.4 \\
and/or & None & 6.3 & 6.1 & 2.9 \\
household assistance & Medium & 16.2 & 14.4 & 9.5 \\
& High & 27.8 & 25.0 & 15.9 \\
N. & Total & 11.3 & 10.7 & 7.0 \\
\hline
\end{tabular}

Source: elaborations on $\mathrm{AVO}_{91}, \mathrm{AVO}_{99}, \mathrm{AVO}_{3}$

Finally, in order to check whether the observed decreased availability of informal care during this period was not caused by new compositions of the elderly dependent population, we have controlled for some key characteristics (age, gender and education of the head of household, type of households and level of need): logistic regression results show that the chances of receiving informal care in 2003 , when controlling for other variables, was indeed significantly lower than in I99I (table A.3.3). 
These figures do not support the hypothesis of the re-familisation of care in the Netherlands during the research period. In fact, they suggest the declining importance of informal care as a source of support and a concentration on neediest situations.

\subsubsection{Formal care}

In I99I, $16 \%$ of the households with at least one elderly person received formal care: $6 \%$ of the households received help with personal care and I3\% with household tasks. ${ }^{5}$ Among households with higher care needs, the proportion that receives formal support peaked at 52\% (32\% received personal care and $38 \%$ received household assistance). Twelve years later, however, the households with at least one elderly person receiving formal help increased to $22 \%$ (9\% received personal care and $19 \%$ received household assistance). However, the higher coverage rate is due to an expansion of home help rather than personal care services, whose coverage rates, especially for the neediest households, actually decreased. Between I99I and 2003, the proportion of households with greater care needs receiving formal care decreased from $32 \%$ to $26 \%$ for personal care, while it increased from $38 \%$ to $43 \%$ for household tasks (table 4.3).

Table 4.3 Households with at least one person aged $65+$ receiving formal help in personal care and household assistance, by level of care needs (weighted cases), the Netherlands, 1991, 1999, 2003

\begin{tabular}{lllll}
\hline Type of help received & Care needs & 1991 & 1999 & 2003 \\
\hline Personal & None & 1.3 & 2.7 & 2.9 \\
care & Medium & 6.5 & 10.0 & 9.3 \\
& High & 32.3 & 34.4 & 25.5 \\
& Total & 5.8 & 8.5 & 8.6 \\
Household & None & 4.9 & 5.3 & 7.9 \\
assistance & Medium & 22.2 & 23.8 & 26.8 \\
& High & 37.8 & 40.4 & 42.7 \\
& Total & 13.1 & 14.7 & 19.4 \\
Personal care & None & 5.7 & 6.6 & 9.2 \\
and/or & Medium & 24.7 & 28.0 & 29.8 \\
household assistance & High & 52.4 & 53.0 & 50.6 \\
& Total & 15.7 & 18.2 & 22.3 \\
N. & & 1096 & 1472 & 1514 \\
\hline
\end{tabular}

Source: elaborations on AVO91, AVO9g, AVOO3

The information concerning the intensity of the help received is not comparable from one year to the other. If we consider the 2003 data, the overwhelming majority of the households with a dependence situation 
$(82 \%)$ received less than five hours of care with household tasks per week and $14 \%$ received five to ten hours of assistance per week. Meanwhile, the frequency of personal care assistant visits (excluding nurses) reached a significant number of times per week with $35 \%$ of households with at least one elderly person with some problems performing daily activities receiving one to two visits per week; $26 \%$ received two to six visits per week; $30 \%$ received seven to eight visits per week and $9 \%$ received more than eight visits per week ( $\mathrm{N}=7 \mathrm{I})$.

The correlation between socio-economic circumstances and the access to formal care is not very clear from the bivariate relation between the educational level of the head of household and the receipt of formal support, particularly among households with greater care needs, where the proportion of households receiving formal support is very high (c. 50\%) among all educational levels (table A3.4). Logistic regression results show that this relationship is not statistically significant, except for I999, when controlling for gender and age of the head of household, type of household and level of needs. Interestingly, for the access to formal services the need variable is the only statistically significant one (table A3.5). When looking at the relation between the access to services and the year of the survey, the chances of receiving formal help in 2003 are significantly higher than in I99I (table A3.6).

These data suggest that an expansion of home care services in the period did occur, even if it involved more household assistance than support in personal care and among those with less rather than more severe care needs. Home care services appear persistently widespread throughout the period: no actual retrenchment can be observed, despite some signs of reorientation and reorganisation of the service supply.

\subsubsection{Market care}

Also in the area of market care, the surveys distinguish between two types of services: help with personal care and help with household tasks. ${ }^{6}$ While the variable "personal care" is defined in the same way in all three observed years, a substantial break in the series concerns "help with household tasks" between 1999 and 2003. ${ }^{7}$

According to these data, commercial services for personal care were virtually non-existent in the Netherlands in all three of the observed years (table 4.4). By contrast, household assistance was quite widespread among households with older (dependent) people. In I99I and I999, between $13 \%$ and $15 \%$ of all households with a dependent older member received help with household tasks from commercial services, but only $2.5 \%$ attributed the use of these services to health and functional care needs of the household members. Moreover, between I99I and I999, no considerable changes seem to have taken place, either when considering the broader or stricter definition of market services. The 2003 data are difficult to interpret compared to the first two years. If we assume 
that 2003 is closer to the "stricter" I99I and I999 definition, we observe an expansion of paid services: $5.7 \%$ of the households with at least one elderly member made use of paid services for household assistance (Iо\% among households with greater care needs) (table 4.4). Even so, this source of support remains limited compared to formal help, which, among the same group, reached $42 \%$ of the households.

The intensity of market-based household assistance is rather low: in $2003,87 \%$ (but also $89 \%$ in I99I and 90\% in 1999) of the households with some limitations purchased less than five hours of home care per week.

Table 4.4 Households with at least one person aged $65+$ receiving commercial help in personal care and household assistance, by level of care needs (weighted cases), the Netherlands, 1991, 1999, 2003

\begin{tabular}{lllll}
\hline Type of help received & Care needs & 1991 & 1999 & 2003 \\
\hline Personal & None & - & 0.2 & \\
Care & Medium & - & 0.2 & 0.5 \\
& High & - & 0.7 & - \\
& Total & - & 0.3 & 0.1 \\
Household & None & $12.4(1.1)$ & $10.2(1.5)$ & 2.4 \\
Assistance & Medium & $20.3(3.5)$ & $17.1(3.5)$ & 8.8 \\
& High & $15.0(5.5)$ & $13.8(5.3)$ & 10.0 \\
& Total & $14.9(2.3)$ & $12.7(2.5)$ & 5.6 \\
Personal care & None & $12.4(1.1)$ & $10.2(1.5)$ & 2.4 \\
and/or & Medium & $20.3(3.5)$ & $17.4(4.0)$ & 9.0 \\
household assistance & High & $15.0(5.5)$ & $13.8(6.0)$ & 10.0 \\
& Total & $14.9(2.3)$ & $12.8(2.7)$ & 5.7 \\
N. & & 1096 & 1472 & 1513 \\
\hline
\end{tabular}

Source: elaborations on AVO91, AVO9g, AVOO3

When we look at the percentage of households that use commercial services for personal or home care by level of education of the head of household and level of need, as one might expect, there seems to be a positive relationship between the use of commercial care and the educational level of older dependent people. However, from the bivariate distribution it also appears that greater care needs do not imply increased use of commercial services, neither when we look at the broader definition of home care (as in I99I and I999) nor when we look at a narrower definition as in 2003 (table A3.7). A logistic regression model confirms these results as it displays a (statistically significant) influence of education on the use of commercial services, while, on the other hand, the parameters relative to the level of care are very similar for medium and higher levels of need (table A3.8). 


\subsubsection{Care packages}

Each household (or individual) may in fact receive care from one or more sources of support, or receive none at all. Table 4.5 shows the care packages at the household level received by Dutch households in the three years we studied. ${ }^{8}$

Let us first consider assistance with personal care. In $2003,73 \%$ of households with greater care needs received no help with personal care tasks. This may be partly due to the fact that some assistance is exchanged within the households; however, given the limited scope of informal support in personal care exchanged within households with heavy care needs (ca. $6 \%$ in 2003 , see table 4.I), the proportion of households receiving no assistance at all is remarkable. ${ }^{9}$ Moreover, the proportion of households receiving no assistance has increased over time. The most important care package is comprised solely of formal services: almost one household with heavy care needs in four received formal care services exclusively both in I99I and 2003. By contrast, both the "informal" package and the "formal and informal" packages show a decline over time, as a consequence of the reduced availability of informal care, as previously observed: they respectively decreased from $4 \%$ to I\% and from $7 \%$ to $2 \%$ between I99I and 2003 .

If we move to the area of assistance with household activities, the proportion of households with severe care needs that are not supported by any source of assistance is much lower (43\% in 2003) but still considerable. Again the "formal" package is the most important one: it reaches one-third of households with high care needs in 2003 (with a slight increase with respect to the two previous years. The mixed "informal and formal" package covers $7 \%$ of these households, which is similar to previous years and represents the second most important package together with the "market" package in 2003. While the "formal and informal" combination has maintained its significance during the period considered, the "market package" increase is difficult to assess, due to the break in the series (see above). Up till now the picture is of a relative stability of the packages over time. By contrast, the most important change observable from the data is the relative decreasing importance of the "informal" package, which concerned I7\% of the households with severe care needs in I99I and only 6\% in 2003.

Overall, the distribution of different care packages across households shows how formal care has remained the keystone of the Dutch care system for the elderly throughout the period considered, despite some tensions expressed by the slightly decreased availability among the more needy households. The importance of informal care - which was already limited - has decreased considerably. Commercial support - which remains restricted to help with household tasks and is barely present in the area of personal care assistance - has increased slightly while remaining rather limited. 
Table 4.5 Household level care packages, the Netherlands, 1991, 1999, 2003

\begin{tabular}{|c|c|c|c|c|c|c|c|}
\hline \multirow[b]{2}{*}{$\begin{array}{l}\text { Type of help } \\
\text { received }\end{array}$} & \multirow[b]{2}{*}{ Type of package } & \multicolumn{2}{|c|}{1991} & \multicolumn{2}{|c|}{1999} & \multicolumn{2}{|c|}{2003} \\
\hline & & Low & High & Low & High & Low & High \\
\hline Personal & No help & 92.4 & 64.3 & 88.2 & 58.3 & 88.7 & 73.2 \\
\hline \multirow[t]{7}{*}{ Care } & Informal & 1.1 & 4.0 & 1.2 & 6.6 & 1.6 & 1.3 \\
\hline & Formal & 6.0 & 24.6 & 8.5 & 29.8 & 8.8 & 23.8 \\
\hline & Market & - & - & 0.2 & 0.7 & 0.5 & - \\
\hline & Informal and formal & 0.5 & 7.1 & 1.9 & 4.6 & 0.2 & 1.7 \\
\hline & Formal and market & - & - & - & - & 0.2 & - \\
\hline & Informal and market & - & - & - & - & - & - \\
\hline & All & - & - & - & - & - & - \\
\hline Household & No help & $47.0(62.7)$ & $29.9(39.4)$ & $50.0(62.7)$ & $36.2(42.4)$ & 61.1 & 43.1 \\
\hline \multirow[t]{7}{*}{ assistance } & Informal & $10.8(11.6)$ & $17.3(17.3)$ & $9.6(10.1)$ & $13.2(13.2)$ & 5.1 & 6.3 \\
\hline & Formal & 18.9 (18.9) & $30.7(30.7)$ & $21.1(21.6)$ & $31.6(32.5)$ & 22.8 & 33.5 \\
\hline & Market & $19.2(3.5)$ & $14.2(4.7)$ & $15.3(2.6)$ & $10.5(4.6)$ & 6.5 & 7.1 \\
\hline & Informal and formal & $3.0(3.2)$ & $7.1(7.1)$ & $2.1(2.1)$ & $5.3(6.6)$ & 2.3 & 7.1 \\
\hline & Formal and market & - & - & $0.2(-)$ & $2.0(0.7)$ & 0.7 & 1.7 \\
\hline & Informal and market & $0.8(-)$ & $0.8(0.8)$ & $1.4(0.7)$ & - & 0.7 & 0.8 \\
\hline & All & $0.3(-)$ & - & $0.2(0.2)$ & $1.3(-)$ & 0.9 & 0.4 \\
\hline Personal care & No help & $45.1(60.3)$ & $24.6(33.3)$ & $47.4(59.8)$ & $25.8(30.5)$ & 58.9 & 37.7 \\
\hline \multirow[t]{7}{*}{ and/or } & Informal & $10.5(11.6)$ & 11.1 (11.1) & $8.2(8.9)$ & $12.6(12.6)$ & 4.4 & 5.0 \\
\hline & Formal & $19.7(20.0)$ & $33.3(34.1)$ & $22.5(23.3)$ & $37.1(39.1)$ & 24.0 & 37.2 \\
\hline & Market & $18.6(3.5)$ & $11.9(3.2)$ & $14.6(2.4)$ & $8.6(4.0)$ & 6.2 & 5.9 \\
\hline & Informal and formal & $4.3(4.6)$ & $15.9(15.9)$ & $4.2(4.2)$ & $10.6(11.9)$ & 3.5 & 10.0 \\
\hline & Formal and market & $0.3(-)$ & $2.4(1.6)$ & $1.2(0.2)$ & $3.3(2.0)$ & 1.4 & 2.9 \\
\hline & Informal and market & $1.1(-)$ & - & $1.6(0.9)$ & - & 0.7 & 0.8 \\
\hline & All & $0.3(-)$ & $0.8(0.8)$ & $0.2(0.2)$ & $2.0(-)$ & 0.9 & 0.4 \\
\hline N. & & 312 & 101 & 431 & 151 & 433 & 239 \\
\hline
\end{tabular}

Source: elaborations on $\mathrm{AVO}_{91}, \mathrm{AVO} 99, \mathrm{AVO} 03$

\subsection{The Italian trajectory}

The analysis of the Italian case suffers from some data limitations. Although we can rely on the data from our surveys for formal and commercial care, we are dependent on indirect evidence when it comes to studying informal care. As a result, it is impossible to reconstruct the full care package picture. We shall therefore look at the importance of each single source of support for households and individuals as well as the prevailing trends over time. 


\subsubsection{Informal care}

The lack of information on informal care in the Italian surveys used for this study means we have to rely on previously published data of various national surveys (ISTAT 1994; 200I; 2006c; Sabbadini 2002). ${ }^{\text {IO }}$ These data do not provide specific information on the informal help received by households with elderly dependents. However, they offer some insight via the figures of assistance received by Italian households with elderly members. According to these data, informal support - encompassing a broad set of activities - received by households with at least one elderly decreased sharply through the I980s and I990s. Italian households receiving some informal assistance constituted $23.3 \%$ in I983, I8.7\% in I990-I99I, I4.8\% in I998, and I6.7\% in 2003 . Nevertheless, this declining trend did not include all types of households to the same extent. Whereas the proportion of double-earner couples with children receiving assistance was stable and that of single parents with children receiving help decreased slightly, the decline in the proportion of single elderly people receiving assistance is remarkable (from $48.6 \%$ in I9 83 to $24.2 \%$ in 1998 and $28.3 \%$ in 2003 ). Moreover, most of the decrease occurred in the I990s, with the proportion in I990-I99I being as high as 4I.I\% (table 4.6).

Table 4. 6 Selected types of households that receive unpaid help from non-members of the household in the last four weeks by type of household and type of help (\%). Italy 1983, 1990, 1998, 2003

\begin{tabular}{lllll}
\hline Type of household & 1983 & 1990 & 1998 & 2003 \\
\hline Single elderly person & 48.6 & 41.1 & 24.2 & 28.3 \\
At least one elderly person and no children & 30.7 & n.a. & 16.0 & 18.4 \\
Couple with children $<14$ (working mother) & 30.9 & n.a. & 31.2 & 33.7 \\
Couple with children $<14$ (mother: housewife) & 20.2 & n.a. & 15.4 & 18.3 \\
Single parent with children $<14$ & 38.9 & n.a. & 30.8 & 34.1 \\
All households & 23.3 & 18.7 & 14.8 & 16.7 \\
\hline
\end{tabular}

Sources: Istat 1994: 285, 290; Istat 2001: 49; Istat 2006c

However, these figures refer to a broad definition of informal support, which ranges from economic to health and care assistance. More specific data on informal assistance received for health care, personal care and household activities are available for the beginning and the end of the I990 In I990, 20.1\% of the households with at least one elderly received unpaid help with personal care and I6.8\% help with household activities from the informal network ${ }^{\mathrm{II}}$ (table 4.7). According to these data, at the beginning of the I990s, unpaid help with personal care and household tasks was available to a larger proportion of households with the elderly compared to the Netherlands. In fact, in I99I Dutch house- 
holds with at least one dependent elderly receiving help with personal care were I.9\% and those receiving help with household activities were I0.4\% (table 4.2). Even considering the fact that the elderly in the Netherlands were less in need of support compared to Italy, this difference also accounts for a differently organised care model, which in Italy, as was expected, was mostly based on family care.

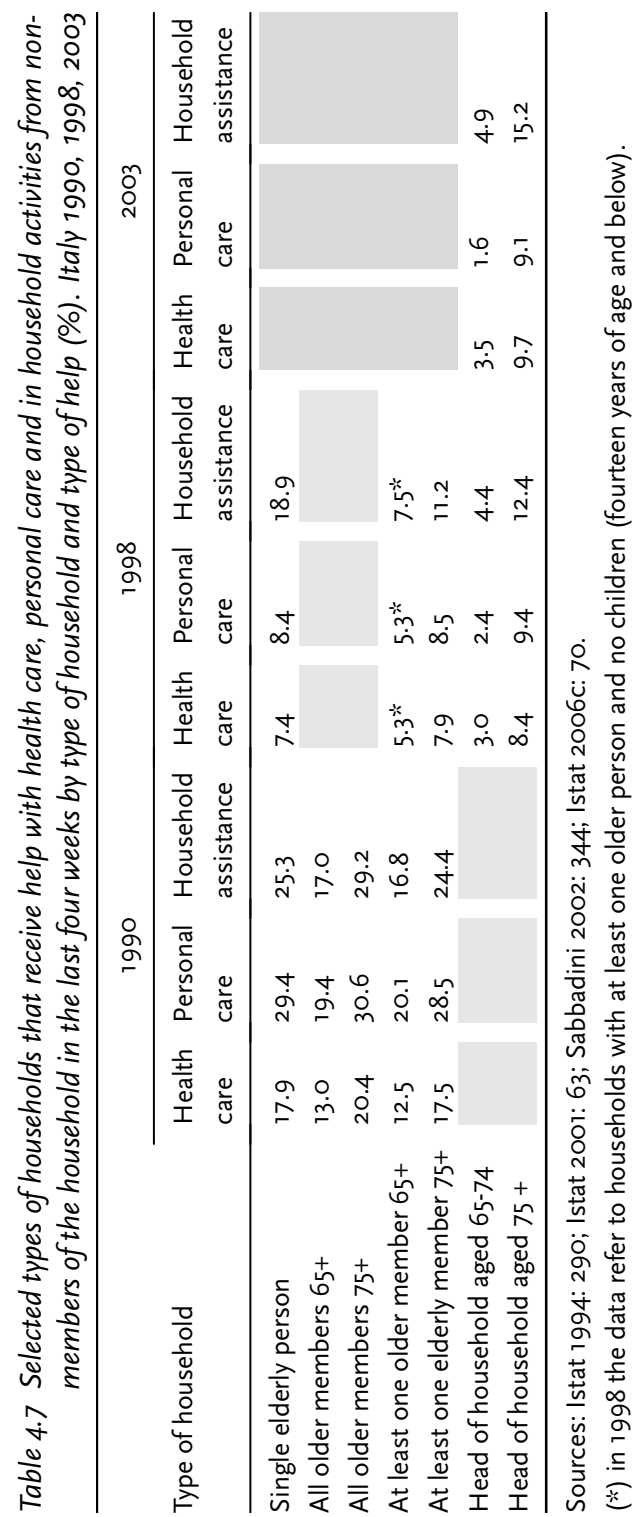


However, only eight years later in Italy the situation appears quite different: in 1998 the households with at least one elderly (and with no children) receiving personal care assistance decreased to $5.3 \%$ and those receiving assistance with household tasks decreased to $7.5 \%$. The only two available indicators for 2003 - proportion of households with the head of household aged 65 to 74 and 75 and over that received unpaid healthcare, personal care and household activities assistance - show signs of stability between 1998 and 2003 (table 4.7). As a result, the differences between the two countries appear drastically reduced at the end of the period: in I999, 3.1\% of the Dutch households with at least one elderly received help with personal care (I.5\% in 2003) and 9.6\% household assistance (6.4\% in 2003) ( table 4.2). Although these trends are probably also affected by a slightly decreased dependence rate among elderly Italians, they also underline the decreasing availability of informal care in both countries. In the Italian case, where we saw that informal care was a crucial resource in the early I990s, this transformation is particularly remarkable.

\subsubsection{Formal care}

In Italy, as one might expect, only a small proportion of households with elderly people and of households with (severely) dependent elderly people received formal care services, either for personal care assistance or for assistance with household tasks. In 1994, $5 \%$ of households with at least one elderly received personal care assistance, compared to respectively $3.9 \%$ and $3.5 \%$ in 2003 . The percentage of households with severe care needs receiving personal care assistance was $15 \%$ in I994, $14.4 \%$ in I999 and $8.9 \%$ in 2003 . No major changes - besides a decrease in the availability of already scarce services - occurred during the period under consideration (table 4.8). Nevertheless, these declining trends are clearly influenced by different trends in territorial macro-areas and, probably, by measurement problems. In the Italian surveys, not only was it difficult to distinguish between personal care assistance from household assistance, but also the questionnaires refer to different types of services received by different (health and care) institutions. The definition of services is itself vague and encompasses health and social care on both a longer term and occasional basis. The difficulties in grasping the fragmented nature of home care services may explain why, especially in the early I990s, Italy's southern regions show - contrary to expectations higher take-up levels than the northern regions. Therefore, instead of interpreting developments throughout the I990s as a further retrenchment of already under-developed services, it is more appropriate to speak of stability at a very low level. This is different from the Dutch case, where it is quite striking that over $50 \%$ of households with important care needs were reached by different types of care services. 
Table 4.8 Households with at least one person aged $65+$ receiving formal help in personal care and household activities, by level of care needs (weighted cases), Italy and Italian macro-areas, 1994, 1999, 2003

\begin{tabular}{lllll}
\hline & Care needs & 1994 & 1999 & 2003 \\
\hline Italy & None & 1.0 & 0.6 & 1.0 \\
& Low & 7.5 & 6.6 & 5.6 \\
& High & 15.6 & 14.4 & 8.9 \\
\multirow{4}{*}{ North } & Total & 5.0 & 3.9 & 3.5 \\
& None & 0.8 & 0.7 & 1.0 \\
& Low & 6.4 & 7.1 & 6.5 \\
& High & 14.5 & 20.8 & 9.5 \\
Centre & Total & 3.9 & 3.8 & 3.5 \\
& None & 0.6 & 0.6 & 1.0 \\
& Low & 5.6 & 6.6 & 5.1 \\
& High & 10.6 & 9.0 & 11.9 \\
South & Total & 3.6 & 3.6 & 3.4 \\
& None & 1.7 & 0.6 & 1.0 \\
& Low & 10.1 & 6.1 & 4.9 \\
& High & 18.3 & 12.6 & 7.3 \\
N. & Total & 7.7 & 4.4 & 3.6 \\
\hline
\end{tabular}

Source: elaborations on Consal94, Consal99, Consalo4

Table 4.9 Households with at least one person aged $65+$ receiving commercial help in personal care, by level of care needs (weighted cases), Italy and Italian macro-areas, 1999, 2003

\begin{tabular}{llll}
\hline & Care needs & 1999 & 2003 \\
\hline Italy & None & 0.5 & 0.8 \\
& Mid & 6.8 & 7.3 \\
& High & 13.2 & 9.8 \\
North & Total & 3.9 & 4.3 \\
& None & 0.6 & 0.6 \\
& Mid & 7.1 & 7.1 \\
& High & 20.3 & 10.8 \\
Centre & Total & 3.8 & 3.6 \\
& None & 0.1 & 1.3 \\
& Mid & 7.5 & 8.4 \\
& High & 15.2 & 14.0 \\
South & Total & 3.9 & 5.1 \\
& None & 0.7 & 0.6 \\
& Mid & 6.1 & 7.1 \\
& High & 8.7 & 7.4 \\
N. & Total & 4.2 & 4.7 \\
\hline
\end{tabular}

Source: elaborations on Consal99, Consalo4 
To summarise, the Italian data confirm the very small presence of home care services and their low intensity as a source of continuous support in the care of the elderly. In the Italian case, the formal care sector maintains its residual character and is also characterised by stagnation.

\subsubsection{Market care}

Information regarding private services in Italy was first gathered in I999 and again in 2003. Two questions that were included in the questionnaires dealt with the presence of privately paid care assistants and to the use of domestic help. In our analysis we refer to the first type of help as "personal care" and the second type as "household assistance", despite the fact that the boundaries between the two are quite ambiguous, as care assistants and home help may end up performing household tasks as well as care tasks.

Commercial personal care services, are quite different from those in the Netherlands where they are practically nonexistent, and represent an important source of assistance for Italian households in both 1999 and 2003: 4.3\% of all households, $7.3 \%$ of households with moderate care needs and 9.1\% of households with severe care needs received paid care (table 4.9). Moreover, when we look at household assistance the percentages are even higher: $12.3 \%$ of all households, $14.7 \%$ of households with low-level care needs and $18.8 \%$ of households with severe care needs (table 4.Io). The level of use of private services for household assistance is not only higher than in the Netherlands, also when we consider the broader definition of household assistance as something not necessarily linked to pre-existing specific care needs. Interestingly, and quite different from the Dutch case, paid household help seems to be related to the level of need of a particular household. If this may be expected for care services, it raises some questions with respect to household help. In the Dutch case, we have observed that when we used the broader definition ${ }^{\text {I2 }}$ the rates of use of these services did not correlate with the dependence level, and when we used the narrower definition they did. It is interesting to note that in the Italian case, despite the fact that a broader definition of home help is used, the purchase of these services seems to correlate with the level of need. In fact, in 2003, when 9.4\% of households with an elderly member without disabilities (which is similar to Dutch figures for I99I and I999) were receiving household assistance, the proportion increased to $14.7 \%$ among households with moderate care needs and to $\mathrm{I} 8.8 \%$ among households with severe care needs (table 4.IO). This indicates either that in the Italian context there is a possible overlap of functions between personal care assistance and household assistance (see above) or, more generally speaking, that commercial household assistance fills gaps produced by care needs that are not taken care of with the same type of assistance in the Netherlands, where, in this domain, there is a much broader level of support provided by social services. 
Table 4.10 Households with at least one person aged $65+$ receiving commercial household assistance, by level of care needs (weighted cases), Italy and Italian macro-areas, 1999, 2003

\begin{tabular}{llll}
\hline & Care needs & 1999 & 2003 \\
\hline Italy & None & 9.4 & 9.4 \\
& Mid & 13.4 & 14.7 \\
& High & 15.2 & 18.8 \\
North & Total & 11.4 & 12.3 \\
& None & 9.2 & 8.6 \\
& Mid & 14.2 & 14.8 \\
& High & 16.1 & 19.4 \\
Centre & Total & 11.4 & 11.5 \\
& None & 10.7 & 11.9 \\
& Mid & 13.8 & 16.4 \\
& High & 13.7 & 19.9 \\
South & Total & 12.2 & 14.3 \\
& None & 8.6 & 9.1 \\
& Mid & 12.1 & 13.7 \\
& High & 15.2 & 17.9 \\
N. & Total & 11.0 & 12.2 \\
\hline
\end{tabular}

Source: elaborations on Consal94, Consal99, Consalo4

Table 4.11 Households with at least one person aged $65+$ receiving commercial help with personal care or household assistance, by level of care needs (weighted cases), Italy and Italian macro-areas, 1999, 2003

\begin{tabular}{llll}
\hline & Care needs & 1999 & 2003 \\
\hline Italy & None & 9.6 & 9.9 \\
& Mid & 17.0 & 19.7 \\
& High & 21.1 & 24.9 \\
North & Total & 13.5 & 15.1 \\
& None & 9.5 & 9.0 \\
& Mid & 17.9 & 19.6 \\
& High & 24.5 & 27.6 \\
Centre & Total & 13.3 & 13.9 \\
& None & 10.8 & 12.6 \\
& Mid & 17.9 & 21.8 \\
& High & 23.7 & 27.9 \\
South & Total & 14.4 & 17.5 \\
& None & 9.0 & 9.6 \\
& Mid & 15.5 & 18.6 \\
& High & 18.4 & 22.0 \\
N. & Total & 13.2 & 15.4 \\
\hline
\end{tabular}

Source: elaborations on Consal94, Consalg9, Consalo4 
Notably, Italian households with dependence problems purchased a considerable amount of hours of care. In $2003,24 \%$ purchased up to ten hours of personal assistance care; $16 \%$ purchased between 10 and 20 hours; $30 \%$ purchased between 20 and 30 hours and 30\% more than 30 hours. Moreover, the amount of hours of assistance purchased is quite high also when one considers household assistance: if $36 \%$ of the households with at least one elderly dependent purchased less than five hours of household assistance per week in 2003 and $21 \%$ purchased between five and nine hours per week, the percentage of households purchasing more than 20 hours of household assistance per week comes to a high of $25 \%$.

The bivariate correlation between commercial assistance and educational level of the head of household is quite clear, particularly when we consider commercial household assistance (A3.9-A3.II). However it is worth noting that the proportion of households that seek commercial personal assistance is also relatively high among the less educated. In I999, $13 \%$ of the households in the lower and intermediate educational groups with high care needs were using commercial personal care, compared to $20 \%$ in the higher educational group. In 2003 , the proportion of low educated households with high care needs that hire a care assistant was 10\%, compared to $16 \%$ and $7 \%$ respectively among the medium and higher educated groups (table A3.9).

The results of a logistic regression model controlling for the age and gender of the head of households, for the type of household, level of need and geographical area, show that the chances of personal care services being purchased increase for households with higher-educated head of households, singles and households with greater care needs (table A3.I2). Similar results are found when we look at the determinants that lead to the purchase of commercial household services (table A3.I3). It is worth noting that in both cases, the territorial variable was not statistically significant.

While it is clear that market-based services were an important source of support among older Italians in the late I990s-early 2000 s, we do not have comparable data for the early I990s because national statistics regarding paid help have only been kept since the second half of the I990s. ${ }^{\mathrm{I} 3}$ This leads to two hypotheses regarding the Italian situation. Either Italy has long been a system that is based on commercial services for the care of the elderly or it has changed in this direction over the last few years. Much evidence points to the second hypothesis. Research on care for the elderly conducted until the early I990s rarely mentions the issue of private care. This is true for both quantitative and qualitative analyses reviewed for this study. A regional survey conducted in I99I in Lombardy (IRER I99I) included a question concerning the types of strategies families would adopt in a critical situation. Open questions addressed the solutions to care problems related to children and elderly family members. ${ }^{14}$ The solutions given by the interviewees were reorga- 
nised into a typology "along a continuum of reciprocity" (Micheli I99I: 73) consisting of the internalisation of care within the household; care provided through the extended family; market services; formal home care and territorial services; institutionalisation. While respondents did take into account market options in the field of childcare ("I would hire a babysitter"), they did not mention paid care for the frail elderly: market services did not appear to be a viable option. Commercial services appeared in research reports in the mid-I990s. A study conducted in I994 on a non-representative sample of older dependents released from a hospital in Milan showed that formal and market services - not distinguished $^{15}$ - represented a relatively important source of support, but only for very specific tasks (i.e. nursing, physiotherapy and injections) and, to some extent, for household services. ${ }^{16}$ Formal and market services together played a marginal role in the areas of care and supervi$\operatorname{sion}^{\mathrm{I7}}$ (Ciorli and Della Croce I994: II6-II7). A qualitative research study on care giving to elderly dependents conducted in the early I990s showed that paid assistance tended to be limited to helping out the main informal caregiver and in some rare cases - when female informal caregivers were unavailable - in performing duties coordinated by a family member (Taccani, ed. 1994). Finally, the key informants report the phenomenon of the "badanti" (foreign caregivers for dependent elderly people) as a relatively recent one, since the late ig9os.

\subsection{A comparative overview}

Table 4.I2 summarises the results discussed this far and highlights the proportions of households with different levels of care needs that received informal, formal or market assistance in the two countries between I99I (I994 for Italy) and 2003-2004.

In the early I990s, informal care provided by non-members of a household was a much more important source of support among Italian households than among Dutch households. Even considering that three times as many Dutch households with at least one elderly dependent had severe care needs (see chapter three), the difference between I.9\% Dutch households receiving informal help in personal care and $20.1 \%$ of their Italian counterparts remains striking. Less striking were the differences in the area of household assistance. These figures confirm substantial differences in the importance of informal support in the two contexts at the beginning of the period considered, consistent with the characteristics of the two care models. Nevertheless, the picture by the end of the period studied appears considerably different, particularly in Italy. There is evidence that during the I990s informal care underwent a dramatic rescaling, particularly with respect to personal care: households with elderly members receiving informal help with personal care comprised no more than $5.3 \%$ in 1999 and there is no reason to believe that 
Table 4.12 Households with at least one older member $\left(65^{+}\right)$receiving different types of care, by level of care needs (\%). The Netherlands and Italy, 1991-2004

\begin{tabular}{|c|c|c|c|c|c|c|c|}
\hline \multicolumn{2}{|c|}{ Informal care from non-members of the households } & \multirow{2}{*}{$\begin{array}{l}\text { NL91 } \\
1.9\end{array}$} & \multirow{2}{*}{$\frac{\text { NL99 }}{3.1}$} & \multirow{2}{*}{$\begin{array}{l}\text { NLO3 } \\
1.5\end{array}$} & \multirow{2}{*}{$\frac{\text { IT91 (*) }}{20.1}$} & \multirow{2}{*}{$\begin{array}{l}\text { ITg9 (*) } \\
5.3\end{array}$} & ITo4 \\
\hline All households & Personal care & & & & & & \\
\hline & Household assistance & 10.4 & 9.6 & 6.4 & 16.8 & 7.5 & \\
\hline & Total & 11.3 & 10.7 & 7.0 & & & \\
\hline \multirow[t]{3}{*}{ Low level of care needs } & Personal care & 1.6 & 3.1 & 1.8 & & & \\
\hline & Household assistance & 14.9 & 13.1 & 8.8 & & & \\
\hline & Total & 12.2 & 14.4 & 9.5 & & & \\
\hline \multirow[t]{3}{*}{ High level of care needs } & Personal care & 11.1 & 11.2 & 2.9 & & & \\
\hline & Household assistance & 25.2 & 19.7 & 14.2 & & & \\
\hline & Total & 27.8 & 25.0 & 15.9 & & & \\
\hline Formal care & & NL91 & NL99 & & IT94 & IT99 & \\
\hline \multirow[t]{3}{*}{ All households } & Personal care & 5.8 & 8.5 & 8.6 & & & \\
\hline & Household assistance & 13.1 & 14.7 & 19.4 & & & \\
\hline & Total & 15.7 & 18.2 & 22.3 & 5.0 & 3.9 & 3.5 \\
\hline \multirow[t]{3}{*}{ Low level of care needs } & Personal care & 6.5 & 10.3 & 9.3 & & & \\
\hline & Household assistance & 22.2 & 23.8 & 26.8 & & & \\
\hline & Total & 24.7 & 28.0 & 29.8 & 7.5 & 6.6 & 5.6 \\
\hline \multirow[t]{3}{*}{ High level of care needs } & Personal care & 32.3 & 34.4 & 25.5 & & & \\
\hline & Household assistance & 37.8 & 40.4 & 42.7 & & & \\
\hline & Total & 52.4 & 53.0 & 50.6 & 15.6 & 14.4 & 8.9 \\
\hline Commercial care & & NL91 & NL99 & & IT94 & IT99 & \\
\hline \multirow[t]{3}{*}{ All households } & Personal care & - & 0.3 & 0.1 & & 3.9 & 4.3 \\
\hline & Household assistance & $14.9(2.3)$ & $12.7(2.5)$ & 5.6 & & 11.4 & 12.3 \\
\hline & Total & $14.9(2.3)$ & $12.8(2.7)$ & 5.7 & & 13.5 & 15.1 \\
\hline \multirow[t]{3}{*}{ Low level of care needs } & Personal care & - & 0.2 & 0.5 & & 6.8 & 7.3 \\
\hline & Household assistance & $20.3(3.5)$ & $17.1(3.5)$ & 8.8 & & 13.4 & 14.7 \\
\hline & Total & $20.3(3.5)$ & $17.4(4.0)$ & 9.0 & & 17.0 & 19.7 \\
\hline \multirow[t]{3}{*}{ High level of care needs } & Personal care & - & 0.7 & - & & 13.2 & 9.8 \\
\hline & Household assistance & $15.0(5.5)$ & $13.8(5.3)$ & 10.0 & & 15.2 & 18.8 \\
\hline & Total & $15.0(5.5)$ & $13.8(6.0)$ & 10.0 & & 21.1 & 24.9 \\
\hline
\end{tabular}

Sources: elaborations on AVO91 AVO9g AVOo3; Consal94 Consal99, Consalo4

(*) Istat 1994: 285, 290; Istat 2001: 490; Sabbadini 2002: 352

the situation in 2003 had improved, as shown by our figures for Italy. In the Netherlands we observed a similar reduction in the availability of informal care, particularly among households with heavier care needs: Households with heavy care needs receiving informal personal care assistance decreased from II.I\% in I99I (II.2\% in I999) to $2.9 \%$ in 2003 , while those receiving household assistance decreased from $25.5 \%$ in I99I, I9.7\% in I999 and $14.2 \%$ to 2003 . When we looked at the number of hours of informal assistance received (household help) we did not 
notice an increase in the intensity of this type of support over time. As a result, the Dutch data do not corroborate the re-familisation of dependence hypothesis. At the end of the period studied, the support received by older dependents appears to have decreased and converged in the two cases, at least in terms of the coverage rate of this type of assistance. ${ }^{\text {I8 }}$

The take-up rates of home care services were, as expected, much higher in the Netherlands than in Italy in the early I990s. The difference is particularly striking when we look at households with heavier care needs. The coverage rate for all services (from personal care to household assistance) was $52.4 \%$ in the Netherlands in I99I versus $15.6 \%$ in Italy in I994. In both cases, there seems to be a relative overall stability or to some extent a readjustment - of this type of support over time. In Italy, the coverage rate actually decreased during the period considered. ${ }^{19}$ In the Netherlands, if we look at all households with at least one elderly member, we observe an increase in the coverage for both personal care and household assistance. However, this increase concerns the help received by households with lower care needs (from $24.7 \%$ in I991 to $29.8 \%$ in 2003) and the household assistance received by households with greater care needs (from $37.8 \%$ in I99I to $42.7 \%$ in 2003). By contrast, we see a decreasing coverage rate for personal care assistance among households with heavier care needs (from 32.3\% in I99I to $25.5 \%$ in 2003). Moreover, it is not just the prevalence of formal services that is so much lower in Italy, but also the intensity of the care provided compared to the Netherlands.

If we consider personal care and household assistance together at the end of the I990s, the shift toward commercial assistance among households with older members is quite similar between the Netherlands and Italy. However, while commercial services are negligible in the area of personal care in the Netherlands, they comprise $4 \%$ of the older households in Italy (and I3\% of the older households with heavy care needs). Moreover, Italian households tend to buy a relevant number of hours of this type of care. Also the recourse to commercial household assistance differs between the two countries. When we consider a broad definition of commercial home assistance, the proportions of households involved are quite similar in Italy and the Netherlands at the end of the I990s: respectively $\mathrm{I} 3.5 \%$ and $\mathrm{I} 2.8 \%$. However, the data suggest that the recourse to these services is much more connected to the presence of care needs in Italy than in the Netherlands. In the Netherlands, household assistance is as widespread among households with at least one older member as among households with heavy care needs, suggesting that dependence does not account for recourse to household assistance. In Italy it is quite different: the use of commercial services appears much more related to dependence, as the proportion of households receiving household assistance increases with an increase of care needs. Moreover, the number of hours of assistance purchased by Italian households is substantially higher than by Dutch households. Indirect evidence sug- 
gests that the importance of market care in Italy increased considerably throughout the I99os.

\subsection{Provisional conclusions and open questions}

Our analysis of the different sources of support for older dependents confirms that, in the early I990s, Italy and the Netherlands represented two distinct care models. While in Italy, informal care was the most important response to care needs and formal and commercial services played a marginal role, in the Netherlands, with formal care being the main source of support, next to important, but comparatively limited, informal support and to commercial assistance not specifically focused on care needs but rather on household assistance. However, developments in social policy should imply a development of paid care and informal care in the Netherlands with no major changes in Italy, but the previous discussion shows that the trajectories of the two care systems differ considerably from expectations.

According to our data, dramatic changes occurred in the Italian context: the care system, traditionally based on (extended) family support to elderly dependents, seems to have shifted to a mixed market and informal support system in a relatively short period of time. One of the main findings is that territorial differences during this shift were limited. By contrast, continuity characterises the Dutch case. Not only did the market have a limited amount of development - confined, in any case, to household assistance - but the decreasing importance of informal care was coupled by constantly high coverage rates of formal services. It is true that formal support increased among households with lower need levels and in the field of home help, and was less able to respond to increasing personal care needs. Nevertheless, these changes may be interpreted as signs of tensions and care system adjustments, rather than trajectory shifts as is the case for Italy. Our data for the Netherlands stops in 2003, so it does not reflect more recent care policy shifts. The most recent care sector reforms separated the provision of household assistance from the more general long-term-care scheme, a development that merits further monitoring in the future.

The resilience of the Dutch formal system and the market shift of the Italian system need to be investigated further. In fact, quantitative analysis has shown tendencies and trajectories of the two systems that need to be interpreted in light of the social mechanisms underlying the construction of care packages. In the next two chapters, we shall concentrate on mechanisms that might explain these two opposing tendencies. 



\section{Care Packages in Practice}

\section{I Disentangling care packages}

In chapter four, we showed that significant changes occurred in the Italian care system throughout the I990s, whereas more limited adjustments took place in the Netherlands. This is the starting point for the next two chapters, which will discuss the nature of the tensions in each of the two care systems and the mechanisms underlying change and stasis. A micro-level of analysis and qualitative data are used to look at the stakes connected with long-term care and at the social mechanisms based on which the care packages are constructed.

\subsubsection{The qualitative study}

The analysis proposed in these two chapters is based on a qualitative study conducted in the period 2003-2004 in Milan and Amsterdam. Besides interviews with key actors and the examination of relevant documents, interviews were carried out with caregivers of elderly dependents, based on 70 cases of elderly dependents, 35 in each city. The sample includes ten cases of elderly dependents living in an institutional environment in both Milan and Amsterdam and 25 cases of elderly people living at home, either alone or with others. For each case, the main (informal) caregiver of the elderly dependent was interviewed, sometimes along with other informants and, when possible, the elderly dependent as well. In all, more than Ioo interviews were conducted. The interviewees were contacted and recruited via care organisations, unions, associations, and other key informants. The caregivers interviewed were asked about both past and present conditions for elderly dependents and the changing care arrangements over time. Besides factual information concerning the care needs and care packages, the questions represented how the "problem" of dependence emerged and was defined, who - the relevant household actors, the family, the broader informal network, social services and other collective actors - took part in this definition and in the decisions concerning the care arrangements, how and when specific decisions concerning the care arrangements were taken.

Considering the relevance of the phenomenon of private care provided for by migrant workers in Italy, I5 additional interviews were conducted in Milan with foreign paid caregivers of the elderly. Care workers 
were recruited either through the elderly themselves or family members, through local organisations and associations or via other migrant workers. In our sample, all I5 interviewees were women; most of them were between their late thirties and early fifties; in most cases, they were married, separated or divorced and had one or more children. Most of them came from Eastern Europe, some from Southern America and Asia. Their educational level, consistent with earlier research findings in this area, was quite high. Most of the interviewees were working as fulltime live-in caregivers while only two worked part-time and lived independently. The migrant workers were asked about their living conditions prior to migration, their migratory experience, the ways they looked for and found jobs, their working conditions and their relations to the elderly as well as their own relatives, motivations and future plans. ${ }^{\text {I }}$

\subsubsection{Looking into care packages}

The quantitative analysis assumed the existence of three types of care resources (formal, informal and commercial) with similar contents and meanings in the two contexts. However, this assumption needs to be addressed. In order to understand the nature of a care system and its transformations we need to qualify both the actual content of the care packages and the logic that underpins their production and allocation. In this chapter, we shall concentrate on the actual content of care packages and their connections within given institutional frameworks, in order to supplement the results of the quantitative analysis and overcome its limitations.

Different combinations of resources prevail among elderly dependents living at home. The quantitative analysis suggested that one type of support tends to prevail in care packages. Besides the three distinctive packages based on a single resource - formal, informal and commercial - the mixture of different types of care appears quantitatively less relevant, particularly in the Dutch case. Our qualitative data confirm this view. Even though the most common situation is that of a mixture of resources, each package tends to exhibit a strong prevalence for one type of care that is possibly supplemented by others. In what follows we shall highlight the characteristics of (mainly) formal, informal and commercial care packages available to the elderly living at home in Milan and Amsterdam. Moreover, we shall look at the characteristics of the institutional care packages in the two cities.

This analysis ${ }^{2}$ will also serve as a background for the next chapter, where we shall move to the analysis of the mechanisms underlying the construction of welfare packages, in order to identify stakes, relevant actors at the micro- and meso-level and diverse outcomes. 


\subsection{Formal home care packages}

The first packages available to the elderly living at home is characterised by the prevalence of formal support, i.e. services publicly funded and organised even if sometimes provided by private not-for-profit or forprofit organisations. While the formal care package is one important form of response to elderly care needs in Amsterdam, it is absent in the Milanese sample.

\subsubsection{The content of formal home care packages in Amsterdam}

In 15 out of 25 cases of elderly people living independently in Amsterdam, the main care providers were professionals working for publicly funded home care services. The elderly received a range of support from health care to social services and household activities, for a significant number of hours per week (in our sample up to 50 hours per week, eight hours per day). A wide range of needs is usually covered by care and health professionals, from health care to help with personal hygiene and support in household activities, as illustrated by this case:

There is a nurse who comes three times a week for medications and treatments. Then a care assistant comes for a couple of hours every morning to take care of the getting up, the washing and so on. They also come back in the evening to make sure that everything is OK and to put her to sleep. Finally, there is somebody who comes to keep the house clean, three times a week. They also bring her a warm meal every day. It is a nice service. She could not do without it. Then, in case of an emergency, she can call me or B ... (a neighbour) (Mrs. LJ - case Aig).

Relatives, friends, neighbours and volunteers often integrate the support that is provided by social services. Nevertheless, within the framework of the formal care package, they play a more supplementary than central care-giving role. Tasks carried out by the informal support network are usually limited to emotional support, assistance with bureaucracies and sometimes household assistance. In this respect, the formal home care package has much in common with the institutional package (se infra), as informal networks perform lighter tasks, such as keeping the elderly company, providing emotional support, and organisational and bureaucratic assistance. The time they dedicate to the older person is devoted to maintaining a relationship with the elderly person rather than carrying out practical tasks.

I come here every day after work and spend some time with her. It is nice for her and for me as well. I like the idea of being there for her (Mrs. FD - case A26). 
Practical matters are often related to organisational issues rather than personal care tasks. Bodily assistance provided by relatives and friends is extremely rare in our sample and absent from this type of package. The informal caregiver is likely to help the older person maintain relations with the outside world and organising care activities, especially in presence of increasing needs over time.

I take care of all of the administration. Last month we had to get more help. She has gotten worse and what she was getting was not enough anymore. I phoned them and took care of it (Mr. VV - case A23).

Several principal informal caregivers tend to assume a care management role, even if they are working together with instead of replacing formal services. The importance of this type of task has also been confirmed in more recent research (Knijn and Da Roit 2008). Moreover, in this type of package, friends and neighbours play a relevant role by providing emotional support and company to older dependents living at home. Their role in the care-giving system is always a supportive one and does not encompass instrumental support, especially in the form of personal care.

Every two weeks her friends A. and G. come to see her. Sometimes they also cook and eat together. They are old as well, but are doing better than she is. They've been friends for years and years. It is important that they are still in touch (Mrs. EE - case AI).

The territorial assessment board in charge of defining care needs and care responses assessed the elderly people who receive this type of package. The board uses standardised assessment instruments in order to define the needs, the type and amount of support to be provided, trying to limit discretional evaluations in the assessment of needs and service allocation. Nevertheless, previous research has shown a certain degree of variation in assessment between different boards and between individual operators (Portrait 2000). In assessing their needs and allocating the home care resources in the Amsterdam region at the time of the research, the availability of informal care was not taken into account, the only exception being household assistance which is expected to be performed, at least in part, by other household members.

We don't ask anybody, not even spouses or co-resident children, to perform personal care unless they explicitly ask to do it. On the other hand, we do require that they carry out some household tasks such as cleaning, keeping the house tidy or doing the washing. And this is not always self-evident; sometimes we have to do some negotiating, especially with husbands (evaluating officer, Amsterdam). 
Moreover, the assessment board is not, in principle, concerned with the actual availability of home care services, because another authority that intervenes later, regulates access to the services.

We do our job without worrying about what is in fact available. Our objective is to assess needs and to allocate resources. Waiting lists are not our problem; it is the problem of the office that deals with waiting lists and co-payments (evaluating officer, Amsterdam).

A co-payment based on income is required and is restricted to the contribution of the elderly and eventually their spouses. The financing of this package is therefore mainly collective - through the national social insurance - and is only privately funded to a limited extent.

It has to be emphasised that those in our Amsterdam sample who received this kind of package were able, at least, to be left alone for significant periods of time, knowing that they could call for help whenever they needed. We did not find any cases of 24/7 care provided by public services. Several key informants explained that continuous care for those with heavy care needs is more likely to be provided by an institution, because it is "too expensive" at home. People with very heavy care needs and constant surveillance are more likely to be in residential care, or they have a strong informal network of support at their disposal.

If you need somebody to be there day and night, all the time, you either have a relative, a wife or a child, or you have to go to a nursing home. No care organisation can provide you with 24-hour care: it is too expensive. It makes no sense (manager of a care organisation, Amsterdam).

In fact, the data provided by the agency in charge of the need assessments under the AWBZ in Amsterdam show a broad range of variation between less than one hour up to - in exceptional cases -20 hours per day. ${ }^{3}$

\subsubsection{The absence of formal home care packages in Milan}

The formal care package in Milan, as opposed to Amsterdam, could not be found because the availability of home care services is limited to very specific nursing or technical tasks or to a reduced number of hours of personal care and home assistance per week. The circumstances of the absence of this kind of package are worth exploring.

Different institutions provide two types of support in Milan, according to different sets of logic: while health care is the responsibility of the local health authority, social care is the responsibility of the municipality. Health domiciliary care is provided in response to specific health needs. Services are offered on a weekly basis for a limited number of times and 
hours. Users tend to consider this as assistance received for specific and technical tasks rather than as part of a home care programme.

The two of them come once a week to bathe him. They stay one hour or so. They get him up and give him a bath. We are lucky that they come to do this. It is a heavy job and he cannot help at all (Mrs. UO - case M2I).

There is a nurse who comes twice a week to take care of his sores. She comes and changes the dressing. She also taught me what to do if she's not here and the dressing needs to be changed (Mrs. AU - case $\mathrm{M}_{3}$ ).

Access to these services - based on need and free of charge - often occurs after a period of hospitalisation or other contact with the health services authority in the city, as explained by several key actors and confirmed by numerous interviewees. To some extent, they represent the domiciliary extension of the hospital and residential care services.

Our services are available to people in need of health care at home. We are very often called upon after a hospital discharge for rehabilitation or physiotherapy. Besides that there are people who have a stable situation and need constant help with bathing or medications (local health authority officer, Milan).

My husband fell and broke his ankle six months ago. He spent a while in the hospital and then in a nursing home for rehabilitation. When he came back home, they sent us a physiotherapist for several weeks. But the therapy has finished for a while now (Mrs. FA - case M23).

By contrast, social domiciliary care for the elderly is provided by the municipality's social services agency and is based on means testing so that the elderly with an income above a given threshold are not entitled to the services. ${ }^{4}$ Moreover, the service is designed for those elderly people who are living alone and in need of light support. It is thus not intended for the more heavily dependent elderly people with important personal care needs. The services provided a few hours of assistance per week and they are not equipped to respond to heavy and continuous care needs. A social service officer in Milan explained that, despite changes in the needs of the elderly population, municipal home care services have maintained their initial characteristics and, also in relation to budgetary constraints, have not undergone substantial innovations over the years.

We provide assistance in personal care and household assistance. However, we cannot do more than a few hours a week per user. We do not have enough people. It is not the goal of our service to provide intensive care. It is true that the needs of the elderly have changed over the years. When these services were created, they were aimed at the elderly living on their own and needed some support in managing their everyday lives, such as taking care 
of the house or cooking. Nowadays care needs have become very heavy. But we still have that kind of service (social service officer, Milan).

\section{$5 \cdot 3$ Informal care packages}

The second type of home care package is dependent on informal caregivers as the main providers of instrumental support, namely direct care, such as nursing, personal assistance and assistance with everyday activities including household tasks.

\subsubsection{A similar hierarchy of informal assistants}

In situations where the resources are mainly informal - generally implying high levels of involvement by spouses and daughters - one or two main caregivers usually play a crucial role, sometimes assisted by one or more supplementary informal assistants, who perform a limited number of hours of care and lighter household-type tasks. They tend to work many hours in providing personal care and household assistance, as well as organisational matters. Moreover, the assistance provided by the main informal caregivers may be complemented by some support from social services and paid assistants. Nevertheless, these additional resources do not cover the high levels of need and are only provided for a very limited number of hours per week, performing very specific and technical tasks.

There is a lady who comes twice a week to clean and tidy the house. I can't do the heavy housework anymore and she is a great support. She cleans the bathroom and the kitchen. Every now and then, she washes the curtains or the windows. I'm not able to get on top of a ladder anymore. If I fall off and get hurt, who is going to help him then? (Mrs. CA - case M22).

For bathing and some of the medications we get some assistance from the home care service (Mrs. PS - case A7).

In several studies, and particularly in the literature on support networks, it was found that most informal support for the elderly comes primarily from spouses and, in the absence of a spouse, from adult offspring (Qureshi and Walker I990; Wenger I993b; Cibulski I98I; Tornstam I992). According to these findings, neighbours are the third most frequent source of assistance (Van Tilburg I995; Schwitzer I990; Wenger I993b). Our study was consistent with the above studies: an older dependent married person usually has his or her partner play the role of the main informal caregiver both in Amsterdam and in Milan. Spouses especially wives - who are usually elderly as well, tend to assume many hours of care and perform heavy care tasks in both contexts. This is particularly true among the Milanese interviewees, where the involvement of spouses in care is extreme; they tend to be the only reference point for 
the elderly dependent and they basically do everything, except a few secondary activities, which are performed by other family members or, as we have seen before, by health or social services.

I am the only one he has. He is completely dependent on me. Of course, my daughter also helps. She goes shopping for us and comes here very often. But for the rest it is just me (Mrs. FA - case M23).

I do what I have done all my life. But now there is also the fact that he is no longer able to do anything alone. I have to take care of all that as well such as the personal things like dressing, undressing, everything. All they do when they come is have him do some gymnastics. Two hours a week. That's it (Mrs. UO - case M2I).

In Amsterdam, the involvement of spouses in care provision is also often important and described in similar ways as in Milan. Partners tend to dedicate a relevant amount of time to care and they are often the main point of reference for the dependent elderly person. Moreover, interviewees often refer to the marital link as the basis for providing support, much like in the past.

I'm the one who takes care of him. He is my husband in the end. I've always taken care of him all my life. I'll just keep doing it (Mrs. SD - case A3I).

I am doing all there is to do for him. We are together all the time. And he needs help with everything. We do get some help from social services. But the one who is always here is me (Mrs. LL - case AI7).

In several cases, the informal caregivers of widowed elderly dependents - particularly women - are mainly the children, either living with their mother or father or nearby. This is very much the case in Milan where the involvement of the offspring in direct care is even more intense.

My husband and I live on the fourth floor [in the same building as her father]. This is good: if we lived far away, I don't know what we would do. We would not be able to take care of him. This way, whatever happens we are here, next door (Mrs. LC - case Mi8).

My shop is down the street. And we all live in the building. It is easier to combine everything. I could not see myself running around like crazy (Mrs. $\mathrm{QV}$ - case M27).

Instances involving informal caregivers other than spouses or children did not exist in the Milanese sample and were rare in the Amsterdam sample, which is consistent with the literature on support networks for the elderly dependent. First, as we have seen, a hierarchy of assistants can be identified: first spouses, then children, and then all the rest. Furthermore, the intensity and the content of care vary in relation to the relationships that exist between the older person and the caregiver. 
Spouses tend to provide both emotional and instrumental assistance to the best of their ability. While adult offspring also provide both emotional and instrumental support, daughters provide more assistance with domestic and personal care tasks while sons provide more assistance with maintenance tasks and financial assistance. Other help - including other members of the extended family, friends and neighbours tend to supply mainly companionship and emotional support, despite offering instrumental help in emergencies and on a short-term basis (Wenger 1993a; Bytheway I987; Qureshi and Walker I990; Broese van Groenou i995).

There was only one case in Amsterdam, where the main informal caregiver of an elderly dependent was a friend. Quite interestingly, the interviewee emphasised the uniqueness of this situation, indicating that in normal circumstances a friend would not be taking care of an elderly dependent.

I am just a friend. Yes, a friend. We met many years ago and we know each other quite well. We did lots of things together. When she started feeling worse I decided to move near her to take care of her. As I am a professional nurse, I know what to do. I am a nurse but also a friend. I think it is a perfect combination (Mrs. FD - case AiG).

\subsubsection{Welfare context variations}

Despite the above-mentioned similarities between the two contexts, several elements differentiate the Amsterdam from the Milan cases with respect to the characteristics of the informal care packages.

First, the informal package is more common in Milan than in Amsterdam. In Milan, almost half of the 25 cases of elderly people living at home belong to this group, while it was about one-quarter in Amsterdam. Moreover, among the cases that fall into this category in Amsterdam, the caregivers have a lighter load, because here the care needs generally tend to be less important among the elderly living at home and, at the same time, to a great extent met by formal care services. Informal caregivers in Amsterdam very rarely perform personal care, personal hygiene and health care-related activities, while this is more common in Milan.

As mentioned above, the primary caregivers of elderly dependents are usually spouses both in Amsterdam and Milan. Nevertheless, the intensity of partners' participation in care in the two contexts is quite different. In Milan, spouses are often the only ones providing care to the older person. Relief provided by formal services and other informal caregivers is limited in scope and intensity. These results are consistent with previous research findings on informal care performed by spouses in several Italian local contexts. A reduction in care performed by spouses was found only among relatively younger couples, in particular, when part- 
ners were working (Gori and Da Roit 2002). In our sample, the involvement of spouses in care appears unconditional and enduring until personal resources are completely exhausted. Health problems are the only limitations for the provision of care: only in presence of a physical limitation of the informal caregiver other solutions are envisaged.

The ladies who come on Mondays and Thursdays are very nice. They do for him what I cannot do myself. Two weeks ago my arm began hurting. I think he is getting too heavy for me. Maybe I'll get some more help in the future. But until now I have managed myself (Mrs. CA - case M22).

By contrast, despite the fact that spouses show a high level of involvement in care, as illustrated above, in Amsterdam social services are more integrated into informal care arrangements, even if it is sometimes for a limited number of hours per week. Formal services, on the one hand, are likely to perform heavy bodily care and, on the other hand, represent a constant relief and point of reference for informal caregivers, while in Milan, they are utterly absent in most cases. Therefore, in Amsterdam, as opposed to Milan, formal services represent an important resource for both the elderly dependent and his or her spouse. Formal services tend to be present and perform direct care, particularly in the area of personal care, also in presence of an informal caregiver who dedicates a lot of time and resources to support the elderly dependent.

I am here with him day and night. Fortunately they come three times a week to take care of what I can't do; they bathe him and give him his medication, but they also check to see if I am doing fine. I don't feel alone thanks to them (Mrs. PS - case A7).

It is hard work. He is completely dependent on me and I can't do anything without first of all thinking 'and him?' But fortunately, I do get some help from social services. Otherwise, I think I would go crazy (Mrs. GH - case A22).

The difference in the nature of informal care is even clearer among children - particularly daughters. Whereas, in Amsterdam, performing bodily care is quite rare and requires limited time among daughters, it may be both intensive (as for the content of care) and extensive (as for the time dedicated to care) in Milan. These results are consistent with other studies carried out in the Netherlands on informal elderly care. In a Dutch study conducted in 1996 , with a representative sample of middleage women, it was discovered that one-third of the informal caregivers were providing "intensive care", i.e. more than four mornings/afternoons/evenings per week. Nevertheless, the most common situation was spending one or two mornings, afternoons or evenings with their elderly parents (Dautzenberg 2000: 42). Moreover, the activities performed by daughters were mainly emotional support, providing compa- 
nionship and to do the shopping. By contrast, personal care was the least provided ( $2 \%$ of the ones providing some care). Differences in involvement in direct care among children do not seem linked to physical distance or to involvement in paid work.

The daughter of an elderly dependent living in the Milan area (or in the same building) and not employed is generally more directly involved in care compared to a daughter in similar circumstances in Amsterdam. Not only is the time spent with their elderly parents longer, but the types of tasks performed are also heavier. The availability of various resources probably plays a role here. Nevertheless, these findings only partially corroborate the formal-informal care substitution hypothesis. It is, however, quite clear that in a system of formal services, informal care tends to assume a lighter nature, this does not necessarily mean that formal services eliminate all reciprocity and solidarity between generations and within families.

Finally, both the elderly and their main caregivers in Milan tend to be much more isolated than their equivalents in Amsterdam. Here the presence of both formal services and a whole range of other caregivers including friends, neighbours and other relatives who all provide light support are more important. By contrast, the care relation between elderly dependent people and their informal caregivers in Milan tends to be enclosed within a much smaller core group. In this respect, different factors may play a role in determining this outcome. First, as mentioned above, Milan's elderly included in the study, on average, suffered greater disabilities compared to the elderly in Amsterdam. As has been observed, along with declining health and disability problems, an elderly person's network of personal contacts tends to shrink over time (Wenger I986; Dykstra 1995), this might help explain the smaller presence of friends, neighbours and other relatives in the informal support networks of Milan's elderly. A second possible explanation relates to the physical and social structure of the two cities: Amsterdam, with its good public transportation system and social organisation may allow some of the elderly to maintain their social contacts, which would probably be more difficult in Milan. Finally, according to previous research studies (Micheli I999), the social network among older Italians tends to be denser - i.e. constituted of stronger and superposed links - and narrower, than those of Dutch elderly people who, on average, have a network that is larger, more open and richer in "weak" ties. Our data confirm this view in the case of the elderly with heavy care needs. In Milan, the elderly in need of care tend to rely on a strong and narrow support network made up of close relatives, while in Amsterdam, they rely largely on formal care and on a wide range of informal caregivers who contribute with their small and lighter tasks. In other words, reciprocity in Milan involves intense responsibilities, while in Amsterdam it is more diffuse and involves lighter overall tasks. Our hypothesis is that there is a connection between the collective responses to social risks and the possible development of 
solidarities that go beyond the narrow family circle. In a way, broader reciprocity is possible as basic and heavy needs are met by professional services. By contrast, in a context of limited collective resources strong and narrow family reciprocity is needed in order to ensure basic assistance and tends to "burn" other informal resources. We shall go back to this point later in discussion.

\subsubsection{Social context variations}

Besides the variation in the nature and importance of informal care packages between Milan and Amsterdam, there are also other observable differences within the two cities, based on the socio-economic conditions of the involved elderly people and their families.

Both in Milan and Amsterdam, informal arrangements were more widespread among the lower social strata. In Milan, recourse to informal care packages - with the relevant and continuous support of family members for the elderly with personal care and household tasks - is predominant among families with lower economic and social resources. As we noted above, the involvement of wives in elderly care is generally relevant. The strong involvement of daughters in direct care on a permanent basis, however, is relatively rare and mainly concerns families in disadvantaged economic and social conditions. This was the case for one daughter who was not employed and married to a bricklayer (Mrs. LK - case M3I) or to another who was unemployed and had occasional jobs (Mrs. LC - case Mi8). The aforementioned daughters live nearby and tended to perform all of the necessary care tasks with no or very limited support from social services or paid caregivers. This type of care arrangement is occasionally associated with co-residence between the older dependent, the caregiver and the relatives.

We all live here in this one flat, my father, my husband, my son and I. In fact, my father moved in when he started feeling bad. He did not want to do this before. But now, he needs help. And I am the one who is taking care of him (Mrs. MM - case Miz).

Comprehensive and "total" informal care therefore tends to be characteristic of the disadvantaged in Milan. As economic and social conditions improve, the direct involvement in care by daughters tends to decline in favour of a combination of informal care performed directly and paid care (see below).

In Amsterdam, despite the fact that the internal variations of informal care packages are mitigated by the important and widespread presence of social services, considerable differences in care arrangements are detectable according to specific social cleavages. The relation between socio-economic circumstances and support networks has previously been shown in the Netherlands (Broese van Groenou and van Tilburg 2003): 
socio-economic circumstances are relevant in determining the size and the type of network available to the elderly. More specifically, there is evidence of the impact of socio-economic status throughout the life course on the personal network characteristics one has in later life. People with low socio-economic conditions during their lifetimes or those dealing with downward mobility tended to have smaller networks, less instrumental and emotional support from non-kin, but high levels of instrumental support from kin, when compared with the upwardly mobile or those with high socio-economic conditions throughout their lifetimes. In our sample, the importance of social inequalities emerges at the point where socio-economic conditions meet the migratory background of Dutch elderly dependents. Among the interviewees in Amsterdam, there was only one case of heavy direct care being performed by children (Mrs. KO - case A6), who were socio-economically disadvantaged. Moreover, in three families of non-Dutch origin included in our sample, informal care was crucial for the involved elderly dependents. A combination of care provided by the women in the family (wife, daughters and sisters) makes both personal care and household assistance available, as illustrated by the following cases.

Fortunately, we all live quite close to each other. I work and am therefore not able to take care of my mother all day. But my aunt lives next door and she keeps an eye open until I get back from work (Mrs. TF - case A33).

My father is there all day. He does not really do anything, but he is there and that is important. And I only work part-time, three half-days a week. So I can be there most of the time as well. And there is also my sister. Well, she has a small child now, but she doesn't have a job. So we share all that there is to do. And there is a lot to do. Cleaning and keeping the house tidy and she also needs help with a lot of things. She has a hard time walking alone and we have to help her. Someone has to prepare the meals. There are a lot of things to do (Mrs. KK - case A34).

My mother is the one who does the most. But she is not so young anymore and she is starting to need help as well. Then, since I live with them, a lot of things are my own tasks, even if I do work (Mrs. OI - case A35).

Several key actors confirmed the image that emerges from these interviews. They tended to draw attention to the significant differences in care responses that characterises elderly people of foreign origin and their families. A widespread view among the interviewees is that the children - namely daughters - of the elderly of foreign origin suffer from greater pressures because of their parents' expectations regarding informal support. The elderly of foreign origin tend to claim more informal support than the elderly Dutch. These children usually do comply with the parents' requests. Key actors noted that, in the case of elderly people of foreign origin, requests for social services are usually submitted at a more advanced stage of dependence and when informal re- 
sources are highly compromised. Moreover, when informal resources are not (or no longer) available, relevant problems emerge as this elderly group finds it increasingly difficult to enter the formal care system, as illustrated by the representative of a not-for-profit organisation that supplies institutional care and home care services.

The foreigners... Turkish, Moroccans, Surinamese... that's a different story. There is usually a lot of pressure on the daughters and sons to take care of the elderly. But the second generation, the children in the second generation are now working, so they don't have as much time to give to the elderly. Other cases present other big problems: sons and daughters do not care for the elderly and the elderly themselves do not know how to find their way to the professional care organisations. They are ashamed when they have to go to a nursing home. In their social surrounding, in the peer groups they talk to each other about the ones who do not get care from their children. They are very ashamed. We hope that our policy in the future will mean that Turkish and Moroccans people do not have to end up in a nursing home or in an elderly home, because they can stay at home and we can give them the necessary home assistance. But to do this we need to talk to the people about professional care, which has to be for everybody in the Netherlands, including them (manager of a home and residential care organisation, Amsterdam).

Important similarities in attitudes concerning care for the elderly thus emerge from the interviewees in Amsterdam of non-Dutch origin and those who are socio-economically disadvantaged in Milan, even though they are in two totally different welfare contexts.

\subsection{Commercial home care packages}

The third type of care package is based on paid care as the main resource in response to elderly care needs. In some of the cases we analysed, the main care resource is someone employed directly by the elderly or their relatives. This is a widespread situation among Milan's elderly dependents, but remains a rare situation in Amsterdam. Moreover, the circumstances are considerably different in the two contexts, as we shall see, so ultimately the commercial care package does not have the same meaning in the two cities.

\subsubsection{Migrant paid caregivers in Milan}

The case of Milan shows the widespread presence of paid care in response to the care needs of elderly dependents, consistently with results of the quantitative analysis conducted on the Italian case. Market care is 
not only disproportionately present in Milan compared to Amsterdam, but it also shows peculiar traits.

There are several cases in the Milanese sample of migrant care workers directly employed by elderly people and their families to provide continuous care. Similar to what was reported in previous studies, migrant care workers who take care of the frail elderly and are hired directly by the families and come mostly from South America, Eastern Europe and specific African and Asian countries such as Mauritius and Sri Lanka. It has been observed that the geographical origins of migrant care workers are considerably different depending on the local context. Specific histories linked to the rise of nationality-specific migratory chains (Reyneri I979) often affect local contexts. There are several factors affecting the specific origin of care workers. Concentrations of migrants according to nationalities are found in specific contexts in relation to the strict link developed between local "agencies" promoting the immigration of care workers and particular countries. Moreover, the relative geographical proximity of North-Eastern Italy to Eastern European countries facilitates the concentration of migrants coming from these countries. The case of Milan is in this respect quite special. The city is one of the most important points of arrival and dispersal of migrant workers through the country, as different migration networks crisscross the city. Milan not only represents a strong attraction point for migrants as such, both for those coming from abroad and for those already living in the country, but it also "serves" adjacent local markets.

Migrant care workers are usually women performing a vast range of activities, from bodily care to household tasks, consisting of everything from a few hours per week to fulltime activities. In ten cases out of 25 , a live-in paid caregiver was found and all of them were foreigners. This type of arrangement emerged in the second half of the I990s in Italy and has rapidly become the norm and almost "natural" for many families. It is not difficult for children to explain, for instance, that an older parent is being assisted by a co-resident migrant woman.

H. is a girl from Mauritius. She has been living with my mother for one year now. She takes care of her when I am not here; she does the cleaning, the shopping and the cooking. In fact, she does a bit of everything. She also takes care of her toilet activities and helps her get dressed and undressed. She is very reliable (Mrs. LR - case M24).

This has become one solution to the care dilemma to the extent that stereotypes concerning the ability, reliability and commitment of people of various nationalities are quite widespread among users and, as well, among social workers.

We hired a woman to take care of her. She is Peruvian. Peruvians are supposed to be very good at taking care of the elderly (Mrs. CA - case M2o). 
South Americans, they have something... They are very good to the elderly. They seem to care (home care social worker, Milan).

The care market is extremely flexible. Work relations begin and are then interrupted either by the family of the older person or by care workers, based on contingent needs, (lack of) satisfaction and the availability of other solutions. In a few cases, some migrant workers were hired and fired one after the other as the relatives of the older person searched for "the right one". On the other hand, care workers also tend to leave the family they are working for if a better job becomes available, in order to improve their economic conditions.

There is a Ukrainian woman who lives with my father. There was someone else until a few weeks ago. But they got into a fight and she decided to leave. They could not stand each other anymore. This new woman seems more reliable and overall, they are getting along quite well (Mrs. GN - case M9).

This type of care market is thus a "real" market that functions based on price, working conditions, personal negotiations and resource exchanges. It is, at the same time, embedded in a dense network of relations that encompass other care workers and other families, but also social services, organisations that help the migrants find satisfactory employment as care workers. It is, moreover, a market that shares some of the most important characteristics of the Italian economy and society, among which is the tendency to develop grey economies and the reliance on undocumented migrant labour. Live-in migrant workers are often undocumented and work in the grey market.

Maybe we will be able to pay her social security some day. But for now, she is working under the table (Mrs. AU - case $\mathrm{M}_{3}$ ).

As between 2002 and 2003 a mass amnesty for undocumented migrants took place in Italy, some of the migrant workers employed by the families of the elderly were in various stages of the regularisation procedures and most already had residence permits at the time of interview. The regularisation process attracted plenty of public debate because it was considered a way of gaining legal status for a large number of migrants working in elderly care. Despite the emphasis put on the link between residency permit and employment, even during and immediately after the amnesty procedures we found several cases in our interviews of regularised migrants still working in the grey market. In many cases, migrant workers meeting the amnesty requirements, which included proof of employment at the time of regularisation, lost their jobs right after obtaining their residency permits and again fell into that grey market area. 
She lives here and she has her own room. This is how everybody does it. We try to treat her as well as possible. Of course, we cannot afford to pay her social security. She now has a permit to stay because she was recently regularised. But she lost her last job and here she is (Mrs. VZ - case M26).

Another element that emphasises the structural character of irregular jobs in this sector is the presence of a few Italian workers who also work in the grey market. The majority of the foreign labour force worked fulltime with live-in arrangements, with a few paid Italian assistants working part-time hours in the grey market, which was the case with this pensioner.

We hired her. Well, hired... we pay her, that's all. It is not like we really hired her. She is only working part-time in the end and she does not really need to be insured. She already has a pension. Oh no, she is not a foreigner. She is Italian, she lives in the neighbourhood and we've known her for a long time (Mr. BA - case M25).

In care arrangements that involve a fulltime live-in caregiver, the paid caregiver performs most of the care work. Nevertheless, in all of the cases, an informal caregiver is also present. He or she makes sure that everything gets done, sometimes fills in for the paid caregiver and also takes care of financial matters. In other words, paid care workers are not a substitute for informal caregivers. Instead, family members who would normally be involved in direct care tasks now play a complementary role that includes care management, supervision, financing and substitution of the care worker in case of absence.

When I come home from work I drop by and see that everything is all right. (Mrs. QV - case M27).

The woman is free on Sunday. Then I stay here all day long (Mrs. LR - case M24).

The quantitative analysis has shown that, despite an educational gradient, access to commercial care in Italy is widespread, also among the lower-educated elderly (chapter four). The qualitative analysis confirms that the previously illustrated care situation pertains to families in a variety of socio-economic circumstances. Not just upper classes, but also the middle and working class households tend to use paid care and only families with very limited socio-economic resources appear to be excluded from this care market. Although we shall go back to this point in reference to the stakes and choices involved in the creation of a care package, it is worth emphasising that one element that explains this paradox is the relative low cost of market care. The wages of the live-in care workers in the grey market are surprisingly similar across the interviews: between 700 and 800 euro per month, plus bed and board. The 
amounts declared are consistent with the observation of several local studies in northern Italy over the past few years, but they are higher compared to wages in southern Italy. In fact, other studies have highlighted the tendency of migrant workers to move from south to north in search of better wages (Da Roit and Castegnaro 2004). The cost of 24/7 care performed by a migrant worker amounts approximately to the sum of the minimum pension that is supplemented by the Indennità di accompagnamento. If the pension exceeds the minimum, the care worker can be paid out of the elderly client's income and care allowance. ${ }^{5}$ Given the relatively low cost of care and the high proportion of homeowners among interviewees, this appears to be a viable solution for most households.

My mother has her pension and my father's pension as well. Then there is the accompagnamento. That's all. Fortunately, she doesn't have to pay for the rent, as the flat is her own. So she can afford to pay for the woman (Mrs. TP - case M34).

As a result, the financial involvement of children is reduced and concerns only the poorer among the elderly. Even when the elderly's resources are not enough to cover the costs, the financial support provided by children is relatively limited.

She does not have much. Her pension is miserably low. We asked for the accompagnamento, but she hasn't received it yet. So we give her a hand (Mrs. BL - case M33).

Despite these general traits of paid care in Milan, the organisation of care has different characteristics depending on the socio-economic circumstances of one's employer. Among better-off families there was a tendency to purchase more and better care, among households with lower economic resources there was a clear tendency to save on care expenses, reducing quality and the cost of labour and integrating paid care with informal care. Care arrangements among higher-income families often encompassed more than one worker in order to cover night shifts and leaves. Moreover, besides the hours of generic care, specialised nursing hours were also purchased.

There are two ladies taking care of him day and night. When one is with her, the other one rests and vice versa. This way he is never left alone. Then there is a nurse who comes three times a week. Ever since he started having these problems ... he needs somebody to take care of him more closely, as well. This is how we arrange things to make him feel as good as possible. My mother is also calmer and more content with this arrangement (Mr. GH case $\mathrm{M} 7$ ). 
This strategy put in place by higher income households also relies on the relatively widespread professional qualifications among migrant workers, which are not recognised and not useful in the official Italian labour market. The high proportion of medium and well-educated women among migrant paid caregivers is a well-known fact of Italian migration flows. In our sample, most of the migrant workers had a higher education. While a nursing diploma cannot be "spent" as a relevant resource in the health and care formal labour market, it does meet the requirements of better-off families.

This lady is a qualified nurse: that's why we trust her. Of course, because she is a foreigner she can't work as a real nurse. But we have been looking for somebody with qualifications (Mr. DN - case Mig).

Ultimately, better-off families tend to have a history of hiring domestic workers. When new care needs arise as an elderly family member becomes dependent on others, new care solutions are integrated into an already structured system of domestic labour.

M. has been working for us for years now. She has grown older together with my mother. But my mother's needs are becoming quite serious. So we had to look for somebody else to help. M. takes care of the house and the kitchen. She also keeps my mother company while the new lady provides personal care assistance and takes care of all her needs (Mrs. SE - case M35).

When the social position and the economic resources of a household are more modest, care arrangements have different constraints and take different shapes, both for the employers and for the employees. Instead of purchasing different types of specialised care, there is a tendency to ask one generic care worker to perform a range of activities for an extensive number of hours per day and per week. What matters here is the continuous presence of a worker and her ability to carry out a variety of nonspecialised tasks. To some extent, what employers want is a substitute for the informal caregiver.

She does all that is needed and she is very good at it; not like the previous one... She used to complain about having to do this and that. I know that it is a heavy job. But it is a job where you have to be available and able and willing to do everything. Otherwise, it does not work out. Otherwise, it is useless. If I had to get somebody to do the cooking and somebody to do the washing and somebody to do the cleaning, it would be an endless search (Mrs. ZA - case M29).

We pay her to be there all the time. Whatever happens she can call us and we run, but she has to be there (Mrs. OP - case $\mathrm{M}_{3} \mathrm{O}$ ). 
The issue of time is a crucial one when it comes to the functioning of the paid care package in Milan. A commercial care package is viable as long as it provides extensive care and ensures as many hours of care as possible. Both parties agree with this. The care workers who were interviewed often report that they are asked to perform a variety of tasks, which usually involves very long hours, without a clear work schedule.

I get up at six and get the breakfast ready. Then I have to get her up, wash her and dress her. In the morning, I have all the housework and shopping to do. Then there is lunch. Fortunately, in the afternoon, she usually sleeps a bit and I am on my own. Then there is the dinner to get ready... And she calls me all the time; you cannot leave her alone one minute (Mrs. MW CI).

I can't even sleep at night. Ever since she's gotten worse she yells all the time and calls me all the time. And during the day there are so many things to do (Mrs. JQ - C8).

The family I'm working for now is a good one. The old lady is very sick and needs continuous assistance. So they hired two people: myself and another woman. Where I was working before I had to do double the job. I don't think they were bad people. They just could not afford to do it differently. I am lucky now (Mrs. LG - C9).

The work day tends to stretch far beyond regular schedules and workers are often required to be on call all the time, as this care worker from Moldova recalled:

I know it is not their fault. They are not bad people. They treat me as one of the family. But I have to be here every day 24 hours a day. I can never go out because he does not want me to. He is afraid of being alone even for one minute. Even when there is nothing to do I am stuck here (Mrs. KA - C4).

There is a general lack of a distinct separation between one's personal life and the workday, there is little privacy, and schedules are undefined. 'Slavery' is the word some use to describe their situations, as was the case of this woman who worked as a fulltime live-in badante.

I am living here but I do not have a life. I do not have any time for myself; when she needs me I have to run. It is true that I am paid for my job. But this is not a job, this is slavery (Mrs. SA - Cio).

\subsubsection{Paid care in Amsterdam}

While in Milan the commercial care packages represent an important response to care needs, this is much less the case in Amsterdam. First, privately hired workers are more significant in the area of household assistance than in actual personal care. Second, commercial solutions 
are usually supplementary to other packages, which represent the primary source of support. Finally, real commercial care packages are rare and linked to peculiar circumstances rather than generalised responses to care needs of dependent elderly people.

Commercial care is usually limited to household assistance for a few hours per week as a supplement to the various care packages (see above) and does not represent an autonomous form of support for elderly people.

She's been working for my mother for a few months now. She takes care of the house because my mother is no longer able to do it on her own. She also helps her get dressed and undressed when she has to go outside. But she mainly does the housework (Mrs. FD - case A26).

Totally private home care arrangements were found only in two cases. The first case was that of very well off older person who was able to purchase many hours of private care. In the second case, the elderly client purchased care with the help of the Persoonsgebondenbudget (PGB personal budget). These two cases represent the typical ways that the elderly access (and create) care markets in the Dutch context. On the one hand, the care market is sustained by the private resources of the better-off households, and on the other hand, it is the result of social policy and funded by collective resources.

In the first case, the care package among wealthier Amsterdam households is quite similar to the situation of upper-class families in Milan. A large number of hours of specialised labour - cleaning, companionship and nursing - are the main components of the commercial package.

We have someone working for us. A nurse comes and takes care of his medical treatment. A caregiver comes everyday for his personal needs. Then, there is the person who's always been taking care of the house, all these years (Mrs. $\mathrm{KO}$ - case A2O).

Private care among particularly well-off households is either paid for outof-pocket or via private insurance policies, as was the case of this elderly man who had been using a private care package from his private insurance provider while he waited to be admitted into the nursing home.

My father is insured. When he got worse the insurance company proposed paying for home care services rather than for a nursing home. That worked out well for a while; he was getting a whole set of services at home, while he waited to enter the nursing home (Mr. PJ - case A2).

In the second case, commercial care is purchased through one's personal budget (PGB). As previously illustrated, disabled people whose needs have been assessed by the territorial board may choose to spend their 
budget allowance on market care or to pay a relative or another informal caregiver. This measure was first experimentally introduced and concerned a limited number of disabled elderly dependents (Miltenburg and Ramakers 1998). Since 200I, this option was expanded to include all people whose care needs were recognised by the regional assessment board. It has thus been deemed as one of the main developments in the organisation of care in the Netherlands. In our sample, we only had two cases of PGB holders who chose commercial care and a combination of commercial care and home care services. This is quite different from the Milan case, where all care allowances could be spent in a completely discretionary manner. Dutch regulations on the use of one's personal budget are quite strict with regard to claiming expenses. In Milan, care allowances were used freely to purchase care in the grey market, while stricter guidelines in the Netherlands prevented this kind of case from developing. In the Netherlands, the personal budget allowance is designed to discourage turning to the grey market, while the Dutch labour market system is generally much less affected by grey market labour. Although one can find undocumented labourers in Amsterdam, the grey market is much less widespread than in Milan where it is the rule rather than the exception. In one case in Amsterdam, a foreign domestic worker was hired by an elderly person who has her suspicions about her employee's background:

I know where she comes from and that she has a few relatives in the Netherlands, but I haven't asked her anything. I am afraid that she might get in trouble. She is a migrant and she might not have a permit. But she is doing a nice job for me and I'd rather not know (Mrs. LL - case Ar7).

In a few other cases the domestic workers - both Dutch and non-Dutchare not employed regularly, working on a part-time basis.

It is only for a few hours a week and we thought it was OK this way. It is not worth making it more complicated (Mrs. OP - case A27).

Therefore, the development of an irregular market, which has become the basis of paid care in Italy, is very restricted by regulations in the Dutch context. These constraints, together with the high availability of home care services within the framework of a collective scheme of social security, help us to better understand the limited development of market care - particularly in the personal care market - in the Netherlands throughout the I990s. The extension of the PGB to all dependent people opened up the possibility to develop a wide care market. Nevertheless, both the public financing of these markets and the more regulated nature of the care market are likely to channel these developments towards a much more regulated market system, especially compared to the Italian case. 


\subsection{Residential care packages}

A smaller sample of elderly people living in an institutional setting at the time of interview was included in the study in both local contexts (ten cases per city). We shall refer to these cases when we discuss the differences between the residential care packages and conditions under which access to residential care takes place in Milan and Amsterdam.

\subsubsection{Changing characteristics of the institutions and of the residents}

All the elderly living in institutions included in this study had significant care needs and, in several cases, they not only needed physical care but also mental health care. They needed assistance with almost everything in their daily lives and most of them needed 24/7 surveillance. These two small samples reflect the evolution of the institutionalised population in both contexts. In recent years, nursing homes and residential care homes both in Amsterdam and in Milan are accepting more and more elderly people with very heavy care needs near the end of their lives.

In Amsterdam, care homes and nursing homes for the elderly have different physical and organisational characteristics, reflecting the prevailing ideas about elderly care which characterised different stages of development of the care system. Some institutions were conceived as family-like environments aimed at people with light care needs and who were possibly alone or poor. For others, providing long-term health care was the core business. These differences reflect the stratification of changing social policy orientations over time, as illustrated by the manager of a large association of residential care suppliers in the city. ${ }^{6}$

If you take the structures affiliated with our organisation, they all look extremely different. Life in them is extremely different. Some look like hospitals, others more like sheltered apartments; the physical environment and the type of services that they originally offered depend very much on the time these organisations were set up (manager of a large non-profit care organisation, Amsterdam).

Moreover, the population of care homes and nursing homes has changed significantly over the years, as newly admitted residents tend to present increasingly heavy care needs. Consequently, the types of services supplied in different institutions have been updated and tend to provide more intensive health care and continuous surveillance. This trend represents a challenge for those services that were originally conceived with a different logic. As social support, shelter and socialisation is substituted for more intensive health and personal care, the organisation of the tasks and that of work have become the subject of some discussion, as one manager at a nursing home in Amsterdam reported: 
This place has changed a lot. It was built in the I980 to house individual elderly clients or elderly couples. Until a few years ago, it was still a familytype environment with everyone having their own privacy; they could lock themselves in their one-room flats, cook for themselves... Now they look more like hospital rooms; nursing shifts and assistance shifts have increased a lot. People stay about one year, maximum two. Socialising has become more and more difficult. The people here make it a totally different place (manager of a nursing home, Amsterdam).

The same type of shift and emphasis on the heavier health care needs of the institutionalised elderly population is also present in the Milanese context. Residential care institutions in Lombardy, like in Italy in general, were originally created to shelter the elderly poor and lonely. Over the past 20 years, a shift took place in regional policies, as they began to concentrate on the severely dependent among the elderly in long-term care institutions, while limiting the institutionalisation of people with lesser health and personal care needs. One nursing home manager in Milan described the situation well:

People living in institutions are no longer lonely poor people. Many of our institutions were founded in the past century in order to give support to those who were abandoned, with no means and no opportunity to work in order to make a living. Now, in the past to to 20 years people coming here need more intensive medical treatment; they often have dementia; they need to be looked after 24 hours a day. It is not only lonely people anymore. In the past, there was this image of the elderly in institutions... people who had no one and who had been abandoned by their children. It is not like that anymore. We deal with people with heavy care needs. Some of them are also lonely (manager of a not-for-profit nursing home, Milan).

Despite different institutional histories and a persistently different level of provision of services, there is, as shown above, a common tendency in the two cities towards the institutionalisation of needier elderly people. This transformation reflects an explicit policy turn in both contexts, more at the national level in the Netherlands, more at the regional level in the region of Milan. In both cases, residential care for the elderly has become an option restricted to the severely dependent among the elderly.

\subsubsection{Who cares in nursing homes and care homes}

Another similarity between residential care in Milan and Amsterdam is linked to the organisation of care and the type of care package that the elderly receive. Support for the elderly living in institutions is mainly formal. Professionals perform health and personal care alongside support in simpler daily activities. Moreover, the support provided by rela- 
tives and friends is limited to emotional support or to activities such as keeping them company, taking the elderly out of their rooms or out of the institution itself or helping with lunch or dinner. In a way, the residential care packages of the two cities, resembles in the types of care offered, the formal home care package in Amsterdam.

In our Milan sample, there is generally a strong presence of family members in the lives of the dependent elderly living in institutions. The spouses and children who live nearby visit quite often.

My mother and I come twice a week: once in the evening and once on Sundays. Sometimes I accompany her and leave her here for a few hours. He sees nobody else. Only once a year or so my brothers come here to see him. Last year, for instance, they came for Christmas (Mr. CU - case Mi3).

Even those who never married and never had children have at least one family member who visits somewhat regularly, depending on the living arrangements prior to institutionalisation.

I [the niece] come once a week and spend some time with her. Sometimes my sister accompanies me or I come with my daughter once in a while. She also has a sister and a brother, but they are old as well and not in very good shape. It takes me one hour to get here by car... We love her very much. All of us do. She's lived with my parents her whole life. She never got married and she's always been part of the family. I grew up with her and she is like a second mother for me (Mrs. MA - case Mi).

In Amsterdam, besides relatives, friends and neighbours appear to be more important to the elderly living in institutions than they are in Milan, where they were never mentioned in the interviews. Besides visits from children and spouses and occasional visits by other relatives and friends from outside the city, the elderly living in a residential setting in Amsterdam tend to see neighbours and friends living in the area more often. Nursing homes are usually located in the same neighbourhood where the elderly were living before institutionalisation, which fosters more intense contacts with the outside world.

There is an old friend of hers who comes here almost every day. She lives in the neighbourhood. She comes and spends one or two hours talking or reading to her (Mr. TR - case AI2).

Frequent contacts with members of the informal network outside of the family sometimes replace family members who no longer come or live too far away. 
She's been living in the neighbourhood all her life. She does not have anybody in Amsterdam. Her family lives abroad. But she does get visits from people in the neighbourhood (Mrs. HG - case Ar3).

Compared to Amsterdam, where the elderly tend to live in institutions located in their old neighbourhood, institutionalised people in Milan are usually "moved" to different neighbourhoods or even other cities, due to the lack of beds in nursing homes. As a result, staying in touch with the institutionalised elderly is "almost a job", in Milan, as the distance between the nursing homes and the closest relative may be significant. This might explain why friends and neighbours play such a small role in the relationships of older dependents living in institutions.

Besides relatives - and in the case of Amsterdam, friends and neighbours - individual volunteers or volunteer organisations also visit institutions in both cities. They tend to carry out similar tasks as members of the informal networks; they are not involved in heavy care assistance, but they do perform emotional support and keep them company and participate in recreational activities. This was the situation both in Amsterdam and Milan as noted by the institutions' managers and confirmed by various volunteers.

There is a volunteers' organisation that operates within the nursing home. They keep the people company; take them out when the weather is nice. It is very important for the residents, especially for those who do not have many relatives. It keeps them in contact with the external world (manager of a nursing home, Milan).

We have volunteers that go to the X nursing home. We help out by making it livelier (activist of a volunteer association, Milan).

Volunteers are active in organising social activities and little parties for the residents. They also come and spend time with the people on a regular basis (manager of a nursing home, Amsterdam).

Residential care in both Amsterdam and Milan, includes a formal package of support for very dependent elderly people, which is supplemented by informal (mostly relational) support performed by relatives, friends, neighbours and volunteers. The presence of paid employees hired directly by the elderly or their families to fulfil specific care needs is an exception. While privately hired assistants were not found in Amsterdam, in one Milanese case a paid worker hired directly by the older person's family performed a few care tasks to supplement the institution's services (Mr FG - case M6).

A social service manager in Milan confirmed this situation and made it clear that the intervention of paid caregivers in institutions used to be quite common until a few years ago, when the services provided by institutions were comprehensive. And, in fact, over the past I5 years, Italy's regional authorities - especially in the north and central part of the coun- 
try - have promoted the upgrading of the services provided by residential structures through the definition of higher standards of services over time by means of financial incentives. ${ }^{7}$ Therefore, the private solution tends to concern either specific institutions that lack proper services or fairly well-to-do people who hire paid help to supplement the care provided by nursing homes.

It used to be much more like this in the past... Up to a few years ago the personnel could not handle demand. There were never enough people from the care facility to take care of all the residents especially at lunch and dinnertime. Many people received assistance either from a family member or from somebody paid by the family. I remember children taking shifts in order to feed their parents or sending somebody to do it. Nowadays, the standards of services have increased considerably. Some people still do receive some extra professional help. But it is mainly rich people who hire a private nurse or a personal assistant (social service officer, Milan).

\subsubsection{Who pays for residential care}

Residential care packages therefore tend to be similar in Amsterdam and Milan, as the services are provided by formal organisations, while informal support is specialised in complementary activities and commercial services are virtually absent. The most prominent differences between the two cases concerns the overall supply of services, their localisation and their costs for the users.

A significant part of residential care costs in both Milan and Amsterdam is financed through collective resources. In Milan, as in Lombardy more generally, nursing homes meeting certain requirements receive funding from the regional health fund for each older person living in the institution. ${ }^{8}$ The remaining costs - in theory, for social services, accommodation and other facilities - are to be paid for by the users or the municipality. In Amsterdam, as is the case generally in the Netherlands, institutional care is financed within the more general social long-term care insurance (AWBZ). Nonetheless, users are required to provide means-tested co-payments.

Despite the fact that both systems include a mix of private and collective resources, the outcome and the burden on private and public finances is quite different. Users pay higher fees in Milan than in Amsterdam. Nursing home fees in Milan and the region are at least twice as much as the total of a minimum pension plus the Indennità di accompagnamento and it varies from one institution to another. In Amsterdam, copayments in residential care are controlled by national regulations: they are a proportion of the older person's income and never exceed his or her net income. ${ }^{9}$ Moreover, while in Amsterdam co-payments are paid out of the income of the elderly (and their spouses), in Milan not only the elderly themselves and their spouses but also their non co-resident 
relatives (mainly children) may be involved in paying part of the fees. The elderly living in institutions usually provide their own pensions and amounts equivalent to the Indennità di accompagnamento if they are entitled to it. In addition to these resources, spouses and children often contribute as well.

My mother only has my father's pension, since he died Io years ago, and the accompagnamento. That makes it about 900 euros a month that she is able to pay herself. Besides that, my brother and I are each paying 450 euro per month (Mrs. TR - case Mi2).

The only option to avoid these kinds of payments is to apply for subsidised access to nursing home care at the municipality level, but this requires a means-testing procedure. When the older person's income is insufficient ${ }^{\mathrm{TO}}$ access to institutional care is regulated by the municipality and the fees are paid for by the local authorities. ${ }^{\text {II }}$

We cannot pay for a nursing home. Myself, I live on my pension, which is not a wonderful pension. And the same is true for my father. The municipality takes his income and pays the rest (Mr. CU 65 years - case Mi3).

In the case of Milan and Lombardy in general, children in the intermediate income groups suffer more than the rest from the extremely high nursing home costs. While relatives with very low incomes are not required to contribute and relatives with higher incomes are largely unaffected by nursing home costs, children in the middle income range are burdened with financial problems as a result of nursing home costs incurred by an elderly family member. This has come to light in other studies as well (Facchini 2003). In recent years, there has been heated debate on the issue and the Municipality of Milan amended its regulations regarding co-payments to residential care facilities. Until 2002, public funding was provided based on an evaluation of the income of the elderly person and the children and children-in-law, but since then, only the income and savings of the elderly dependent (and spouse) are counted. This change has promoted a rise in residential care applications, clearly suggesting that nursing home costs severely limit the demand for residential care in the Italian context.

Finally, access to an institutional care facility follows quite distinct paths in the two contexts. In Amsterdam, the procedures are uniformly based on AWBZ's administrative requirements, while Milan has experienced significant fragmentation and dispersal. In Amsterdam all of the local actors tend to channel their requests for admission directly through the administrative board responsible for financing long-term care in institutions within the framework of the AWBZ requirements. Admission into a nursing home - like other services financed via the AWBZ - is a two-step process. First, the older person's care needs are assessed by the 
regional assessment board. Second, one must apply for nursing home admission via the local institution that handles admissions and waiting lists (Zorgkantoor, care office).

The first thing is to get an assessment from the RIO; without an assessment we can't do anything (manager of a nursing home and home care provider in Amsterdam).

People are sent here by their doctors, by the nursing homes in the city, or by their children who know the process. They might find their way on their own. Of course, we don't recruit people, but there are many institutions that know us and refer people to us (evaluating officer, Amsterdam).

In Milan, the path towards admission into a nursing home is much more complicated and depends on the abilities of the elderly and their relatives to go to the right institution. One way is to go directly to one or more nursing homes and apply in person. Another method is to approach the municipality of Milan and apply for free means-tested admission into a residential care facility and be added to the official waiting list. This process is just another filter for accessing residential care, as it produces time delays and makes one's relations to the services more complex.

It took us one month to figure out whom we were supposed to ask. We went to three different nursing homes and we eventually ended up in this one (Mrs. LO - case Mr5).

My uncle was put on four different waiting lists and the first home care facility that had an opening got him (Mr. TA - case Mir).

\subsection{Preliminary conclusions}

The qualitative analysis of care packages highlights important differences between the two contexts. Formal home care remains scarce in the Milanese case, which mirrors the quantitative analysis at the national and macro-territorial level (chapter four), but it also does not represent a package in itself. The type and level of support provided by social and health services do not respond to complex, intensive and extensive care needs. These services are generally provided within different kinds of arrangements: an informal package characterised by the prevalence of informal resources, or a commercial package, where the main caregivers are paid workers. In this respect, the difference between the Dutch and the Italian case is not only a quantitative one but also a qualitative one because formal care does not offer elderly dependents in Milan a real opportunity, while it does in Amsterdam.

Informal care packages present clear similarities in the profile of the informal caregivers and in the related intensity of involvement in care 
for dependent elderly people, as emphasised by the literature on support networks. However, it is not just informal care packages that are more widespread in the Milanese sample, which is to be expected, but also the meaning they assume for informal caregivers are different. In Amsterdam, informal caregivers tend to perform more organisational tasks and household assistance rather than direct bodily care and they tend to be supplemented and supported by formal care services. By contrast, informal caregivers in Milan are more intensively involved, both in how much time they devote to care and to the type of care they perform. In both contexts, however, a differentiation based on socio-economic circumstances emerged from the analysis.

The qualitative data also highlight the nature of the commercial package in Milan. Not only is there widespread use of paid care for both household tasks and personal care, but the number of hours of care purchased is considerable. This solution is also available to the lower and middle classes due to the relatively low cost of hiring migrant workers (often in the grey market). A similar solution is not available in the case of Amsterdam. If commercial care is present, in most cases it entails a limited number of hours of support, mostly for household assistance.

Finally, despite the fact that residential care includes similar content, the access procedures and the financing differ greatly in the two contexts.

These differences represent important elements that shape the opportunity structure for the making of care packages. The next chapter looks at how these distinct care packages are constructed, and which actors, stakes and decisions are relevant in arranging a package. 


\section{The Creation of Care Packages and the Transformations of Care Systems}

Care packages - the characteristics and qualitative differences of which we illustrated in chapter five - may be regarded as the result of the course of action and the choices undertaken by individual and collective actors. In this chapter, we shall concentrate on how specific care packages emerge, by looking at how they are constructed by the relevant actors. The reconstruction of care strategies (Wallace 2002) will then be linked to the transformation paths of the two care systems.

\section{I Contextualising care strategies: Who decides what and when}

As Anderson et al. (I994) emphasised when addressing the issue of choices, a crucial distinction has to be made between long-term strategies and short-term decisions taken in presence of a critical event, such as the onset or the worsening of an illness or disability. Preventive strategies are likely to exert an influence in the subsequent course of action, while short-term coping is likely to be influenced by both contingent constraints and previous long-term strategies.

Moreover, it is crucial to observe which actors participate in choices about care arrangements. The loss of decision-making power of dependent elderly people involves a process that has been described as "progressive surrogacy" (High and Rowles I995). The latter is particularly strong for the elderly living in an institutional setting (Lidz et al. I992) due both to poor physical and mental health conditions and to the characteristics of nursing home organisations, but needs to be addressed for dependent people living at home as well. Identifying the actors that are relevant for care strategies is in part related to the timing and context of choices, particularly in the domain of elderly care. Given a progressive loss of autonomy, the timing of decision-making is extremely relevant in defining the involvement of the elderly in decisions concerning their care arrangements.

Finally, choices concerning elderly care and the creation of care packages do not occur in a void. A set of actors operating in each local context interacts with individuals and households in the construction of care packages. The presence and specific functions of social services, professionals, elderly organisations, migrant worker organisations, pri- 
vate care suppliers, etc., reflect, on the one hand, the ways in which the welfare arrangements are designed and crystallised and, on the other hand, how they are likely to influence individual and family decisions. In the interaction with individuals and families, these intermediate local actors may contribute either to social change or to the crystallisation of the system.

\subsubsection{Long-term vs. short-term decisions; strategies vs. coping behaviours}

Care strategies in the two contexts appear quite different in terms of both the timing and the involvement of the informal networks in making decisions. In the case of Amsterdam, long-term strategies are more common and the elderly person's condition appears crucial in defining specific care arrangements. The interviewees in Amsterdam often emphasise that the elderly have expressed clear preferences about their future care needs a long time before the onset of health problems and dependence.

My father has always said that when he needed constant care he would rather go to a nursing home than be cared for at home. He has always been very clear about that (Mr. PJ - case A2).

In Amsterdam, different long-term strategies are observable among the elderly or among the ageing children of older dependents. Among the better-off households, for instance, there are private insurance plans to turn to. One reason why they purchased insurance was to "fill the gaps" of the social security system that is available to each and every citizen.

There is an insurance scheme in the Netherlands and you know what it offers. You also know, for instance, that in order to get into a nursing home or to receive home care via public insurance you might have to wait a few months. This is why my father and my mother decided to take out a personal insurance policy and I did the same for the future. This is to be sure that whenever he needed support he would never have to depend on anybody else (Mr. HH - case A29).

Similarly, residential strategies as a preventive move are rather widespread in Amsterdam. Several interviewees in Amsterdam report many older relatives making residential strategic choices to take care of future care needs with regards to type of facility, the neighbourhood, the city: an environment adapted to the mobility requirements of the elderly, the easier accessibility to services, a friendly social environment emerge as elements that matter in the individual residential choices. 
They [uncle and aunt] used to live in an old house in the centre. But as they got older they thought of moving over here. It is maybe less nice, but it is more convenient for older people; there are no steps inside the flat and they can get out easily (Mrs. GY - case A28).

This is a neighbourhood where you have all sorts of services. If my mother ever needed to go to a nursing home, she would go to the one next door and not to any other one. She's always said so, ever since she moved here ten years ago (Mrs. $\mathrm{HH}$ - case $\mathrm{A}_{3} \mathrm{O}$ ).

By contrast, coping is usually a short-term matter in Milan, which is dealt with mainly by the elderly person's family members. Most of the interviewees referred to the onset of disability or health problems as the time when the family - not the older person - was confronted with difficult choices. A possible explanation for this difference is related to the smaller range of opportunities available to the elderly in Milan compared to Amsterdam. First, the restricted supply of formal services does not allow the luxury of being able to depend on social care for one's future needs. Decisions regarding care do not depend exclusively on the will of the elderly or on the accessibility of specific care facilities, but revolve around the monetary and care resources of the children and other relatives, which mean that the decision to enter a nursing home or engaging home care is not an independent decision made by an elderly person and it is usually postponed until the children have their say. Second, in Amsterdam long-term private insurance plans may supplement a basic general health insurance, while in Milan, private insurance schemes are less feasible, more expensive and not very accessible, as they are not built on top of a basic social security scheme. Third, long-term residential strategies are much less available in Milan, also given the high incidence of homeownership. As the majority of the elderly own their apartments, their residential mobility is limited. The elderly in Milan- either living in their own house or social housing - have often been living in the same flat for decades and show a very high level of resistance to the idea of moving.

This is her flat. It is the flat she moved into when she married my father and where we [the children] grew up. I think she never even thought of moving, not even when I got married and I started living in the province. It is her house (Mrs. TP - case M34).

When my wife got worse and she started not being able to walk up and down the stairs, the housing corporation asked us if we wanted to move. But where should we go? Why should we move away? We are old now (Mr. BA - case M25).

While the interviewees in Amsterdam often referred to the possibility of planning the most desirable care arrangements for the future, the only type of (implicit or explicit) planning made in Milan concerned the per- 
son on whom the older relative will rely on. Instead of making individualised preventive choices regarding their future care needs, the elderly in Milan tend to rely on the presence of family members who will, at the right time, intervene in providing support. Who the main caregiver will be is decided implicitly according to considerations linked to gender, age, marital and work involvement or specific family histories. In several cases, becoming a caregiver implicitly resulted from a series of events in the lives of family members, their residential strategies and choices made during the life course. All of the (daughters) caregivers interviewed in Milan were well aware of the fact that at a certain point they would become the designated main caregivers of one of the parents, either because they were the only ones living nearby, or had limited family or work commitments, or simply were the emotionally closest to the elderly dependent. The obligation to devote more time to the care of an older person is generally made by the designated informal caregivers well ahead of time.

Nobody ever said anything, but it was obvious that I was the one who was supposed to take care of him. My brother was certainly not going to do it and his wife not either. It is normal in a way. We all knew it (Mrs. LK - case M3I). I have a sister who married in Rome and a brother who lives in Canada. When they left, it was clear what was going to happen when Mom and Dad needed help. It was absolutely clear (Mrs. GN - case M9).

Besides this long-term process of the construction of the main informal caregiver, choices about care arrangements have a shorter-term character in Milan than in Amsterdam and they appear more like responses to specific events than planned trajectories. Spouses and children taking care of elderly dependents tend to describe their situation as a precarious one, with no long-term vision, where daily new problems might emerge and require new decisions.

We live day by day. It is impossible to make plans. For now, things have worked out well. We'll see what happens tomorrow (Mrs. LC - case Mi8).

I am the one who does everything for him. If I get sick I wouldn't know what would happen (Mrs. AA - case MiG).

Differences in the ability to foresee and plan responses to the elderly's care needs have been previously studied in different welfare contexts (Pinquart et al. 2003), with specific attention paid to a comparison between a liberal welfare state - the US - and a continental European welfare state - Germany. It was discovered that older Americans are more likely to prepare for their future care needs (gather information, decide on preferences, make concrete plans), understand the services, and were more satisfied with their preparations than older Germans. The underlying hypothesis is that the existence of a public social security system - 
Germany in this case - allows one the luxury of having less to worry about regarding future care needs and that people living in liberal welfare states bear a more individualistic attitude with respect to coping with specific risks. Our evidence suggests the alternative hypothesis that a context with a stronger welfare provision based on individual rights tends to empower the elderly and to offer choices, compared to a system that is based on family solidarity and informal care. What emerges from the interviews is that the specific resources available in a particular context tend to structure the scope and nature of long- and short-term strategies in response to elderly care needs. Further evidence of this view is provided by the analysis of the differences within each of the two local contexts. Despite the above-illustrated differences between Amsterdam and Milan, important internal variations in strategic attitudes emerge based on the socio-economic differences of the elderly and their relatives. Long-term and individual strategies are more common in both contexts among the upper classes. But the time variable of the choices and actions undertaken by the lower socio-economic strata tends to be smaller, even if relevant differences persist between Milan and Amsterdam. Therefore, welfare state variations seem to have more of an effect on medium and lower socio-economic groups, where short-term and less individualised strategies tend to be adopted. Again, the individualisation of rights introduced by the Dutch system seems to allow more independence among the elderly (and the elderly's children), even for people with less privileged backgrounds.

\subsubsection{Individual vs. family decisions}

The prevalence of short- vs. long-term decisions contributes to defining the relevant actors for making decisions with respect to care arrangements. Whereas in Milan short-term decisions prevailed and the opinions of spouses and children were much more important, in Amsterdam long-term decisions were more common and the elderly themselves tended to exert more influence in defining their care packages. The children of elderly dependents in Amsterdam usually refer to their parents as the ones who make the decisions - usually ahead of time concerning their lives in the later phases and in cases involving dependence. When choices concerning care arrangements are mentioned, the relatives of the elderly tend to indicate the elderly as the ones who have made their own choices.

When she realised that she would no longer be able to make it by herself, she decided to enter a nursing home (Mrs. KZ - case Air).

She does not want to have any help from us children. She does not want to depend on us at all. She has always been a very independent type of person and she knows what she wants (Mr. $\mathrm{HH}$ - case A29). 
He took out an insurance policy when he was younger. He always claimed that he had to make it on his own, that he did not want to be a burden on us (Mrs. UT - case A2I).

One day, all of the sudden, she hired someone to take care of her housework. She said it and she did it (Mrs. EE - case AI).

By contrast, the role of relatives in Milan is crucial for the construction of care arrangements, as their work constitutes the basis for any kind of care package. Interestingly, when discussing decisions on how to respond to care needs, relatives tend to talk about themselves rather than about their parents.

We decided to take her with us (Mr. SE - case M2).

I could never send her to a nursing home (Mrs. LC - case Mr8).

I know she would agree that she is getting all she needs (Mrs. DD - case M32).

This situation reflects the fact that, unlike Amsterdam, children and other relatives in Milan are directly involved in the care arrangements and constitute themselves possible care resources. In Amsterdam an older person may make decisions about his or her own care without necessarily involving the children's lives. This would be impossible in Milan. The strategies of the elderly in Amsterdam do not necessarily take into account the availability of informal care provided by children: their involvement in providing some support to parents is usually supplementary to established care arrangements. In other words, children are more often "stepping into" care, independent of their parent's decisions, as they are less "expected" to take care of their parents. In the case of Milan, the decision-making process is utterly different and involves not only those who are expected to take care of the older person, but also a complex network of subjects related to potential caregivers. In Milan, decisions about caring, not caring, how much and in which ways are often intertwined, mediated (and conflicting) with the needs and interests of spouses and children of the older person's potential caregivers. Dependence and responses to care needs tend to become a family matter at large, involving the decisions and choices of several households linked to the older dependent. In this sense, the "familisation" of the risk of dependence entails discussions, negotiations and conflicts over the amount of time, money and space to be devoted to elderly care, that take place to a much more limited extent in a system based on care as a collective resource and on individual rights.

My husband and I almost broke up because of this. I was never home anymore. I could not take care of our house. I could hardly do anything for him or with him. We had to find a different solution for my father (Mrs. CA case $\mathrm{M} 2 \mathrm{O})$. 
At a certain point my mother was no longer able to live on her own. And we had to decide what to do... to take her with us... it was a difficult decision for my husband and me, very difficult (Mrs. LO - case Mi5).

Because the care provided by children and other non-co-residential relatives for the elderly in Amsterdam is much less demanding, these problems generally do not emerge in the interviews. If, on the one hand, the elderly enjoy more independence in making their care packages, on the other hand, becoming a caregiver is much more an individual rather than a family matter.

Of course, I am dedicating a good deal of time to my mother in this period. But the children are grown up and my husband understands that I have some commitments; they are just a little different from those in the past. I am the one who has given up my swimming pool to go and visit my mother; what should he have to say about it? (Mrs. HH - case A30).

Thus care decisions in Italy appear to be much more complex and linked to the views, interests, aims, resources and boundaries of a broader set of actors compared to the Netherlands, where they tend to concern the older person and a small circle of close relatives. In the Milanese cases, decisions were much more the result of complex conflicts and mediating processes that occurred within different households and between households. The decision-making structure may become very complex when several children and their respective families are present. Therefore, discussions often take place between siblings, between each one of them and their partners, and between the partners, so that care for the older person becomes an extended family issue.

My husband said right away that he would be available for helping out. Without his agreement, we could not be doing what we are doing. On the other hand, my brother's wife is not at all like that. She wants to participate in every discussion, but she doesn't do much. Family matters are sometimes difficult (Mrs. ZA - case M29).

To summarise, when speaking of strategies of elderly care in two very different welfare contexts, the difference in stakes and in the decisionmaking structures has to be taken into account. The institutional setting not only affects and structures the type and quantity of available resources, but it also contributes to the defining of who the relevant actors are in making decisions and designing the strategies.

\subsubsection{Intermediate organisations in the making of care packages}

In both contexts, decision making is influenced and mediated by social services and its professionals. Nevertheless, the importance of these ac- 
tors and their influence differ considerably between Milan and Amsterdam. In the Dutch case, social service professionals and organisations play a much more important and direct role in shaping welfare packages. Given the greater importance of collective resources in responding to the care needs of the elderly, the administration of these resources at the local level interacts with individuals and households in the construction of care packages. Traditionally, regional assessment committees in the Netherlands not only evaluated care needs of applicants, but also decided whether the right solution could be found in residential or home care arrangements. This notably raised many criticisms, as care organisations were seen as patronising and responsible for limiting the client's freedom. Nevertheless, the image that emerges from the interviews is more that of a negotiation between individuals and professionals from the angle of professionals as well as the informal caregivers.

I think you noticed that people do know what they want. You cannot just tell them what to do. They want to be an active part of any decisions that are taken. You cannot just tell them that this is what you get (social worker, Amsterdam).

They asked my mother what she wanted and told her what, according to them, was possible and what was not possible. Then they came to an agreement (Mrs. LL - case A5).

The Dutch long-term-care system is organised around the admission to formal care administered by regional boards that are particularly important both in orienting individual strategies and in implementing institutional change. During the research period for this study in Amsterdam, major changes were occurring, as new regulations were introduced that affected access to care services that were meant to increase freedom of choice (see chapter two). As was also emphasised by the professionals themselves, they, because of their position, could influence the outcome of the reform in everyday practice. They were confident that they could maintain an open negotiation with users regarding individual care solutions. Recent policy innovations had also fostered discussions among professionals concerning the practical implementation of the new regulations. The practicalities and the discretionary power in administrating the reforms were at stake and the professionals interviewed clearly expressed the need for negotiations concerning changes in regulations. Finally, the particular characteristics of Amsterdam's regional board - in terms of organisational identity, shared aims and principles - was acknowledged and protected. An ally for the professionals in this respect was the configuration of the care supply. Even if the new system of assessment introduced in the Netherlands was based, in principle, on a greater power of demand over supply, it has to be acknowledged that the constraints of supply in social services will probably change rather 
slowly. All these elements point to the pivotal role that professionals play in administering the access to formal long-term care and the likelihood of slow and regulated change.

The position of social services and professionals in Milan is, as already noted, strikingly different. Given the reduced importance of social services in Italy compared to the Netherlands, their importance is reduced both in its power to orient users' demands and strategies and in implementing social change at the institutional level. The influence of welfare agencies in the local context is much more indirect and mostly expressed through their general absence and unavailability rather than their active presence. Social services in Milan are less visible and less accessible than in Amsterdam and they usually do not represent a reference point for the elderly and their relatives.

I went to see a social worker to find out what could be done. I was desperate and had no idea about what to do and who to ask. She told me they could not do anything. So I came home and we had to deal with it on our own (Mr. TA - case MiI).

Social service professionals in Milan are not mediators in finding a satisfactory care solution and do not have enough resources to intervene and respond to their needs. When potential users apply for social services, they either obtain a limited number of hours of support or care allowances or they are redirected to informal or commercial solutions, given the restricted availability of formal care resources.

When my father came home from the hospital last time, it was clear that my mother could not take care of him as she used to. We asked at the municipal office but they told us the only thing we could do was to hire somebody (Mr. BA - case M25).

Social service professionals in Milan, unlike in Amsterdam, are not considered powerful actors who can influence changes in social policy and in the institutional framework. Given their limited development, social services do not play a role in reinforcing a collective approach to longterm care, but rather contribute fostering social demands for market solutions. In other words, commercial care for professionals of social services represents the way out of the rising care crisis in the city. As professionals are aware of the limited availability of collective solutions involving heavy care needs at home, they consider access to the care market as a response to the increased social demand and as a way of reducing the pressure on social services. In this respect, the migrant care workers are considered a blessing for the local care system. 
Luckily they are here, the badanti. I don't know what we would do without them. How could we be facing such a high demand for these services? (social service officer, Milan).

Even after the regularisation process of foreign migrants had begun, actors in the field observed a continuous flow of undocumented migrant women. Formal home care officers also agreed that the sustainability of the newly established care model was important.

They [undocumented migrant workers] are still coming. This is a blessing for us. What would we do without them? They have solved a lot of our problems. And if they stopped coming, it would be a disaster (home care service officer, Milan).

Third sector and volunteer organisations are very relevant in both Italy and the Netherlands because they provide support to elderly dependents. Not-for-profit organisations are the main providers of residential and domiciliary care services financed by the public sector. Moreover, various organisations provide information, support and advice to the elderly and their families, assuming a mediating role between individuals and families on one side, and welfare institutions and to some extent the care market on the other. Nevertheless, the different levels of collective resources available in the two systems and to the different institutional settings mean that their roles in shaping care packages are considerably different.

A broad range of associations in Amsterdam, provide information and counselling to the elderly and their relatives about care options, their rights and the procedures for admission into the formal care sector. Many of them are trained to respond to the needs and problems of specific groups of elderly people. Women's associations and those organisations that help older migrants negotiate their way through the formal care sector are two examples. In cases involving elderly dependence, all of these organisations process the requests of support and send them to the regional assessment board while they further support the elderly throughout the process of constructing their care arrangements. Care providers who offer home, day or residential care are also aware that the end users will be able to access their services only if they have been approved by the board and thus promote utilisation of the national insurance scheme. Interviews with informal caregivers and service providers consistently provide evidence on this point.

This is a nursing home, but since last year, we started offering home care to the people in the neighbourhood. We have many small service points in the neighbourhoods where people can go whenever they need to. ... When someone needs help we first try to get them assessed. We can't do much without an assessment (manager of a nursing home, Amsterdam). 
There is a daily centre next door. When my mother fell sick I first went there to find out what could be done. They told me that the first thing I needed to do was get an assessment. Without an assessment, everything is too expensive and too complicated. And they helped us out in getting an appointment to have the assessment done (Mrs. EG - case A24).

Even for-profit organisations, which have more recently been included in the long-term care system in the Netherlands, have an interest and channel the demand for care into the general long-term-care scheme and its institutions. The development of the Dutch care market has thus far been mainly based on a publicly financed and regulated system, so that private for-profit providers are aware that their chances on the market depend on their ability to attract clients, and on the ability of clients to access social security insurance benefits. Market costs are obviously too high, which means that private services are not really an option for the majority of the population.

Some people just come to us for help. They do not realise how expensive home care services are. The first thing we do is make an appointment for them with the [assessment board]. We take care of everything. When the assessment is done and they receive their budget (PGB), then it is possible to help them out further. Otherwise, they have to be very rich to be able to afford this service. It is not that we are particularly expensive. Home care is just expensive in general (manager of a private home care business, Amsterdam).

To summarise, in Amsterdam, the network of for-profit and not-for-profit providers and associations in the domain of elderly care is highly involved and interested in the development and consolidation of the public scheme of support for dependence. If they have in recent years promoted campaigns to empower the users and have encouraged a change in the balance of power between the care professionals and the users themselves, they are nevertheless embedded in socio-economic stakes related to the development of social insurance policy. Accordingly, they play a generalised coordination role in providing information to the public and in processing the demands via the various welfare institutions.

The picture that emerges from the case in Milan is quite different in this respect. Local social organisations, associations and care providers are not interested in channelling demand to a weak local care system that is not able to meet demand and, moreover, to a system that does not represent a relevant source of support for these organisations. As we have seen in Amsterdam, not only do associations and pressure groups tend to channel care demands to social services, but also the for-profit and not-for-profit organisations publicly financed within the framework of the national long-term care scheme. This is not the case in Milan at all. Here non-profit organisations work almost exclusively for public ad- 
ministrations that outsource their services and they have not developed a private personal service market, not even a publicly financed one. Similarly, volunteer associations and other local organisations that provide support to the elderly tend to not process informal caregivers through social services. Local public resources, according to our interviewees, are so limited and rationed in their ability to respond to the care needs of the elderly that in most cases it is not even worth trying to access formal support. This is consistent with the residual social service model, with the only exceptions being potential users in very difficult economic situations and without informal support. This is particularly the case for the elderly living alone and with no available relatives. Sometimes volunteer associations happen to come across these types of cases and forward them to social services.

We came across this woman two months ago. She lives alone. She has nobody. I don't know how she has survived until now. When we went to see her for the first time her house was a complete mess. She had not cooked for weeks. And she never goes out. We asked social services to do something about this (volunteer, Milan).

Sometimes we get incredible cases of people who are completely abandoned. It is usually the volunteers who notice and tell us (social service manager, Milan).

However, generally speaking, the organisations operating in the city tend to deny the possibility that social services are helpful in cases of elderly people with heavy care needs. The relatives of the elderly are often advised not to count on these services.

The X [a volunteers' organisation] told us that it was useless and they don't offer more than a few hours of help per week. This is not what we need. We need someone to be here all the time. We have to do it all ourselves (Mrs. OP - case M30).

Milan's situation is linked to the limited availability of resources and to the low level of involvement in the system of the existing organisations. The counter-evidence of this is given by the substantially different attitude that the same organisations show towards the more structured national cash provision available to the severely dependent elderly, the Indennità di accompagnamento (see chapter two). Not-for-profit organisations, especially volunteer associations, parishes and pensioners' unions tend to support access to the only universal scheme that characterises the Italian long-term care system. Moreover, as several interviewees reported, these organisations provide support throughout the bureaucratic application process required for the national care allowance. 
The first thing we ask is: does your father or your mother receive the accompagnamento? It is a right (responsible of a volunteer organisation, Milan).

At the pensioners' union, here next door, they told me to demand my accompagnamento. Then they fortunately took care of everything for me (Mrs. AU - case $\mathrm{M}_{3}$ ).

I don't know how it works. Apparently, it is quite complicated. But the church took care of everything. I only had to take my mother to visit and wait. It went well (Mrs. DD - case M32).

By contrast, when it concerns finding solutions for care needs, volunteer organisations and other associations tend to advise families to seek paid care. The solution of a live-in paid caregiver is often suggested as the only option in response to heavy care needs.

We know some women working as caregivers for the elderly. It is a good solution for a family. This is the kind of advice we often give to people with very heavy needs and no one in the family able to take care of them (director of a volunteer organisation, Milan).

We went to the church and they told us that the only thing we could do was to get a badante (Mrs. QV - case M27).

Some of the organisations that suggested this solution to informal caregivers also provide help, assistance and training to foreign migrant women. They thus represent a reference point for both relatives of the elderly dependent people and the migrant workers. They sometimes function either formally or informally as meeting points for the demand and supply of care (see also Da Roit and Castegnaro 2004; Mesini et al. 2006). Several organisations that assist migrants represent a reference point for people looking for a badante. Reports on this topic by both care workers and the relatives of the elderly are quite representative of the situation.

When I got to Milan I slept for two weeks at the ... [voluntary association]. I did not know anybody, I was frightened. Then a man came with one of the people working there. He was looking for a woman to take care of his mother. He was looking for a strong person because his mother had to be lifted on to and from the bed. He looked at all the women that were there and then said to the other man: I think she is the one. And he chose me (Mrs. HJ - C6).

Before leaving home I was told that there was a church where every Sunday people come to look for women caregivers. So I went there three Sundays in a row. This is how I got my job (Mrs. OO - CiI).

I asked the church if there was always somebody available to work for us through them (Mrs. OP - case M30). 
As a result, the attention and the interests of social services and of private non-profit organisations seem to converge at the point of the development of the care market in Milan.

\subsection{Crucial choices}

At the onset of disability and throughout the progressive process of losing autonomy, many choices about how to respond to care needs arise. As illustrated above, these choices involve elderly people, their relatives and other network members, social services and other actors like volunteers and care professionals. Nevertheless, the different level of participation of each of these actors, the stakes and interests, as well as perceived and actual opportunities and boundaries, vary greatly between the two contexts and within them. We shall now consider a few significant turning points in the dependence histories collected to further highlight the different logics underlying the construction of care packages.

\subsubsection{Gradualism vs. shocks}

Analysing care choices is not obvious, as the actors involved in making care packages do not view and represent the definition of care strategies as a homogeneous process. Reported histories of dependence and ways of coping differ in the pace of events and decisions made. In several cases, slow and consistent development was observed, while in others a series of dramatic turning points occurred. Several interviewees observed that the dependence history of their relative was characterised by a slow and progressive loss of autonomy and underlined that no major decision was ever taken about care packages. This is particularly true regarding care packages that include a certain level of informal care. In many cases, informal caregivers directly involved in providing support to the elderly tend to see their involvement as something that just happened rather than something they chose (see also Dautzenberg 2000). Care arrangements in these situations are the results of a series of small events rather than the outcome of choices made by relevant actors.

It is not that I've ever chosen anything. Things just happened. One day she started being unable to go out and do her own shopping. And I started doing the shopping for her. A little later I realised she could not cook for herself anymore. And I started preparing her meals. Then she could not wash herself, and then she became unable to stay alone anymore. It is not that I've chosen to become the one who cares for her. It has just happened little by little (Mrs. LC - case Mi8).

Informal caregivers often acknowledge that their current involvement in informal care was the result of a hidden, implicit and to some extent out- 
of-control process of escalation of informal care inputs. They therefore ex post realise and admit that their involvement in elderly care slowly increased without any explicit or rational decision being made in response to increased demands as the needs grow. For these reasons, reconstructing when and how changes in informal care involvement took place is usually difficult.

Ever since she broke her ankle, things have not been the same. Up till then she was doing fine and even after the accident she seemed to recover quite quickly. But one day we suddenly realised that she had become more and more needy and that we were spending a lot of time with her. We did not realise it right away. We realised it when it became too heavy for us (Mrs. LK - case M3I).

I used to go and see her once a week, then twice and then every day. Little by little she could not be left alone any more. If you ask me how or when it happened, I don't really know (Mrs. FD - case Ar6).

In Amsterdam, where the importance of formal services is greater, a similar process occurs with reference to the development of formal care packages. It is quite interesting how the increase of formal care inputs may be described in similar ways as the growth of informal care. As care needs increase, the reliance on home care services increases, with no apparent shocks or decisions being made.

At the beginning, when she was no longer able to take care of the house and to move around freely, someone from the home care service started coming twice a week to help out. And little by little they started coming more and more often. It happened like this, until now, when she always has somebody around and can't live without this (Mrs. IU - case A8).

By contrast, several histories are marked by accidents, the sudden worsening of health conditions or the loss of a former caregiver - typically a spouse. In these circumstances, the interviewees clearly realise that there was a crisis and that different alternatives and choices had to be made. When a consolidated equilibrium is under stress due to a shock, "what-to-do" questions do emerge and usually require rapid decisions.

When he spent a month in the hospital the last time he was really bad. They said he was ready to go home. But in fact he needed to be looked after all the time. And we had to decide: to take him home or to look for a place in a nursing home (Mr. TA - case Mir).

My mother was taking care of him and they were doing fine, after all. When she got sick, we suddenly realised that we had two sick people in the family. What a dilemma! (Mrs. $\mathrm{AU}-\mathrm{M}_{3}$ ). 
As earlier emphasised, these experiences are much more common in the Milan case than in Amsterdam. Among Dutch elderly people, contacts with formal services tend to start at a much earlier stage in the dependence history, even if there are initially low care needs. Thereafter, every subsequent event is managed in a more "fluid" way. By contrast, in Milan, families tend to deal with dependence by themselves, until they "explode", to use the expression of several Milanese informal caregivers. It is at this point that choices become evident and extremely difficult, due to time constraints and to the exhaustion of informal care resources.

These contextual differences have to be taken into account, together with other variables illustrated above - such as the timing of decisions and the direct involvement of the elderly, the position of collective actors in the local context and the institutional framework structuring opportunities and constraints - in order to analyse the logics underlying different choices in the making of welfare packages.

\subsubsection{Staying at home vs. moving to an institution}

One relevant choice in the care of elderly dependents concerns the decision to access a nursing home or not. Our analysis is aimed at grasping who decided what and when and what are the driving forces that lead to the institutionalisation or non-institutionalisation of an elderly dependent. In our qualitative sample, we rely on the observation of two elderly subgroups: those who have already entered a nursing home and those who are being cared for at home.

The paths towards institutionalisation - according to the histories of the institutionalised elderly - are markedly different in the two local contexts. In Milan, in most cases, institutionalisation is a last resort. A long time - several years - passes between the onset of health problems and disability and access to residential care. This residential care package tends to follow an extended period of informal - and in some cases commercial - care at home, organised by the relatives of older dependent people.

She was at home until six months ago. It was heavy for everybody, but we managed somehow. We took shifts. For a while, we also had a badante. But at a certain point we had to take her here. She needs to be looked after all the time because she's always at risk of hurting herself. If something happened what could we do? (Mrs. HL - case Mi4).

The informal-commercial package - a combination of informal and commercial resources - at home is a common experience in the past of the elderly living in institutions and included in the study. The possibility of entering a nursing home emerges when care needs become particularly heavy and are considered no longer manageable at home with informal and paid care. Dementia and related behavioural problems, ac- 
cording to the interviewees, are often among the causes of there being no other choice but to take the older person out of the home and to a nursing home.

We could not deal with it anymore. We tried everything. We were running back and forth between the hospital and home. I was spending all my time looking after her. At the end, she could not be left alone even for one minute. It just became too much for all of us (Mrs. LO - case Mi5).

The option of institutionalisation usually comes up at a very late stage in the dependence history of the older person and the decision to enter a nursing home is often made by the children at a time when they realise that care at home is no longer an option. However, if one only has very limited informal resources, the possibility of being admitted into residential care may occur earlier. In these cases, the decision is mediated by social services and other care organisations and takes place earlier in the disability path of the older person.

She does not have anybody. She was living alone and they realised that she could not take care of herself anymore. She was spending a lot of time in and out of hospitals until they found this place for her (Mrs. RE - case Mio).

In Milan, the decision to enter a nursing home is either left to family members or to social services at a time when all other resources at home have been exhausted, while in Amsterdam, the elderly have more say about their living arrangements, which is also due to timing. At the onset of disability and at each step along the path to dependence, the elderly (sometimes their relatives) and the assessment board are confronted with alternatives concerning the type of care to be delivered. The elderly thus have the opportunity to express their wishes before the need for more intensive residential care arises.

She decided to enter a nursing home so as not to be a burden on anybody. That has been her idea since the beginning (Mrs. KZ - case AII).

In Milan, as we have seen, informal resources are usually exhausted before one enters a nursing home, while in Amsterdam the prerequisite for gaining access to residential care is an inadequacy of the formal resources available. Therefore, the institutionalisation decision is much more mediated by professionals, as they provide both the assessments for home care services and for admission into residential care. Above a given amount of hours of care needed the assessment board usually prescribes or suggests admission to a nursing home or a home for the elderly. 
When my husband started feeling worse we called again [the assessment board].... They said that, if we wanted, he could be admitted into a nursing home, as he was in need of much more care than before. Of course, I could not take care of him properly and the help we were getting at home was not enough anymore (Mrs. AH - case Ais).

The attitude expressed about residential care by the informal caregivers is also quite different when we compare the two contexts. In Milan, most of the interviewees considered residential care as extreme and undesirable, which occurs only when no other alternatives are available. There were, in fact, some interviewees who just did not accept the idea of a nursing home as an alternative. According to a traditional view, residential care is described as inhuman, unsuited for older relatives (with a family) and does not meet the standards of care at home.

We took her there to take an examination last summer. I could see how depressed she became when she saw all those old sick people around. I think she was afraid of being abandoned by her children (Mr. SE - case M2). I would never have the heart to take her to a nursing home. It would be like killing her (Mrs. UO - case M2I).

By contrast, in Amsterdam, the idea if institutionalisation is accepted as a more natural evolution of a care arrangement when available (formal) resources are no longer sufficient to keep an older person at home. This difference highlights the stronger orientation towards family-based care in Italy and a more individualised approach in the Netherlands. However, the interviews provide a much more nuanced account and several elements that emphasise how these normative views are also linked to the particular welfare arrangements that characterise the two contexts.

Despite the fact that several interviewees expressed some resistance to the idea of institutionalising dependent elderly people, this normative view does not seem to be able to wholly explain the (non) recourse to residential care. Other relevant factors eventually emerged during the course of the interviews. First, the norm against residential care acquires a less absolute value when extreme care needs are obvious and when other solutions are longer viable.

We'll keep her at home as long as possible. Then we'll see (Mrs. LR - case $\mathrm{M} 24)$.

The Italian respondents who, despite contrasting normative convictions, chose a residential solution, often provide need-based justifications: in the face of the pressure of "need", social norms become a secondary concern. While institutionalisation as such is not preferred and may result in social disapproval, when there are intense care needs and after a 
long period of care at home, it may become suitable and socially acceptable.

Up to a few months ago I thought I could never take her to a nursing home. But in the face of necessity, you eventually change your mind. You realise that what is good is not necessarily what people think is good. It is not easy for us to have her here. But there was no other solution (Mrs. MA - case Mi).

Moreover, factors linked to the availability and nature of residential care supply play a role in defining the image of residential care and its desirability as a solution for elderly care. In Amsterdam, nursing homes are viewed as suitable places for the elderly with heavy care needs while in Milan the image of a nursing home is generally negative. The perceived physical and social environment of nursing homes represents a disincentive for considering this option, and, in fact, is only turned to as an option when care needs become extremely high.

You become a number. They are like hospitals. And you can live in a hospital for a few days or for a few weeks. But not for the rest of your life. If they were a bit nicer, maybe. Some of them look better. I know somebody who lives in a smaller one, with only a few people. It seems more like a family place. But usually there are hundreds of people, screaming and... It is not pleasant. You do it only if you have no choice (Mrs. VZ- case M26).

The limited availability of openings, long waiting lists and the likelihood that you will end up in a nursing home far away from one's family are often cited by Italian interviewees as barriers to applying for institutional care.

We are not yet in that situation, but I already know that it will be a difficult decision to make. Moreover, everybody knows that it takes a lot of time to get a place. And you never know where you might have to go in the end. If it was nearby, maybe. But I know people who have been waiting for places in who knows where (Mrs. QV- case M27).

Finally, money matters according to the interviewees in Milan. This is different from Amsterdam, where a nursing home is not, per se, an economic hardship for the older person (as well as his or her family). The spouse and children of the elderly in Milan often cite the high nursing home fees as a barrier to institutionalisation.

When my daughter asked for information about a place in a nursing home for my husband and they told us how much it would be, we almost could not believe it. If it ever happens, I don't know how we are going to do it (Mrs. $\mathrm{UO}$ - case M2I). 
If it was only for a short time... But how can you think of paying I,500 euro per month, without knowing for how long (Mrs. LR - case M24).

On the other hand, when adequate resources are available, financial constraints are kept to a minimum and it is possible to choose the "right" nursing home the acceptability of the institutionalisation choice increases greatly, as one Milanese professional explained.

When she was still able to communicate she told us to bring her to a nursing home. Therefore, we did. There is a private nurse who comes every day to make sure she is being properly treated; and someone goes to visit her almost every day. We did everything possible and everything within our means as a family (Mr. FG - case MG).

To summarise, in Milan, residential care emerges as an option only for the extremely dependent elderly, also in relation to the features of the welfare context and not only as a result of a generalised refusal of institutionalisation as a care solution. The hypothesis that access to residential care in the Italian and Milanese contexts is limited more by structural aspects than by normative views is supported by several elements. First, there is evidence that a limited supply restricts the demand for this type of service. Until the mid I990s one of Lombardy's provinces displayed particularly high institutionalisation rates of the elderly for historical reasons. However, one could not speak of "inappropriate" use of residential care, as the elderly living in the institutions in this area had similar characteristics - with respect to age, reasons for admission and duration of stay - as the ones living in areas with lower supply. This situation provided indirect evidence that the lack of supply (in other areas) was containing the demand for residential care (Da Roit 200I). Second, and more recently, several key actors noted that as the Municipality of Milan broadened its eligibility criteria for subsidised residential care the demand for institutionalisation in the city exploded together with waiting lists.

\subsubsection{Staying at home vs. moving into a child's home or moving to a parent's home}

Changing residential arrangements in response to the dependence of an older family member represent another crucial choice. In both Amsterdam and Milan, co-residence remains a remote possibility, despite the difference in the institutional contexts and the diversity of resources and constraints of the actors, and it is usually not taken into account by the elderly person's children.

In the Amsterdam sample, the possibility of moving into an offspring's home is utterly out of the question. Residential autonomy is regarded as an important aspect in the life of both the elderly and their 
relatives. Co-residence between the elderly and their children is deemed as a characteristic of the past.

It used to be that way. When you got older, you maybe had to go and live with your parents. In my grandparents' generation, the elderly did not have their independence. Now it is different. Both children and parents have their own lives (Mrs. $\mathrm{HH}$ - case A3O).

Interestingly, a daughter, worried about the ongoing transformations in social policy and in care for elderly dependents in the Netherlands, refers to co-residence as a risk of "going back to the past" and of losing the autonomy secured by welfare arrangements, both for the elderly and their relatives.

I am afraid that we are going back to the past. Everybody is talking about changing the system of care for the elderly. I agree that care has to be more humane. But if this means losing one's freedom and independence, it creates a problem (Mrs. KZ - case AII).

In Milan, the option of co-residence is also only occasionally considered by the interviewees. While declaring they are available to provide care and support, children tend to put some distance and separation between their own household and their parents. If close proximity is acceptable or even considered convenient, since it facilitates contacts and exchanges of support, living together represents an unacceptable limitation of autonomy and freedom.

I am ready to do anything. But living together... that would be too much, for all of us. We need our own independence. Myself, my family and my mother (Mrs. OP - case $\mathrm{M}_{3} \mathrm{O}$ ).

Living close by is very comfortable. We can help. We can be very close. But we need to have our own space. Living together is out of question (Mrs. LQ case M29).

Nevertheless, in the case of Milan, a few exceptions to this shared view are linked to specific stakes and motives. In one case, the decision to host a mother living far away from her children is explicitly linked to the absence of affordable alternatives. In this case, co-residence is an example of the strained familisation of care.

My mother was living far away, in her home town. She has nobody there anymore. When she started having problems, we were the only ones who could take care of her. What could I do but take her with us? We certainly could not get her another apartment. My sister and I live in the same building. As I live alone, my mother moved into my flat, where there is more room (Mr. SE - case M2). 
Other cases reveal the economic stakes involved in the care of the elderly within the family and the importance of calculations concerning the most profitable, or less costly, care solution. Economic motives - concerning income and assets - are relevant in the negotiations and decisions made concerning living arrangements, particularly among low-income households. Decisions concerning the residential arrangements of the elderly and their children sometimes parallel explicit or implicit decisions concerning monetary exchange and inheritance. Taking care of an older parent who is in very poor health and has a low level of functionality in-house also means doing his or her bookkeeping. If this is true for cases involving residential separation between households, the income of the older person in the case of co-residence is even more likely to be included in the overall income of the hosting household. Better-off children often judge living with the older person hampering and invasive and, given their higher economic status, do not consider the possibility of giving up some of their freedom in exchange for additional income. By contrast, for low income children the older person's income may represent a valuable resource.

She does not have much: just her pension, the minimum pension, and the accompagnamento. That's it. She lives here. We take care of everything and, of course, we manage her money. What we do for her is normal, it is the bare minimum (Mrs. MM - case Mi7).

Sometimes, besides the income of the elderly person, his or her house also represents a resource that is taken into consideration in constructing the care arrangements. The daughter of an elderly dependent moved into her mother's flat with her entire household before the onset of her mother's disability, thus preparing for her future care needs. This care solution, involving co-residence, was also discussed with other members of the family. In these circumstances, economic stakes that are usually absent or hidden among better-off families in Milan clearly emerge.

We moved into her house when it became clear that I should take care of her. In fact, it was clear before. She has been living alone for years. Sooner or later, she would no longer be able to take care of herself. My brother would never be able to do what I'm doing here. We all know it. And we agreed that I'd move in with my husband and my children. I'm now the one who takes care of everything (Mrs. LQ - case M28).

The issue of housing and inheritance among lower-income households in general is often the focus of family discussions, even before the onset of a disability. There is the notion that care tasks should be compensated, often via the use or inheritance of a parent's house. As a result, a complex set of arguments and negotiations between various family members of the elderly person arise when it comes to choosing an informal care- 
giver and to designating the child who will use or eventually inherit the family house. Again, the familisation of care in lower socio-economic households points to a mix of family commitment, economic interests and contested gender relations.

I have four brothers and I am the only woman. When you are the only woman, you know that sooner or later it will be your turn to take care of your parents. As my mother died young, my father has survived her for many years. When two years ago my brother and his family wanted to move into my father's house I told them right away that either my sister-in-law was going to end up taking care of him or it wasn't going to work out at all. I am not stupid. I did not want to leave them the house and have to work for them again as soon as my father got worse (Mrs. GN - case M9)!

In Amsterdam, the welfare state and its care arrangements for the elderly fosters autonomy and allows individual decisions concerning elderly care to be made that have nothing to do with economic circumstances. Co-residence is not an issue given the reciprocal independence - from an economic and care perspective - of the elderly and their children. By contrast, in Milan, the familisation of care and dependence of the elderly on their children contribute to the rise of economic stakes necessity when making decisions about residential choices for the elderly and their caregivers, particularly among the lower socio-economic strata. As highlighted above, the elderly may represent either a financial burden or a resource for the children's family, depending on their socioeconomic conditions. Children in disadvantaged socio-economic conditions therefore tend to regard the resources granted by the presence of an older dependent person in the household as quite important, alleviating a significant care burden.

\subsection{Who assumes the care tasks at home?}

As we illustrated in chapter five, home care arrangements differ greatly between Milan and Amsterdam and within each one of the two contexts, according to socio-economic differences. This dual differentiation of care packages will now be interpreted by considering the tensions between normative views concerning elderly care, on the one hand, and the resources perceived, available and mobilised in the creation of care packages, on the other hand. We shall concentrate on the attitude and actual contribution to the care and support of the children of the elderly dependents, as an interesting angle for understanding the actual content of intergenerational solidarity. Normative views on intergenerational responsibilities are important because they serve as guidelines directing individual decisions and they provide a framework that people use to justify and explain their behaviour to others (Finch 1987; 1989). Never- 
theless, correspondence between general social norms and action is not straightforward. Finch and Mason (I99I) emphasised that several basic assumptions about family obligations on which there seems to be general agreement - among which the assumption that most people are able to indicate what "the proper thing to do" is - are, in fact, much more contested and complex in everyday life. Their analysis suggests that people's judgments about the course of action that should be taken varies and is complex so that most people do not give unconditional consent to the principle of kinship obligations (p. 356 ). Even parent-child obligations are treated as conditional by the social actors, who see a variety of legitimate ways to offer assistance (pp. 357-358). Widely held beliefs about family obligations can thus be used as a framework for individuals in which to negotiate their responsibilities and actions taken. In fact, several studies underpin the idea that there is no strict correspondence between social norms and actual behaviour in care for the dependent elderly. Dautzenberg (2000) found that the probability that a middleaged daughter in an urban Dutch context would become a caregiver was strongly affected by structural factors and much less by normative or cultural factors. ${ }^{\text {I }}$ There is strong and consistent evidence that proximity has an important impact on the exchange of help: contacts, exchange of support and even feelings of obligations are strongly affected by geographical distance (see Lye I996: 97 for a review). Moreover, as Aronson (I992) observed, daughters caring for disabled mothers tend to give general normative explanations about caregiving as a duty. Nevertheless, when they consider their own experience, feelings of responsibility emerged less as a matter of adherence to social norms of filial obligation and more as a matter of necessity ("Who else is going to do it?" I992: I5). This emphasises the importance of alternatives perceived by caregivers, which is strictly linked to the welfare context in which their social circumstances are embedded.

We will further show that, in Amsterdam and Milan, despite important similarities in normative views, the specific definition of family solidarity and the actual content of support are shaped by available resources, institutional constraints and social relations. Notwithstanding an overall agreement on the duty to support one's older relatives, the actual content of the normative frame of reference of the interviewees varies greatly according to the welfare context in which they are embedded and their socioeconomic circumstances.

\subsubsection{Filial responsibility in Milan and Amsterdam}

Declarations about filial responsibility towards older parents are strikingly similar, in principle, between Amsterdam and Milan (see also Da Roit 2007a). The general idea that children should support parents who need assistance is shared by interviewees in both cities. ${ }^{2}$ Filial obligations are sometimes defined as an absolute duty because the relation- 
ship between parents and children encompasses obligations that cannot be questioned.

It is my mother. What else is there to say (Mr. VV - case A23)?

He is my father. A father should always be able to get help from his own children (Mrs. AU - case $\mathrm{M}_{3}$ ).

In other cases, both in Amsterdam and Milan, the reciprocity dimension of filial obligation is made more explicit. The opinion that children should help their older parents is viewed as a form of recognition and restitution of support received in the past from parents, as an expression of reciprocity over the course of a lifetime.

A mother is a mother. When she needs help you're supposed to give her support because she supported you in the past. I will always be there for her as she has been there for me (Mrs. EG - case A24).

She took care of us when we were small children and now it is our turn to help her out (Mr. DN - case Mig).

Sometimes love and affection are put at the centre of the discussion and become the basis of the support relationship, while in other cases obligations and constraints are more commonly emphasised.

Things are not always easy between mother and daughter, but I love her. That is all that counts (Mrs. HL - case $\mathrm{A}_{3}$ ).

Do we have a choice as children (Mrs. MM - case MI7)?

However, if we take a closer look, at least two major differences emerge between Amsterdam and Milan, concerning the extent to which the support of elderly people is a "family matter" and the specification of this norm. The main difference in attitude of the elderly and their relatives is that people in Amsterdam tend to be more "welfare state" centred, while in Italy, they tend to be more family-centred. In other words, the idea and function of intergenerational solidarity are less perceived as solely a family matter in Amsterdam than in Milan. In Amsterdam there is a general acceptance that intergenerational solidarity may be expressed, other than within the family, in a broader sense through social security. Intergenerational solidarity, as expressed by this interviewee, takes place within the family and in society as well as through welfare institutions.

There is health insurance in the Netherlands. This is how we manage it. It is not that we don't care about the elderly. We all contribute to their care since we pay for that insurance. And we all contribute to our own care in the future. This does not mean that people should stop loving their parents, visiting them and taking care of them. I think you show your love and affec- 
tion when you are not obligated to do so. Maybe you do it better even in this situation (Mr. BV - case A27).

Even if the principle of generalised intergenerational solidarity serves as - also in the Italian context - the foundation of social security schemes for specific social risks, in the domain of elderly care in Milan this issue is neglected by most of the interviewees. According to the most widespread view, intergenerational solidarity in the field of care needs occurs within the boundaries of the family.

In a family there is always somebody who needs help. At a certain time it is you, then it is your own child, and then your mother. The others are there when somebody needs assistance. It is a matter of giving and receiving (Mrs. CA - M2O).

The second general difference between the two local contexts - which is very much related to the previous one - is the actual content of the support that, according to the interviewees, should be provided to elderly dependents. In Amsterdam, according to most of the offspring interviewed, the tasks that fulfil one's filial responsibilities include "being available", "being a reference point", giving emotional support and some instrumental support for everyday activities.

I've always been there for my mother since she started having problems. And I think this is what it is all about to be a child when your parents get older and needy (Mrs. HL - case $\mathrm{A}_{3}$ ).

For most of the interviewees in Milan, however, filial responsibility is expressed through the offer of care, either directly or indirectly. What children should do is either provide direct instrumental support or make sure that their parents receive the necessary support. ${ }^{3}$

I am her daughter so who could take better care of her than I do? This is what she expects and this is what I think is right (Mrs. LC - case Mi8).

Several differences in nuances in attitudes towards care that emerge between Amsterdam and Milan, are also found within each local context. The meaning of filial responsibility toward elderly dependents differs greatly along socio-economic lines in both cities, but more so in Milan. For interviewees who belong to upper classes, solidarity and reciprocity does not necessarily mean providing direct care, and is more about emotional and organisational support to arrange the necessary assistance. One Milanese professional with dependent parents thought that filial obligations were important but depicted them as mainly "managing" proper care. 
Our father has always been very demanding. Now that he's no longer able to look after himself, my brother and I are making sure that he has everything he needs: the company, care, everything. It is our duty as children. Whenever there is something wrong or something new the ladies who care for him will call us to ask what should be done. It is working out well (Mr. GH - case M7).

The attitude of upper-class children in Amsterdam is quite similar: fulfilling filial obligations and "taking care" entails ensuring that the care needs of the elderly dependent are met with the help of some others. One private sector manager in Amsterdam expressed this as follows:

My sister and I are taking care of everything. Well, in fact it is more me because my sister lives quite far away. But we do discuss almost everything. My mother is no longer able to negotiate with her health insurance company on her own so we do it for her. We are organising her care along with the assistance of the health insurance company. There are choices that have to be made. This - I believe - is part of our duty as children (Mr. VV - case A23).

Quite interestingly, no relevant differences in attitude emerge between men and women among the better-off and higher-educated households. Both men and women tend to interpret solidarity as an organisational matter. A similar view among Milan's upper classes is so strong that one interviewee - an upper-class woman - felt the need to explain and "justify" why she had decided to provide direct care (instead of care management).

My husband says I should not be doing this. And I know he is right: my mother is getting everything she needs and I should just be keeping her company. But I do enjoy doing things for her. Even if there is someone else who is paid to do this (Mrs. SE - case M35).

By contrast, interviewees with a lower socio-economic status tend to mainly identify support with direct care. In the case of Milan, this more often implies personal care, while in Amsterdam, personal care is seldom mentioned and interviewees tend to refer to household assistance and other practical matters. It is quite common for lower-class women in Milan to associate filial obligations with the provision of personal care and often think that the care they provide "out of love" or "out of duty" is the best kind of care an older person can receive. Sometimes, they reinforce this view by underlining that their parents would never want anybody to care for them.

I am her daughter. I know that nobody could take care of her better than me. And I am sure she agrees. That does not mean that we always get along. 
Sometimes it is hard and we argue a lot. But we are still mother and daughter (Mrs. LC - case Mi8).

I know that he would not want anybody else to touch him. It is my duty as a daughter (Mrs. MM - case Mi7).

In Amsterdam, interviewees from lower socio-economic backgrounds expressed similar views. "Doing things" is the direct expression of filial responsibility, as "organising things" is for the upper classes.

I come here every day. And my sister as well whenever she is in Amsterdam. We take care of everything that needs to be taken care of. She can't do much on her own and the house needs to be kept tidy. There is always some problem to solve or something to purchase. This is what we are supposed to be doing. That's it (Mrs. KO - case A6).

There is never one minute left over for me. I'm running in and out of this place all the time. I know this is what I am supposed to be doing. I do not complain. But still it is hard work (Mrs. EG - case A24).

There is also a vast range of individuals and households in both Milan and Amsterdam who find themselves between these two extremes in intermediate socio-economic conditions and they often turn to a combination of the two approaches to elderly care responsibilities and filial obligations. Interviewees with an intermediate socio-economic status in Amsterdam tend to have an attitude similar to upper classes, while in Milan, there are signs that transformations in this direction are taking place. In Amsterdam, meeting filial responsibility for middle-class children mainly means providing company, emotional support, assisting with organisational matters and spending time with the older person.

I drop by three times a week in the afternoon after work. Maybe I also do something around the house, so I'm not always staring at him. I know I am mainly expected to be there. What I do is not really important. Of course, I have to make sure that he is fine and that he has everything he needs from the people who take care of him every day. Sometimes I also bring flowers... It is my way of letting him know that I care for him (Mrs. LL - case A5).

In Milan, by contrast, many children - especially daughters - in intermediate socio-economic positions seem to be shifting from a conception of filial obligation based on direct care to one more centred on care management. Several interviewees rejected traditional views of filial obligations and expressed newer opinions, because they were aware of the fact that this was still a socially contested matter. They did not argue that elderly care was not their concern, they just tended to give a different shape and character to intergenerational solidarity, shifting away from the idea that direct care is the only possible expression of support and 
interpreting solidarity as a more articulated matter, which encompasses management, organisation, financing, and supervision.

Some think that if you don't do it yourself, you're not a good daughter. But in my opinion what counts is that he's not missing anything (Mrs. LK - case M33).

\subsubsection{Resources, opportunities and variations in care packaging}

The above-mentioned differences regarding filial obligation - both between and within contexts - signal a strong link between available resources and opportunities and normative views on intergenerational solidarity. On the one hand, the shared responsibility between collective instruments and private-family solidarity for coping with dependence seems to be interiorised by actors in Amsterdam, while it is absent in Milan. On the other hand, the content of the support that, according to interviewees, should be provided by children largely reflects the different level of engagement in care observed in Milan and Amsterdam. None of the Dutch interviewees felt like "excusing" or finding explanations for not providing (more) personal or direct care for their elderly parents. By contrast, in Milan the intergenerational obligation is seen more as a private matter entailing, coherently with the type of support provided to elderly people by their children, heavier care tasks. However, the available opportunities - which differ across social classes - make a difference in what is conceived as "proper care".

General welfare arrangements represent a key aspect in the home care packages, as they define - or exclude - a set of opportunities that is indeed extremely important in the construction of strategies. In Amsterdam, where formal resources represent an actual possibility for responding to the care needs of the elderly and providing crucial support to allow them to live independently, what matters is if and when to ask for formal support.

Up to a certain point I took care of him. Then he needed more and more help. So I called up the home care services and now she is also getting support from them (Mrs. PS - case A7).

The interviewees generally have a good understanding of how the system works and they explain that the elderly person him/herself or someone in the immediate social network has at a certain point activated formal resources. This sometimes occurred with the help of one of the public or private organisations acting in the domain of the elderly person's care that we have previously mentioned. The availability of considerable amounts of formal support via social services and - in case these are not sufficient - of institutional care as an alternative exclude intensive informal caregiving as an option. 
By contrast, the elderly and their relatives in Milan do not have the option to turn to formal services for substantial help - besides the possibility of institutionalisation which was discussed earlier - and are confronted with a choice between intensive informal care provided by spouses, children and other relatives and private care, mostly purchased, as we have seen, in the irregular market. Formal care at home is at best considered a supplementary service, which does not represent a real solution to care problems as such.

When something like this happens what can you do? You just have to deal with it on your own. No one is there to help (Mr. BA - case M25).

She came home from the hospital four months ago. At the beginning, we did not know what to do. We did not even know whom to ask. I went to the social worker to find out what was available. She told me there was nothing they could do. They claim we are too well off (Mr. SE - case M2).

What you learn right away in such a situation is that it is completely your own business. The municipality, they can't do much. Everybody is giving you advice, but no one is available to help with anything. When they send you somebody for two hours they think they have done so much. But in fact there are 22 more hours in a day (Mrs. AU - case $\mathrm{M}_{3}$ ).

Given these general differences in the opportunity structure between Milan and Amsterdam, within each system the socio-economic conditions of the elderly and their relatives are relevant in defining opportunities and constraints. Care packages among upper-class families included in the study tend to be similar in the two cities. In these situations, direct care is usually not an option for the relatives. Even though the elderly with this type of background tend to have a relatively large network of support that provides company and emotional support, bodily care is mainly outsourced. By contrast, the lower classes tend to rely more on informal support in both cities, and even more so in Milan. Here access to market care is limited by financial constraints and, given the lack of formal resources, intensive informal care is the only viable solution.

What could we do, take him to a nursing home? He would never accept such a thing. And then, who would pay for the fees? We do not have the money. That is something for the rich. It is too expensive. And who else could take care of her if not us. We can't pay anybody else to do it (Mrs. LQ - case $\mathrm{M} 28)$.

Lower class interviewees in Amsterdam, besides using social services, tend to perform tasks that middle or upper class interviewees would outsource (additional housekeeping, company and supplementary care). 
This is how things are. When something like this happens you have to deal with it. There is nobody who is going to help you. We are not rich people. We just do it like this (Mrs. KO - case A6).

Intermediate socio-economic groups have the most complex situations in both cities. They tend to rely more on a combination of market and formal care in Amsterdam, similar to upper classes, and a mixture of market and informal support in Italy. Since home care services in Milan are not available on a regular or intensive basis, the choice of externalising the care to a migrant worker is compared to two alternatives: residential care or informal care. The advantages of market care are manyfold. First, for a relatively low price, many hours of care can be purchased. This significantly reduces the amount of informal care needed and allows avoiding much more expensive residential care solutions. Many interviewees spontaneously compared the amount of money paid by relatives in cases of institutionalisation with the costs of private home care.

This does not mean it solves all of the problems, but I cannot imagine what we would do without X. Of course, it is still expensive, but not as much as a nursing home (Mrs. TP - case M34).

Moreover, hiring a badante is preferred not only because it is cheaper than institutionalisation, but also because using a domiciliary care arrangement fits in with the traditional view that nursing homes are made for "those who do not have anybody" and are used as a last resort (see above). The perceived "informal" character of the care arrangements based on a paid badante often represents an explicit reason for "accepting" a similar solution.

$\mathrm{N}$. is wonderful; she takes care of her as if she were her own mother (Mrs. LK - case M33).

To some extent, this solution squares the circle from the point of view of the family because it provides very flexible care at a reasonable price while the older person is taken care of at home.

For us it is a perfect solution (Mrs. DD - case M32).

A badante clearly represents a way of substantially reducing the burden of the presence of a dependent elderly person in the (extended) family. More specifically, this strategy reduces the engagement of women in unpaid care, redirecting it to paid work. Nevertheless, the responsibility for ensuring care to the older parent remains within the (extended) family because women tend to assume a role of care managers and secondary direct caregivers. They are the ones who find and choose the workers, who supervise them and who pay them. 
Don't think that there is nothing to do. I go there twice a day to see that everything is fine. That she does not need anything. Whenever there is a problem she calls me. And you should know what we went through when six months ago my mother decided that the girl that was working for her was not the right one. I don't even want to think about it anymore... (Mrs. LR - case M24).

I have my shift on Sundays. When the badante has her day off I stay with my mother (Mrs. VZ - case M26).

In a way, the content of intergenerational solidarity tends to be more similar in the Netherlands and Italy than it was a few years ago as a result of the externalisation of some care tasks for the elderly people to migrant workers in Italy. This is also compatible with the decrease in assistance provided the older households that were analysed in chapter four. While the daughters of the elderly dependent would have traditionally taken care of their parents by providing time and instrumental support, this arrangement is now more restricted to lower socio-economic and less-educated offspring who still find the exchange relatively balanced, or simply do not have enough resources to switch strategies. Meanwhile, middle-class and upper-middle-class women now have more opportunity to combine some informal care with paid care. How did this transformation come about?

The hypotheses on the diminishing care potential (especially among women) tend to concentrate on the decreasing availability of informal caregivers, due to "structural" reasons: less children, more women active in the labour market, geographical distance. The recourse to paid care should therefore be related to the lack of potential informal caregivers. The absence of one or more potential informal caregivers able to provide extensive care is clearly one condition under which paid care develops. The elderly without a strong potential support network - such as older couples or widowed elderly people without children, those elderly who never married and the widowed with one or more children who live too far away to get involved in extensive care - tend to fall into this group. In these circumstances, paid care is definitely a solution to a general lack of informal care resources. Paid care often represents a solution after other informal care resources have been exhausted. An 80-year-old woman living with her husband in need of continuous support explained it:

I have always taken care of everything: the house, him, and myself. I must admit it. I am getting tired as I get older and older. There are always so many things to do. It is worse than a real job... Until six months ago I managed to do it myself, I did not need anybody's help. Then, after I broke my shoulder, it became impossible for me to do what I used to do. We have no children and we had to get some help (Mrs. AA - case Mi6). 
Nonetheless, paid care is not a total substitute for informal care because, to a certain degree, some informal support is needed to properly access paid care. Given the heavy care needs of the elderly, somebody from the informal network is usually in charge of finding a careworker and of monitoring the care activity that is being performed. The elderly who live alone with no relatives and other potential caregivers are not likely to be living independently and relying solely on commercial support. Even when these informal resources are very low, some interaction between the paid worker and the informal network of the elderly takes place, as in the case described by this Ukrainian woman who worked fulltime as a live-in paid caregiver.

The lady has two children, but they don't live here. They come here every week to make sure that everything is fine. One of them comes one week and the other the second week. They are good to her, but they cannot take care of her because they live too far away (Mrs. MD - case M8).

However, the objective lack of care resources is not the only situation where relatives of the elderly access the care market. In many cases, the lack of informal resources is the consequence of an explicit choice made by potential caregivers not to provide direct care. In several cases, the elderly included in the study had one or more children with whom they had frequent contact. Despite this high level of involvement in arranging care, they are not involved in the direct provision of services as we would expect in the framework of the traditional Italian model, but rather arrange, organise and oversee paid care for their older parents and relatives. The job situation of the offspring (especially daughters) was cited in a few cases as the main reason why they were unable to provide direct care. Sometimes a job is cited as being the main 'obstacle' to the provision of direct care:

I work fulltime. Of course, when I get home from work I run over here to see what has to be done. But I cannot do more than this. I can't stop working to take care of my father. I know it sounds cruel. But I need my job and I will need it for some time to come (Mrs. GN - case M9).

Besides the "need" to work, choosing to work instead of providing informal care for a parent is also justified by one's level of job commitment, involvement and satisfaction. Several interviewees expressed the view that they have the "right" to choose not to take care of their parents, as long as they are able to arrange a reasonable care setting. This was explained by one woman:

I like my job. It is important to me. I know that my mother thinks that a good daughter should stay at home and take care of her. But I'm not doing 
anything wrong and she has everything she needs and I'm here whenever I am not at work (Mrs. LR - case M24).

Many of the daughters and daughters-in-law of the elderly in our sample are, however, not actively employed because they have either retired or have been housewives for most of their lives. Many of them in these circumstances, however, still preferred not to provide direct care, but to arrange some form of private care for the older parents instead. Competing care demands from other family members - such as husbands, children and grandchildren - are sometimes referred to as the main obstacle to the provision of direct care and the motive for turning to paid care. Moreover, in quite a few cases, paid care is depicted as an option that allows one to keep one's autonomy, free time and freedom.

I retired two years ago after 35 years of working. My husband retired last year too. We thought we could finally have some time for ourselves. Then his mother became worse and worse. At the beginning, we were taking care of her and we were doing everything. Now it has become impossible. She needs someone to be there all the time. It would mean giving up our lives. I don't think it is right. Of course, we are doing everything necessary. She is never alone. When the 'woman' [paid caregiver] is not there, we stay with her. But we all deserve a life (Mrs. TP - case M34).

This market strategy, however, would not be viable in the absence of a set of conditions that we find in the Italian and Milanese contexts. The combination of a relative abundance of cash resources and the low cost of services clearly emerges as a condition for the development of a care market. On the one hand, a generous pension system and a national care allowance - representing the most important support provided by social policies and usually used to supplement the overall household income - expand one's options when purchasing care. On the other hand, the supply of an inexpensive and under-regulated care labour market has made paid care more affordable for the middle classes. As previously mentioned, the average pay of a fulltime live-in careworker hired in the grey market equals approximately the sum of the minimum pension plus the national care allowance for dependents. Given that the elderly are very often homeowners and do not have to face expensive housing costs (rents or mortgages), paid care is relatively affordable if someone has a higher-than-minimum pension or receives a relatively small cash contribution from the children. Care services purchased in the regulated market would not be accessible for a vast majority of the public, however. In fact, hiring a worker in the grey market is cheaper for several reasons, of which all the interviewees were well aware. First, social security payments and taxes do not apply in the grey market. Nevertheless, given the low fiscal and social security wedge in this sector (Da Roit 2003), this is not the main reason for preferring the grey market. In cases involving 
fulltime employment and live-in care arrangements, the most relevant differences between the regular and irregular market occur when the schedules and other contractual and social rights of the workers are taken into account. National agreements on domestic work establish a weekly schedule and the conditions under which overtime work can be performed, it also regulates paid leaves, sick leaves and holidays, while informally defined working relations usually entail an extended and nonremunerated work schedule together with 24-hour-per-day availability. When the older person needs constant care, one worker hired in the grey market is equal to three hired in the regular market working three different shifts. Moreover, also a formally regulated employment relation usually implies a substantial compression of costs thanks to a "flexible" and informal management of contractual norms. A minimum amount of hours of work is often declared for administrative, social security and tax purposes in order to minimise the related costs. Furthermore, the employment relationship, even when a formal working contract exists, tends to be administered similarly to jobs in the grey labour market, as informal arrangements continue to regulate working hours, permits, leaves and wages. In this respect, the traditional features of the Italian welfare system appear to have fostered a considerable shift in care arrangements for the elderly. The prevalence of cash allowances used as social policy measures and the existence of a widespread and tolerated underground economy (Mateman and Renooy 200I; Schneider and Enste 2000) attracts undocumented migrant labour (Reyneri 200I) and have sustained the growth of a widespread care market by opening up opportunities for a new generation of daughters of the elderly.

\subsection{Care strategies and care systems' transformations}

Pressures on the traditional care models are observable both in Amsterdam and in Milan, and were voiced by interviewees when discussing care solutions that contrast with traditional views and that communicate worries about the present and future of elderly care. Nevertheless, whereas in Milan dramatic changes are occurring within the family care model in the creation of elderly assistance packages, this is less so in Amsterdam where the formal care package shows a certain degree of resilience.

Welfare institutions and social organisation play a relevant role in the creation of care packages, by defining the stakes, providing resources and constraints to individual and collective actors. This produces variations not only in the outcomes (care arrangements), but also in the social processes that form the basis of the creation of care packages, and thus also in the possible ways of changing the prevalent modes of responding to care needs in a specific context. We have thus observed variations in the content given to social norms and in the actual content and social 
meaning of care packages not only between Amsterdam and Milan, but also within each of the two contexts based on relevant social inequalities and differences.

This evidence suggests an interpretation of the overall trajectories of the two systems. On the one hand, the expected dramatic changes in the Dutch care system did not happen. This is due to the combined resistance of individual and collective actors within a consolidated institutional framework. On the other hand, institutional features have undergone a considerable shift in the mode of care production, where a generation of women has played a significant role. This shift questions gender roles and social inequalities in the familistic and increasingly commodified care model.

\subsubsection{The changing family care model}

Despite the fact that the interviewees in Milan tend to portray intergenerational solidarity as a family matter, a few interviewees have insisted on a broader socialisation of the risk of dependency. This is often used to explain the feeling that the burden of providing care on families is becoming unbearable. The combination of the responsibility of care of a dependent parent with one's own family responsibilities and other kinds of obligations, such as participation in the labour market, seems to destabilise the traditional support for an intergenerational contract within the family. Several interviewees in Milan thus reported stressful situations in which they insisted on a more collective sense of responsibility in providing support for the elderly.

The children of an old person in need of care cannot do everything. They cannot give up their jobs to take care of their parents. They cannot sacrifice their own families. This is not right. And I think more and more people are realising this (Mr. SE - case M2).

I love my mother and so does my sister. But this is not just a matter of love... we've been doing everything possible for her, but it is never enough. People like us need help. The elderly cannot solely be seen as the burden of their own children (Mrs. DD - case M32).

Similarly, a few interviewees expressed solidarity with those who cannot or do not take care of their elderly parents, in contrast with the generalised normative view of filial obligations.

In many cases, you hear about the elderly who do not have anybody because their children live too far away; or who have children who cannot help them. Imagine, if you're working, how can you manage to help your own mother? You have to work. I don't think we can blame it on the children. Some children just do not care, it is true. But in general I just think it has become very hard to combine everything (Mrs. SE - case M35). 
Further elements that may signal tensions between normative views and practice and the reconsideration of the limits of filial obligation are the opinions expressed by some about the future of elderly care. When they were referring to their own future care needs, current caregivers of elderly people tended to think that their own children would not provide them with the same kind of care and amount of support that they were providing their parents. Moreover, the interviewees appear much more pessimistic about the future and responses to their own care needs.

\begin{abstract}
My mother belongs to a generation that believed that children should do everything for their parents. And she is getting everything from me. But I know myself that this will not be the case between me and my daughter: I cannot expect her to do for me what I am doing for my mother. It is a different generation. I think we are the last generation of women doing this for our parents. The problem is that I just can't see what will come next (Mrs. LC - case Mi8).
\end{abstract}

These views contrast sharply with the traditional image of intergenerational solidarity in a family-based system and are symptomatic of a tension between established institutional rules, pressures determined by increasing needs, increasing resources in the hands of the caregivers and the perception that other possibilities exist. However, these tensions were not resolved via the development of social services but rather via a new and peculiar care market.

According to our analysis, the described development of a care market occurred under a set of conditions and motives, which include the reduced accessibility of informal resources, the availability of monetary resources and the compression of the costs of services. But it is the combination of the action of individuals and households (and of migrant care workers), on the one hand, and of different collective actors that can explain the emergence of the care market with these characteristics. The development of private care in Italy is responding to the needs and requests of all of the relevant actors involved. The underlying conflicts are either hidden or administrated within the private sphere between familyemployers and care workers.

Women are more involved in the provision of both informal and paid care, which means that these transformations should also be understood in terms of power relations between genders and within genders. First, the long-established gendered division of labour is likely to be affected by the changing modes of the organisation of care and by the new forms arising through intergenerational solidarities. Traditionally, the informal care work was almost exclusively carried out by women, but the (partial) commodification of care (Ungerson 1997) taking place in the familistic care model and the changing forms of intergenerational support are challenging the division of responsibilities and work between men and women. Among families that hired a paid worker to take care of an el- 
derly dependent, the fulfilment of filial obligations has become more a money and organisational matter than a matter of direct care provision. Cases involving care workers being hired after a period of direct provision of care by one or more members of the family highlight the potential change embedded in such a shift: as soon as paid care is at stake a broader concern of family members becomes evident. The shift from informal caregiving to some extent represents a turning point for the explicit involvement of men (partners and brothers) in decisions concerning care, as this woman indicated.

My brother was not doing much. He would come here and ask me about things. That was all. I have been the one taking care of everything since the beginning. But as soon as I said 'enough' we had to discuss what to do, where to find the person, how much to pay her. And we did it together (Mrs. TP - case M34).

Moreover, the new role played by women in organising and supervising care instead of offering direct care are more easily shared with male partners or brothers compared to direct care. Accordingly, several women report that they were sharing responsibilities with their husbands and brothers in terms of visiting and overseeing care provided by paid caregivers. Asking a male family member to perform bodily care was out of the question, but it was not unusual to ask them to make some of their time available to take care of organisational tasks. This is particularly evident when the occupational and family circumstances of the male and female members of the family are similar.

My brother stopped working a couple of years ago. We both live more or less in the same neighbourhood. The things I do, he can do as well. There is nothing difficult about coming here and taking a look. I must say that he is very cooperative (Mrs. DD. - case $\mathrm{M}_{32}$ ).

Organisational tasks are becoming more easily shared with male partners or brothers compared to direct care assistance, and the Milanese sample offered examples of a good number of sons who were involved in the management, financial and emotional support areas of elderly care. In other words, a new balance in the division of care responsibilities between men and women is not being achieved through the increasing involvement of men in caregiving, but rather through the decreasing involvement of women in direct care. The shift from informal care to commodified care entails a higher degree of shared responsibility for financing and organising responses to care needs.

Second, the shift from a care system dominated by informal support to a mix of informal and paid care is likely to have relevant implications on relations with a specific group of women: the migrant care workers. The issues of power and control that are crucial in the caregiving rela- 
tionship also arise in the relationships between former informal caregivers - now employers - and their employees. As previously shown, paid work has developed with little formal regulation and formalisation. This not only means that jobs in the care sector tend to be low paid and less protected, but also that tensions typically present in informal care tend to get reproduced within the employment relationship. Through the externalisation of care, tasks that family members previously did in an unpaid capacity show a tendency to create tensions, conflicts and power confrontations in the employee-employer relationship. Some of the conflicts over time and space, which often characterise the informal care relationship, are widely spread in employment relations. Many paid workers, as mentioned earlier, live with the elderly person they care for. Although this represents an advantage for foreign women working as elderly caregivers because they are provided safe and free housing, it does present some rigid constraints.

To summarise, families - and particularly the women in families - are also trying to redefine the terms of their obligations through the externalisation of care work and to redistribute the care burden. A similar redefinition crucially involves the role of paid workers, who, given the informal basis of their employment relation and their weak bargaining position, are likely to absorb part of the tensions previously managed within the informal care relation. The reduction of gender gaps in unpaid labour becomes possible through the creation of a new social stratification (of mainly women), which involves as a relevant source of social difference (Andall 2000; Parella Rubio 2000). However, care remains a family matter in the new care market system as it was in the past.

\subsubsection{The resilience of the formal care model}

The tensions observable in the case of Amsterdam are strikingly different. As previously shown, the general attitude of the Dutch interviewees attributes a crucial role to the collective social security system and to a level of independence among the elderly. On the other hand, the emotional and supportive role of the informal network was emphasised and equally important in fulfilling family intergenerational obligations. Nevertheless, in recent years there has been a shift in the public discourse over the distribution of responsibility between the family and the state in caring for elderly people, which emphasises the need for a redistribution of tasks between the individual, the family and civil society on one side and the state or collective arrangements on the other side.

The interviewees' accounts testify to the fact that there are signs of a reconsideration of the role of intra-family responsibilities in the care of elderly people. Some claim that how the care for the elderly people has been handled over the past few decades had exaggerated decreases in personal and family responsibility. 
I think we have gone too far in the past. At a certain point, our old parents' problem was not our problem anymore. We stuck them in a home for the elderly and that was it. I think a time for rethinking all this has come. A new point of equilibrium has to be sought. We need new ideas. And it is not easy because it means that everything is up for discussion (Mr. HH - case A29).

The (possible) revision of the traditional approach in the Netherlands questions not only the involvement of family members in the care of the elderly, but also the independence of the elderly themselves with respect to their relatives.

When they gave my father the notification [the evaluation of needs provided by the regional assessment board] they suggested that he try to spend some more time at home instead of going into a nursing home, he became very worried. He said he did not want to depend on us. He was afraid that staying at home meant demanding more help from his children and relatives. He is afraid that all this means going back to the past and I understand him. I have the same fear: I don't want to depend on my children when I am old but I do not want to be left without any help either (Mrs. FD - case A26).

Furthermore, key actors have noted that the integration of the ethnic minority elderly into the Dutch care system is one of the major challenges. This is a very traditional view of elderly care, which is quite similar to that expressed by elderly Italians and their children until a few years ago and are still expressed by the lower classes today.

My father would never enter a nursing home. It is not in his culture. $\mathrm{He}$ thinks the elderly should stay with their families and that they should take care of them. And to take him there would be impossible for us. It would be too much (Mrs. OI - case A35).

In this respect, the presence of elderly people with a migratory background represents both a challenge and support for the transformation of the Dutch care system at the same time. Although it may challenge the organisation of services, it may also facilitate discourses on the relevance of family responsibilities related to long-term care. Whereas the experience of the daughters of working-class, second-generation immigrants is strikingly similar to that of Italian daughters and shows a perceived normative contradiction between them and their parents, the availability of welfare solutions to care needs clearly distinguishes the two situations.

I know what my father thinks. He would like me and my sister to stay at home with him all day long. But I do have a job. And she has a family. Of course we do help out. But we can't be there all the time (Mrs. KK - case A34). 
Despite the existence of clear tensions, the Amsterdam/Dutch long-term care system appears to have undergone - at least until the early 2000 s few significant changes. The qualitative analysis confirms the centrality of the formal care system in providing care to elderly dependents. All of the key actors emphasise the deep changes that the supply system of elderly care and the access to the social insurance scheme are undergoing, but these changes have seemed to only have a very slight effect on the overall system.

Undoubtedly a market logic was introduced not long ago into the system that produces care in the Netherlands, as for-profit organisations have become a more common phenomenon than in the past. However, as we have seen, the logic of the market system has only affected the allocation of care resources to a very limited extent. Buying care in the market via out-of-pocket payments is a strategy restricted to a minority of particularly well-off families, and does not concern a large portion of the Dutch population. Moreover, even when responses to care needs are provided through market providers, public funding and regulations are crucial in granting the necessary resources.

Even for the interviewees who expressed sympathy for the idea of greater involvement among relatives in the care of the elderly, "more care" meant reinforced presence, emotional support and concern, rather than heavy direct care. It is clear from an informal care point of view, that there is little room for an increased involvement by the children of the elderly in care provision in Amsterdam, at least with respect to heavy care needs.

Social insurance remains an important national factor because all of the involved social actors at the local and national level are clearly interested in maintaining and further developing the system. This was particularly evident in the previous discussion of relations between individuals and families, the collective social actors at the local level and the care system's institutions. As we have shown, for-profit and non-profit providers in the domain of care for the elderly are very involved and interested in the development and consolidation of the collective longterm care scheme. They have recently campaigned to empower the users which contributed to shifting the balance of power between the care professionals and the users themselves, but they are nevertheless still embedded in a system based on the development of social insurance. They do play a generalised coordination role both in providing information to the public and in processing demands for formal care through the proper welfare institutions.

The consequences of the most recent developments in the Dutch care system could not be assessed by this study. This includes the impact of the 2007 reforms that decentralised the responsibility for social assistance and enlarged the scope of the role played by municipalities in providing social services still has to be assessed. Responsibility for some of the home care services - namely household assistance - shifted from the 
national long-term care insurance to the municipalities under the WMO (Social Support Act). At the same time, great emphasis has been put on self-responsibility and informal care before someone should turn to social services. This is different from in the past because this policy divides the functions that were previously integrated - home care and household assistance - and makes a distinction between the universal and national long-term care system and decentralised and territorially diverse social-assistance-based arrangements. The actual consequences this will have on the opportunity structures of individuals and households, the constellation of relevant social actors and on the ways care is arranged are still open to further investigation. 


\section{Conclusions}

The idea when we began this research study was that the configurations and transformations of care systems cannot be understood by only looking at developments in social policy. While social policy and the changes it undergoes play a crucial role in structuring care systems, they also allow enough space for social - individual and collective - actors to construct their strategies and, ultimately, to contribute to the transformation of the care system itself. Comparing the trajectories of Italy and the Netherlands was empirically interesting and served as an opportunity to explore this working hypothesis. The two cases were chosen as paradigmatic contrasting models of social policy in the domain of care for the elderly undergoing different trajectories since the early I990s. The research presented has highlighted the policy context and directions taken by the two societies, the incidence and evolution of dependence as a problem, the transformations of care packages over time together with how they are constructed as a way of signalling the logic of transformation and stasis embedded in each system.

\section{I The Dutch resilience and the Italian shift}

Since the late I960s, the Netherlands has been endowed with a national collective insurance that covers the costs of long-term care. This scheme - mainly through cash transfers to care providers - has long represented inclusive and universal protection against dependence and reduced individual and family responsibility regarding care. By contrast, Italy had no coherent long-term care policy with territorially fragmented services scarcely available next to a national care allowance for the very dependent among the elderly. Family (financial and care) responsibilities, instead of being supported have been taken for granted by social policies (Saraceno 2003), and have long been the cornerstone of elderly care.

\subsubsection{The context and the problem}

Since the early I990s, new policies in the Netherlands were aimed at reducing the costs of an increasingly expensive long-term care scheme and at empowering care users. Users were made more responsible for their own care, but they were also given more choice and power in their relationships with various care professionals. These policies encompassed deinstitutionalisation, recourse to consumers' choice schemes 
(the "personal budget"), the introduction of competition between care providers, and an increase in the monetary contribution of the users to the costs of services. These innovations represented a serious challenge to the consolidated formal care system, as they questioned universalism and equality, fostered the re-familisation and/or marketisation of care (Knijn 200I). By contrast, no relevant policy changes emerged in Italy (Naldini and Saraceno 2008; Da Roit et al. 2007), despite recent debate in the domain of long-term care that produced, at most, only scattered and inconsistent innovations at the local and regional levels (Da Roit 2009). To summarise, if we look at the policy trajectories of the two countries, we have a case (the Netherlands) of a traditionally strong social welfare system that is undergoing retrenchment and a traditionally familised system with consistent residual policies.

However, the picture changes considerably if, instead of considering the care policy trajectories, we look at the trajectories of the two care systems - defined as stable combinations of different agents of welfare that prevail in providing support to individuals and families exposed to the risk of dependence. In fact, the empirical analysis presented in the book shows few transformations in the Netherlands, while highlighting a major shift in Italy.

\subsubsection{The two care system's trajectories}

The analysis of dependence among the elderly and households (chapter three) shows that in the early I990s, there was a much higher incidence in Italy than in the Netherlands, due both to the demographic and social structures of the older populations and to the traditionally limited availability of residential care services in Italy. However, in the early $2000 \mathrm{~s}$ there were some signs of convergence. In the Dutch case, particularly in the first half of the 2000s, we observed an increasing incidence of dependence among the elderly living at home, which was also a result of the deinstitutionalisation process. The effects of the reduction of the number of beds in care homes was initially (in the I980s and I990s) mitigated by the possibility of giving residential care to the needier among the elderly compared to the past and, as a consequence, the proportion of dependent and severely dependent among the elderly living independently increased very slowly until recently. A sharper increase in the needs of the population living at home was observed since the early $2000 \mathrm{~s}$. By contrast, during the period considered the proportion of (severely) dependent the elderly on the older population living at home in Italy declined slightly even though the ratio between the older dependent population and the adult population did not. However, this process was uneven geographically: the northern regions, in part due to the transformation of the existing stock of residential care facilities, showed a considerable reduction in the incidence of elderly people living at home between 1994 and 2004, while the this was not the case in central and 
southern Italy. To summarise, while dependence among the elderly living at home was a more widespread problem in Italy in the early I990s, it did not exert an increasing pressure throughout the i990s (the northern regions, in particular, showed increases in the proportion of autonomous people among the elderly living at home). By contrast, it is possible to observe the increasing pressure of care needs among people living independently in the Netherlands.

Against this background, the results of the quantitative investigation of care packages (chapter four) suggest that, while in the Netherlands the traditional formal care model persists, in Italy considerable transformations of the system have occurred between the early I990s and the early 2000 s. In the Netherlands, the analysis does not support the hypothesis of the re-familisation or marketisation of elderly care. There was neither an increase in informal care (which, in fact, decreased) nor a considerable increase in commercial care (except, perhaps, for household assistance). If some tensions were detected in the area of formal care - a slightly decreasing coverage rate of formal services for more severely dependent elderly people and for personal care - social services did not lose their essential importance as a source of support for older dependents. The qualitative study (chapter five) shows that, in Amsterdam, formal care remained the key resource for responding to the needs of elderly care, while both informal and commercial support played a complementary role and did not represent relevant "packages".

In Italy, as revealed by the quantitative analysis of care packages (chapter four), the use of formal services among households with an elderly dependent remained limited between the early I990s and the first half of the 2000s, confirming the persistence of a residual social care model. However, and in the absence of any explicit policy in this direction, the proportion of households with older dependents utilising commercial services became relevant, matching the decreasing availability of informal care. The data suggest that a considerable shift towards market solutions took place in Italy, confirming that the emergence of the migrant care market observed in the later years of our study was not a residual phenomenon, but a keystone of a substantially altered care system. At the end of the I990s, paid care emerged as a primary source of support in Italy, not only for home assistance, but above all for help with personal care. The qualitative analysis of care packages (chapter five) gives substance to these findings. In Milan, a mix of informal and paid care is the most relevant care package among households with elderly dependents. This combination of market and family resources takes place via the development of care arrangements based on migrant care workers. Private care purchased by Milanese households consisted almost exclusively of the direct employment of migrant care workers, mostly in the grey market and often undocumented, confirming the results of several studies conducted in local Italian contexts over the past few years (Castegnaro 2002; Da Roit and Castegnaro 2004; Gori and Da Roit 2002; Caponio 
and Colombo 2005; Colombo and Sciortino 2005; Mesini et al. 2006). The continuity of this new care arrangement with the past resides in the fact that care remains largely a family responsibility, even if the "production" of care has been (partly) externalised to a peculiar care market.

\subsection{Explaining change and resilience}

A micro-level of analysis of how the care packages are constructed in Milan and Amsterdam, looks at the actors that are mobilised in each context, at their orientation and interactions. We made an attempt to reconstruct the different logics that underpin the system shift in Italy and the system's persistence in the case of the Netherlands (chapter six). The two cases studied provide examples of both a policy-driven change that produced a limited impact, at least for the time being, and a situation of relative policy stability associated with a considerable shift in care arrangements. In both cases, it is possible to understand the trajectories of the two societies only by considering the role played by the relevant social actors within a set of opportunities and constraints defined by the institutional setting.

\subsubsection{The role of organisations and families in the Netherlands}

In the Netherlands, our qualitative analysis suggests that the effects of the reforms implemented since the early I990s had a limited ability to induce change in how care packages are produced. Despite all of the policy changes, access to care services remained a universal individual right uniquely based on need. Moreover, if out-of-pocket co-payments for services increased, they did not involve the extended family. These two elements are crucial in defining the stakes of elderly care and the actors involved in making decisions with respect to care arrangements. The reciprocal independence between the elderly and their relatives (namely children) that these two elements ensure in the Netherlands emerges very clearly from our qualitative materials and remains a keystone of the Dutch care system thus far. The provision of social services, besides being partly marketised from the production point of view, remains the main point of reference for the elderly and their informal caregivers and is still widely available. Our results underpin the hypothesis that the Dutch welfare state, also in the care sector, has undergone a "managed liberalisation" (Van der Veen and Trommel I999) - the partial privatisation of the administration of social security within the framework of stronger state control - while "the state is still taking responsibility for a sufficient production of welfare" (ibid.: 308). However, if this persistence of the formal care model was the result of the limited ability (or willingness) of policymakers to produce drastic reforms and of difficult policy retrenchment (Pierson 1996; Clayton and Pontusson 1998; 
Green-Pedersen 200I; Ferrera I998), it was also partly produced, as shown by our analysis, by the resistance exerted by relevant individual and collective actors to the transformation of care practices.

For their part, the relatives (namely the children) of the elderly do acknowledge an increasing pressure towards the familisation of care, and more responsibilities regarding the care of the elderly. However - given the possibilities currently offered by existing care arrangements - the family members (particularly the children) of the elderly are not keen on becoming more involved in intensive caregiving. Even the interviewees who expressed sympathy with the idea of the increased involvement of relatives in the care for the elderly referred to this as a reinforced presence, emotional support and concern, rather than more involvement in heavy direct care.

A set of collective actors active within the functioning of the care system contribute in the channelling of this standpoint. Long-term care insurance is a consolidated national stake and all of the involved social actors at the local and national levels are clearly interested in maintaining and developing the system. As the qualitative analysis has shown, for-profit and non-profit providers in the domain of care for the elderly are very involved and interested in the development and consolidation of the long-term care scheme. If they have in recent years campaigned to empower the users and contributed to changing the balance of power between the care professionals and the users themselves, they are nevertheless embedded in socio-economic stakes related to the development of social welfare insurance. They also play a general coordination role both in providing information to the public and in processing the demands for formal care through the welfare institutions.

It is worth noticing that the most recent policy reform introduced in the Netherlands - the Social Support Act, WMO, which became law in January 2007 (the effects of which could not be included in this study) is likely to represent a critical challenge for the system precisely from this point of view. The reform is based on the disintegration of the national insurance system and on the shift of the responsibility for part of the long-term care policies to the municipalities. However, the effects are far from clear at this moment.

\subsubsection{The role of organisations and families in Italy}

In the Italian case, the market shift can only be understood when we consider the institutional context along with the effects produced by the interaction of the relevant actors in the field. There are several institutional features of the Italian context that might explain the expansion of the market: the importance of monetary allowances instead of services in social policy, the preference of care at home, the existence of a widespread and socially accepted underground economy, the traditional importance of domestic work in Italy and the concentration of migrants in 
this sector. The combination of a relative abundance of cash resources and the low cost of services are no doubt key factors in the development of the Italian care market. Italy's quite generous pension system, together with the availability of care allowances - these being the most important form of support provided by social policies and which are usually used to supplement overall household income - are probably partly responsible for the development of a care market, as they make it easier to purchase care. On the other hand, the loose regulation of migration and the labour market made it possible to create a low paid and under-regulated care market based on immigration. In fact, the Italian market shift is barely comprehensible without considering these institutional conditions: the migrant care model could only have developed within the framework of a low-cost and loosely regulated care and domestic services labour market. However, it should be acknowledged that the use of monetary support for older dependents dates back to the midI98os period and that the informal labour market regulations are a traditional feature of the Italian social system, while the development of the private care market did not occur until the second half of the I99os. In other words, it must be explained why and under which conditions the link between cash allowances and family care has switched to a link between cash allowances and market care.

The current outcome was not the only viable one. One could imagine at least two alternatives: the families might have continued to care for the elderly (more than they do now) and internalise the economic resources that social policies distribute to the dependent elderly; or an organised social demand for more inclusive social services in the domain of long term-care could have emerged. Only when we consider the strategies of families and other relevant social actors in the field can we begin to understand its development. The Italian solution - accompanied by the lack of claims for new and more comprehensive social policies in the field of long-term care - involves the decreasing availability of families (daughters mainly) to provide direct care and the externalisation of these tasks to paid domestic workers.

As noted in chapter six, the externalisation of elderly care in Italy may be interpreted as a strategy enacted by (part of) a given generation of daughters of elderly dependents endowed with more socio-economic resources than in the past and a favourable context that allows and fosters the development of a relatively cheap care market. The role of the middle classes is an important reference point for understanding these developments in the family care system. While better-off households have enough resources to respond to care needs in a (for them) traditional way while lower socio-economic groups do not have enough resources to voice and question, it is the middle-class offspring (namely the daughters) who take care of the elderly, which has become a heavy and "unreasonable" burden. It is worth emphasising that women at the centre of this transformation belong to a specific generation that is clearly more 
endowed with resources than the previous ones and that benefits from a greater degree of freedom in the defining of its position in care relations. The daughters of elderly dependents today are between 50 to 65 years old and were thus born in the I940s. Besides considerable changes in views concerning gender roles, they also benefit from consistent economic resources. Moreover, their desire to reduce their care burden was coupled with the availability of cheap labour, organised and sustained by specific social actors.

On the other hand, localised social actors - various organisations, public authorities and their professionals - sustained and encouraged these developments by facilitating the encounter between the supply and demand of care and/or by legitimising these new practices, instead of voicing an emerging social demand. Besides working through informal networks, the interaction of the supply and demand of care work takes place through the mediation of voluntary and other not-for-profit organisations on a more informal basis. The social regulation of care work involves third sector organisation and, to some extent, formal services. The development of the care market has been recognised and subsequently encouraged by formal services. In several local contexts, new projects for the inclusion of private care in the network of publicly organised services have recently been launched (Mesini et al 2006; Da Roit and Castegnaro 2004). These projects usually include the provision of training for care workers; initiatives aimed at favouring the encounter between the supply and demand of services; the creation of registers of accredited (and reliable) care workers for the families. However, these projects usually suffer from a contradiction; it is said that their chief aim is the qualification and regularisation of care work while, the regularisation and qualification of care work should take place with no additional resources and without changing the working arrangements that characterise the care work in the grey and unregulated market. If the chances of success of these experiences in regularising and qualifying this market are limited, they do play a role in legitimising the care market. In a way, the emergence of the private care market has undergone a rapid process of institutionalisation. The Italian case thus represents an interesting example of bottom-up transformation that has radically altered the care system and led to the subsequent institutionalisation of new modes of production and allocation of care.

\subsubsection{Actors within institutions}

Our observations emphasise the importance of social policies and the broader institutional framework in structuring the risk of dependence in old age, in defining responses to care needs of older dependent people and in making room for innovation or in fostering conservation. The institutional context is clearly a powerful factor that structures the risk of dependence in old age, contributes to defining how many and who 
the older dependents are who live in institutions and at home, structures the system of (perceived) opportunities for actors both at the micro- and meso-level, and defines the stakes and the players. The (perceived) availability of resources not only conditions choices in care packaging, but also frames the problem, defines the who, when and how that are involved and profiles the possible outcomes. The possibility of finding innovative solutions are limited and guided by the institutional framework. The possibility of placing the costs of the production of care on a low paid and little protected labour force considerably depends on the institutional context in which such developments are embedded. The type of solution "invented" in Italy involving paid care provided by migrant workers would not be very viable in the Dutch context where the "discharging" of costs onto the care labour market is severely limited by existing regulations of care work and employment regulations in this sector, together with the way cash allowances for the dependents are designed. Nevertheless, a perspective uniquely based on the influence of institutions would not account for the transformations that have occurred since the I990s, neither in Italy, nor in the Netherlands.

The qualitative study has emphasised the key role played by the organisations that are found at an intermediate level between individuals and families, on the one hand, and the political institutions, on the other. It is these organisations that are in a position to transmit and contribute to reproducing social norms and institutional features in the creation of care packages at the individual level and, at the same time, to channel (or not) social demands toward the policy level or to find alternative solutions to care needs. The specific way in which they act is influenced by the institutional configuration, by social instances and by their own interests and orientation. We have shown how their strategies greatly depend on the existing institutional framework and on the resources on which they can effectively count.

Finally, families - and each family member - emerge as an important independent variable that contributes to making sense of the observed transformations. Changes in strategies are not simply a reaction to tensions and to challenges posed by the increasing importance of dependence in old age, but also the result of explicit choices that matter greatly in defining a system's trajectory. 


\section{Appendices}

\section{Appendix I}

Data and methods of the quantitative analysis

\section{A.1.1 Dutch and Italian data}

For the quantitative part of this study we used two large surveys based on national representative samples. For the Dutch case, the study is based on the Aanvullend voorzieningengebruik onderzoek (AVO) (Amenities and Services Utilisation Survey), which was repeated in I99I, I999 and 2003 (AVO9I, AVO99, AVO03). For the Italian case, the study uses the ISTAT Multiscopo - Indagine sulle condizioni di salute (Multipurpose survey Health conditions), which was repeated in 1994, I999-2000 and 20042005. Therefore, the reference year for the early I990s in the Netherlands is I99I, while in Italy it is I994. The reference year for the late I990 in the Netherlands is 1999 and in Italy it is $1999-2000$. The reference year for the early 2000 s in the Netherlands is 2003 , while in Italy it is $2004-2005$.

Both surveys collected information on households and individuals within households. The Dutch samples are smaller. Moreover, the Consalog and Consalo4 provide an exceptionally high number of cases (table Ar.I)

Table A1.1 Number cases (at the individual and family level): older individuals aged $65+$ and households with at least one older individual

\begin{tabular}{lll}
\hline & Individuals & Households \\
\hline AVO91 & 1514 & 1116 \\
AVO99 & 2029 & 1506 \\
AVOo3 & 2132 & 1557 \\
Consal94 & 9168 & 7391 \\
Consal99 & 25301 & 18911 \\
Consalo4 & 25183 & 18628 \\
\hline
\end{tabular}

\section{A.1.2 Operationalisation of dependence in old age}

Dependence in old age was operationalised as the partial or total inability of individuals aged 65 or above to autonomously carry out a set of basic activities of daily living (ADLs). The selected surveys provide information on a set of functionalities that are comparable between the two countries and across time, despite a few differences with respect to the 
Table A1.2 Operationalisation of dependence. Original and created variables

\begin{tabular}{|c|c|c|c|}
\hline Item n. & Function & AVO91; AVO99; AVOo3 & Consal94; Consal99; Consalo3 \\
\hline 1 & $\begin{array}{l}\text { Sit down and get up } \\
(\min 0, \max 2)\end{array}$ & $\begin{array}{l}\text { Sit down and get up } \\
\text { - } \text { with no difficulty }=0 \\
\text { - } \text { with difficulty }=1 \\
\text { - only with help }=2\end{array}$ & $\begin{array}{l}\text { Sit down and get up } \\
\text { - } \text { with no difficulty }=0 \\
\text { - } \text { with difficulty }=1 \\
\text { - only with help }=2\end{array}$ \\
\hline 2 & $\begin{array}{l}\text { Getting in and out of bed } \\
\text { ( } \min 0, \max 2)\end{array}$ & $\begin{array}{l}\text { Getting in and out of bed } \\
\text { - with no difficulty }=0 \\
\text { - with difficulty }=1 \\
\text { - only with help }=2\end{array}$ & $\begin{array}{l}\text { Getting in and out of bed } \\
\text { - } \text { with no difficulty }=0 \\
\text { - } \text { with difficulty }=1 \\
\text { - only with help }=2\end{array}$ \\
\hline 3 & $\begin{array}{l}\text { Dressing } \\
(\min 0, \max 2)\end{array}$ & $\begin{array}{l}\text { Dress and undress } \\
\text { - } \text { with no difficulty }=0 \\
\text { - } \text { with difficulty }=1 \\
\text { - only with help }=2\end{array}$ & $\begin{array}{l}\text { Dress } \\
\text { - } \text { with no difficulty }=0 \\
\text { - } \text { with difficulty }=1 \\
\text { - only with help }=2\end{array}$ \\
\hline 4 & $\begin{array}{l}\text { Going up and down the stairs } \\
(\min 0, \max 2)\end{array}$ & $\begin{array}{l}\text { Going up and down the stairs } \\
\text { - } \text { with no difficulty }=0 \\
\text { - } \text { with difficulty }=1 \\
\text { - only with help }=2\end{array}$ & $\begin{array}{l}\text { Going up and down the stairs } \\
\text { - } \text { with no difficulty }=0 \\
\text { - } \text { with little difficulties }=1 \\
\text { - } \text { with many difficulties }=2 \\
\text { - totally unable }=2\end{array}$ \\
\hline 5 & $\begin{array}{l}\text { Washing (limited) } \\
(\min 0, \max 2)\end{array}$ & $\begin{array}{l}\text { Washing face } \\
\text { - } \text { with no difficulty }=0 \\
\text { - } \text { with difficulty }=1 \\
\text { - only with help }=2\end{array}$ & $\begin{array}{l}\text { Washing hands (and face 99;04) } \\
\text { - with no difficulty }=0 \\
\text { - with difficulty }=1 \\
\text { - only with help }=2\end{array}$ \\
\hline 6 & $\begin{array}{l}\text { Washing (extended) } \\
(\min 0, \max 2)\end{array}$ & $\begin{array}{l}\text { Washing body } \\
\text { - } \text { with no difficulty }=0 \\
\text { - } \text { with difficulty }=1 \\
\text { - only with help }=2\end{array}$ & $\begin{array}{l}\text { Bathe (or shower: } 99,03 \text { ) } \\
\text { - with no difficulty }=0 \\
\text { - with difficulty }=1 \\
\text { - only with help }=2\end{array}$ \\
\hline 7 & $\begin{array}{l}\text { In-house mobility } \\
(\min 0, \max 2)\end{array}$ & $\begin{array}{l}\text { Moving inside the house } \\
\text { - with no difficulty }=0 \\
\text { - } \text { with difficulty }=1 \\
\text { - only with help }=2\end{array}$ & $\begin{array}{l}\text { Confined in bed or on a chair } \\
- \text { Not confined }=0 \\
\text { - Confined }=2\end{array}$ \\
\hline 8 & $\begin{array}{l}\text { Out-of-house mobility } \\
(\min 0, \max 2)\end{array}$ & $\begin{array}{l}\text { Moving outside the house } \\
\text { - } \text { with no difficulty }=0 \\
\text { - } \text { with difficulty }=1 \\
\text { - only with help }=2\end{array}$ & $\begin{array}{l}\text { Confined in the house } \\
- \text { Not confined }=0 \\
\text { - Confined }=2\end{array}$ \\
\hline 9 & $\begin{array}{l}\text { Long-distance mobility } \\
(\min 0, \max 2)\end{array}$ & $\begin{array}{l}\text { Walk } 10 \text { minutes } \\
\text { - } \text { with no difficulty }=0 \\
\text { - } \text { with difficulty }=1 \\
\text { - only with help }=2\end{array}$ & $\begin{array}{l}\text { Longest distance that can } \\
\text { be walked without stopping } \\
\text { - } 200 \text { meters or more }=0 \\
\text { - less than } 200 \text { meters }=1 \\
\text { - only a few steps }=2\end{array}$ \\
\hline
\end{tabular}

definitions of the variables. Table Ar.2 provides a list of the nine items used to compute dependence at the individual level, together with the original variables extracted from the six original datasets. Each item has a score between zero and two: "o" corresponds to complete autonomy in 
a given functionality; "I" corresponds to limited dependence; " 2 " corresponds to full dependence. The way in which the score is calculated starting from the original variables is highlighted in the corresponding cell.

Each individual aged 65 or over has been given a score that is represented by the sum of the scores for each item. Individuals scoring $\circ$ have been classified as "non-dependent'; individuals scoring between one and two have been classified as "moderately dependent"; individuals scoring three or more have been classified as "severely dependent".

For each household, the score of the household members has been added up to derive a "household dependence score". Households scoring - have been classified as "dependence-free households" (as no older member of the household has any form of dependence); households scoring between one and three have been classified as "moderately dependent households" (one household member has a dependence level of up to three or two or more members of the households have dependence levels that total three); households scoring four or above have been classified as "severely dependent households" (one household member with a dependence level above three or more household members have dependence levels that together total at least four). It should therefore be noted that the household dependence level neither takes into account the household's composition, nor whether the dependence strongly affects one household member in particular or if it is more diffused among the household members.

The analyses were carried out in chapter three both at the individual and household levels. First, the incidence and distribution of disability among individuals was analysed. Second, a similar analysis was conducted at the household level to investigate the incidence and distribution of disability among households according to their characteristics.

\section{A.1.3 Operationalisation of different sources of support and care packages}

The selected datasets provide relevant information on the available sources of support for elderly dependents. In general, the Dutch datasets provide a more complete and coherent set of variables: the questionnaires from all of the studied years include consistent questions regarding the different sources of support received at the household level both with respect to personal care, nursing and help with household activities. By contrast, in the Italian case, the construction of care packages was more difficult because of limited access to information.

Information regarding informal help was only available for the Netherlands. In all of the involved years it is possible to analyse informal support received by households from different members of the informal network: household members, other relatives, friends, neighbours, and volunteers. Similar information was not available for Italy for our survey, 
while another survey ("ISTAT -Survey on social networks and childhood conditions" I99 $8^{\mathrm{I}}$ ) provides information on informal help received from non-household members only. Nevertheless, this survey does not contain information relative to disabilities and did not therefore suit comparability criteria. Therefore, for the analysis of informal support we referred to published aggregated data for households with elderly members based on several comparable surveys (ISTAT I994; 200I; 2006c; Sabbadini 2002).

Information relative to formal help was available for both countries in each year. While in the Dutch case it is possible to distinguish between help in the areas of personal care and household assistance as supplied by social services, this was not the case in the Italian datasets, where the only question on the questionnaire was about the types of assistance. In the Dutch dataset, moreover, the variable is at a household level and represents the support provided by formal services to the household as a whole. By contrast, in the Italian datasets relative to 1994 and I999, the same variable was collected at the individual level. For comparison purposes, this individual-level variable has been transformed into a household level variable, which represents the presence of at least one household member receiving formal assistance. The Italian 2003 survey encompasses two household-level variables that have been used to calculate a new household level variable representing the use of formal services.

Finally, variables relative to commercial care were present in all of the years in the Dutch datasets and only in the second and third year of the Italian figures. In both cases, a distinction was made between commercial assistance received by the household for personal care, and for household tasks. The variable "commercial household assistance" is defined differently in $\mathrm{AVO}_{9 \mathrm{I}}$ and in $\mathrm{AVO}_{99}$ than in the $\mathrm{AVO}_{3}$. In the first and second years, the interviewees were asked if their household received household assistance and, subsequently, if this assistance was linked to specific care needs of household members. The question of whether the household received household assistance as a consequence of specific care needs of household members was only asked in the third year. There is therefore a break in the series between 1999 and 2003. In the Italian case, two specific questions were asked at the household level: whether there was a paid home assistant in the household and whether there is a paid care worker in the household.

The time reference in the variables used to analyse the different sources of support and care packages differ between the two countries. In the Netherlands, the interviewees were asked whether their household received specific forms of support on a constant basis in the twelve months prior to the interview. In Italy, with respect to formal care in I994 and I999, the time frame was three months. In all of the other cases, interviewees were asked whether their households were receiving assistance at the time of the interview. 
Table Ar.3 summarises the way in which formal, informal and commercial care has been operationalised on the basis of the original variables contained in the six surveys.

Table A1.3 Operationalisation of formal, informal and commercial support. Original and created variables

\begin{tabular}{|c|c|c|c|c|}
\hline \multirow[t]{2}{*}{ Created variables } & \multicolumn{4}{|c|}{ Original variables } \\
\hline & AVO91 - AVO99 - AVOO4 & Consal94 & Consalg9 & Consalo4 \\
\hline $\begin{array}{l}\text { Informal care for per- } \\
\text { sonal care }\end{array}$ & $\begin{array}{l}\text { Help in personal care and nursing } \\
\text { received by the household on a } \\
\text { regular basis in the past twelve } \\
\text { months from members of house- } \\
\text { hold, non-co-resident relatives, } \\
\text { friends, neighbours, volunteers, } \\
\text { others (available separately) }\end{array}$ & $\begin{array}{l}\text { n.a. } \\
\text { (reference is } \\
\text { made to ISTAT } \\
\text { 1994; ISTAT } \\
\text { 2001; Sabbadini } \\
\text { 2001) }\end{array}$ & $\begin{array}{l}\text { n.a. } \\
\text { (reference is } \\
\text { made to ISTAT } \\
\text { 1994; ISTAT } \\
\text { 2001; Sabbadini } \\
\text { 2001;) }\end{array}$ & $\begin{array}{l}\text { n.a. } \\
\text { (reference is } \\
\text { made to Istat } \\
2006 \text { c) }\end{array}$ \\
\hline $\begin{array}{l}\text { Informal care for } \\
\text { household assistance }\end{array}$ & $\begin{array}{l}\text { Household assistance received by the } \\
\text { household on a regular basis in the } \\
\text { past twelve months from members of } \\
\text { household, non-co-resident relatives, } \\
\text { friends, neighbours, volunteers } \\
\text { (available separately) }\end{array}$ & & & \\
\hline $\begin{array}{l}\text { Formal care for per- } \\
\text { sonal care }\end{array}$ & $\begin{array}{l}\text { Help in personal care and nursing } \\
\text { received by the household on a } \\
\text { regular basis in the past twelve } \\
\text { months from nursing and home care } \\
\text { services }\end{array}$ & $\begin{array}{l}\text { Help received by } \\
\text { at least one } \\
\text { member of the } \\
\text { household from } \\
\text { home care ser- } \\
\text { vices in last four } \\
\text { months }\end{array}$ & $\begin{array}{l}\text { Help received by } \\
\text { at least one } \\
\text { member of the } \\
\text { household from } \\
\text { home care ser- } \\
\text { vices in last four } \\
\text { months }\end{array}$ & $\begin{array}{l}\text { a) the household } \\
\text { receives care } \\
\text { services from } \\
\text { the municipality } \\
\text { or the health } \\
\text { services } \\
\text { b) the house- } \\
\text { hold receives } \\
\text { care services } \\
\text { from the munici- } \\
\text { pality or the } \\
\text { health care ser- } \\
\text { vices }\end{array}$ \\
\hline $\begin{array}{l}\text { Formal care for } \\
\text { household assistance }\end{array}$ & $\begin{array}{l}\text { Household assistance received by the } \\
\text { household on a regular basis in the } \\
\text { past twelve months from home care } \\
\text { services }\end{array}$ & & & \\
\hline $\begin{array}{l}\text { Commercial care for } \\
\text { personal care }\end{array}$ & $\begin{array}{l}\text { Help in personal care and nursing } \\
\text { received on a regular basis in the past } \\
\text { twelve months by the household } \\
\text { from commercial nursing and care } \\
\text { services }\end{array}$ & n.a. & $\begin{array}{l}\text { Presence of a } \\
\text { paid carer for } \\
\text { elderly or handi- } \\
\text { capped member } \\
\text { of the household }\end{array}$ & $\begin{array}{l}\text { Presence of a } \\
\text { paid carer for } \\
\text { elderly or handi- } \\
\text { capped member } \\
\text { of the household }\end{array}$ \\
\hline
\end{tabular}


Table A1.3 Continued

\begin{tabular}{|c|c|c|c|c|}
\hline \multirow[t]{2}{*}{ Created variables } & \multicolumn{4}{|c|}{ Original variables } \\
\hline & AVO91 - AVO99 - AVOO4 & Consal94 & Consalg9 & Consalo4 \\
\hline $\begin{array}{l}\text { Commercial care for } \\
\text { household assistance }\end{array}$ & $\begin{array}{l}\text { Help in personal care received by the } \\
\text { household on a regular basis in the } \\
\text { past twelve months from commercial } \\
\text { home care services. } \\
\text { AVO9ı and AVOg9: distinction is } \\
\text { made between help received in rela- } \\
\text { tion to specific health problems and } \\
\text { disabilities and other type of help. } \\
\text { AVOg9: only help received in relation } \\
\text { to specific health problems and dis- } \\
\text { abilities is considered. }\end{array}$ & $\begin{array}{l}\text { Presence of a } \\
\text { paid home help- } \\
\text { er in the house- } \\
\text { hold }\end{array}$ & $\begin{array}{l}\text { Presence of a } \\
\text { paid home help- } \\
\text { er in the house- } \\
\text { hold }\end{array}$ & \\
\hline
\end{tabular}

The available data highlight a set of general obstacles in applying a welfare-package approach to the study of care needs and responses to care needs, when using secondary data analysis. First, given the previously illustrated limitations of available data, the analysis has been carried out by comparing the presence of different kinds of support in the two countries over different points in time. Subsequently, when possible, the combination of different types of cases has been observed. Given these above-mentioned limitations, the analysis proceeds first to an observation of the different sources of support separately. It then looks at the combination of different sources of support whenever possible.

It should also be emphasised that the operationalisation of care packages reflects the traditional division between informal, formal and commercial support on the supply side, while it provides no information on the financing side. For instance, it is difficult to say whether commercial services were paid by public funds or not. In the Netherlands where, for instance, the most recent survey specifies that informal care provided by a relative on the basis of a personal budget is designated as informal care - this should not be a major problem since care allowances were still developing in 1999 and 2003. As for Italy, the problem mainly concerns the Indennità di accompagnamento and (to a lesser extent) other care allowances in relation to access to paid care. This represents a relevant problem in studying welfare packages, which should be tackled especially in the future, when the spread of mixed forms of financing and provision of services is likely to increase.

Because care resources and care packages are or have been constructed as household-level variables, the analysis in chapter four was conducted at the household level. 


\section{A.1.4 Control variables}

Besides the descriptive analyses, which identify trends over time in the incidence and distribution of dependence and of specific care resources and care packages, logistic regression models were also used to define factors affecting disability and recourse to different care solutions.

A relevant problem relates to the individuation of pertinent variables as indicators of social inequalities. The usual variables used for discriminating between social groups are profession, education and income. Nevertheless, several problems had to be addressed, either due to the structure of the datasets or in relation to specificities of the population observed. As all of the datasets provided information on the educational level, this variable has been used as an indicator of socio-economic inequalities throughout analysis. Nevertheless, two problems emerged in this respect. First, there is a substantial level of difficulty comparing educational levels in the Netherlands and in Italy. Second, a high concentration of cases in the lower educational group among the elderly might affect results and reduce the discriminating power of the variable. As for information about income, only the Dutch dataset contained appropriate variables. By contrast, Italian data provided only a self-evaluation of the economic condition of the household made by the person of reference. Despite the non-comparability of these two types of variables, they were included in the models. Finally, professional categories could not be used in the analysis for several reasons. The Italian questionnaires did not include this information, while the Dutch ones did. Nevertheless, its use was seriously undermined, particularly due to the characteristics of the respondents and their positions with respect to the labour market. When interviewees declared they were currently unemployed, as was the case with the pensioners, of course, they were asked to declare their last occupations. This solved the bulk of the problem regarding male respondents, but it did not among the females where the proportion employed prior to retirement age was limited. This problem was often dealt with by noting the husbands' occupation instead. Despite the limitations and criticisms embedded in a similar procedure, as we are specifically dealing with older women, among whom there is a relevant percentage of widows, the viability of this solution is limited.

The dependent variable used in chapter three is dependence at the individual level. The independent variables used are age, gender and educational level for both countries and regional areas for Italy.

The dependent variables used in chapter four are formal, informal, commercial care at the household level. The independent variables are age, gender and educational level of the head of household, type of household, level of dependence of the household and, for Italy, regional areas. 


\section{Appendix 2}

Tables not included in the text - chapter 3

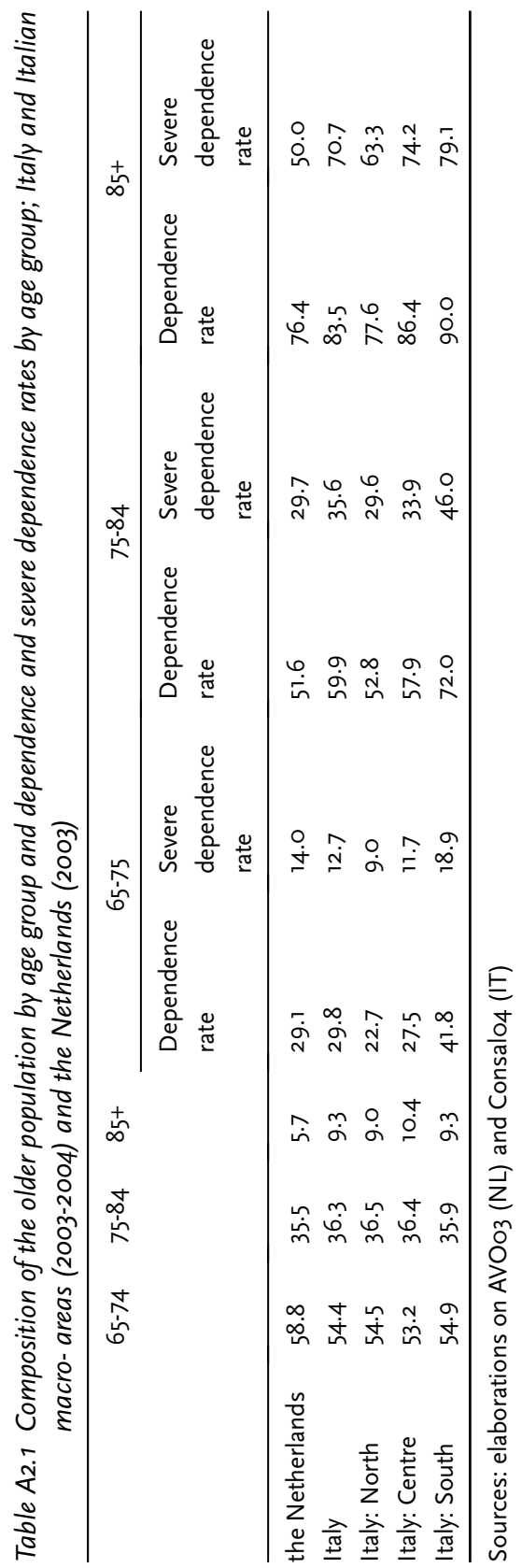


Table A2.2 Educational level (*) of the population living at home by age group; the Netherlands (2003); Italy (2004)

\begin{tabular}{lllllll}
\hline & \multicolumn{3}{c}{ The Netherlands } & \multicolumn{3}{c}{ Italy } \\
\cline { 2 - 7 } & Low & Medium & High & Low & Medium & High \\
\hline $35-54$ & 9.1 & 63.6 & 27.3 & 51.0 & 36.5 & 12.5 \\
$55-64$ & 16.6 & 61.9 & 21.5 & 70.4 & 21.1 & 8.5 \\
$65-74$ & 32.0 & 55.0 & 13.0 & 83.3 & 12.2 & 4.5 \\
$75+$ & 45.2 & 44.3 & 10.5 & 88.8 & 7.8 & 3.4 \\
\hline
\end{tabular}

Sources: elaborations on AVOo3; Consalo4

(*) Low: up to primary school; Medium: three to five years high school; High: university degree

Table A2.3 Educational level of the elderly population living at home by age group; Italian macro-areas (2004)

\begin{tabular}{lllllllllll}
\hline & \multicolumn{3}{c}{ North } & \multicolumn{4}{c}{ Centre } & \multicolumn{3}{c}{ South } \\
\cline { 2 - 10 } & Low & Medium & High & Low & Medium & High & Low & Medium & High \\
\hline $35-54$ & 49.7 & 37.8 & 12.5 & 43.1 & 41.3 & 15.6 & 57.3 & 31.9 & 10.8 \\
$55-64$ & 69.9 & 21.8 & 8.3 & 67.7 & 23.0 & 9.3 & 72.9 & 18.7 & 8.4 \\
$65-74$ & 82.4 & 13.4 & 4.1 & 81.5 & 13.3 & 5.2 & 85.6 & 9.7 & 4.6 \\
$75+$ & 87.9 & 8.5 & 3.6 & 88.2 & 8.0 & 3.8 & 90.5 & 6.7 & 2.8 \\
\hline
\end{tabular}

Source: elaborations Consalo4 


\section{Appendix 3}

\section{Tables not included in the text - chapter 4}

Table A3.1 Households with at least one person aged 65+ receiving informal help in personal care and/or household assistance from non-members of the household, by level of care needs and educational level of the head of household (weighted cases), the Netherlands, 1991, 1999, 2003

\begin{tabular}{lllll}
\hline Care needs & Education & 1991 & 1999 & 2003 \\
\hline None & Low & 9.4 & 8.7 & 3.5 \\
& Mid & 5.1 & 4.0 & 2.3 \\
\multirow{2}{*}{ Low } & High & 2.0 & 4.3 & 2.9 \\
& Low & 19.9 & 17.0 & 14.9 \\
& Mid & 9.2 & 9.9 & 6.2 \\
High & High & 8.3 & 5.6 & 6.8 \\
& Low & 28.0 & 30.0 & 17.9 \\
& Mid & 15.8 & 13.6 & 13.1 \\
$\mathrm{~N}$ & High & 26.4 & 8.3 & 13.3 \\
\hline
\end{tabular}

Table A3.2 Logistic regression: households with at least one older member (65+) receiving informal care from non-members of the household, the Netherlands, 1991, 1999, 2003 (in bold statistically significant results at the 0.05 level)

\begin{tabular}{llllllll}
\hline & & \multicolumn{2}{c}{1991} & \multicolumn{2}{c}{1999} & \multicolumn{2}{c}{2003} \\
\cline { 3 - 8 } Sex of head of $h$ & Female & 0.302 & 0.937 & 0.309 & 0.790 & 0.616 & 1.957 \\
Age of head of $h$ in years & & 1.036 & 1.104 & 1.031 & 1.092 & 1.008 & 1.074 \\
Education of head of $h$ & Low (ref) & & & & & & \\
& Mid & 0.370 & 1.000 & 0.280 & 0.758 & 0.436 & 1.109 \\
& High & 0.296 & 1.140 & 0.202 & 0.926 & 0.394 & 1.735 \\
Type of household & Single & 1.774 & 5.881 & 1.987 & 5.411 & 1.039 & 3.642 \\
Need level & None (ref) & & & & & & \\
& Low & 1.316 & 3.341 & 1.047 & 2.439 & 1.830 & 5.644 \\
& High & 2.240 & 7.285 & 1.802 & 5.110 & 2.721 & 9.170 \\
Constant & & 0.000 & 0.001 & 0.001 \\
Pseudo Rsq & & 0.167 & 0.158 & 0.140 \\
$\mathrm{~N}$ & & 1031 & 1384 & 1434 \\
\hline
\end{tabular}


Table A3.3 Logistic regression: households with at least one older member (65+) receiving informal care, the Netherlands (three years); (in bold statistically significant results at the 0.05 level)

\begin{tabular}{llcc}
\hline & & \multicolumn{2}{c}{$95 \%$ C.I. Exp (B) } \\
\cline { 3 - 4 } Sex of head of $h$ & Female & 0.465 & 0.851 \\
Age of head of $h$ in years & Low (ref) & 1.039 & 1.076 \\
Education of head of $h$ & Mid & 0.439 & 0.761 \\
& High & 0.373 & 0.851 \\
Type of household & Single & 2.020 & 3.870 \\
Need level & None (ref) & & \\
& Low & 1.584 & 2.716 \\
Year & High & 2.678 & 5.079 \\
& 1991 (ref) & & \\
Constant & 1999 & 0.597 & 1.038 \\
Pseudo Rsq & 2003 & 0.356 & 0.654 \\
$\mathrm{~N}$ & & & 0.001 \\
\hline
\end{tabular}

Table A.3.4 Households with at least one older member (65+) receiving formal help in personal care and/or household assistance, by level of care needs and educational level of the head of household (weighted cases), the Netherlands, 1991, 1999, 2003

\begin{tabular}{lllll}
\hline Care needs & Education & 1991 & 1999 & 2003 \\
\hline None & Low & 7.9 & 9.4 & 12.6 \\
& Mid & 2.4 & 5.6 & 8.3 \\
\multirow{2}{*}{ Low } & High & 3.9 & 1.7 & 6.6 \\
& Low & 29.3 & 32.7 & 36.0 \\
& Mid & 24.5 & 17.4 & 25.5 \\
High & High & 13.3 & 16.7 & 31.8 \\
& High & 53.9 & 52.7 & 58.1 \\
& Mid & 50.0 & 68.2 & 41.4 \\
$\mathrm{~N}$ & High & 50.0 & 40.1 & 50.0 \\
\hline
\end{tabular}


Table A.3.5 Logistic regression: households with at least one older member (65+) receiving formal care, the Netherlands, 1991, 1999, 2003; (in bold statistically significant results at the 0.05 level)

\begin{tabular}{|c|c|c|c|c|c|c|c|}
\hline \multirow[b]{2}{*}{ Sex of head of $h$} & \multirow[b]{2}{*}{ Female } & \multicolumn{2}{|c|}{$\begin{array}{l}1991 \\
95 \% \text { C.I. } \operatorname{Exp}(B)\end{array}$} & \multicolumn{2}{|c|}{$\begin{aligned} & 1999 \\
& 95 \% \text { C.I. } \operatorname{Exp}(B)\end{aligned}$} & \multicolumn{2}{|c|}{$\begin{array}{l}2003 \\
95 \% \text { C.I. } \operatorname{Exp}(B)\end{array}$} \\
\hline & & 0.729 & 2.359 & 0.888 & 2.115 & 0.860 & 1.860 \\
\hline Age of head of $h$ in years & & 1.058 & 1.125 & 1.042 & 1.097 & 1.044 & 1.092 \\
\hline \multirow[t]{3}{*}{ Education of head of h } & Low (ref) & & & & & & \\
\hline & Mid & 0.526 & 1.307 & 0.456 & 0.995 & 0.592 & 1.104 \\
\hline & High & 0.271 & 1.019 & 0.188 & 0.788 & 0.423 & 1.183 \\
\hline Type of household & Single (ref) & 0.783 & 2.649 & 1.518 & 3.891 & 1.876 & 4.306 \\
\hline \multirow[t]{3}{*}{ Need level } & None (ref) & & & & & & \\
\hline & Low & 2.960 & 7.449 & 2.461 & 5.173 & 2.430 & 4.843 \\
\hline & High & 11.097 & 34.646 & 7.826 & 20.046 & 5.783 & 12.846 \\
\hline & \multicolumn{2}{|c|}{0.000} & \multicolumn{2}{|c|}{0.000} & \multicolumn{2}{|c|}{0.000} \\
\hline Pseudo Rsq & & \multicolumn{2}{|c|}{0.339} & \multicolumn{2}{|c|}{0.329} & \multicolumn{2}{|c|}{0.330} \\
\hline \multicolumn{2}{|l|}{$\mathrm{N}$} & \multicolumn{2}{|c|}{1031} & \multicolumn{2}{|c|}{1384} & \multicolumn{2}{|c|}{1434} \\
\hline
\end{tabular}

Table A.3.6 Logistic regression: individuals aged $65+$ with some limitations in daily activities receiving formal care in different years, the Netherlands (three years); (in bold statistically significant results at the 0.05 level)

\begin{tabular}{lllc}
\hline & & \multicolumn{2}{c}{$95 \%$ C.I. Exp(B) } \\
\cline { 3 - 4 } Sex of head of $h$ & Female & 0.994 & 1.665 \\
Age of head of $h$ in years & Low (ref) & 1.058 & 1.089 \\
Education of head of $h$ & Mid & 0.626 & 0.958 \\
& High & 0.405 & 0.809 \\
Type of household & Single (ref) & 1.759 & 3.051 \\
Need level & Low (ref) & & \\
& Mid & 3.021 & 4.696 \\
& High & 8.829 & 15.058 \\
Year & 1991 (ref) & & \\
& 1999 & 0.803 & 1.326 \\
& 2003 & 1.018 & 1.665 \\
Constant & & & 0.000 \\
Pseudo Rsq & & & 0.330 \\
$\mathrm{~N}$ & & & 3849 \\
\hline
\end{tabular}


Table A3.7 Households with at least one person aged 65+ receiving commercial help in personal care and/or household assistance from members of the household, by level of care needs and education (weighted cases), the Netherlands, 1991, 1999, 2003

\begin{tabular}{lllll}
\hline Care needs & Education & 1991 & 1999 & 2003 \\
\hline None & Low & $7.6(0.9)$ & $4.7(1.2)$ & 2.0 \\
& Mid & $15.8(1.2)$ & $15.3(2.8)$ & 2.6 \\
\multirow{3}{*}{ Low } & High & $20.3(1.3)$ & $21.6(0.9)$ & 2.2 \\
& Low & $11.5(1.6)$ & $10.0(2.2)$ & 4.3 \\
\multirow{4}{*}{ High } & Mid & $23.5(5.1)$ & $34.1(7.7)$ & 11.5 \\
& High & $36.7(5.0)$ & $36.1(2.9)$ & 13.6 \\
& Low & $8.0(3.9)$ & $10.0(4.5)$ & 6.0 \\
& Mid & $28.9(7.9)$ & $28.2(4.8)$ & 13.1 \\
& High & $29.1(8.0)$ & $31.7(5.0)$ & 7.1 \\
& N. & 1031 & 1348 & 1434 \\
\hline
\end{tabular}

Table A3. 8 Logistic regression: households with at least one person aged 65+ receiving commercial care, the Netherlands, 1991, 1999, 2003; (in bold statistically significant results at the 0.05 level)

\begin{tabular}{llllllll}
\hline & & \multicolumn{2}{c}{1991} & \multicolumn{2}{c}{1999} & \multicolumn{2}{c}{2003} \\
\cline { 3 - 8 } Sex of head of $h$ & Female & 1.036 & 3.205 & 0.992 & 2.636 & 0.668 & 2.504 \\
Age of head of $h$ in years & & 1.018 & 1.079 & 1.033 & 1.092 & 1.031 & 1.109 \\
Education of head of $h$ & Low (ref) & & & & & & \\
& Mid & 2.263 & 5.654 & 3.005 & 6.690 & 1.615 & 5.304 \\
& High & 4.389 & 12.252 & 5.374 & 14.358 & 1.599 & 8.136 \\
Type of household & Single (ref) & 1.033 & 3.307 & 0.852 & 2.334 & 1.360 & 6.192 \\
Need level & None (ref) & & & & & & \\
& Low & 1.006 & 2.273 & 1.231 & 2.644 & 1.993 & 6.968 \\
& High & 0.570 & 2.205 & 1.005 & 3.098 & 1.800 & 7.819 \\
Constant & & 0.001 & 0.000 & 0.000 \\
Pseudo Rsq & & 0.161 & 0.175 & 0.180 \\
$\mathrm{~N}$ & & & 1031 & 1384 & 1434 \\
\hline
\end{tabular}


Table A3.9 Households with at least one older person receiving commercial help in personal care, by level of care needs and educational level of the head of household (weighted cases), Italy, 1999, 2003

\begin{tabular}{llll}
\hline Care needs & Education & 1999 & 2003 \\
\hline None & Low & 0.4 & 0.8 \\
& Mid & 0.8 & 0.1 \\
\multirow{4}{*}{ Medium } & High & 2.5 & 0.5 \\
& Low & 6.5 & 7.0 \\
& Mid & 10.0 & 9.3 \\
High & High & 6.6 & 12.3 \\
& Low & 13.1 & 9.5 \\
& Mid & 13.0 & 16.0 \\
& High & 20.2 & 7.3 \\
& N. & 11622 & 11633 \\
\hline
\end{tabular}

Table A3.10 Households with at least one older person receiving commercial household assistance, by level of care needs and educational level of the head of household (weighted cases), Italy 1999, 2003

\begin{tabular}{llll}
\hline Care needs & Education & 1999 & 2003 \\
\hline None & Low & 5.2 & 4.9 \\
& Mid & 20.3 & 19.2 \\
\multirow{3}{*}{ Low } & High & 44.2 & 39.8 \\
& Low & 11.3 & 12.2 \\
High & Mid & 26.3 & 28.8 \\
& High & 36.6 & 42.5 \\
& High & 14.0 & 16.7 \\
& Mid & 30.9 & 30.8 \\
& High & 20.2 & 45.6 \\
\hline
\end{tabular}


Table A.3.11 Households with at least one older person receiving commercial help with personal care and/or household assistance, by level of care needs and educational level of the head of household (weighted cases), Italy, 1999, 2003

\begin{tabular}{llll}
\hline Care needs & Education & 1999 & 2003 \\
\hline None & Low & 5.5 & 5.5 \\
& Mid & 20.6 & 19.6 \\
Low & High & 44.6 & 39.8 \\
& Low & 15.0 & 17.1 \\
High & Mid & 29.5 & 33.6 \\
& High & 38.7 & 48.8 \\
& High & 20.2 & 22.8 \\
& Mid & 33.6 & 41.7 \\
& High & 20.2 & 45.6 \\
& N. & 11622 & 11633 \\
\hline
\end{tabular}

Table A3.12 Logistic regression: households with at least one member aged $6_{5}+$ receiving commercial care (personal care), Italy, 1999, 2003 (in bold statistically significant results at the 0.05 level)

\begin{tabular}{llllll}
\hline & & \multicolumn{2}{c}{1999} & \multicolumn{2}{c}{2003} \\
\cline { 3 - 6 } Sex of head of $h$ & Female & $\mathbf{1 . 1 8 1}$ & 1.764 & 1.212 & 1.761 \\
Age of head of $h$ in years & $65-74$ (ref) & 1.043 & 1.063 & 1.061 & 1.083 \\
Education of head of $h$ & Low (ref) & & & & \\
& Mid & 1.419 & 2.427 & 1.495 & 2.394 \\
& High & 1.597 & 3.735 & 1.317 & 2.700 \\
Type of household & Single (ref) & 1.064 & 1.599 & 1.186 & 1.726 \\
Need level & None (ref.) & & & & \\
& Low & 8.406 & 15.764 & 5.255 & 8.892 \\
Macro regions & High & 17.470 & 38.685 & 9.788 & 20.217 \\
& North & & & & \\
Centre & 0.763 & 1.188 & 1.096 & 1.619 \\
Constant & South & 0.745 & 1.046 & 0.867 & 1.214 \\
Pseudo Rsq & & & 0.000 & & 0.000 \\
$\mathrm{~N}$ & & & 0.173 & & 0.176 \\
\hline & & & 18905 & & 18618 \\
\hline
\end{tabular}


Table A3.13 Logistic regression: households with at least one member aged 65+ receiving commercial care (household assistance), Italy (in bold statistically significant results at the 0.05 level)

\begin{tabular}{llllll}
\hline & & \multicolumn{3}{c}{1999} & \multicolumn{2}{c}{2003} \\
\cline { 3 - 6 } Sex of head of $h$ & Female & 0.912 & 1.183 & 0.846 & 1.070 \\
Age of head of h in years & $65-74$ (ref) & 1.031 & 1.044 & 1.033 & 1.045 \\
Education of head of $h$ & Low (ref) & & & & \\
& Mid & 4.360 & 5.725 & 3.938 & 5.061 \\
& High & 10.474 & 15.219 & 9.504 & 13.087 \\
Type of household & Single (ref) & 1.584 & 2.066 & 1.658 & 2.108 \\
Need level & None (ref.) & & & & \\
& Low & 1.437 & 1.799 & 1.591 & 1.976 \\
Macro regions & High & $\mathbf{2 . 2 6 9}$ & 3.658 & 2.390 & 3.779 \\
& North & & & & \\
Contre & 0.907 & 1.204 & 1.140 & 1.463 \\
Constant & South & 0.949 & 1.190 & 0.982 & 1.221 \\
Pseudo Rsq & & & 0.003 & & 0.082 \\
$N$ & & & 0.138 & & 0.154 \\
& & & 18905 & & 18618 \\
\hline
\end{tabular}

Table A3.14 Logistic regression: households with at least one member aged 65+ receiving commercial care (personal care and/or household assistance), Italy (in bold statistically significant results at the 0.05 level)

\begin{tabular}{llllll}
\hline & & \multicolumn{2}{c}{1999} & \multicolumn{2}{c}{2003} \\
\cline { 3 - 6 } Sex of head of $h$ & Female & 0.943 & 1.198 & 0.920 & 1.142 \\
Age of head of $h$ in years & & 1.036 & 1.048 & 1.043 & 1.055 \\
Education of head of $h$ & Low (ref) & & & & \\
& Mid & 3.925 & 5.116 & 3.624 & 4.624 \\
& High & 9.231 & 13.411 & 8.668 & 11.947 \\
Type of household & Single (ref) & 1.590 & 2.031 & 1.652 & 2.059 \\
Need level & None (ref.) & & & & \\
& Low & 1.914 & 2.368 & 2.061 & 2.528 \\
& High & 3.257 & 5.008 & 3.419 & 5.165 \\
Macro regions & North (ref) & & & & \\
& Centre & 0.906 & 1.177 & 1.177 & 1.481 \\
Constant & South & 0.910 & 1.121 & 0.973 & 1.188 \\
Pseudo Rsq & & & 0.002 & & 0.001 \\
$N$ & & & 0.150 & & 0.177 \\
& & & 18905 & & 18618 \\
\hline
\end{tabular}




\section{Appendix 4}

Note on the qualitative study

\section{A.4.1 Reconstruction of the context}

The qualitative study was carried out in Amsterdam and Milan between 2003 and 2004. The local welfare context - in Milan and Amsterdam has been reconstructed via the analysis of policy documents, data and interviews with key actors. Key actors in both cities include managers working for social services, private for-profit and non-profit providers, various organisations active in the field of elderly care and, in the case of Milan, an organisation dealing with migration. Key actors were also requested to recommend possible other interviewees for the qualitative study such as caregivers and care managers of older dependent people as well as migrant care workers (in Milan).

\section{A.4.2 The cases of dependent the elderly}

Semi-direct interviews were carried out with caregivers of elderly dependents, which refers to 70 cases of elderly dependents, 35 in each city. The sample includes ten cases of elderly dependents living in an institutional setting and 25 cases of elderly people living at home, either alone or with others in both Milan and Amsterdam.

As the aim of the study was to analyse the welfare packages among severely dependent elderly people, in principle, the cases were selected based on the inability to carry out several everyday activities and the level of need for continuous care due to mental and/or physical disability. For the purposes of comparison, it has to be emphasised that the levels of dependence are not homogeneous between the Milan and Amsterdam samples. The overall care needs of elderly people included in the Dutch sample are on average lighter than their Italian counterparts, particularly among people living independently. While in Milan finding severely dependent elderly people living alone was relatively easy, the task proved more difficult in Amsterdam. This situation partly reflects the different composition of the elderly population living independently in Amsterdam and in Milan. In fact, the higher availability of beds in residential care and the selection of highly dependent elderly people for these services greatly reduced the presence of very dependent elderly people in Amsterdam. By contrast, in Milan it was still quite common for a highly dependent elderly person to still be living at home.

Given the expected relevance of socio-economic conditions in the creation of welfare packages, an attempt was made to include the elderly in the study who came from different socio-economic circumstances, based on income, occupation prior to retirement of the older person and/or spouse, and their children's occupation. The final sample in both 
cities includes a variety of situations, ranging from poor and deprived households (more in Milan than in Amsterdam) to well-off households. Moreover, a few elderly among the migrant populations were included in the sample for Amsterdam. The small number of interviewees with a migratory background certainly does not allow us to make any conclusions about the possible differences between the native and non-native Dutch population. Nevertheless, the inclusion of a few cases of the elderly of foreign origin is useful to draw a clearer picture of the complexity and to sketch the tensions that have arisen in the Dutch case, as suggested by several key actors.

The number of interviewees used for each case was one or more. In most cases, the main interviewee was the most important caregiver, the elderly household member. In general, informal caregivers were included, but sometimes, especially in Amsterdam, formal professional caregivers were interviewed instead. Semi-structured interviews with caregivers were, when possible, supplemented with interviews with elderly people themselves. Given the high level of dependence of the elderly involved in the study, carrying out interviews with them was not always possible. Moreover, language barriers still existed among the elderly in the Netherlands.

We are aware of possible distortions caused by concentrating the attention mainly on one actor's point of view. Studies on care arrangements for the elderly have pointed out that the "central caregiver model" is not sufficient in order to understand how family responsibilities are distributed, as different people within a family will tell different stories about the distribution of responsibilities (Potting 200I). Therefore, the reconstruction of the strategies used by family members is here filtered through a very specific point of view. For example, in quantitative analysis, it was found that in accounting for support given to parents by children there was a difference between the reports parents and children presented, as children tended to report that they provided more care. It is often impossible to determine whether there was underestimation or overestimation, as data on actual support given and received were not available (Klein Ikkink and van Tilburg I999).

The interviews were carried out in Italian in Milan and in English in Amsterdam. The quotes from the interviews conducted in Milan included in chapters five and six were translated from Italian into English by the author.

\section{A.4.3 Migrant care workers}

Given the relevance of the phenomenon of private care supplied by migrant workers in Italy, I5 additional interviews were conducted in Milan with foreign paid caregivers of the elderly. Care workers were recruited for interviews either through the elderly themselves or family members, through local organisations and associations or via other migrant work- 
ers. In fact, only a few caregivers working with the elderly were interviewed for this study. Given the high incidence of undocumented migration and grey market access, the informal caregivers of the elderly or the elderly themselves employing a migrant worker were not always willing to ask their employees to participate in the study. Conversely, the migrant workers contacted were not always willing to involve their employers in the research. A good relation of trust between employers and employees existed in only a few cases, which allowed the inclusion of both as interviewees.

Moreover, the characteristics of the care market, rife as it is with irregularities regarding migratory, labour and social security regulations, raise some problems with respect to the reliability of the informants. A few refused to participate in the study altogether, while others showed reticence in providing information on particularly sensitive issues such as irregular or illegal immigration, relations with so-called immigration agencies, payments made to intermediaries in exchange for contacts with possible employers or of immigration papers. Despite some difficulties in this respect, in most cases, the migrant workers interviewed were willing to provide extensive information on their positions, including rather sensitive issues.

\section{A.4.4 The territorial contexts}

Both Milan and Amsterdam represent special cases within their national contexts in terms of the ageing process. Milan is, in fact, the oldest city not only in Italy but also in all of Europe: in $2003,23.5 \%$ of the inhabitants were 65 years or older; while $5.9 \%$ were 80 years or older. ${ }^{2}$ By contrast, Amsterdam is a very young city - as residents aged 65 and over comprised II. $8 \%$ of the total population in $2002^{3}(\mathrm{O}+\mathrm{S}) .{ }^{4}$ Moreover, instead of experiencing an aging process the city has seen a decline since the I980s in the percentage of older people. ${ }^{5}$

Regarding economic conditions, in Milan, the average income tends to be higher than the national and regional averages both for the employed and retired populations (Benassi 200I). Furthermore, the rate of participation of women in the labour market is particularly high, especially among younger cohorts. ${ }^{6}$ In Amsterdam, data show a polarisation of income among the elderly population: on the one hand, a large portion of the older population lives below the minimum pension level, while another relevant portion has an income considered high $(\mathrm{O}+\mathrm{S}$ I993, I998). This situation is also affected by increases of the migrant population reaching retirement age without meeting the requirements for a full basic pension, due to the fact that their participation in the Dutch labour market and insurance schemes does not meet minimum requirements.

The supply of formal care services for dependent elderly is particularly meagre in the Milanese context compared to the regional situation. 
There are historically fewer beds in institutional care facilities, which was a fact throughout the I99os because they often "moved" the elderly to available facilities in other provinces or regions (Regione Lombardia I998). In 2000, the number of elderly of Milan in institutions within the city or the immediate suburbs was approximately 3,500, i.e. I.2\% of Milan's total elderly population of the city.7 Despite certain levels of growth in the city, the availability of beds in institutions has remained very limited: 4,600 in 2004 (I. $5 \%$ of the older population), against an average of $3 \%$ in the Region ${ }^{8}$ ). Home care services appear equally underdeveloped, even in relation to the regional context. Home care users totalled some 4,700 in 2000 , or $1.6 \%$ of the elderly population (Comune di Milano 2002: IOO-IOI), each of whom received an estimated 2.3 hours of home care per week. ${ }^{9}$ The limited number of hours of home care available was a widespread fact of Italian home care services, while the uptake rate is considerably lower than the regional average.

By contrast, the supply of formal services in Amsterdam is traditionally higher compared to the Netherlands on average. The availability of beds in nursing home facilities corresponded to $3.6 \%$ of the population aged $6_{5}$ and over, compared to a national average of $2.6 \%(\mathrm{O}+\mathrm{S}$ I998:83) in 1996 . Since I980, consistent with national trends, there has been a steep decline in the number of available beds in elderly homes ${ }^{\mathrm{IO}}(\mathrm{O}+\mathrm{S}$ I998: 84). By contrast, the supply of beds in homes for the elderly is slightly lower than the national average - around $4.5 \%$ of the population aged 65 and over in Amsterdam at the end of the I990s (O+S I998), compared to $5.0 \%$ in the Netherlands (De Klerk and Hessing-Wagner I999: I35-136). Therefore, the total supply of residential care is higher in the city compared to the country as a whole. As for the supply of home care services, the amount of hours of services provided per inhabitant supplied in the Amsterdam region was above the national average in $2002 .^{\text {II }}$

In both cities, informal support networks tend to be looser than the national averages. This is true in Milan, particularly for very old women (Facchini 1997), due to the specific demographic and residential developments, namely the permanence of the ageing population in the city and the emigration of the offspring in the metropolitan area. The weakness of informal support is a characteristic of the Amsterdam case as well. According to several studies conducted in the Netherlands, the elderly living independently in large cities tend to receive less informal support in cases of need compared to the elderly living in more rural areas, and have to rely more on other sources of support. The core social networks of older adults living in big cities tend to be smaller because of the lower number of children and siblings and due to the fact that they have less contact with their neighbours, friends and other non-kin in general. Despite the fact that the network outside the neighbourhood tends to compensate the weaker proximity networks, the total amount of instrumental support received by the elderly living in urban areas is low- 
er, because their non-local network is not likely to represent a viable form of support (De Jong Gierveld and Fokkema I998). Similarly, results from a longitudinal study show that older adults who live in large cities have less potential assistance and fewer potential supporters available: older adults in cities are in a less favourable position if their health declines and their need for social support increases (Van Tilburg and Broese van Groenou 2002).

The special position of the two cities with respect to migration flows is also a relevant issue. In the Italian case, migratory influxes are a relatively recent and growing phenomenon. The city of Milan represents an important destination for migrant workers, including those in irregular employment, to work especially in the service sector (Zincone, ed., 200I). The supply of paid care employment is therefore particularly high in the city compared to other local contexts, as is demand. The city of Milan was one of the first in Italy where the badanti became a public issue and a mass phenomenon. In the framework of the ongoing regularisation process of undocumented foreign workers, 35,922 applications were presented in the province of Milan for domestic workers (Caritas 2003). Given that not all of them work for elderly dependents, key actors estimate a number of care assistants in Milan ranging between fifteen and 20 thousand. If these estimates are reliable, paid care for the elderly dependents is a far more significant response to care needs of the elderly, when compared to formal services. ${ }^{\text {I2 }}$

The city of Amsterdam has an exceptionally high percentage of inhabitants of migrant origin within the Dutch context. In 2002, the inhabitants of non-Dutch origin comprised $48 \%$ of the overall population; with $35 \%$ of this population being originally from non-European and non-industrialised countries (O+S 2004, Amsterdam figures). Moreover, because modern migration to the Netherlands started earlier than in Italy, an increasingly important proportion of the elderly has a migratory background in Amsterdam: in 2004, 12\% of the older population came from the former colonies, non-industrialised countries or southern Europe $(\mathrm{O}+\mathrm{S}) .^{\mathrm{I3}}$

To a certain degree, both cities represent extreme cases within their national contexts. Milan, embedded in a society with a significant elderly population, has particularly high care needs, relatively large monetary resources, limited formal care resources and relatively low informal resources. Amsterdam, on the other hand, embedded in a society with a less dramatic ageing process and higher formal resources, is a particularly young city where the care supply is particularly low in the informal sector and particularly high in the formal sector. This study tried to show the process underlying the construction of welfare packages, tensions and transformations in each system, and the motives and conditions underlying these changes. Even if what happens in Amsterdam and Milan is not considered representative of the welfare context and transformation of the two nations as a whole, the social processes that can be ob- 
served and analysed in the two cities should provide a useful framework for further analysis of the current transition.

\section{A.4.5 The timing of the study}

With respect to the timing of the study, it has to be recalled that the massive regularisation of migrant workers that took place in Italy between 2002 and 2003 was accompanied by significant coverage in the press as well as various social and political campaigns, with special reference to the involvement of an allegedly very high number of undocumented migrant workers employed in domestic services and elderly care. As the topic of private care for the elderly provided by non-documented migrants became a publicly debated issue, the interviewees felt rather comfortable in discussing the issue. Nevertheless, at the time, it was particularly difficult to gather specific information in presence of undocumented migrants that were not going to benefit from the amnesty procedure.

On the other hand, research in the Netherlands took place long after the implementation of the deinstitutionalisation processes of the elderly, which represents one of the main transformations in the field of longterm care. By contrast, recent changes in social policy were ongoing at the time of the fieldwork. More specifically, since April 2003 relevant changes in the administration of formal care services have started to be implemented. According to the new regulations, a greater freedom of choice should be granted to users so that they can choose between different care packages or cash payments. The 2007 reform (WMO) introduced even more dramatic changes in the organisation of the long-term care interventions. Therefore, a full understanding of implications of the most recent changes would require a follow-up study. 


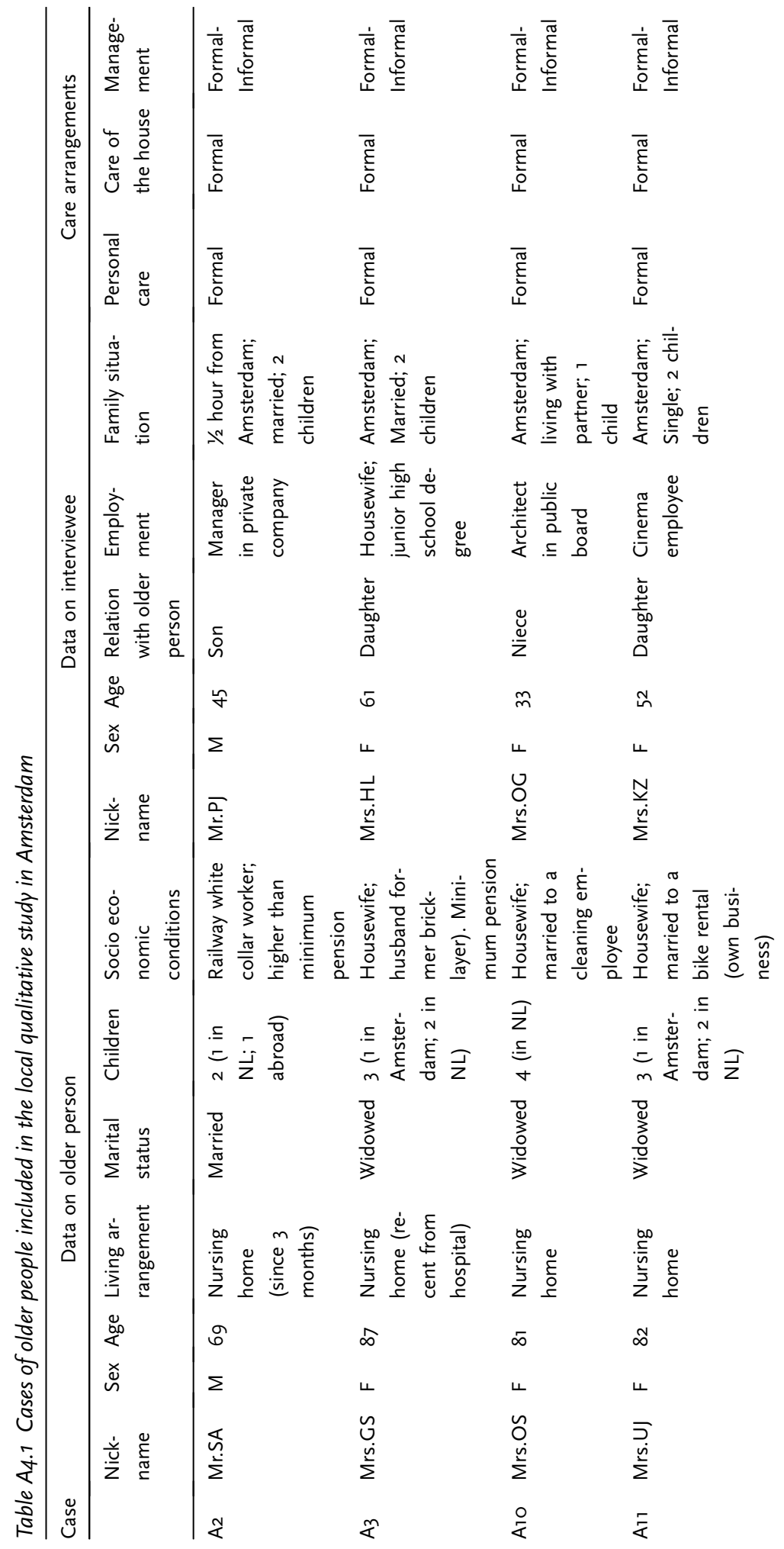




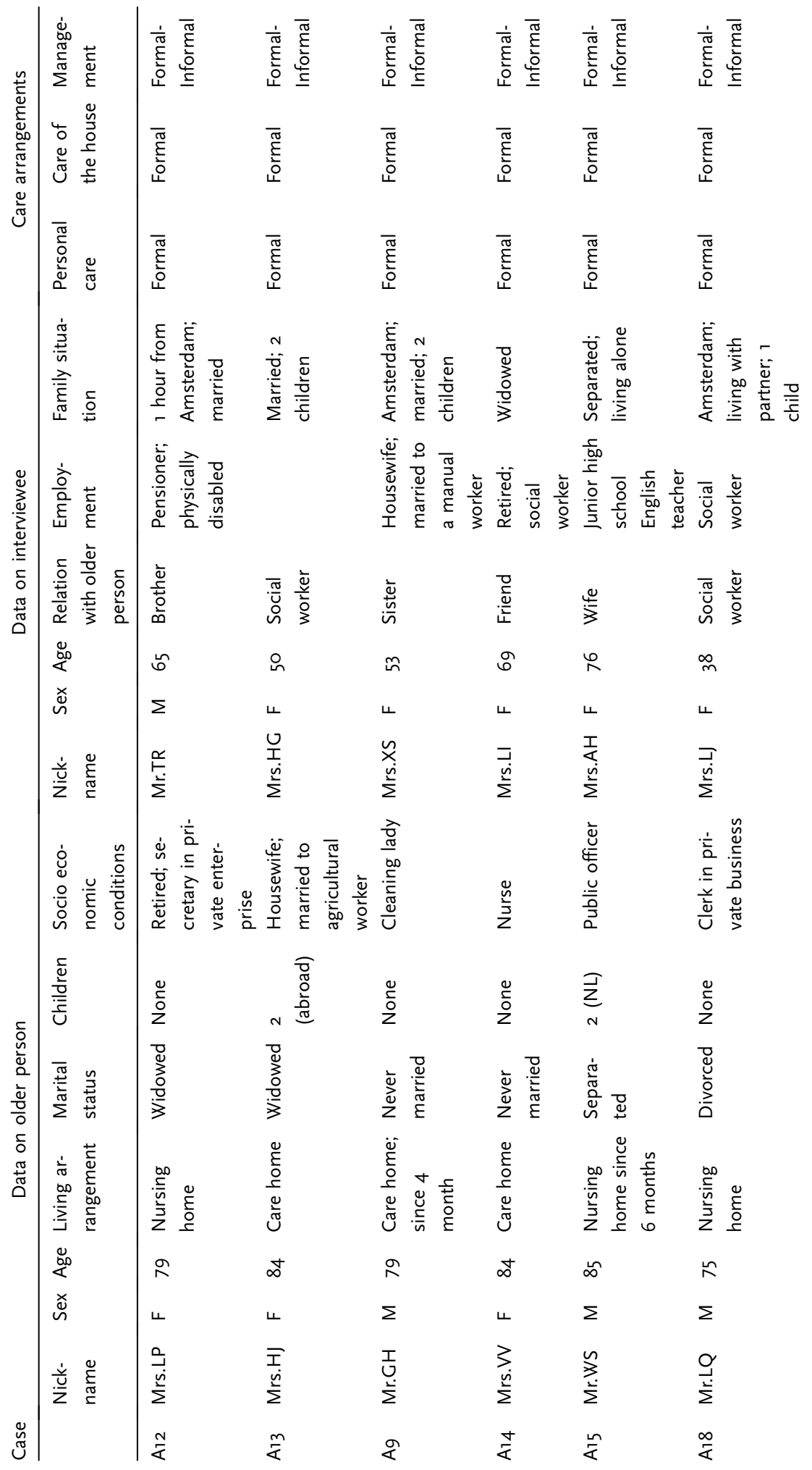




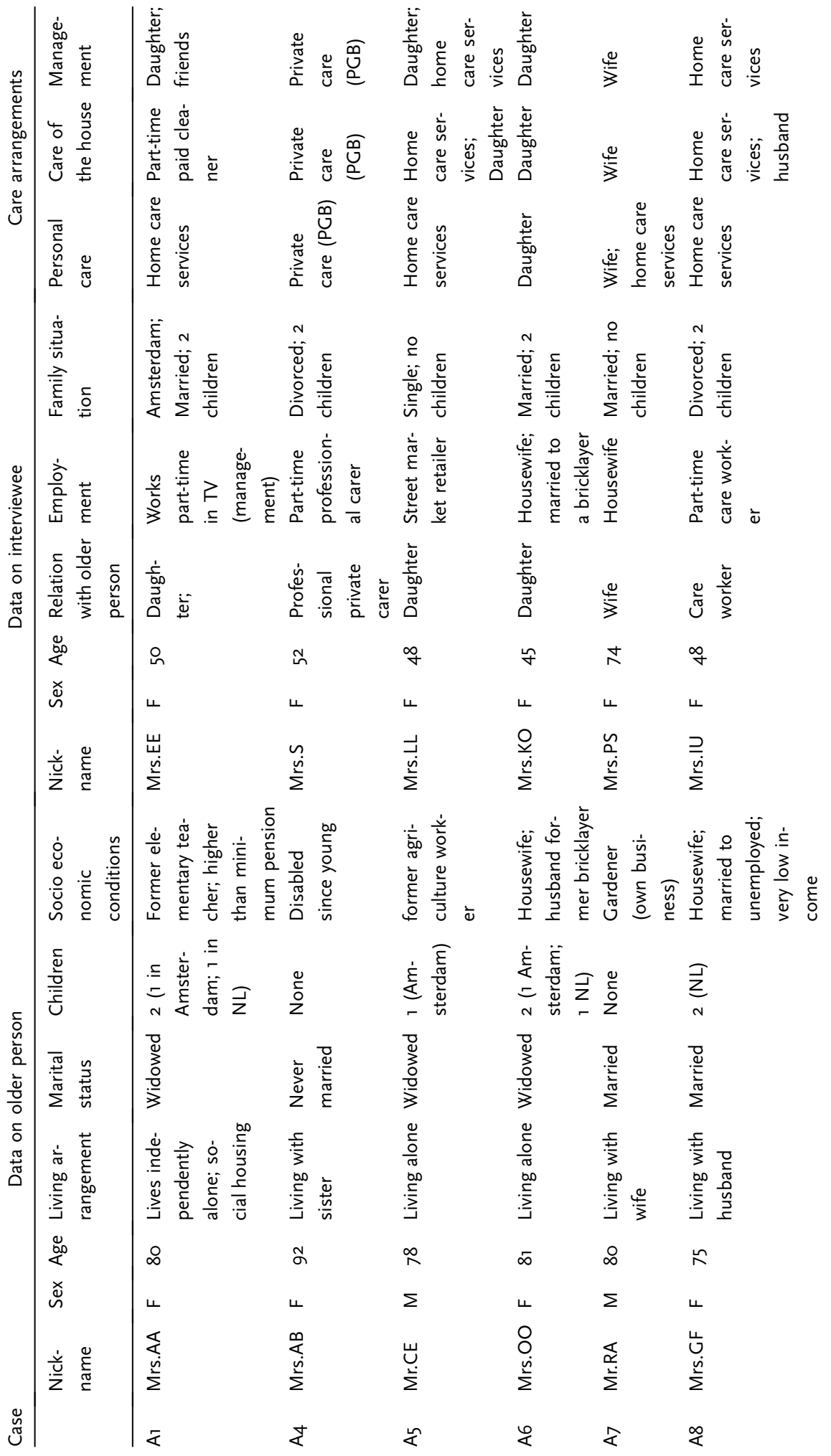




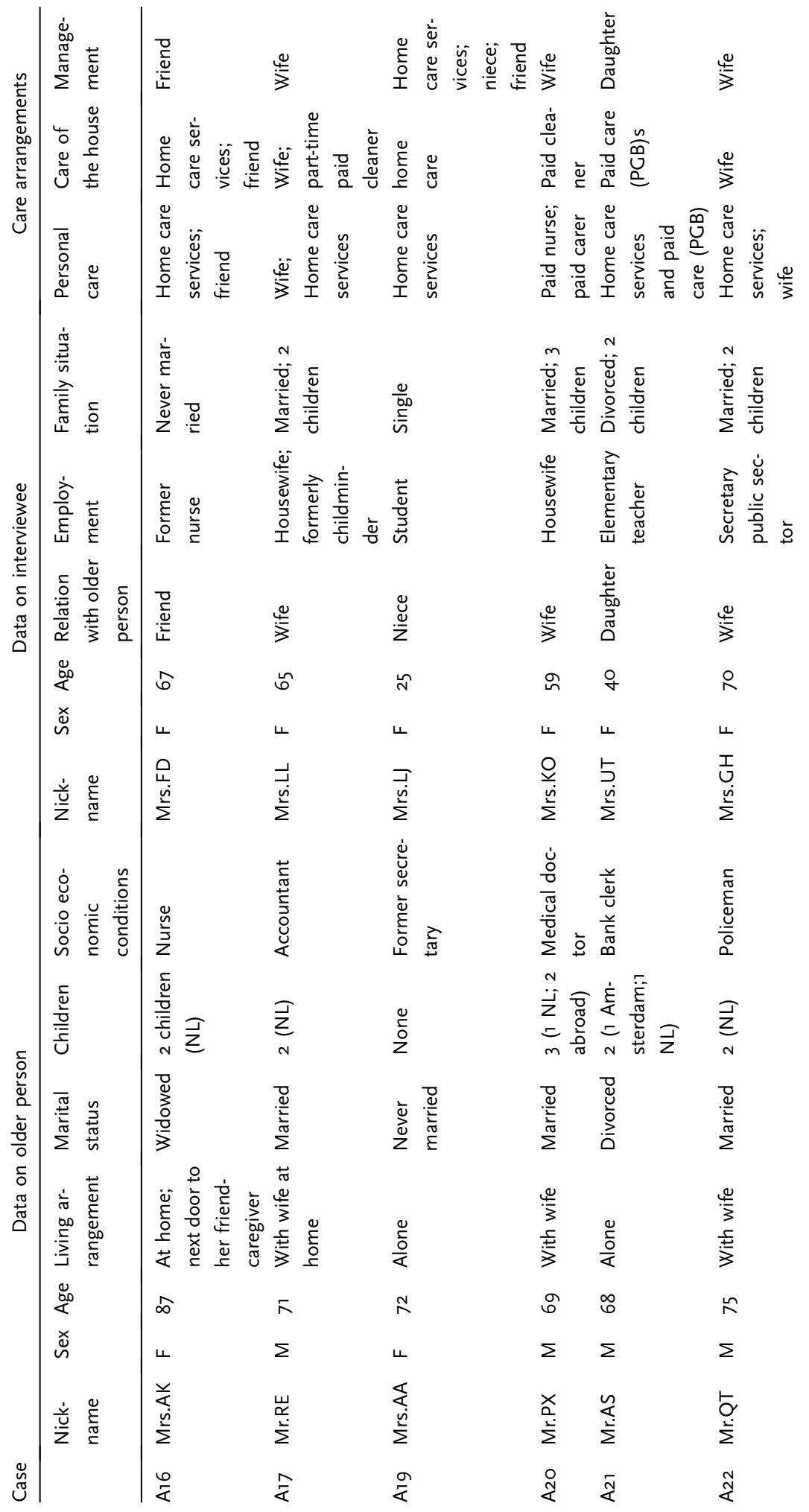




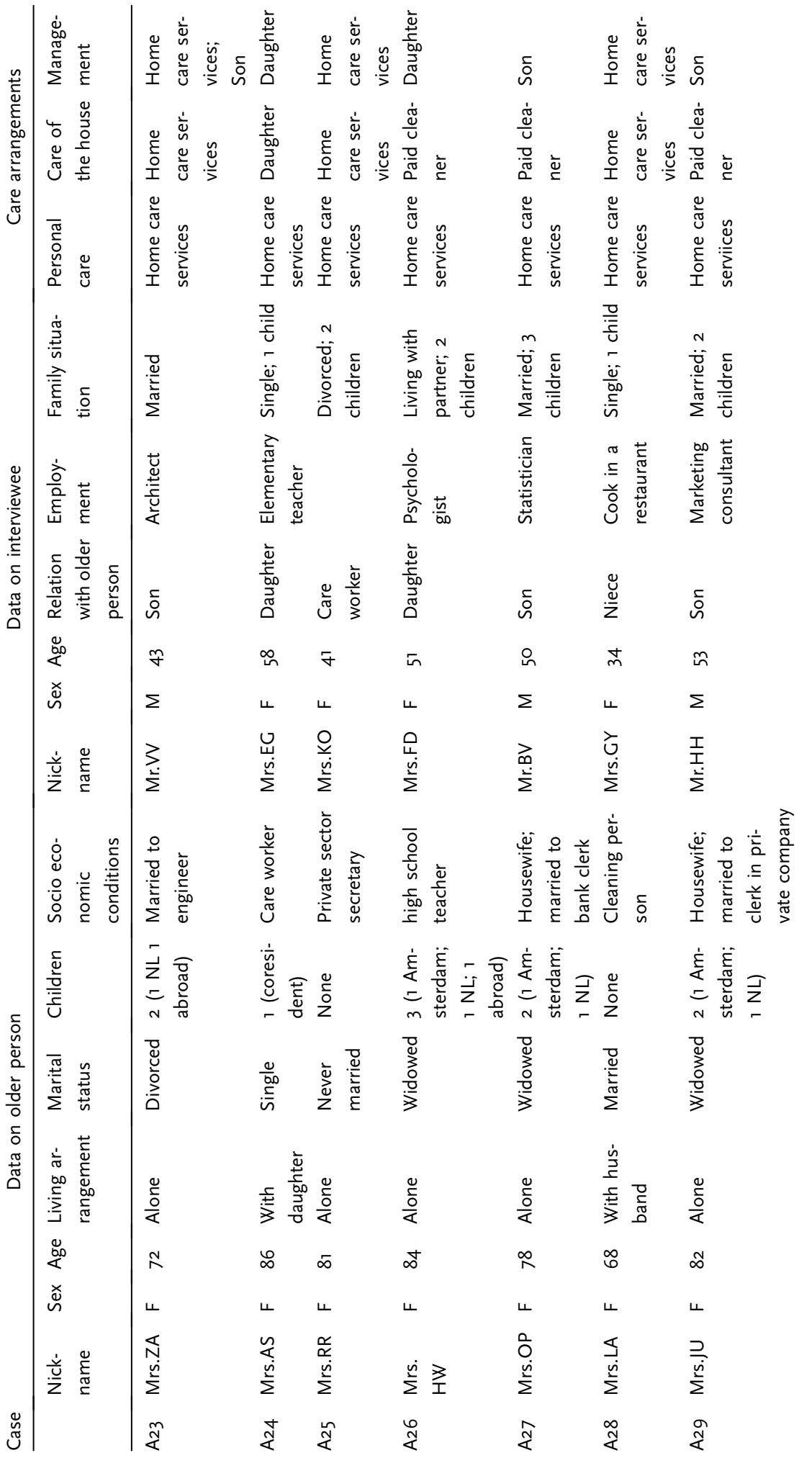




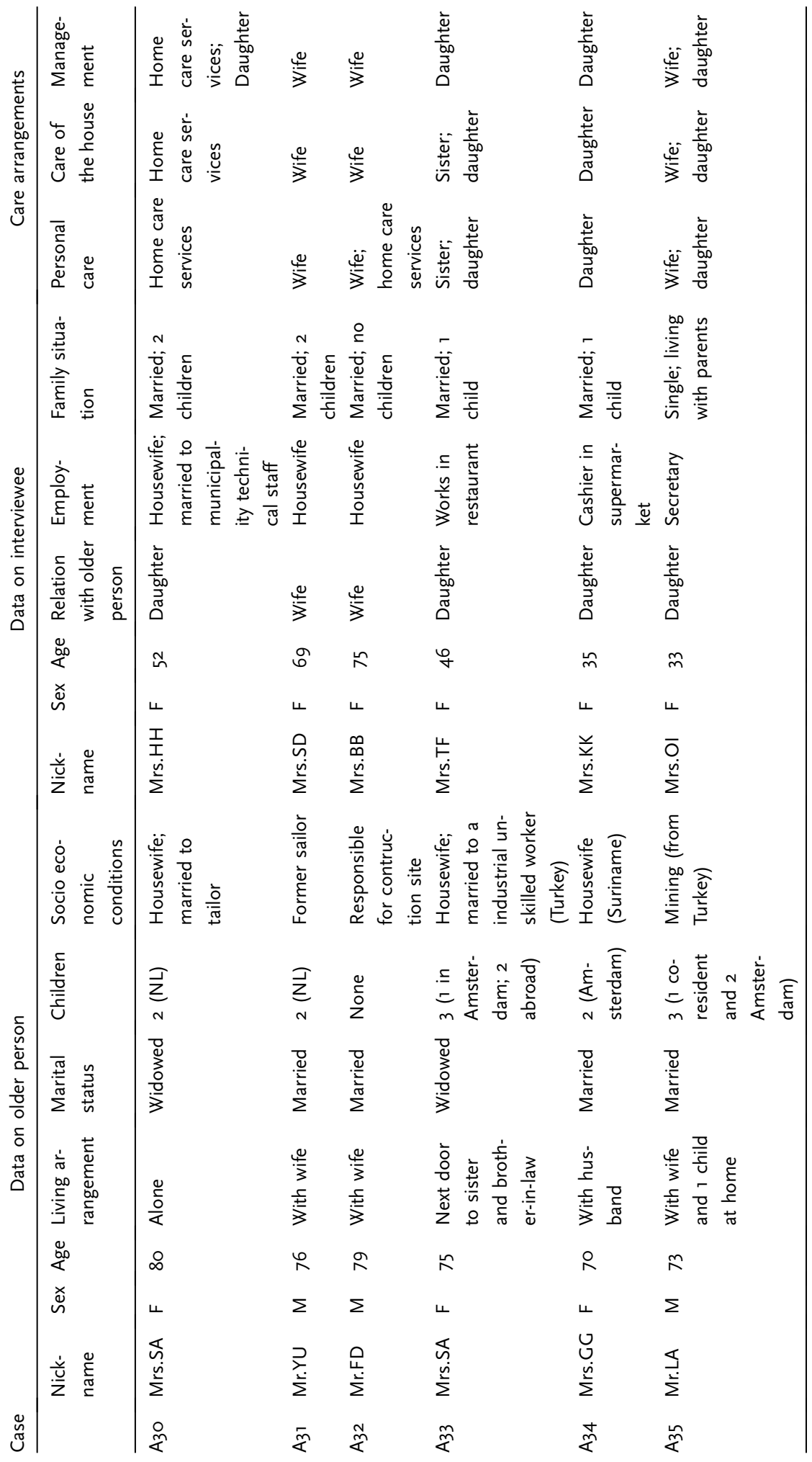




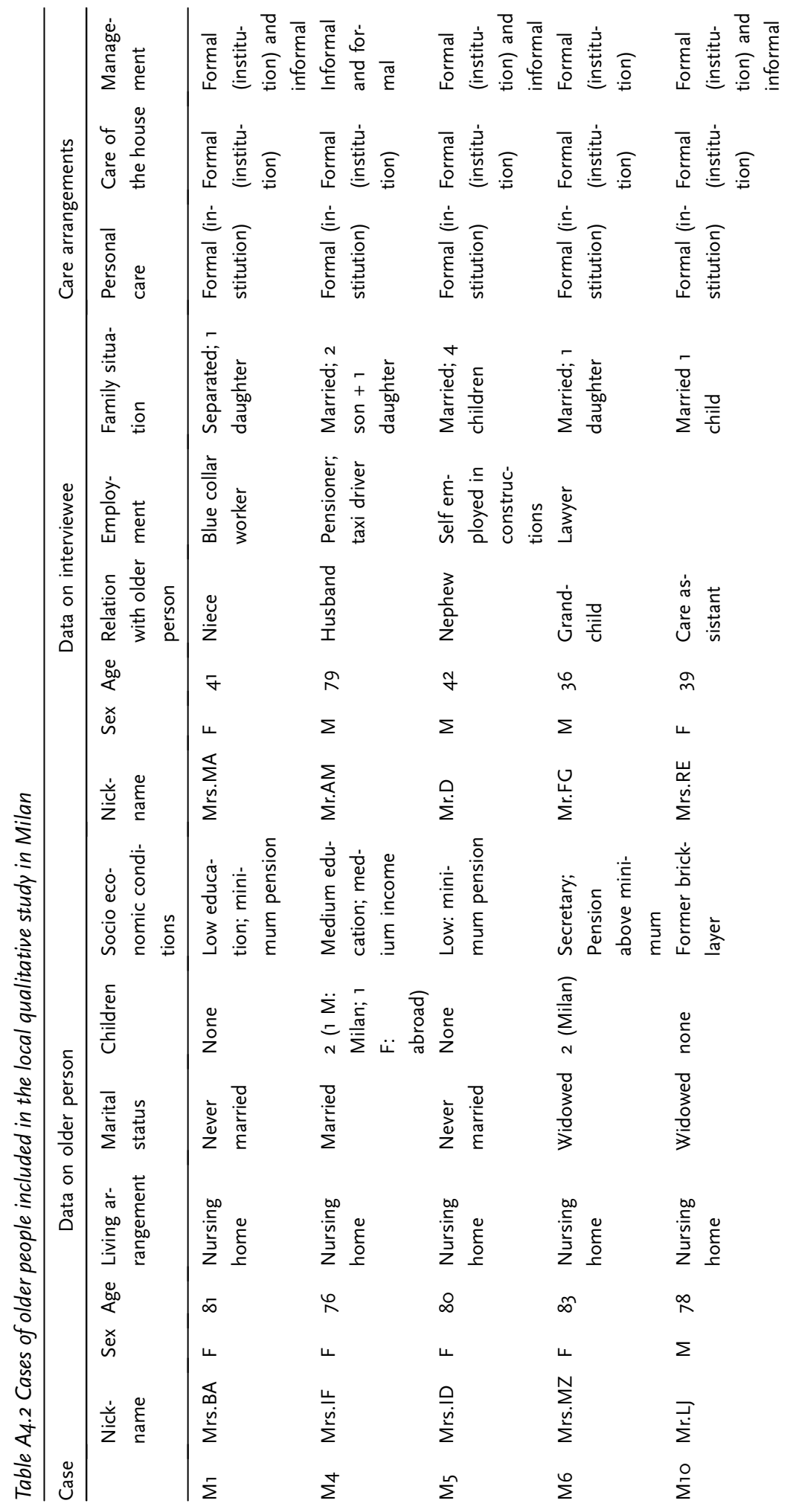




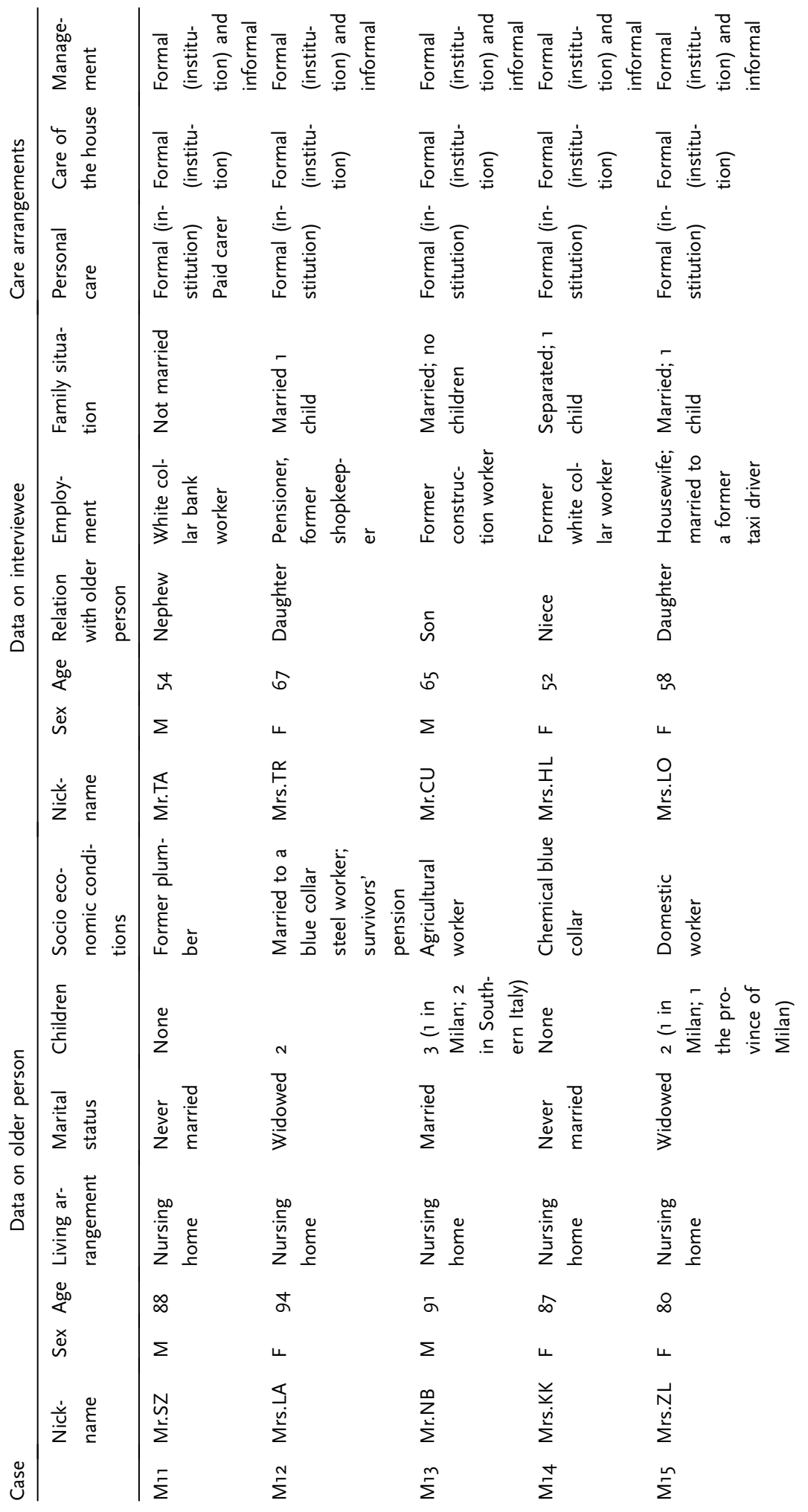




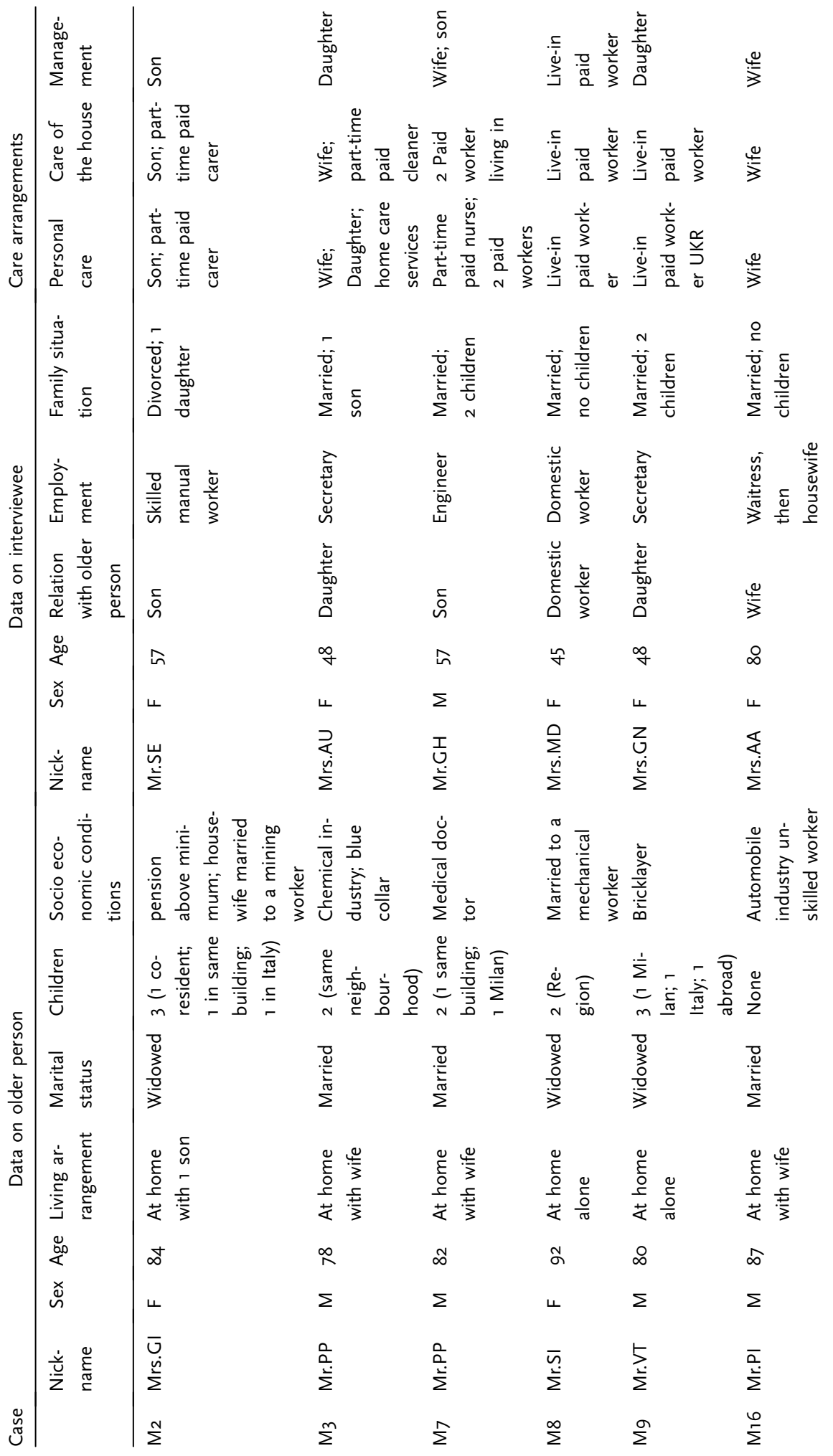




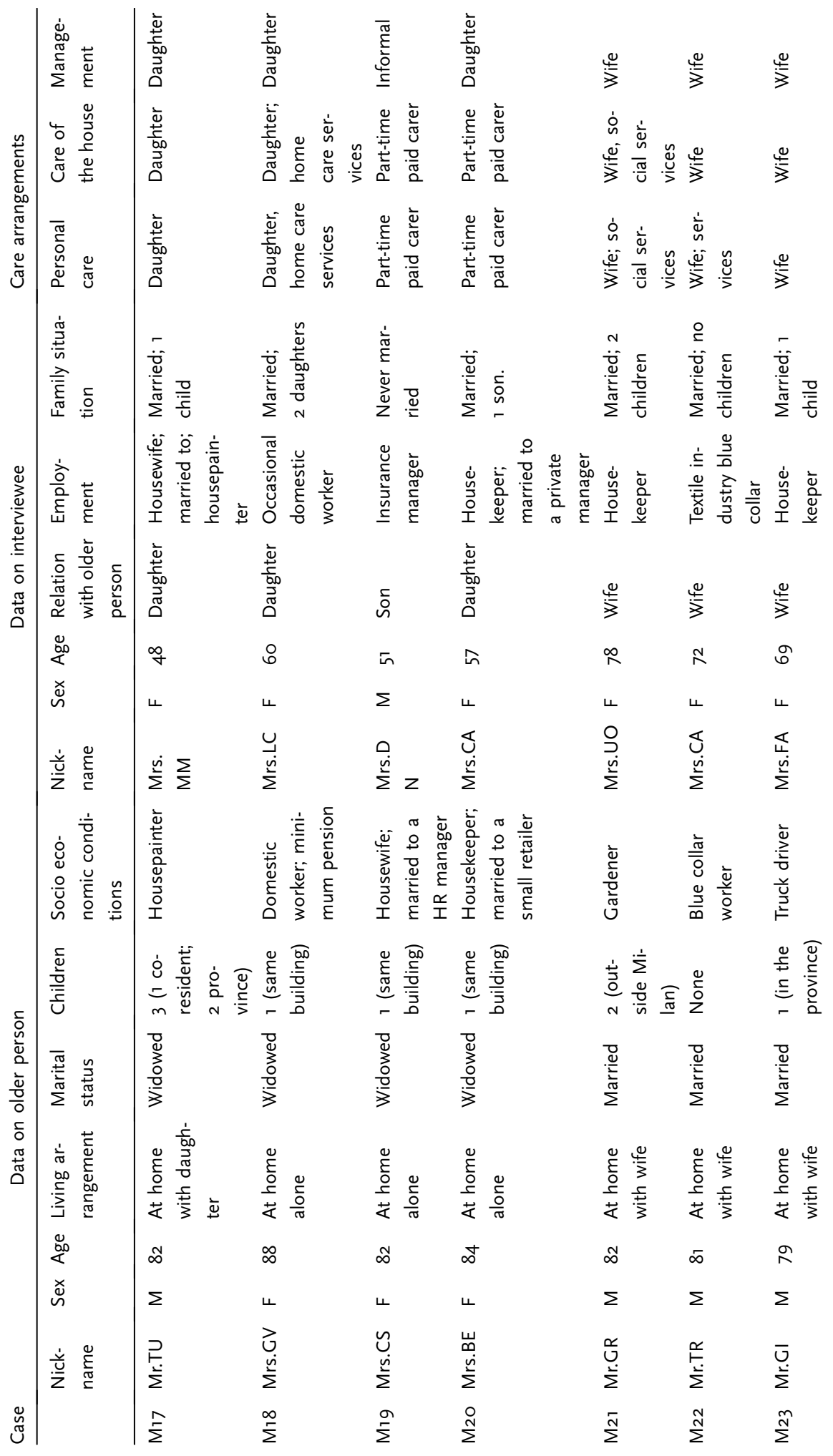




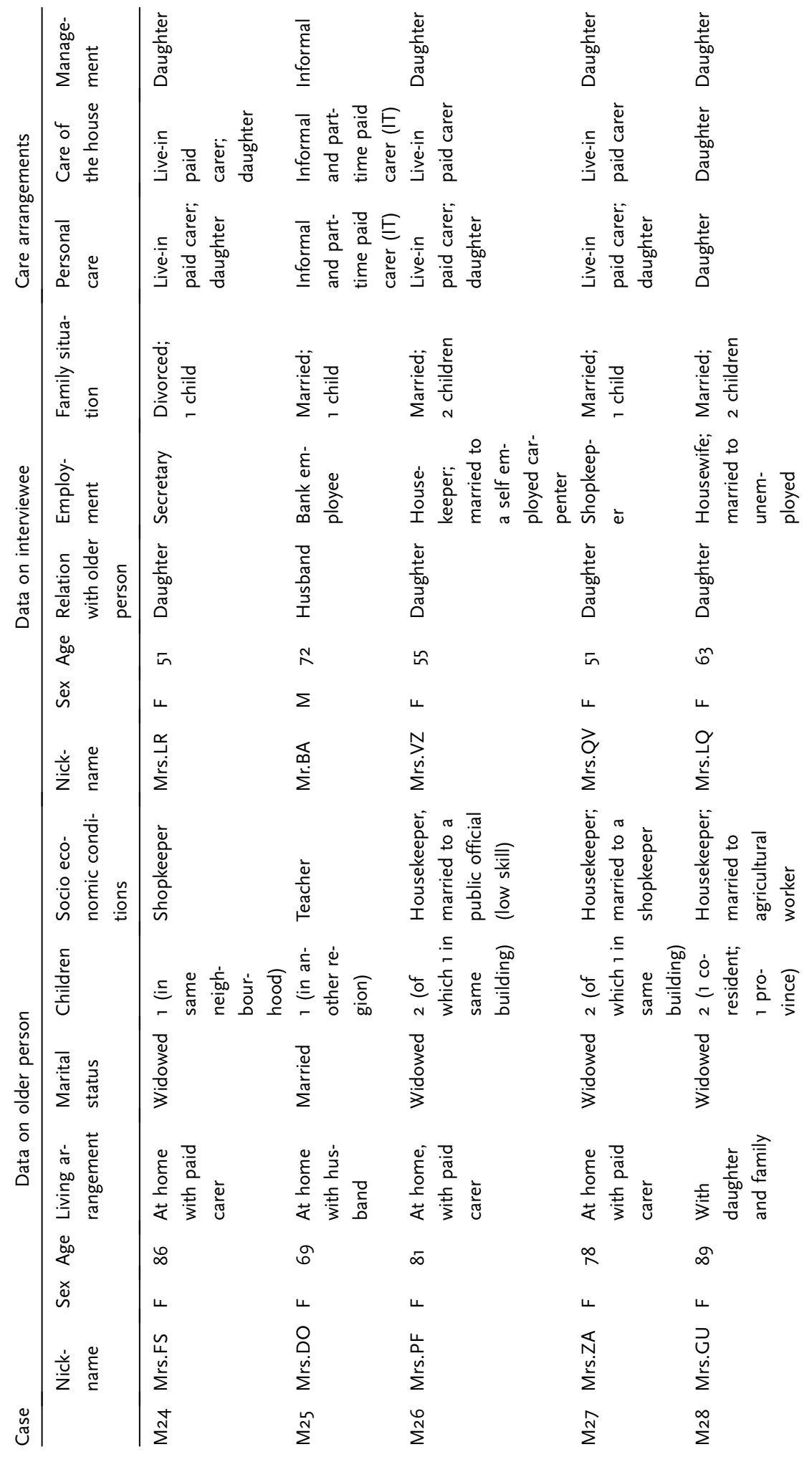




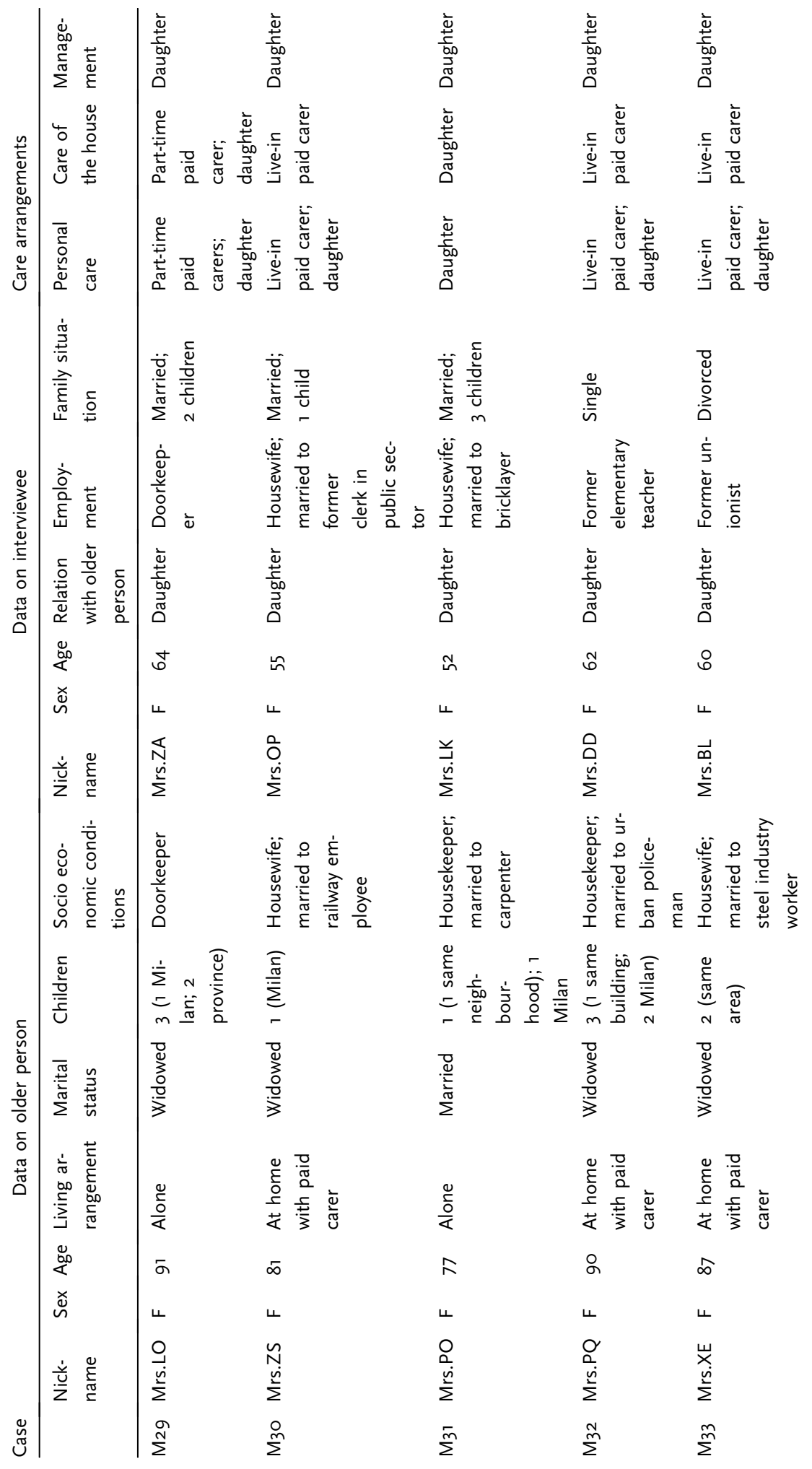




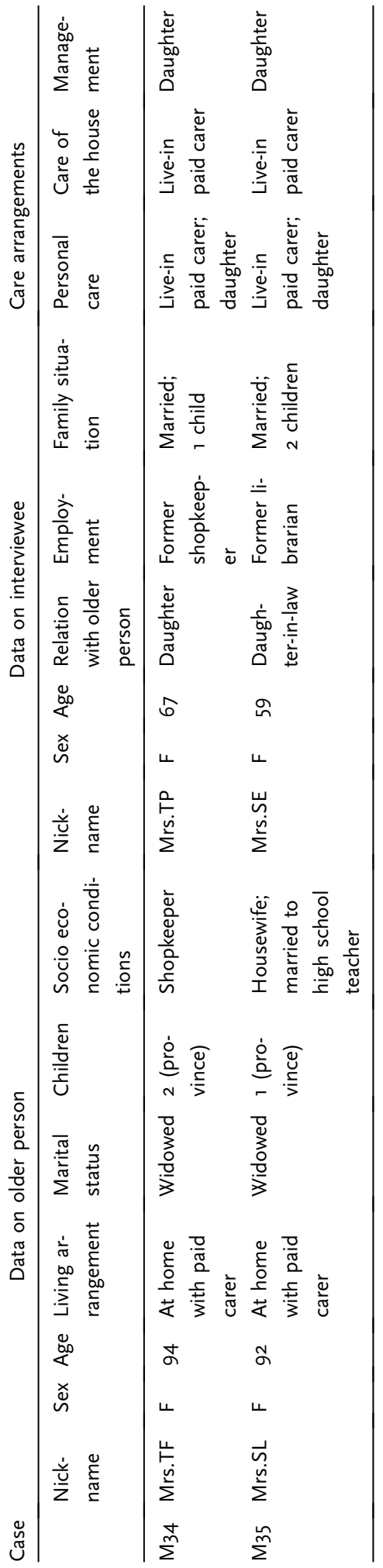




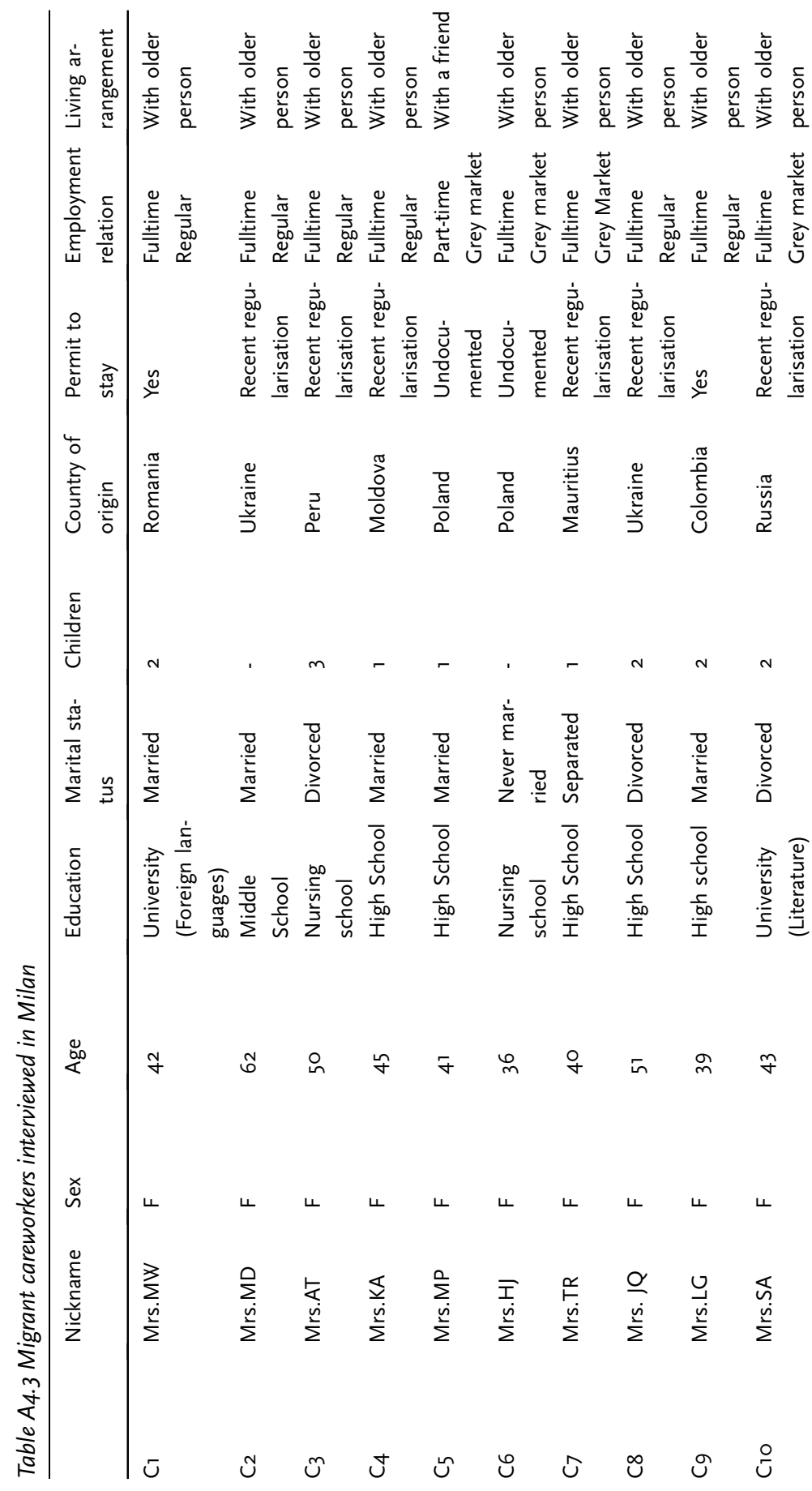




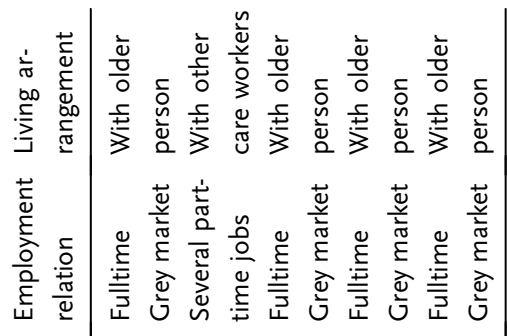

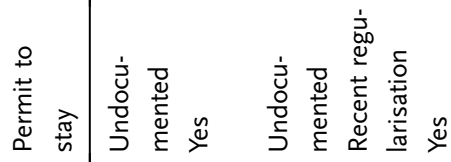

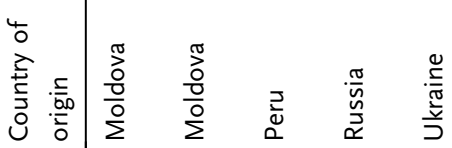

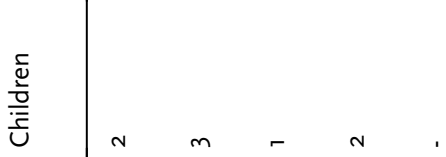

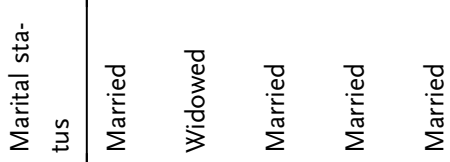

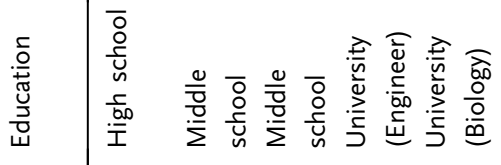

$\stackrel{\infty}{\infty}$ โ

ڤ

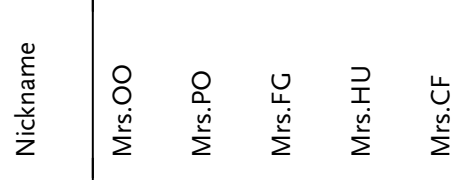

$\bar{U} \quad \stackrel{v}{\tilde{U}} \quad \stackrel{\Xi}{\tilde{U}}$ 



\section{Notes}

\section{Chapter I}

I. This overview is limited to Western European countries.

2. Here we are not concerned with the effective implementation of such obligations in each country, but only with the institutional design.

3. Within "quasi markets", public authorities are responsible for purchasing services from a series of accredited suppliers. The choice of the suppliers is therefore left to the public bureaucracy and not to the consumers.

4. As the welfare regime framework was originally devised for the analysis of employment-related risks and previsions, the application of the concepts of de-commodification, de-familisation and re-stratification (and subsequent societal integration) to the care domain needs a specification. Care differs from monetary resources, as it has to be produced before being allocated.

5. Appendix I provides details on the datasets, on the comparability and limits of the data as well as on the methods.

\section{Chapter 2}

I. Since the nineteenth century, the bad housing conditions of a high proportion of the urban population pushed towards the adoption of health and social measures, with an increasing competence given to local authorities. Nevertheless, such policies were since the beginning managed with the intervention of publicly funded private organisations like churches or political parties. It was the birth of the woningcorporaties (housing associations), which currently own the bulk of the housing asset in the country.

2. On the one hand, the national government took responsibility for income support to guarantee a basic income for the elderly based on a minimum pension. The "Emergency Act for Social Security" passed in 1947 granted a modest income to all elderly people with no means. In 1957 the minimum pension legislation (AOW) was passed, next to which occupational pension funds developed.

3. The "Homes for the Elderly Act" (WBO) of I963 provided a national regulation regarding the elderly's homes.

4. The "Algemene Wet Bijzondere Ziektekosten" (AWBZ) or "General Exceptional Medical Expenses Act" was introduced in I968.

5. The AWBZ represents one of the three "compartments" of the Dutch health care system. The statutory public health insurance and the medical expenses insurance are in a second compartment. In addition, in the third compart- 
ment are found supplementary care insurances (Van Ewijk and Kelder I999).

6. The employer withholds the employees' contributions from their wages and pays them to the tax authorities. Non-employees liable for tax and national insurance contributions pay the AWBZ contribution based on an assessment made by the tax authorities. Insured people under the age of fifteen and above fifteen with no personal income are not liable for contribution.

7. Until 2003 RIO - Regionaal Indicatie Orgaan, subsequently CIZ - Centrum Indicatiestelling Zorg.

8. Besides the AWBZ, the Services for the Disabled Act (WVG), since the midI990s gave local authorities responsibility for the delivery of housing adaptation, transport services and other mobility facilities for the handicapped, including elderly dependent people.

9. In 2007840,214 people received AWBZ-financed care. 653,300 were aged 65 and above, 490 ,I30 of which received extramural care (CBS 2008: I22I23)

Io. The seven new types of care are: domestic help, personal care, nursing, psychosocial support, rehabilitation, treatment, admission to an institution (temporary or long term).

II. Examples are meals on wheels, personal alarming and so on.

I2. As a result of the "Legge Crispi", passed in I89o, the Opere pie, i.e. religiousbased charities, were nationalised and became "Public institutions for assistance and charity" (Ipab - Istituzioni pubbliche di assistenza e beneficienza).

I3. The law was finally passed in 2000 (Law 328/2000 "Legge quadro per la realizzazione del sistema integrato degli interventi e dei servizi sociali”), after some 20 years of discussion.

I4. A comprehensive analysis of the new policy is beyond our aims: therefore, only selected items will be presented. For a review of the principles and the implementation of the law see for instance Gori (ed) 2004 .

I5. The presence of undocumented migrants was estimated at about $75 \%$ of total migrants in 2000 (Reyneri 2003).

16. Law I89/2002 - commonly designated as "Law Bossi-Fini".

I7. Not only because domestic work is one of the most important areas of insertion of migrants in the Italian labour market, but also because regularisation procedures in this sector are usually simpler and follow less strict criteria (Zincone (ed.) 200I).

I8. Figures at: www.inps.it.

\section{Chapter 3}

I. See for a review: Doblhammer and Kytir 200I.

2. See Appendix I for the operationalisation of dependence at the individual and family level and for a discussion of the comparability of the data.

3. The issue of differentiated recourse to invalidity pensions according to territorial areas in Italy refers on one side to clientelistic practices (Ferrera 1996; 2000) and on the other side to the improper use of such instruments against poverty (Saraceno 2003). For a partial revision of this hypothesis, 
see Da Roit 2008. It cannot however be excluded that a higher availability of benefits for disabled people influences individual self-reported (dis)abilities.

4. Tables not included in the text are presented in Appendix 2. They are numbered as A2 followed by the number of the table.

5. The exclusion of the institutionalised individuals from surveys on health conditions is particularly relevant for the older population compared to the general population, among which institutionalisation rates are lower. For instance, only $2 \%$ of the general population lives in institutional settings and is therefore excluded from surveys in the Netherlands (see e.g. Dalstra et al 2002: 932). Nevertheless, this percentage becomes much higher among older age groups, certainly affecting research results of surveys conducted only on the population living independently.

\section{Chapter 4}

I. The operationalisation of the three types of care is explained in more detail in Appendix I.

2. It should be noted that care delivered by (co-resident or non co-resident) relatives on the basis of a personal budget is explicitly included in "informal care" in the 2003 survey.

3. This can only be considered a general indication as the number of households for which we have the information is limited (91, 95 and 72 respectively in I991, I999 and 2003).

4. Tables not included in the text are presented in Appendix 3. They are numbered as $\mathrm{A}_{3}$ followed by the number of the table.

5. The two types of help may be combined.

6. This encompasses services that are purchased via out-of-pocket payments of thanks to a collectively funded personal budget.

7. In I99I and I999 the questionnaires gathered information on the use of paid household assistance and separately asked to indicate whether this help was necessary due to the health conditions of one of the members of the household. Table 4.4 presents both figures (the more restrictive definition is in brackets). By contrast, in 2003 only one question was asked with respect to the recourse to paid services that are necessary due to the health conditions of the elderly. The variable should then be comparable with the stricter definition in the two previous years; however the way in which the question has been asked may have affected the answers.

8. Only households with some dependent members are considered.

9. This phenomenon has already been observed (De Boer et al 200I: r88; De Boer en De Klerk 2006: 147). Different hypotheses have been put forward. First, there is the possibility that part of the elderly - namely the less dependent ones - despite some limitations do not need special assistance in daily living or are sufficiently supported by their household members (De Klerk and Hessing-Wagner I999: I22). Second, it is possible that part of the elderly do not ask for help, as they are not able to complete the administrative procedures in order to request professional help (De Boer en De Klerk 2006: I47; De Klerk and Schellingerhout 2006). Finally it has been hypothesised that a part of the older dependent people do not ask for help as 
they feel that that would man giving up part of their autonomy (De Boer en De Klerk 2006: 147).

Io. The Italian surveys used in this study only provide information on formal and commercial support. A different survey from ISTAT - Parentela e Reti di Solidarietà (Family and Solidarity networks) conducted in 1990, I998 and 2003 provides data on informal care received and given; however it does not include variables relative to dependence.

II. Help received from members of the household is excluded.

I2. In the Dutch case we saw two different definitions of commercial household assistance: a broader definition that encompassed all of the services and a narrower one that included only those services dealing with the health and disability issues of one or more household members.

13. In the I994 survey on health conditions and recourse to health services the question was not asked, differently from the I999-2000 survey. The information was collected for the first time in 1997, in a survey that does not contain variables regarding the functional ability of the interviewees, but only information on health status.

I4. "What would you do if you were not personally able to take care of your small children during the day?" "What would you do if one of your parents or a close relative was no more able to live on his/her own?"

I5. The missing distinction between formal care and commercial care is in itself an indicator of the limited relevance that researches attributed to market solutions at the time.

I6. Out of 65 people ten received injections, five of which from formal or commercial services; thirteen received physiotherapy, four of which from formal or commercial services, 59 received help with household activities; nineteen of which from formal and commercial services (Ciorli and Della Croce I994, p. пі6).

I7. Out of 65 people, 27 received help with personal care, two of which from formal and commercial services; 40 received continuous supervision, three of which from formal and commercial services (Ciorli and Della Croce I994, p. II7).

I8. The intensity of the assistance received cannot be compared due to the lack of data from Italy.

I9. However, this figure should be interpreted carefully, as shown earlier in this chapter.

\section{Chapter 5}

I. The interview template used for migrant care workers follows the same lines as the one used in the research conducted that same year but in different geographical contexts (see Da Roit and Castegnaro 2004). Moreover, as local studies on the badanti have flourished over the past few years in Italy, usually based on local qualitative samples, some terms of reference both in the same local context (Gori and Da Roit 2002) and in other territorial areas (Castegnaro 2002; Da Roit and Castegnaro 2004; Piva 200I) are available.

2. In the text that follows quotations from the interviews are used. Each quotation is followed by the nickname of the interviewee and the code of the rela- 
tive case. The cases are coded with A (Amsterdam) or M (Milan) followed by the number of the case. The code for care workers is made with the letter "C" (care worker) followed by the number of the case. The full list of cases is provided in Appendix 4, where the overall strategy of the qualitative study is presented.

3. The data provided by Tot\&Met show that out of all assessments for home care for the elderly (n. 15354) within in a year time (between march 2002 and march 2003) the help provided ranged between fifteen minutes per week and 20 hours per day (only very few cases); the mean was slightly less than one hour per day and the median 3.5 hours per week.

4. This represents a specific feature of the Milanese case. In most municipalities care services have been, in principle, made available to all citizens, despite their income and assets. Sometimes income related co-payments are applied.

5. Next to the Indennità di accompagnamento, in other researches it was found that local care allowances played a role in financing commercial care (Da Roit and Castegnaro 2004). In our sample we have no examples of this, also in relation to the low incidence of local benefits in Milan (for a similar result see: Da Roit and Naldini 2008).

6. English quotes of Italian interviews are own translations. When quoting key actors, the role is mentioned in brackets. When quoting an interview with a caregiver of an elderly dependent, the initials of the interviewee and the reference code of the case will be reported. Within codes of the cases of the elderly ' $M$ ' indicated that the interview refers to a Milanese case and ' $\mathrm{A}$ ' that the interview refers to a case in Amsterdam).

7. The standards, besides structural requirements of the buildings hosting a residential service, are expressed in terms of time per resident performed by each professional (medicines, nurses, care assistants etc.). Meeting such requirements is a necessary condition for accessing the funding through the health fund.

8. The funding is meant for covering health care expenses.

9. The co-payment system is decided at the national level and applies to anyone staying in a nursing home based on an assessment and financed by the national insurance. There are two levels of fee. For the first six months of stay in an institution a lower fee applies: since 2003 I0\% of the overall income with a minimum of 100 to a maximum of 556 euro per month). After six months a higher fee applies that corresponds to the net income with several deductions (maximum I,624 euro per month since 2003). At least 240 euro per months are available to the elderly residing in an institution. The data were collected from the website of the College voor Zorgverzekeringen (CVZ) in 2003, at the time of the interviewing.

Io. Since 2002 new means-testing rules have been introduced by the municipality of Milan, which exclude the income of non-cohabiting children and relatives from calculations. At the time of the research the old rule was still in use. See infra.

II. If the older person's income (and before 2004 that of a set of non-cohabiting relatives) exceeds a certain threshold the municipality does not provide any income support in accessing residential care services. If the income is below the threshold, the fees are entirely paid by the municipality when a place in a 
nursing home becomes available. The rules may differ also considerably in other municipalities.

\section{Chapter 6}

I. For instance, being employed significantly reduced the probability of being a caregiver; a high level of impairment, geographical proximity and being an only child increased such probability.

2. It has to be recalled here that, as the interviewees were caregivers of the elderly their opinions might in fact be biased by their involvement in care. This is a recurrent limitation in studies on filial obligations, when conducted on people presently or previously involved in providing instrumental support. Nevertheless, studying variations among caregivers might provide useful insights into the factors affecting different attitudes and different levels and types of engagement.

3. We shall come back to this second point later.

\section{Appendices}

I. ISTAT, Indagine Multiscopo reti sociali e condizioni dell'infanzia.

2. The Italian figures were respectively I9.0\% and $4.6 \%$ in the same year (ISTAT on line; www.istat.it).

3. The Dutch average was I3.7\% (CBS - StatLine; www.cbs.nl).

4. www.onstat.amsterdam.nl.

5. People aged $6_{5}$ and above were $15.8 \%$ in $\mathrm{I}_{9} 80$ and $14.9 \%$ in $1990(\mathrm{O}+\mathrm{S}$ online; www.onstat.amsterdam.nl).

6. In Lombardy, the region to which Milan belongs, the activity rate of women between 35 and 44 years of age was $74.0 \%$ in 2003 , against a national average of $63.6 \%$ (ISTAT, Indagine sulle forze di lavoro, elaborated by CNEL; www. cnel.it).

7. People living in institutions on 31.I2.2000 amounted to 3,892. Nevertheless some $10 \%$ of people entering and leaving institutions during the year were younger than 65 (Comune di Milano 2002: III).

8. www.regione.lombardia.it.

9. The estimate is based on data published from the Municipality of Milan (Comune di Milano 2002: IOO-IOI), according to the following criteria. The service was organised both using municipality employees (65) and operators of different cooperatives (344). The hours of home help provided through cooperative workers were on average in all 485,665, meaning I,4II hours per year per person. Applying the same number of hours worked to employees of the municipality we obtain some 577,380 hours of home help provided throughout the year, i.e. 2.3 hours per week per user.

Io. Beds passed from 8384 in I988 to 4372 in I997, while the number of homes has diminished less steeply, from 52 to 44 (O+S I998:84).

II. According to the Dutch Institute for health research, in the Netherlands in I998, on average 2.3 hours of home care were provided per independently living inhabitant (the population is weighted according to age structure). Re- 
gional differences ranged from I.83 in Mid-Holland to 2.7 in The Hague. In Amsterdam the ratio is higher than 2.5 according to the data provided by Nivel with reference to 2002; http://www.nivel.nl/oc2/page.asp?PageID= 426).

I2. It is useful to recall that the elderly receiving social home care amounted to 4,700 in 2000 (Comune di Milano 2002: 100), beneficiaries of the Indennità di accompagnamento aged 65 and above in the city are estimated at 18,000 ( $6 \%$ of people aged 65 and above) and beneficiaries of the local cash allowance amounted to 599 in 2000 (Comune di Milano 2002: 106).

I3. www.onstat.amsterdam.nl. 



\section{Bibliography}

Abrahamson, P. (I999), "Le modèle scandinave de protection sociale", in DREES, Comparer les systèmes de protection sociale en Europe du Nord et en France. Rencontres de Copenhague, vol. 4-I, Collection MiRe, Maison des Sciences de l'Homme. Ange-Guépin: Nantes: 3I-64.

Alber, J. (1996), “The Debate about Long-Term Care Reform in Germany”, in OECD (I996b), Caring for Frail Elderly People. Policies in Evolution, Paris: OECD.

Albertini, M., M. Kohli, and C. Vogel (2007), "Intergenerational Transfers of Time and Money in European Families: Common Patterns Different Regimes?”, Journal of European Social Policy I7(4): 319-334.

Ambrosini, M., and P. Boccagni (2002), L'inserimento delle donne immigrate nel mercato del lavoro e nei servizi di cura. Rapporto di ricerca Equal Promo Care, Trento: Università di Trento.

Andall, J. (2000), Gender, Migration and Domestic Service: The Politics of Black Women in Italy. Aldershot: Ashgate.

Anderson, M., F. Bechhofer, and J. Gershuny (I994), "Introduction”, in M. Anderson, F. Bechhofer, and J. Gershuny (eds.), The Social and Political Economy of the Household, Oxford: Oxford University Press: I-I6.

Anttonen, A., and J. Sipila (I996), "European Social Care Services. Is it Possible to Identify Models?", Journal of European Social Policy 6(2): 87-Ioo.

Arber, S., and J. Cooper (2000), "Gender and Inequalities in Women's Health Across the Life Course”, in E. Annandale, and K. Hunt (eds.), Gender Inequalities in Health, Buckingham: Open University Press.

Arber, S., and J. Ginn (I993), "Gender and Inequalities in Health in Later Life", Social Science and Medicine 36(I): 33-46.

Aronson, J. (I992), “Women's Sense of Responsibility for the Care of Old People: 'But Who Else is Going to Do It?’”, Gender and Society 6(ז): 8-29.

Artoni, R., and E. Ranci Ortigosa (I989), La spesa pubblica per l'assistenza in Italia, Milan: Angeli.

Arts, S.E.J. (2002), Caring as an Occupation: Content and Quality of Working Life among Home Helps, Utrecht: Nivel - Universiteit van Maastricht.

Attias-Donfut, C., N. Lapierre, and M. Segalen M. (2002), Le nouvel esprit de famille, Paris: Odile Jacob.

Barbagli, M., A. Colombo, and G. Sciortino (eds.) (2004), I sommersi e i sanati, Bologna: Mulino.

Bartlett, W., and J. Le Grand (I993) Quasi-markets and Social Policy. Palgrave: Macmillan.

Baumol, W. (I967), "The Macroeconomics of Unbalanced Growth", American Economic Review 57(3): 415-426.

- (ig68), "Macroeconomics of Unbalanced Growth: Comment", The American Economic Review 58(4): 896-897. 
Benassi, D. (200I), "Le pensioni in Lombardia”, in C. Facchini (ed.), Anziani, pluralità e mutamenti. Milan: Angeli.

Bettio, F., and J. Plantenga (2004), "Comparing care regimes in Europe", Feminist Economics IO(I): 85 -II3.

Bettio, F., A. Simonazzi, and P. Villa (2006), "Change in Care Regimes and Female Migration: the 'Care Drain' in the Mediterranean”, in: Journal of European Social Policy I6 (3): 27I-285.

Bison, I., and G. Esping-Andersen (2000), “Unemployment, Welfare Regimes and Income Packaging", in D. Gallie, and S. Paugam (eds.), Welfare Regimes and the Experience of Unemployment in Europe, Oxford: Oxford University Press.

Bonarini, F. (2002), "La popolazione anziana degli istituti assistenziali secondo i dati del censimento del I99I", in R. Ongaro (ed.), In famiglia o in istituto. L'età anziana tra risorse e costrizioni, Milan, Angeli: I47-I72.

Bonoli, G. (2005). "The Politics of the New Social Policies: Providing Coverage against New Social Risks in Mature Welfare States", Policy and Politics 33(3) 43I-49.

Bouget, D. (2003), "Vieillesse, dépendance et protection sociale en Europe", in C. Martin (ed.) (2003): 27I-292.

Bradshaw, J.R. (I998), "Politique sociales: exemples de simulation”, in Comparer les systèmes de protection sociale en Europe. vol. I, Rencontres d'Oxford, Paris: Mire: 47I-492.

Bradshaw, J.R., J. Ditch, H. Holmes, and P. Whiteford (I993), "Support for Children: a Comparison of Arrangements in Fifteen Countries", Department of Social Security Research Report, n.2I, HMSO.

Breeze, E., A. Sloggett, and A.E. Fletcher (I999a), "Socioeconomic Status and Transitions in Status in Old Age in Relation to Limiting Long-Term Illness Measured at the I991 Census; Results from the UK Longitudinal Study", European Journal of Public Health 9(4): 265-70.

Broese van Groenou, M. (I995), "The Proximate Network", in P.M. Knipscheeret et al. (eds.), Living Arrangements and Social Networks of Older Adults, Amsterdam: Free University Press: II5-I30.

Broese van Groenou M., and D.J.H. Deeg (2000), "Sociaaleconomische gezondheidsverschillen bij ouderen”, Tijdschrift voor sociale gezondheidszorg 78: 294302.

Broese van Groenou, M., and T. van Tilburg (2003), "Network Size and Support in Old Age: Differentials by Socio-Economic Status in Childhood and Adulthood", Ageing and Society 23(5): 625-645.

Bytheway, B. (1987), "Care in the Families of Redundant Welsh Steelworkers", in S. Di Gregorio (ed.), Social Gerontology: New Directions, London: Croom Helm: I77-I87.

Caponio, T., and A. Colombo (2005), Migrazioni globali, integrazioni locali, Bologna: Mulino.

Carchedi, F., G. Mottura, and E. Pugliese (eds.), (2003), Il lavoro servile e le nuove schiavitù, Franco Angeli, Milan.

Caritas (2003), Dossier statistico immigrazione 2003, Rome.

Castegnaro, A. (2002), "La rivoluzione occulta nell'assistenza agli anziani. Le aiutanti domiciliari”, Studi Zancan, 2: I-24. 
Centraal Bureau voor de Statistiek (CBS) (2008), Gezondheid en zorg in cijfers 2008, The Hague and Heerlen: CBS

Ciorli, A., and F. Della Croce (I994), Per forza e per amore. L'assistenza ad anziani non autosufficienti dimessi da un ospedale milanese, Milan: IRER-Angeli.

Clayton, R., and J. Pontusson (I998), "Welfare-State Retrenchment Revisited: Entitlement Cuts, Public Sector Restructuring, and Inegalitarian Trends in Advanced Capitalist Societies", World Politics, 5I(I): 67-98.

Colombo, A. (2003), "Razza, genere, classe. Tre dimensioni del lavoro domestico in Italia”, Polis I7(2): 3I7-342.

Colombo, A., and G. Sciortino (2005), Sistemi migratori e lavoro domestico in Lombardia, Ires Lombardia.

Comailles, J., and C. Martin (I998), Les enjeux politiques de la famille, Paris: Bayard.

Commissie Sociaal-Economische Deskundigen (CSED) (I999), Gezondheidszorg in het licht van de toekomstige vergrijzing (Health care in light of the future greying of the population), The Hague: Sociaal Economische Raad.

Commissione per l'analisi per le compatibilità macroeconomiche della spesa sociale (Commissione Onofri) (I997), Relazione finale, Rome.

Comune di Milano (2002), I servizi sociali a Milano, Milano: Angeli.

Costa-Font, J., and A. Garcia-Gonzalez (2007), "Long-term Care Reform in Spain", Eurohealth I3(I): 20-22.

Daatland, S. O. (I990). “What are Families for?’ On Family Solidarity and the Preference for Help", Ageing and Society IO(I): I-I5.

Dahl, E., and G.E. Birkelund (I997), "Health Inequalities in Later Life in a Social Democratic Welfare State", Social Science and Medicine 44(6): 87I-8I.

Dalstra, J.A.A., E.A.Kunst, J.J.M .Geurts, F.J.M. Frenken, and J.P. Mackenbach (2002), "Trends in Socioeconomic Health Inequalities in the Netherlands: I98I-I999", Journal of Epidemiology and Community Health 56(I2): 927-934.

Daly, M., and J. Lewis (I998), "Introduction: Conceptualising Social Care in the Context of Welfare State Restructuring", in Lewis J. (ed.) (I998), Gender, Social Care and the Welfare State Restructuring in Europe, Aldershot: Ashgate.

Da Roit, B. (200I), Politiche pubbliche per l'assistenza. Attori, cambiamenti, risorse in Lombardia, Milan: Angeli.

- (2002) "Il mercato privato dell'assistenza in Italia", in C. Gori (ed.) Il welfare nascosto, Rome: Carocci: 39-57.

- (2007a), "Changing Intergenerational Solidarities within Families in a Mediterranean Welfare State. Elderly care in Italy", Current Sociology 55(2): 250268.

- (2007b), "Gli assegni di cura in Italia, un primo bilancio", in S. Pasquinelli (ed.), Nuovi strumenti di sostegno alle famiglie. Assegni di cura e voucher sociali, Carocci, Rome: 39-57.

- $(2007 \mathrm{C})$, "Politiche regionali per la non autosufficienza a confronto: Lombardia, Emilia-Romagna e Veneto”, in G. Costa (ed.), Politiche per la non autosufficienza e sistemi locali di welfare, Rome, Carocci.

— (2008), "Gli anziani beneficiari dell'indennità di accompagnamento. Risultati di un'indagine esplorativa”, C. Ranci (ed.), Tutelare la non autosufficienza. Una proposta di riforma dell'indennità di accompagnamento, Rome: Carocci.

- (2009), "Le politiche per gli anziani non autosufficienti", in Y. Kazepov (ed.), Le politiche sociali territoriali, Rome: Carocci. 
Da Roit, B., and C. Castegnaro (2004), Chi cura gli anziani non autosufficienti?, Milan: Angeli.

Da Roit, B., and A. Gambino (2005), "La spesa", in C. Gori (ed.), Politiche sociali di centro destra, Rome, Carocci.

Da Roit, B., B. Le Bihan, and A. Oesterle (2007). "Long-Term Care Reforms in Italy, Austria and France. Variations in Cash-for-Care Schemes”, Social Policy Q. Administration 4I(6): 653-67I.

Da Roit, B., and M. Naldini (2008), "Working and Caring for an Older Parent in Italy", Woups Project, Italian National Report on the Qualitative Study, August 2008.

Da Roit, B., and S. Sabatinelli (2005) "Il modello di welfare mediterraneo tra famiglia e mercato. Come cambia la cura di anziani e bambini in Italia”, Stato e Mercato, 74(2): 267-90.

Dautzenberg, M. (2000), Daughters Caring for Elderly Parents, Maastricht: Universitaire Pers Maastricht.

De Boer, A. (I999), Housing and Care for Older People: a Macro-Micro Perspective, Nederlandse Geografische Studies 253, Utrecht: Urban Research Centre.

De Boer A., J. Hessing-Wagner, M. de Klerk, and S. Kooiker (200I), "Take up of services and care provisions", in de Klerk M.M.Y. (ed.), Report on the Elderly 2001. Changes in Living Situation, The Hague: Social and Cultural Planning Office of The Netherlands: I67-2II

De Boer, A., and J. De Klerk (2006), "Physical Disabilities and Care", in A. De Boer (ed.), Report on the Elderly 2006. Changes in the Lives and Living Situation of Elderly Persons in the Netherlands, Social and Cultural Planning Office of the Netherlands, The Hague, December 2006: I42-I66.

De Boer, A., J. Hessing-Wagner, M. de Klerk, and S. Kooiker (200I), “Take up of Services and Care Provisions", in M.M.Y. de Klerk (ed.), Report on the Elderly 2001. Changes in Living Situation, The Hague: Social and Cultural Planning Office of the Netherlands: I67-2II.

De Jong Gierveld, J., and T. Fokkema (1998), "Geographical Differences in Support Networks of Older Adults", Tijdschrift voor Economische en Sociale Geografie, 89(3): 328-336.

De Jong Gierveld, J., R. Plomp, and T.G. van Tilburg (I997), "Intimacy, but at a distance: De relatie tussen ouders en hun volwassen kinderen in Nederland en Italië", Afstand en betrokkenheid, Amsterdam: Koninklijke Nederlandse Academie van Wetenschappen.

De Klerk, M., J. Hessing-Wagner (I999), "Health, Well-Being and the Uptake of Healthcare", in M.M.Y. de Klerk, and J.M. Timmermans (eds.), Report on the Elderly 1998, The Hague: Social and Cultural Planning Office of the Netherlands.

De Klerk, M., and R. Schellingerhout (2006). Ondersteuning gewenst. Mensen met lichamelijke beperkingen en hun voorzieningen op het terrein van wonen, zorg, vervoer en welzijn. Den Haag: Sociaal en Cultureel Planbureau.

Dechaux, J.-H. (I990), “Les échanges économiques au sein de la parentèle”, Sociologie du Travail 32(I): 73-94.

Doblhammer, G., and J. Kytir (200I), "Compression or Expansion of Morbidity? Trends in Healthy-Life Expectancy in the Elderly Austrian Population between I978 and I998", Social Science and Medicine 52: 385-391.

Domberger, S. (1998), The Contracting Organization: A Strategic Guide to Outsourcing. Oxford: Oxford University Press. 
Dykstra, P.A. (I995), “Network Composition”, in C.P.M. Knipscheer, J. de Jong Gierveld, T.G. van Tilburg, and P.A. Dykstra (eds.), Living Arrangements and Social Networks of Older Adults, Amsterdam: Free University Press, 97-II4.

Egging, E., E. Pommer, and I. Woittiez (2008), De ontwikkeling van de AWBZuitgaven, Sociaal en Cultureel Planbureau, The Hague, April 2008.

Esping-Andersen, G. (I990), The Three Worlds of Welfare Capitalism, Cambridge: Polity Press.

- (I999), The Social Foundations of Postindustrial Economies, Oxford: Oxford University Press.

Evers, A. (I998), “The New Long-Term Care Insurance Program in Germany”, Journal of Aging and Social Policy Io(I): 77-98.

Facchini, C. (1996), “Tipologia familiare, reti di relazione e reti di supporto”, in Mauri L., and L. Breveglieri, Vivere l'età anziana. Indagine sociologica in un'area avanzata, Milan: Angeli

Facchini, C. (I997), "Invecchiare in una grande città. Gli anziani milanesi tra nuovi rischi e nuove opportunità", Senectus 4(I2): 59-73.

- (2003), Anziani e rete dei servizi, Provincia di Milano-Università degli Studi di Milano Bicocca.

Fargion, V. (I997), Geografia della cittadinanza sociale in Italia, Bologna: Il Mulino.

Ferrario, P. (200I), Politica dei servizi sociali. Strutture, trasformazioni, legislazione, Rome: Carocci.

Ferlie, E., L.E. Lynn Jr , and C. Pollitt (2007) The Oxford Handbook of Public Management, Oxford: Oxford University Press.

Ferrera, M. (1996), “The 'Southern Model' of Welfare in Social Europe”, Journal of European Social Policy 6(I): 17-37.

Ferrera, M. (1998), Le trappole del welfare, Bologna: Il Mulino.

Finch, J. (1987), "Family Obligations and the Life Course", in A. Bryman, P. Allatt, T. Keil (eds.), Rethinking the Life Cycle, London: MacMillan: $155^{-169}$

- (1989), Family Obligations and Social Change, Oxford, Polity Press.

Finch, J., and J. Mason (I99I), "Obligations of Kinship in Contemporary Britain: is there Normative Agreement?”, The British Journal of Sociology 42(3): 345367.

FORMEZ (2003), L'attuazione della riforma del welfare locale, Rome: FORMEZ.

Fries, J.F. (I989), “The Compression of Morbidity: Near or Far?”, Milbank Memorial Foundation Quarterly/Health and Society 67: 208-232.

Gaymu, J, P. Festy, M. Poulain, and G. Beets (eds.) (2008), Future Elderly Living Conditions in Europe, Paris: Institut National d'Etudes Démographiques.

Giumelli, G. (I994), Anziani e assistenza. Dalla carità verso la sicurezza sociale, Milan: Angeli.

Goerke, L. (I996), "Introduction of Long-Term Care Insurance in Germany", International Social Security Review 49(4): 25-38.

Götting, U., K. Haug, and K. Hinrichs (I994), “The Long Road to Long-Term Care Insurance in Germany", Journal of Public Policy I4(3): 285-309.

Gori, C. (ed.), (2002), Il welfare nascosto, Rome: Carocci.

Gori C. (ed.) (2004), La riforma dei servizi sociali in Italia. L'attuazione della legge 328 e le sfide future, Rome: Carocci. 
Gori, C., and B. Da Roit (2002), "Tra mercato privato e risorse familiari”, in C. Gori (ed.), Il welfare nascosto. Il mercato privato dell'assistenza in Italia e in Europa, Rome: Carocci.

Gori, C., and R. Torri (200I), "Gli assegni di cura in Italia", in C. Ranci (ed.), L'assistenza agli anziani in Italia e in Europa: verso la costruzione di un mercato sociale dei servizi, Milan: Angeli.

Green-Pedersen, C. (200I), The Politics of Justifications. Party Competition and Welfare State Retrenchment in Denmark and the Netherlands from 1982 to 1998, Amsterdam: Amsterdam University Press.

Gruenberg, E.M. (I977), “The Failure of Success”, Milbank Memorial Foundation Quarterly/Health and Society 55(I): 3-24.

Hanssen, J.I. (I997), "The Scandinavian Model as Seen from a Local Perspective", in J. Sipila (ed.) (I997), Social Care Services: the Key to the Scandinavian Welfare Model, Aldershot: Ashgate.

High, D.M., and G.D. Rowles (I995), "Nursing Home Residents, Families and Decision Making: Toward an Understanding of Progressive Surrogacy", Journal of Aging Studies 9(2): IOI-II7.

Huisman, M., A.E. Kunst, and J.P. Mackenbach (2003), "Socioeconomic Inequalities in Morbidity among the Elderly; a European Overview", Social Science and Medicine 57(5): 86I-873.

Hutten, J.B.F., and A. Kerkstra (I996), Home Care in Europe, Aldershot: Arena.

Igel, C., M. Brandt, K. Haberkern, and M. Szydlik (2009) "Specialization between Family and State Intergenerational Time Transfers in Western Europe", Journal of Comparative Family Studies 40(2): 203-226.

IRER (I99I), L'indagine sociale in Lombardia, Milan: Angeli.

- (2000) Anziani, stato di salute e reti sociali. Un'indagine diretta sulla popolazione anziana della Lombardia, Milan, Guerini e Associati.

ISTAT (1994), Indagine multiscopo sulle famiglie. Anni 1987-1991. La condizione degli anziani, Rome.

- (200I), Parentela e reti di solidarietà, Indagine multiscopo sulle famiglie "Aspetti della vita quotidiana". Anno 1998, Rome: ISTAT.

- (2002), I presidi residenziali socio-assistenziali: anno 1999, Argomenti, Rome: ISTAT.

- (2006a), L'assistenza residenziale in Italia: Regioni a confronto, Anno 2003 http://www.istat.it/dati/dataset/2006030I_oI/.

- (2006b), La prima indagine censuaria sugli interventi e i servizi sociali dei Comuni. Anno 2003, Rome.

- $(2006 \mathrm{c})$, Parentela e reti di solidarieta. Indagine Multiscopo sulle famiglie "Famiglia e soggetti sociali". Anno 2003. Informazioni, no. 26, Rome.

Jacobzone, S., E. Cambois, E. Chaplain, and J.M. Robine (I999), “The Health of Older Persons in OECD Countries: Is it Improving Fast Enough to Compensate for Population Ageing?", Labour Market and Social Policy Occasional Papers 37, Paris: OECD.

Jensen, C. (2008), "Worlds of Welfare Services and Transfers", Journal of European Social Policy I8; I5I 
Jenson, J., S. Jacobzone (2000), "Care Allowances for the Frail Elderly and their Impact on Women Care-Givers", Labour Market and Social Policy Occasional Papers 4I, Paris: OECD.

Johansson, L., G. Sundstrom, and L.B. Hassing (2003), "State Provision Down, Offspring's Up: the Reverse Substitution of Old-Age Care in Sweden", Ageing and Society 23(3): $269-280$.

Johnson, R., A. Lo Sasso (2006) "Family Support of the Elderly and Female Labor Supply: Tradeoffs among Caregiving, Financial Transfers, and Work", in S. Harper (ed.) Families in Ageing Societies, Oxford: Oxford University Press: II442.

Klein Ikkink, K., T. van Tilburg, et al. (I999). "Perceived Instrumental Support Exchanges in Relationships between Elderly Parents and Their Adult Children: Normative and Structural Explanations", Journal of Marriage and the Family 6I(4): 83I-844.

Knijn, T. (200I), "Care Work: Innovations in the Netherlands", in Daly M. (ed.), Care Work. The Quest for Security, Geneva: ILO: 159-I74.

Knijn, T., and B. Da Roit (2008), "Working and Caring for an Older Parent in the Netherlands", Woups Project, Dutch National Report on the Qualitative Study, August 2008.

Knijn, T., and M. Kremer (1997), "Gender and the Caring Dimension of Welfare States: Toward Inclusive Citizenship“, Social Politics 4(3): 328-36I.

Kraan, R.J., J. Baldock, B. Davies, A. Evers, L. Johansson, M. Knapen, M. Thorslund, and C. Tunissen (1991), Care for the Elderly: Significant Innovations in Three European Countries, Frankfurt: Campus Verlag.

Kremer, M. (2006). "Consumer in Charge of Care: the Dutch Personal Budget and its Impact on the Market, Professionals and the Family". European Societies 8 (3), 385-40I.

Kroger, T. (I997), "Local Government in Scandinavia: Autonomous or Integrated into the Welfare?", in J. Sipila (ed.) (I997), Social Care Services: the Key to the Scandinavian Welfare Model, Aldershot: Ashgate.

Kuiper, D.Th, C. Bremmer, et al. (1983), "Van verzorgingstaat naar verzorgingsmaatschappij”, Aantekening over de christendemocratische inzet in de jaren '80, in Extra Edities CdAktueel, Oktober 32-48.

Kuiper, D.Th, C. Bremmer, et al. (1987), Discussienota over de verantwoordelijke samenleving, The Hague, CDA.

LABOS (I992), Regioni e politiche socio assistenziali. IV Rapporto, Rome: TER.

- (I994), Regioni e politiche socio assistenziali. V Rapporto, Rome: TER.

Leibfried, S. (I993), “Towards a European Welfare State”, in C. Jones (ed.), New Perspectives on the Welfare State, London: Routledge (republished as "Towards a European Welfare State: on Integrating Poverty Regimes in the European Community", in C. Pierson, F.G. Castles (2000), The Welfare State Reader, Cambridge: Polity Press: 190-206.

Lewis, J. (I992), "Gender and the Development of Welfare Regimes", Journal of European Social Policy 2(3): I59-73.

- (1997a), "Gender and Welfare Regimes: Further Thoughts", Social Politics: International Studies in Gender, State Society 4(2): IGo-I77. 
— (I997b), "Family Policies and Role of the Families. Introduction", in B. Palier (ed.) (I997), Comparing Social Welfare Systems in Southern Europe vol. 3, Florence Conference, Paris: Mire: 305-313.

- (2002a), "Gender and Welfare State Change", European Societies 4(4), 33I-357.

- (2002b), "Le 'community care' au Royaume Uni: le tournant des années I990”, in Martin C. (ed.), La dépendance des personnes âgées. Quelles politiques en Europe?, Rennes: Presses Universitaires de Rennes.

Lewis, J., M. Campbell, and C. Huerta (2006). "Patterns of Paid and Unpaid Work in Western Europe: Gender Commodification, Preferences and the Implications for Policy", Journal of European Social Policy I8(I), 2I-37.

Liao, Y., D.L. McGee, J.S. Kaufman, G. Cao, and R.S. Cooper (I999), “Socioeconomic Status and Morbidity in the Last Years of Life", American Journal of Public Health 89(4): 569-572.

Lidz, C.W., L. Fischer, R.M. Arnold (1992), The Erosion of Autonomy in Long-Term Care, New York: Oxford University Press.

Lundsgaard, J. (2005) "Consumer Direction and Choice in Long-Term Care for Older Persons, Including Payments for Informal Care: How Can it Help Improve Care Outcomes, Employment and Fiscal Sustainability?", OECD Health Working Papers no. 20, Paris: OECD.

Lye, D.N. (I996), "Adult Child-Parent Relationships", Annual Review of Sociology 22: 79-IO2.

Martin, C. (ed.) (2002), La dépendance des personnes âgées. Quelles politiques en Europe?, Rennes: Presse Universitaire de Rennes.

Mateman, S., and P.H. Renooy (200I), Undeclared Labour in Europe: Towards an Integrated Approach of Combating Undeclared Labour, Regioplan, Amsterdam.

Mesini, D., S. Pasquinelli, and G. Rusmini (2006), Il lavoro privato di cura in Lombardia. Caratteristiche e tendenze in materia di qualificazione e regolarizzazione. Rapporto di ricerca Irs, Milan.

Micheli, G.A. (I99I), "I servizi socio-assistenziali e sanitari”, in IRER, Social survey in Lombardia. Contributi sulla formazione della domanda sociale, Milan: Angeli: 2I-9I.

- (I996), "Piantar radici perché non avanzi il deserto", in L. Mauri, and L. Breveglieri, Vivere l'età anziana. Indagine sociologica in un'area avanzata, Milan: Angeli

-(I999), “'Vis resistiva': come indurre a ridefinire lo spazio-azione dell'anziano”, in E. Mingione (ed.), Le sfide dell'esclusione: metodi, luoghi, soggetti, Bologna: Mulino.

Micheli, G.A., and A. Rosina (2008), "Venticinque anni di indennità di accompagnamento in Italia: bilancio demografico e linee di tendenza", in C. Ranci (ed.), Tutelare la non autosufficienza, Rome: Carocci: 40-83.

Millar, J., and A. Warman (1996), Family Obligations in Europe, London: Family Policy Studies Centre.

Miltenburg, T., C. Ramakers (1998), Beleidsgerichte evaluatie persoonsgebonden budget 1996-1997. Nijmegen: Instituut voor Toegepaste Sociale Wetenschappen.

Mingione, E. (1997), Sociologia della vita economica, Rome: Carocci.

Ministero della Salute (2005), Annuario Statistico del Servizio Sanitario Nazionale. Flussi informativi delle unità sanitarie locali e delle aziende ospedaliere, Sistema 
informativo nazionale, Rome, on line: http://www.ministerosalute.it/servizio/ sezSis.jsp?label=ssn.

Naldini, M. (2002), "Le politiche sociali e la famiglia nei Paesi Mediterranei. Prospettive di analisi comparata", Stato e Mercato, 64: 73-99.

- (2006), Le politiche sociali in Europa. Trasformazione dei bisogni e risposte di Policy. Rome: Carocci.

Naldini, M., and C. Saraceno (2008). "Social and Family Policies in Italy: Not Totally Frozen But Far From Structured Reforms”, Social Policy Q Administration 42:7, 733-748.

OECD (I996a), Ageing in OECD countries, Paris: OECD.

- (1996b), Caring for frail elderly people. Policies in Evolution, Paris: OECD.

Ogg, J., and S. Renaut (2006), "The Support of Parents in Old Age by Those Born during I945-I954: A European Perspective”, Ageing and Society 26(5), 723-743.

Olshansky, S.J., M.A. Rudberg, B.A. Carnes, B.A. Cassel, and J.A. Brady (I99I), "Trading Off Longer Life for Worsening Health: The Expansion of Morbidity Hypothesis", Journal of Aging and Health 3: 194-216.

Orloff, A.S. (I993), "Gender and the Social Rights of Citizenship: The Comparative Analysis of Gender Relations and Welfare States", American Sociological Review 58(3): 303-328.

Österle A. (200I), Equity Choices and Long-Term Care Policies in Europe. Allocating Resources and Burdens in Austria, Italy, the Netherlands and the United Kingdom. Ashgate: Aldershot.

O+S (I993), Ouderen in Amsterdam 1993 (Older People in Amsterdam), Amsterdam: Gemeente Amsterdam.

- (I998) Ouderen in Amsterdam 1997 (Older People in Amsterdam), Amsterdam: Gemeente Amsterdam.

- (2000), Ouderen in Amsterdam 1999 (Older People in Amsterdam), Amsterdam: Gemeente Amsterdam.

- (2004), Ouderen in Amsterdam 2003 (Older People in Amsterdam), Amsterdam: Gemeente Amsterdam.

Pacolet, J., R. Bouten, H. Lanoye, and K. Versiek (2000), Social Protection for Dependency in Old Age. A Study of the Fifteen EU Member States and Norway, Aldershot: Ashgate.

Parella Rubio, S. (2000), "El trasvase de desigualdades de clasa y etnia entre mujeres: los servicios de proximidad", Papers. Revista de Sociologia. Inmigracion feminina en el sur de Europa 6o: 275-289.

Pavolini, E., and C. Ranci (2008), "Restructuring the Welfare State: Reforms in Long-Term Care in Western European Countries”, Journal of European Social Policy I8(4): 246-259.

Pedersen, A.W. (2004), "The Privatization of Retirement Income? Variation and Trends in the Income Packages of Old Age Pensioners", Journal of European Social Policy I4(I): 5-23.

Pierson, P. (I996) "The New Politics of the Welfare State" World Politics 48(2): I43-I79. 
Pinquart, M., S. Sorensen et al. (2003), "National and Regional Differences in Preparation for Future Care Needs: a Comparison of the United States and Germany", Journal of Cross-Cultural Gerontology I8: 53-78.

Piva, P. (200I), Anziani accuditi da donne straniere, Venezia: Comune di Venezia.

Poort, E.C., J. Spijker, H. Dijkshoorn, and A.P. Verhoeff (200I), Turkse en Marokkaanse ouderen in Amsterdam '99-'oo, Amsterdam: GG\&GD Amsterdam.

Portrait, F.R.M. (2000), Long-Term Care Services for the Dutch Elderly. An Investigation into the Process of Utilization, Amsterdam: Vrije Universiteit.

Potting M. (200I), Van je familie. Zorg, familie en sekse in de mantelzorg, Amsterdam: Aksant.

Qureshi, H., and A. Walker (I990), The Caring Relationship: Elderly People and their Families, London: Macmillan.

Rahkonen, O., and P. Takala (I998), "Social Class Differences in Health and Functional Disability among Older Men and Women”, International Journal of Health Services 28(3): 5II-524.

Rainwater, R., M. Rein, and M. Schwartz (1986), Income Packaging in the Welfare State: a Comparative Study of Family Income, Oxford: Clarendon Press.

Ramirez, A. (I999), "La valeur du travail. L'insertion dans le marché du travail des immigrées marocaines en Espagne”, Revue Européenne des Migrations internationales I5(2): 9-36.

Regione Lombardia (1998), Le residenze sanitarie assistenziali in Lombardia, Milan: Giunta regionale della Lombardia. Direzione generale interventi sociali.

Reyneri, E. (1979), La catena migratoria, Bologna: Mulino.

- (200I) Migrants' Involvement in Irregular Employment in the Mediterranean Countries of the European Union, Geneva: International Labour Office.

- (2003), Sociologia del mercato del lavoro, Bologna: Mulino.

Robine, J. M., C. Mathers (I993), "Measuring the Compression or Expansion of Morbidity Through Changes in Health Expectancy", in J.M. Robine et al. (eds.), Calculation of Health Expectancies, Harmonization, Consensus Achieved and Future Perspectives, Paris: Libbey: $169-286$.

Rostgaard, T., and T. Fridberg (1998), Caring for Children and the Elderly: a Comparison of European Policies and Practices. Copenhagen: Danish National Institute of Social Research.

Sabbadini, L.L. (2002), "La rete di aiuti informali", in Osservatorio nazionale sulle famiglie e le politiche locali di sostegno alle responsabilità familiari, Famiglie: mutamenti e politiche sociali, Vol.II: 329-356.

Saraceno, C. (2003), Mutamenti della famiglia e politiche sociali in Italia, Bologna: Mulino.

Saraceno, C., and M. Naldini (2007). Sociologia della famiglia. Bologna: Mulino.

Schneider, F. and H. Enste (2000) "Shadow Economies: Size, Causes and Consequences”, Journal of Economic Literature 38(I): 77-I44.

Schoemakers-Salkinoja, I., and J. Timmermans (200I), "Health", in M.M.Y. de Klerk (ed.), Report on the Elderly 2001. Changes in Living Situations. Social and Cultural Planning Office of the Netherlands, The Hague, December 200I: I07-I42. 
Schwitzer, K.P. (I990), “Family Life Cycles: Their Effects on Old People’s Family Relations", in J. Mogey (ed.), Aiding and Aging: The Coming Crisis in Support for the Elderly by Kin and State. Westport, CT: Greenwood Press, 227-236.

Simonazzi, A. (2009), "Care Regimes and National Employment Models", Cambridge Journal of Economics 33(2): 2II-232.

Simonen, L., and A. Kovalainen (I998), "Paradoxes of Social Care Restructuring: the Finnish Case”, in Lewis J. (ed.), Gender, Social Care and the Welfare State Restructuring in Europe, Aldershot: Ashgate.

Skolka, J.V. (I977), "Unbalanced Productivity Growth and the Growth of Public Services", Journal of Public Economics 7: 27I-80.

Sueur, J-P. (2000), L'aide personnalisée a l'autonomie: un nouveau droit fondé sur le principe d'égalité, Rapport commissionné par le Ministère du Travail et de la Solidarité sociale.

Sundström, G. (I994), "Les solidarités familiales: tour d'horizon des tendances", in Protéger les personnes âgées dépendantes, nouvelles orientations, OCDE, Etudes de politiques sociales, I4: $15-58$.

Sundström, G., L. Johansson, and L. Hassing (2002), "The Shifting Balance of Long-Term Care in Sweden", Gerontologist 42(3): 350-356.

Sunesson, S., S. Blomberg, P.G. Edebalk, L. Harrysson, J. Magnusson, A. Meeuwisse, J. Petersson, and T. Salonen (I998), “The Flight from Universalism”, European Journal of Social Work I(I): I9-29.

Szebehely, M. (2005), "Care as Employment and Welfare Provision. Child Care and Elder Care in Sweden at the Dawn of the 2Ist Century", in H.M. Dahl, and T. Rask Eriksen (eds.) Dilemmas of Care in the Nordic Welfare State. Continuity and Change, Aldershot: Ashgate, 80-97.

Taccani, P. (ed.) (I994) Dentro la Cura. Milan: Angeli.

Timmermans, J.M., F. de Beer, M.M.Y. and de Klerk (1997), Report on the Elderly 1996, Social and Cultural Planning Office, Rijswijk, July I997.

Timmermans, J.M., A.H. de Boer, C. van Campen, M.M.Y. de Klerk, J.S.J. de Wit, and I.B. Woittiez (200I), Vrij om te helpen, Verkenning betaald langdurig zorgverlof, Den Haag, Sociaal en Cultureel Planbureau.

Taylor-Gooby, P. (2004) New Risks New Welfare: Oxford: Oxford University Press.

Tornstam L. (I992), "Formal and Informal Support to the Elderly in Sweden", in H.L. Kendig, A. Hashimoto, and L.C. Coppard (eds.) Family Support for the Elderly: The International Experience. Oxford: Oxford University Press, I38I46.

Trydegard, G.B. (2003), "Swedish Care Reforms in the I990s. A First Evaluation of their Consequences for the Elderly People", Revue française des affaires sociales $4: 443-460$.

Trydegard, G.B., and M. Thorslund (200I), "Inequality in the Welfare State? Local Variations in Care of the Elderly. The Case of Sweden", International Journal of Social Welfare IO: I74-I84.

Ungerson, C. (1997), "Social Politics and the Commodification of Care", Social Politics, International Studies in Gender, State and Society 4 (3), 362-38I.

- (2000), "Cash in Care", in M. Harrington Meyer (ed.), Care Work: Gender, Labour and the Welfare State, London: Routledge: 68-88.

Ungerson C., and S. Yeandle (eds.) (2007) Cash for Care in Developed Welfare States, Basingstoke: Palgrave MacMillan. 
Vaiou, D. (2002), "In the Interstices of the City: Albanian Women in Athens", Espace, Populations, Sociétés, 3: 373-85.

Van den Heuvel, W. (I997), "Policy Towards the Elderly: Twenty-Five Years of Dutch Experience", Journal of Aging Studies II (3): 25I-58.

Van der Veen, R., and W. Trommel (I999), "Managed Liberalization of the Dutch Welfare State: a Review and Analysis of the Reform of the Dutch Social Security System, I985-1998", Governance: an International Journal of Policy and Administration I2(3): 289-310.

Van Doorne-Huiskes, J., et al. (2002), Mantelzorg: tussen vraag en aanbod (Informal Care: Between Demand and Supply), Report no. 63, The Hague: NIDI.

Van Ewijk, H., and T. Kelder (I999), Who Cares? An Overview of the Dutch System of Health Care and Welfare, Utrecht: Netherlands Institute of Care and Welfare (NIZW).

Van Tilburg, T. (I995), "Delineation of the Social Network and Differences in Network Size”, in C.P.M. Knipscheer, et al. (eds.), Living Arrangements and Social Networks of Older Adults. Amsterdam: Free University Press, 83-96.

Van Tilburg, T.G., and M. Broese van Groenou (2002), "Network and Health Changes among Older Dutch Adults", Journal of Social Issues 58(4): 697-713.

Visser, J., and Hemerijk A. (I997), A Dutch Miracle. Job Growth, Welfare Reform and Corporatism in the Netherlands, Amsterdam: Amsterdam University Press.

VWS (Ministerie van Volksgezondheid, Welzijn en Sport) (2005), Memorie van Toelichting; Nieuwe regels betreffende maatschappelijke ondersteuning (Wet maatschappelijke ondersteuning). Tweede Kamer, vergaderjaar 2004-2005, 30, I3I, no. 3. URL: https://www.ggdkennisnet.nl/kennisnet/uploaddb/down1_object.asp?atoom $=30747 \& \mathrm{VolgNr}=0$.

VWS (2007). "Feiten en cijfers persoonsgebonden budget", available at http:// www.minvws.nl/dossiers/persoonsgebonden_budget_pgb/feiten-en-cijfers$\mathrm{pgb} /$.

Waidmann, T.A., and K.G. Manton (I998), "International Evidence on Disability Trends among the Elderly", US Department of Health and Human Services, June I998.

Wallace, C. (2002). "Household Strategies: Their Conceptual Relevance and Analytical Scope in Social Research”. Sociology 36(2): 275-92.

Weekers, S., and M. Pijl (I998), Home Care and Care Allowances in the European Union, Utrecht, NIZW.

Wegner, E.L. (200I), "Restructuring Care for the Elderly in Germany", Current Sociology 49(3): I75-I88.

Weissert, W.G., and C.M. Cready (1989), "A Prospective Budgeting Model for Home and Community-Based Long-Term Care", Inquiry 26: iı6-I29.

Wenger, G.C. (1986), "A Longitudinal Study of Change and Adaptation in the Support Networks of Welsh Elderly over 75", Journal of Cross Cultural Gerontology I: 277-304.

- (I993a), "The Ageing World: Longevity, Culture and the Individual”, Generations Review: Journal of the British Society of Gerontology 3: 2-5.

- (I993b), "The Formation of Social Networks: Self Help, Mutual Aid and Old People in Contemporary Britain", Journal of Aging Studies 7: 25-40.

Yerden, I. (200I), Zorgen over zorg. Traditie, verwantschapsrelaties, migratie en verzorging van Turkse ouderen in Nederland (Worries about Care. Tradition, Kinship, 
Migration and Care of Turkish the Elderly in the Netherlands), Amsterdam: Het Spinhuis.

Young, S. (2000), "Outsourcing: Lessons from the Literature", Labour and Industry IO(3): 97- II7.

Zandbergen, J. (I995), Mantelzorgbeleid in Zweden en Nederland. Een vergelijkende studie naar de stimulering van mantelzorg voor ouderen, Vrije Universiteit Amsterdam, Faculteit der Sociaal Culturele Wetenschappen, Vakgroep Sociologie en Sociale Gerontologie.

Zincone, G. (ed.) (200I), Secondo rapporto sullintegrazione degli immigrati in Italia, Bologna: Mulino. 



\section{Index}

AWBZ (Algemene Wet Bijzondere Ziektekosten) 22-23, 25-26, 28, 8I, IO3-IO4

Badanti see migrant paid caregivers Cash-for-care schemes I3-I4, I7 Dutch personal budget 25-28, 97-98, II7, I50, I62 Indennità di accompagnamento 30, 32, 94, I03-IO4, II8-II9, I28

Care packages I7-I9, 55-75, 77-IO7, II3-II4, I59-I62

Care strategies I8, 27, IO7-II3, I2O, I35, I4I, I49, I56, I74

Care systems I5-I8, 55-56, 75, I4I152

Deinstitutionalisation I2, I4, I7, 23$24,50-53, \mathrm{I} 49-\mathrm{I} 50$

Dependence 9, I2, 37-53

Disability see dependence

Dutch personal budget see cash-forcare schemes

Extra-muralisation see deinstitutionalisation

Familisation of care I6-I7, 22, 27$28,55,60,74$, II2, I27, I29, I5OI5I, I53

Formal care $56,77-78$
Formal home care $79-82$

Formal residential care 99-I04 Home care see Formal home care Indennità di accompagnamento see Cash-for-care schemes

Informal care II, I3-I5, I7-I8, 23-26, $28,30,56,57-60,63,65-67,72-$

$73,77-78,83-90$

Informalisation of care I3, 27

Institutionalisation

Institutionalisation (process of) I22-I26

Institutionalisation rates $23,50-$ 53,126

Long-term care policies IO-I3

in Italy 28-32

in the Netherlands 22-28

Market care I0-I8, 56, 6I-62, 69-72, 77-78, 90-98

Marketization of care I3, I7, 22, 2728, I50-I5I

Migrant paid caregivers $32-34$, 9096, II6, II9, I22, I37-138, I77

Residential care see Formal residential care

Re-familisation of care see Familisation of care 